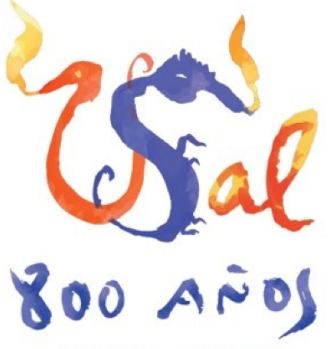

$1218 \sim 2018$ ixic

INSTITUTO UNIVERSITARIO de INTEGRACIÓN en la COMUNIDAD

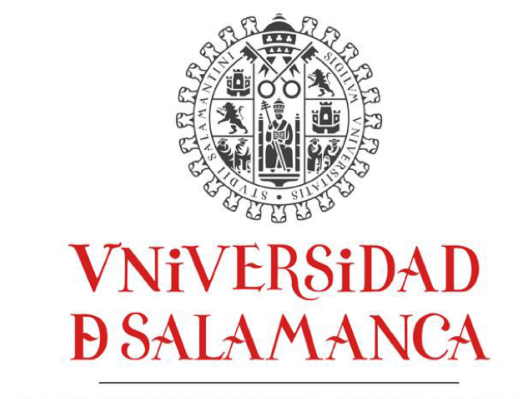

CAMPUS DE EXCELENCIA INTERNACIONAL

TESIS DOCTORAL

Formación musical y uso de la música para la inclusión en

Educación Infantil:

evaluación en maestros y futuros maestros

ANA Mạ GARCÍA HERRERA

DIRECTORAS:

Dra. Da FRANCISCA GONZÁLEZ GIL

Dra. Dạ ELENA MARTÍN PASTOR

Salamanca, 2017 

Dạ. Francisca GONZÁLEZ GIL, Profesora Titular y Dạ. Elena MARTín PASTOR, Profesora Ayudante Doctor de la Universidad de Salamanca.

\section{HACEN CONSTAR}

Que la Tesis Doctoral titulada "Formación musical y uso de la música para la inclusión en Educación Infantil: evaluación en maestros y futuros maestros", realizada bajo su dirección por Dña. ANA Mạ GARCÍA HERRERA, reúne los requisitos de calidad, originalidad y presentación exigibles a una investigación científica y está en condiciones para ser presentada y defendida públicamente.

Por todo ello manifestamos nuestro acuerdo para la presentación del trabajo referido.

Salamanca, 10 de julio de 2017

LAS DIRECTORAS DE TESIS

Dra. Dạ Francisca GONZÁLEZ-GIL

Dra. Dạ Elena MARTÍN PASTOR 



\section{AGRADECIMIENTOS}

Deseo manifestar mi agradecimiento a las directoras de mi tesis doctoral Paqui y Elena, por su cercanía y calidad humana ya que, sin su apoyo incondicional, dedicación, paciencia, ayuda y ánimos me hubiera sido imposible presentar esta investigación.

También agradezco su inestimable colaboración a mis estudiantes del Grado en Maestro en Educación Infantil y a los maestros y alumnos de los centros de Educación Infantil donde he realizado mi investigación, quienes, sin saberlo, me han empujado a investigar y a realizar este trabajo. Espero que las propuestas que planteo a lo largo de esta tesis doctoral constituyan una oportunidad para impartir una educación musical de calidad para todos los alumnos y mejorar su presencia en los planes de formación de los maestros.

$\mathrm{Y}$, por último, quisiera manifestar mi más sincero agradecimiento a todas aquellas personas que me han estado apoyando y alentando en todo este proceso, pues sin sus ánimos no hubiera sido posible la realización de esta tesis doctoral. Deseo dedicar una mención especial a José Manuel, a mis compañeros y amigos de la Facultad Carmen, Javier, Ricardo, Vicente, Mers, África, Viviana, Fernando, María y Esther, por su colaboración en esta fase final del proceso y a la música, porque como decía San Isidoro de Sevilla siglos atrás "sin música no puede haber enseñanza perfecta, pues nada hay que carezca de ella". 
EL logro primordial más elevado de la educación debe ser el de formar y desarrollar seres con mayor humanidad y contenido interno.

Darío Salas Sommer. Moral para el S.XXI 

ÍNDICE

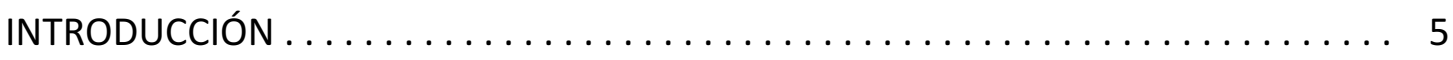

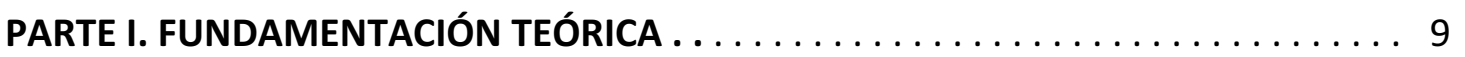

CAPÍTULO I: EL GRADO EN MAESTRO EN EDUCACIÓN INFANTIL DE LA

UNIVERSIDAD DE SALAMANCA $\ldots \ldots \ldots \ldots \ldots \ldots \ldots \ldots \ldots \ldots \ldots \ldots \ldots \ldots \ldots \ldots$

1.LAS TITULACIONES DE MAESTRO

1.1- Origen y evolución de las titulaciones de maestro en el sistema

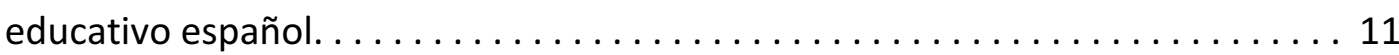

1.2 - Las enseñanzas Universitarias en el Espacio Europeo de

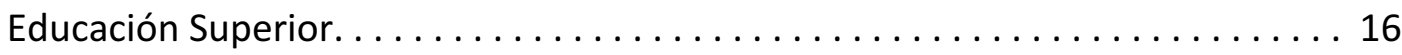

1.3.- Los estudios del Grado en Maestro en Educación Infantil de la

Universidad de Salamanca. . . . . . . . . . . . . . . . . . . . . . . . 19

1.3.1. El plan de estudios . . . . . . . . . . . . . . . . . . . . . . . 20

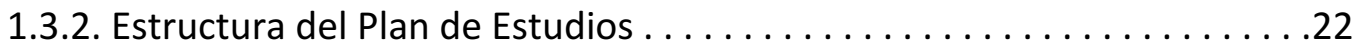

1.3.3. Las Menciones del Grado en Maestro en Educación Infantil . . . . . . . . . 27

1.3.4. Las prácticas externas en el grado en maestro en

Educación Infantil . . . . . . . . . . . . . . . . . . . . . . . . . 29

2. LA FORMACIÓN EN EXPRESIÓN MUSICAL EN EL GRADO EN MAESTRO

EN EDUCACIÓN INFANTIL. . . . . . . . . . . . . . . . . . . . . 31

2.1. La enseñanza de la música en los estudios de Maestro. . . . . . . . . 32

2.2. La enseñanza de la música en el Grado en Maestro en Educación

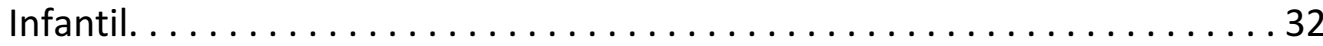

3. LA FORMACIÓN EN EDUCACIÓN INCLUSIVA EN EL GRADO EN

MAESTRO EN EDUCACIÓN INFANTIL

3.1. La educación inclusiva en los estudios de Maestro . . . . . . . . . . . 35

3.2. La educación inclusiva en los estudios del Grado en Maestro

en Educación Infantil. . . . . . . . . . . . . . . . . . . . . . . . . . . . . . 37

\section{CAPÍTULO 2: LA EDUCACIÓN MUSICAL}

1. LA EDUCACIÓN MUSICAL TEMPRANA ....................... 42

2. LA IMPORTANCIA DE LA EDUCACIÓN MUSICAL EN LA EDUCACIÓN INFANTIL . . . . 44

3. LA MUSICA EN LA EDUCACIÓN ESPAÑOLA $\ldots \ldots \ldots \ldots \ldots \ldots \ldots \ldots \ldots \ldots$

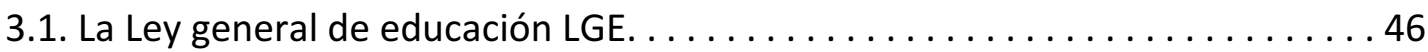


3.2. La renovación de las enseñanzas musicales a partir de $1981 \ldots \ldots \ldots \ldots \ldots 48$

3.3. La Ley orgánica de ordenación general del sistema educativo LOGSE . . . . . . . 49

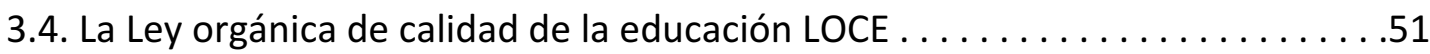

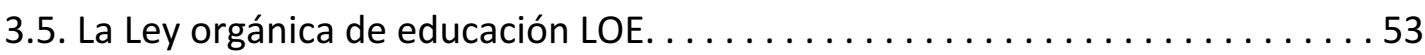

3.6. La Ley orgánica para la mejora de la calidad educativa LOMCE . . . . . . . . . 55

4. LA MÚSICA EN EL CURRÍCULO ACTUAL DE EDUCACIÓN INFANTIL

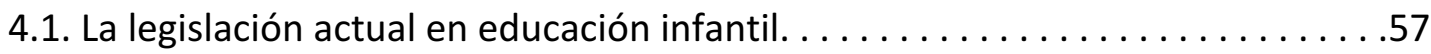

4.2. Las Áreas de conocimiento en Segundo ciclo de Educación Infantil. . . . . . . . . 58

4.3. La expresión musical en el currículo del segundo ciclo de Educación Infantil en Castilla y León. . . . . . . . . . . . . . . . . . . . . . . . . . . . 61

4.5. la impartición del currículo de expresión musical. . . . . . . . . . . . . . . 64

\section{CAPÍTULO 3: LA EDUCACIÓN INCLUSIVA}

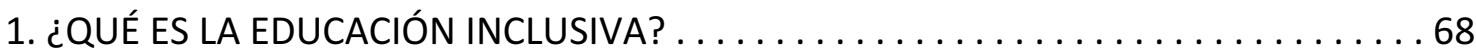

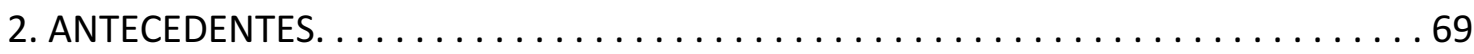

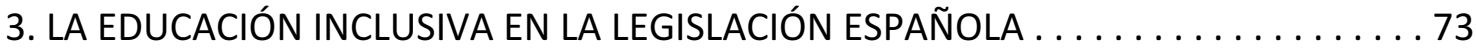

4. LA EDUCACIÓN INCLUSIVA EN LA LEGISLACIÓN DE LA COMUNIDAD

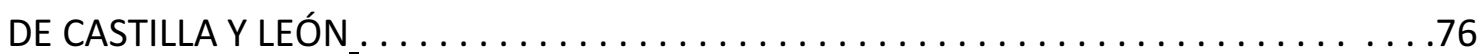

5. LA FORMACIÓN DEL PROFESORADO COMO AGENTE FUNDAMENTAL

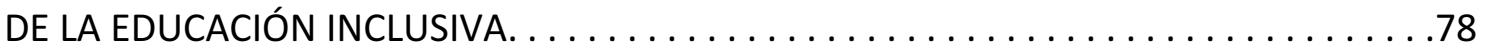

6. LA MÚSICA COMO RECURSO PARA LA EDUCACIÓN INCLUSIVA $\ldots \ldots \ldots \ldots \ldots \ldots 81$

\section{PARTE II. ESTUDIO EMPÍRICO}

CAPÍTULO 4: INVESTIGACIÓN 85

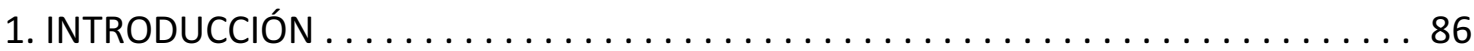

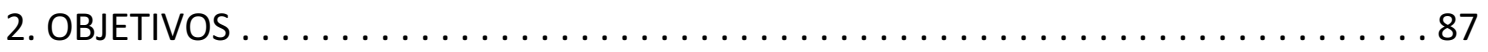

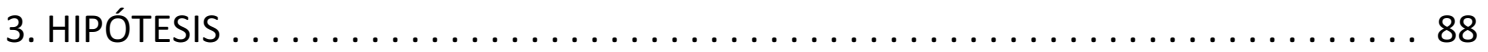

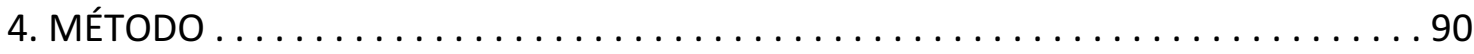

4.1. Participantes . . . . . . . . . . . . . . . . . . . . 90

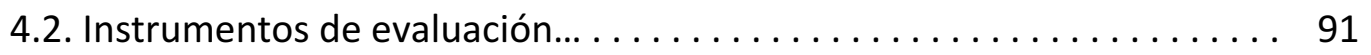




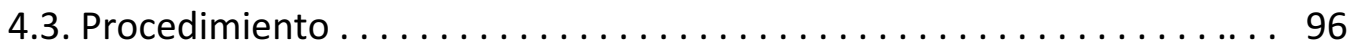

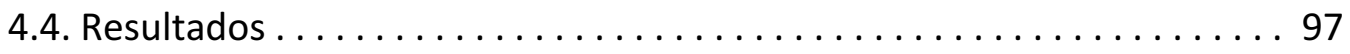

\section{CAPÍTULO 5: CONCLUSIONES Y DISCUSIÓN}

1. VALORACIÓN DEL GRADO DE CONSECUCIÓN DE LOS OBJETIVOS . . . . . . . . . . . 139

2. ANÁLISIS Y DISCUSIÓN DE LOS RESULTADOS . . . . . . . . . . . . . . . 137

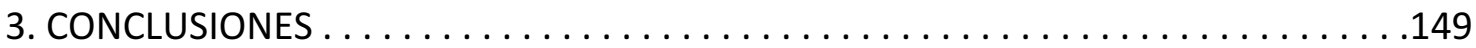

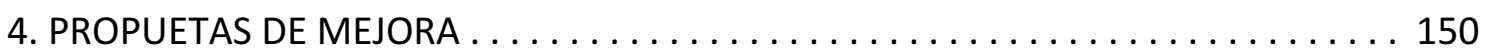

5. LIMITACIONES DE NUESTRO ESTUDIO Y SUGERENCIAS . . . . . . . . . . . 155

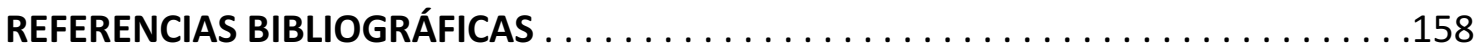

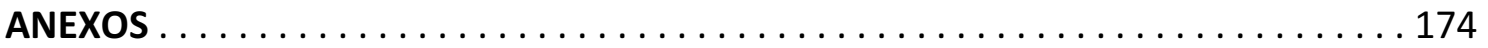

Anexo I: Cuestionario 1: formación musical de los estudiantes . . . . . . . 175

Anexo II: Cuestionario 2: conocimientos / habilidades y destrezas musicales de los estudiantes . . . . . . . . . . . . . . . . . . . . . 180

Anexo III: Cuestionario 3: el uso de la música en los centros

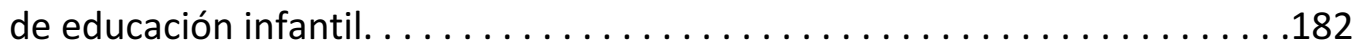

Anexo IV: Cuestionario 4: competencias y currículo de expresión musical en Educación infantil. . . . . . . . . . . . . . . . . . . . . . . 190

Anexo V: Carta dirigida a los directores de los centros educativos de Educación Infantil. ............................. 200

Anexo VI: Carta dirigida a los Maestros-tutores de los centros de Educación Infantil . . . . . . . . . . . . . . . . . . . . . . . . . 203

Anexo VII: Tablas comparativas de los estudiantes de los cursos 2013-14 y 2014-15. 



\section{INTRODUCCIÓN}

La diversidad de alumnos que asisten a los centros de Educación Infantil y el reto que supone su formación hacen necesario el planteamiento de cambios en el sistema educativo que afectan, inevitablemente, a la formación de los futuros maestros. Los centros de Educación Infantil y cada una de sus aulas constituyen una recreación a pequeña escala del mundo: una recreación que permite educar a los niños y en la que cultivan todo lo que es necesario para la vida, donde desarrollan sus sentidos y aprenden a vivir. En este mundo de experiencias diversas y demandas cada vez más exigentes, la figura del maestro de Educación Infantil se convierte en un elemento de estabilidad y seguridad que requiere, por tanto, una formación adecuada.

La música, como elemento de la educación integral, está presente en todo momento en el aula y es el maestro de Educación Infantil la persona encargada de la educación de los niños. Pero esto solo es posible si la formación mencionada incluye una preparación que haga capaz la transmisión de la música a los niños, pues la música constituye un recurso de primer orden mediante el que podemos propiciar la participación de todos los alumnos. En consecuencia, debemos formar un profesorado competente, musicalmente formado, que pueda hacer un uso adecuado y suficiente de la música en el segundo ciclo de Educación Infantil, que sea capaz de enseñar música y, sobre todo, de enseñar con la música.

Las actividades musicales deben ser practicadas por todos los niños en todas sus manifestaciones: vocal, rítmica, auditiva, instrumental y de movimiento, dando paso así a una educación integral que utilice la música como un componente más donde todos los niños, sin excepción, participen en forma colectiva, atendiendo más al trabajo de grupo que al individual.

Dado lo anterior, el presente trabajo, pretende, por una parte, realizar un análisis de la formación que los futuros maestros de Educación Infantil reciben en la Universidad de Salamanca, prestando especial atención a la formación musical y a la formación en educación inclusiva, de cara a conseguir las competencias necesarias para 
llevar a cabo su futura práctica profesional. Por otra parte, se propone recoger la situación actual de la práctica de la música en las aulas de segundo ciclo de Educación Infantil y las necesidades de formación que tienen los maestros en ejercicio para convertir la música en un recurso que favorezca la participación, en igualdad de condiciones, de todo el alumnado, ya que cantar, bailar, tocar instrumentos, etc., favorece la socialización, la expresión y la comunicación entre todos sentando así las bases para una escuela inclusiva donde tengan cabida todos los alumnos.

Para avanzar hacia la consecución de estos dos objetivos, en la primera parte de este trabajo, revisamos los fundamentos teóricos que sostienen y justifican el estudio realizado.

En el Capítulo 1, en primer lugar, analizamos la evolución de las titulaciones de maestro en el sistema educativo español y, en segundo lugar, nos centramos en los estudios del Grado en Maestro en Educación Infantil que actualmente se imparten en la Universidad de Salamanca, analizando su plan de estudios y poniendo especial interés en la formación en educación musical y en educación inclusiva tanto en la actual titulación como a lo largo de la historia de los estudios de Maestro.

El Capítulo 2 se dedica a la educación musical. En él, comenzamos analizando la importancia y los beneficios que aporta una educación musical temprana; continuamos repasando el tratamiento que la educación musical ha recibido en las distintas leyes educativas hasta formar parte de la enseñanza obligatoria y concluimos el capítulo centrándonos en el tratamiento que recibe la música en el currículo de segundo ciclo de Educación Infantil en la Comunidad Autónoma de Castilla y León.

Por último, el Capítulo 3 está dedicado a la educación inclusiva. En él, en primer lugar, conceptualizaremos el término inclusión: qué es, cómo se concibe la educación desde este enfoque, en qué principios se apoya y cuáles son los valores que defiende, para con posterioridad analizar cómo queda reflejada la educación inclusiva en la legislación educativa y el papel del profesorado para conseguir con éxito una educación de calidad con todos y para todos. Por último, se estudia el papel de la música como recurso ideal para conseguir la inclusión. 
En la segunda parte del trabajo, se presenta el trabajo empírico.

En el Capítulo 4, se recoge el enfoque metodológico diseñado para alcanzar los tres objetivos fundamentales que dan inicio a esta tesis: (1) analizar la formación musical de los estudiantes que cursan el Grado en Maestro en Educación Infantil en la Universidad de Salamanca, (2) evaluar la utilización de la música en la etapa de Educación Infantil en los centros educativos de Castilla y León, y (3) diseñar propuestas para mejorar la formación de los maestros y futuros maestros. Una vez definidos estos objetivos se presentan las principales características metodológicas que han guiado el trabajo. Así, se plantean las hipótesis del estudio, se detallan las características de la muestra analizada, se describen los instrumentos empleados en las distintas fases del desarrollo de la investigación y se muestran los resultados obtenidos.

Concluiremos con el Capítulo 5, con la presentación de las conclusiones y la discusión del estudio, la valoración del grado de consecución de los objetivos planteados inicialmente y el análisis de los resultados que nos permitan formular planes de mejora, tanto para la formación inicial del futuro profesorado como para la permanente del profesorado en ejercicio.

Este trabajo, por lo tanto, pretende mostrar la escasa importancia que se le viene dando a la formación musical en los estudios de Grado en Maestro en Educación Infantil, en detrimento del desarrollo integral del niño, y otorgar a la educación musical la importancia que se merece en la formación del futuro maestro en Educación Infantil, para adecuarse a las necesidades reales del colectivo al que se dirige y a las necesidades relacionadas con la formación permanente. 
PARTE I: FUNDAMENTACIÓN TEÓRICA 


\section{CAPITULO 1. EL GRADO EN MAESTRO EN EDUCACIÓN INFANTIL DE LA UNIVERSIDAD DE} SALAMANCA

En este capítulo vamos a abordar cómo se estructura el Grado en Maestro en Educación Infantil que se imparte en la Universidad de Salamanca. En primer lugar, analizaremos los orígenes de estos estudios, así como su evolución hasta la inmersión en el Espacio Europeo de Educación Superior. En segundo lugar, nos detendremos en el plan de estudios que actualmente plantea dicho Grado con especial hincapié en lo relativo a la formación en educación musical e inclusiva que reciben los estudiantes universitarios de cara a su trabajo como futuros profesionales de la educación.

\section{LAS TITULACIONES DE MAESTRO}

\subsection{Origen y evolución de las titulaciones de maestro en el sistema educativo español.}

La Universidad de Salamanca viene impartiendo los títulos correspondientes a la formación de maestros no sólo desde que ésta se incorporó al sistema universitario con la promulgación de la Ley 14/1970, de 4 de agosto, General de Educación y Financiamiento de la Reforma Educativa (LGE), pues el inicio de la formación de maestros se remonta al S.XIX donde se ofertaban estudios de maestro en las Ilamadas Escuelas Normales de maestras y maestros ${ }^{1}$.

Los comienzos de la formación de los estudios de maestro en España comienzan con la creación de la primera Escuela Normal en Madrid en 1839: el Seminario Central de Maestros del Reino, dirigida por Pablo Montesinos, fundada a raíz de la Ley de 1938 que regulaba las enseñanzas Primarias.

La Ley de Instrucción Pública de 9 de septiembre de 1857, conocida como Ley Moyano, se constituye como el primer texto jurídico en el ámbito de la educación en nuestro país (Embrid Irujo, 2000). Estructuraba las enseñanzas en tres niveles: Primera Enseñanza, Segunda Enseñanza y Facultades y Enseñanza Superior y Profesional. Lo anterior dio lugar a una renovación de las Escuelas Normales en Escuelas profesionales

\footnotetext{
${ }^{1}$ El término de escuelas Normales tiene su origen en los primeros seminarios de maestros acontecidos en Francia a finales del S. XVII.
} 
existentes en casi todas las capitales de provincia españolas (Escolano, 1982, Gómez Rodríguez de Castro, 1994) reguladas por el Real Decreto de 20 de septiembre de 1858, que planteaba una estructura de un plan de estudios en cinco cursos: primer y segundo curso (maestro elemental), tercero y cuarto (maestro superior) y quinto curso (maestro normal). Pero, a pesar de esta estructuración, "la formación recibida no se correspondía con la adquisición de conocimientos y competencias profesionales propias del ámbito pedagógico, sino que más bien se encaminaba al dominio del ámbito mediocre cultural" (Ávila Fernández y Holgado Barroso, 1999, p. 71). El Real Decreto de 23 de septiembre de 1898 de reforma de las Escuelas Normales, nace para dar respuesta a la necesidad de realizar una mejora de los estudios de maestro en España, modificando con ello su plan de estudios con la aparición de asignaturas denominadas pedagógicas y artísticas como Derecho y legislación escolar, Historia de la pedagogía, Teoría completa de la educación, Música y canto o Higiene y Gimnasia.

En 1901, la formación de maestros se incorpora a los Institutos Generales y Técnicos de segunda enseñanza dando lugar a la titulación de Magisterio de primera enseñanza con dos grados: elemental y superior. Hecho que desemboca en la posterior creación de la Escuela Normal Superior del Magisterio en 1909.

El Real Decreto, de 30 de agosto de 1914, consolida y regula definitivamente el funcionamiento de la nueva Escuela Normal Superior a la que designan con el nuevo nombre de Escuela de Estudios Superiores del Magisterio. Comienza así, una nueva etapa en la formación de los maestros con la puesta en marcha de un plan de estudios que se mantendría hasta 1931, y que constaría de tres secciones: Ciencias, Letras y Labores, repartidas a lo largo de cuatro años. Un aspecto que nos gustaría resaltar en este punto es la presencia de la música como parte de la formación de futuros maestros.

El 14 de abril de 1931 con la proclamación de la Segunda República y la promulgación del Decreto de 9 de septiembre de 1931, se transformaron las normas relativas a la preparación del Magisterio primario y las Escuelas Normales con una profunda reforma de los planes de estos estudios de maestro, atendiendo a la necesidad de una formación de calidad. Con esta idea surge el llamado "plan profesional" que organizaba la formación de los futuros maestros en tres períodos: uno 
cultura general; otro de formación profesional, desarrollado en las escuelas normales y un tercero de práctica docente. Las materias del plan, se articulan en torno a tres grupos de estudio: a) conocimientos pedagógicos, filosóficos y sociales; b) metodologías especiales y c) materias artísticas y prácticas. En los dos primeros cursos la formación artística se consolida al impartir las asignaturas de Música y Dibujo y en tercer y último curso se introduce por primera vez en la historia de la formación de maestros contenidos relacionados con lo que en su momento se denominaban "las enseñanzas especiales: párvulos, retrasados, superdotados, etc." (Escolano, 1982, p.70). Una de las medidas más importantes recogidas en el mencionado decreto fue la unificación de las Escuelas Normales de maestras y maestros en una única que se denominaron Escuelas Normales del Magisterio Primario. (Santander Díaz, 2010)

Años más tarde, con la aparición del primer plan de estudios de la época franquista resultante de la Ley de 17 de julio de 1945 sobre Educación Primaria, se establecieron por primera vez los requisitos para acceder a los estudios de maestro que consistían en la realización de una prueba de acceso y tener catorce años de edad. De manera paralela se dictó a través de la Orden de 9 de octubre de 1945, las normas para el funcionamiento de las que serían las Escuelas del Magisterio.

Posteriormente, a partir del Decreto de 7 de julio de 1950 por el que se aprueba el Reglamento para las Escuelas del Magisterio, se realiza una nueva modificación de las enseñanzas de maestro en tres cursos y con la asistencia obligatoria a campamentos y albergues organizados por el frente de Juventudes o la Sección Femenina al finalizar segundo y tercero. En estos planes, la música se contemplaba como una base para la enseñanza de canciones populares y patrióticas.

En 1967 la creación de un nuevo plan de estudios para la formación del maestro, dictado por la Orden de 1 de junio de 1967 por el que se fija el Plan de Estudios de las Escuelas Normales, supuso el comienzo de una nueva etapa formativa marcada por el desarrollo económico y la construcción de un perfil técnico de maestro (Ávila Fernández y Holgado Barroso, 2008, p.195) con un predominio de las didácticas especiales. Se desarrolla en dos cursos tras los que se realizaba una prueba de madurez, para una vez superada continuar con un tercer curso en el que los alumnos hacían prácticas remuneradas en una escuela primaria. Sin embargo, fue un plan de corta duración pues 
en 1970 se aprobaría una nueva Ley General de Educación y en 1971 un nuevo plan de estudios.

La LGE 14/1970, de 4 de agosto, supuso un nuevo intento de generar una reforma del sistema educativo. Es considerada, tras la Ley Moyano, el segundo intento de abordar tras doscientos años, una reforma profunda del sistema educativo español precedida por leyes parciales y por un libro blanco que, por primera vez, efectuó un análisis a fondo del sistema educativo existente y esbozó grandes líneas para su reforma (MEC, 2001, p.120). Aún bajo el franquismo, se integran las Escuelas Normales a la Universidad, modificando su nomenclatura por el de Escuelas Universitarias de Formación del Profesorado de Educación General Básica. Con ella, "España se convierte en uno de los primeros países europeos en dar un carácter universitario a la formación inicial de maestros del nivel educativo equivalente a Educación Primaria" (Valle, 2012, p. 429). Esta ley, por tanto, marcó un cambio importante tanto en la aproximación pedagógica como en la valoración de la figura del maestro (Oriol, 2005). Este nuevo plan de estudios tenía una duración de 3 años con un año de formación común (maestro generalista) y dos años de especialidad. Entre estas se podían cursar: Ciencias, Ciencias Humanas y Filología (francesa o inglesa) y se realizaban prácticas escolares. La educación musical formaba parte de los contenidos de Educación Primaria dentro del área denominada Expresión Dinámica. Con posterioridad con el Plan de Perfeccionamiento del Profesorado de 1977 se añadirían las especialidades de Preescolar y de Educación Especial.

Posteriormente y con la finalidad de poder dar respuesta a los preceptos de la Constitución de 1978, se promulga la Ley orgánica 11/1983, de 25 de agosto, de Reforma Universitaria (LRU) que regulaba las funciones, el personal docente e investigador, y la estructura de la Universidad, además de reconocer su descentralización a favor de las Comunidades Autónomas. Esta ley, permitió una mayor democratización interna y la conquista de la autonomía universitaria necesaria tras el periodo de la dictadura franquista. Esto derivó en el incremento de las relaciones académicas y científicas con otras instituciones de educación europeas, en las que la cultura de la calidad ya estaba bastante instalada (Jiménez, Ramos y Ávila, 2012) y supuso acercar la formación universitaria a la realidad social y profesional a través de 
una oferta coherente de titulaciones académicas dando respuesta así a las nuevas demandas del mercado de trabajo (Delgado López-Cortázar, 1992).

En base a ello, para el desarrollo de los planes de estudio de Magisterio, se promulga el Real Decreto, 1297/1987, de 27 de noviembre, por el que se establecen directrices comunes generales de los planes de estudio de los títulos universitarios de carácter oficial y validez en todo el territorio nacional. Para la formación inicial y oficial de los futuros profesores de Educación General Básica, se ofertaban cinco especialidades: Ciencias, Ciencias Humanas y Sociales, Educación Especial, Filología y Educación Preescolar.

Desde el ámbito escolar, con la promulgación de Ley Orgánica 1/1990, de 3 de octubre, de Ordenación General del Sistema Educativo (LOGSE), se estableció una reforma por la que desapareció la enseñanza general básica, y se implementó la etapa de Educación Infantil, (0 a 6 años de edad) de carácter no obligatorio, y la etapa de Educación Primaria (6 a 12 años de edad) obligatoria. Ello obligaba, tal y como se reflejaba en la disposición adicional duodécima de dicha ley, un nuevo modelo de formación para los maestros en donde "el título de Profesor de Educación General Básica se considera equivalente, a todos los efectos, al título de Maestro al que se refiere la presente ley". Al amparo de la mencionada disposición adicional y por el RD 1457/1991, de 27 se creó la Facultad de Educación-Centro de Formación del Profesorado de la Universidad Complutense de Madrid, la primera de un proceso de sucesivas creaciones que supuso el comienzo de la desaparición de las Escuelas Normales en España.

Para atender a estas demandas se dictamina, el Real Decreto 1440/199, de 30 de agosto, por el que se establece el Título Oficial de Maestro en sus diversas especialidades, y las directrices generales propias de los planes de estudio conducentes a su obtención, dando lugar a una nueva titulación de Maestro con siete especialidades: Educación Infantil, Educación Primaria, Educación Especial, Audición y Lenguaje, Educación Física, Lengua Extranjera y Educación Musical. Aunque la elaboración de los planes de estudio correspondía a las universidades, primero se fijaban a través de los reales decretos, las directrices generales comunes aplicables a todos los planes de estudio conducentes a cualquiera de los títulos universitarios oficiales, y las directrices 
generales propias de cada título. Posteriormente, el Consejo de Universidades era quien proponía los títulos universitarios oficiales y las directrices generales propias de cada título. Éstas incluían la denominación del título, los objetivos, el perfil profesional del titulado, la estructura cíclica, la duración máxima y mínima de cada ciclo y las materias troncales, así como unos descriptores de los contenidos de las mismas, los créditos de enseñanza teórica y práctica de cada materia troncal y su vinculación a una o varias áreas de conocimiento. Con independencia de la especialidad elegida, el currículo se organizaba en materias troncales, comunes en todas las universidades de España, obligatorias y optativas, establecidas por cada Universidad para esa titulación, y de libre configuración que el alumno podía cursar, incluso, de diferentes titulaciones. La elaboración de los planes de estudio corrió a cargo de las comisiones que a tal efecto se constituyeron en las universidades, y los resultados fueron unos planes de estudio que comenzaron a implantarse paulatinamente a partir de 1992. Las Universidades han ido introduciendo algunas modificaciones sobre los planteamientos iniciales, pero poco significativas porque las directrices de 1991 eran de obligado cumplimiento y no podían alterarse.

Lo anterior supuso un gran avance en cuanto a la consideración de la asignatura de música ya que por primera vez en nuestro país se lograba que la educación musical se impartiese en el currículum de educación primaria por un profesor especialista.

En diciembre de 2001 se aprobaba la Ley Orgánica 6/2001, de 21 de diciembre, de Universidades (LOU), sustituyendo y derogando a la LRU. Precisamente, uno de los objetivos de esta ley fue "mejorar la calidad docente, investigadora y de gestión de la universidad e integrarse competitivamente junto a los mejores centros de enseñanza superior en el nuevo espacio universitario europeo que se estaba comenzado a configurar" (Jiménez, et.al., 2012, p.33).

\subsection{Las enseñanzas Universitarias en el Espacio Europeo de Educación Superior}

En la década de los 90 nace la idea del Espacio Europeo de Educación Superior, EEES, cuando se reunieron en 1998 en la Sorbona Ministros de Educación europeos que redactaron la llamada Declaración Conjunta de los Ministros de Educación Europeos de 
Bolonia en 1999, movimiento reformista conocido como Plan Bolonia. El objetivo de dicha Declaración era armonizar los estudios superiores en los países que se integraban en el EEES con una estructura semejante basada en tres niveles: Grado, Máster y Doctorado, e implantar, con ello, una reorientación del sistema universitario acorde con los mecanismos de adaptación al mercado laboral, todo ello, a través de una formación en competencias. A partir de esta idea, se plasmará en la Declaración de Bolonia de 1996, algunas propuestas para la reforma del sistema universitario como la adopción de un sistema basado en dos ciclos principales, el establecimiento de un sistema de créditos ECTS ${ }^{2}$, la promoción de la movilidad de estudiantes y profesores, lo que posteriormente culminará en la actual reforma de estudios universitarios.

De manera paralela, en España se elabora el Informe Universidad 2000 o más conocido como Informe Bricall en el que se hacía especial hincapié en la necesidad de potenciar la calidad y en orientar la formación hacia las salidas profesionales de los alumnos a las demandas del mercado (Holgado Barroso, 2014).

El resultado del trabajo mencionado fue la Ley Orgánica 6/2001, de 21 de diciembre, de Universidades (LOU). En ella aparecen cambios importantes en la estructura y organización de la universidad española. La ley establece que habrá tres ciclos que conducirán a los títulos de Diplomado universitario, Arquitecto Técnico, Ingeniero Técnico, Licenciado, Arquitecto, Ingeniero y Doctor (Art. 37). Sin embargo, la necesidad de adaptación de la universidad española al Espacio Europeo de Educación Superior prevista en la propia LOU en sus artículos 37 a 39, llevarían a la formulación de nuevas estructuras de la enseñanza universitaria que culminarían con la creación de los estudios de Grado.

Para revisar los aspectos concernientes a la formación de los maestros, una red de universidades españolas coordinadas desde la Universidad Autónoma de Madrid, se reunieron "con el objetivo explícito de realizar estudios y supuestos prácticos en el

\footnotetext{
${ }^{2}$ El concepto de crédito ECTS (European Credit Transfer and Accumulation System) es un nuevo sistema de valoración de las enseñanzas (asignaturas) universitarias, que constituye una de las principales medidas de la implantación del EEES.

Hasta ahora, el concepto de crédito en España estaba establecido en 10 horas lectivas teóricas, prácticas o equivalencias (prácticas en empresas, estudios en el extranjero, etc.) y se regulaba por el RD.1497/1987, de 27 de noviembre Art. 2.7. por el que se establecen las directrices generales comunes de los planes de estudio de los títulos de carácter oficial y validez en todo el territorio nacional (Actualizado por los Reales Decretos 1267/1994, 2347/1996, 614/1997 y 779/1998).
} 
diseño de un Título de Grado adaptado al Espacio Europeo de Educación Superior". (Moreno González, 2011, p.14). El resultado fue el Libro Blanco, Título de Grado en Magisterio, publicado en dos volúmenes, en 2005, por la ANECA. Con anterioridad, en 2002 la Dirección General de Educación y Cultura de la Comisión Europea publicó, un documento ${ }^{3}$ que sugería a los países miembros de la Comunidad Europea las competencias clave para el periodo formativo de educación primaria y secundaria, lo que se tuvo en cuenta para la elaboración de los nuevos planes de estudio por parte de las universidades.

Con el Real Decreto, 55/ 2005 de 21 de enero, se establece la estructura de las enseñanzas universitarias y se regulan los estudios oficiales de Grado. Se transforman las Diplomaturas de magisterio en Grados de cuatro años con dos titulaciones para los niveles educativos de Infantil y Primaria y con cuatro itinerarios formativos (Educación Especial, Lengua extranjera, Educación Musical y Audición y Lenguaje) suprimiendo de esta forma la excesiva especialización del Plan anterior. La creación de un perfil generalista para Educación Infantil y para la Educación Primaria permite una mayor adecuación a las necesidades de estas etapas; también se revalorizan las prácticas educativas que se desarrollarán en centros de educación infantil y primaria.

Los títulos de Graduado en Maestro en Educación Infantil y en Educación Primaria responden a lo prescrito de los artículos 92 y 93, respectivamente, de la Ley Orgánica 2/2006, de 3 de mayo, de Educación, LOE, dedicado al profesorado de Educación Infantil y Primaria. Ambos grados contemplan la posibilidad de que las universidades incluyan en los planes de estudio menciones cualificadoras que respondan a las necesidades educativas de ambas etapas educativas.

Con la aprobación del Real Decreto 1393/2007, de 29 de octubre, se estableció la ordenación de las enseñanzas Universitarias oficiales de acuerdo con las líneas oficiales y los plazos marcados a nivel europeo, y cada Universidad estableció su propio calendario para que en 2010 todas las enseñanzas se adaptaran a la nueva estructura de las titulaciones. En el caso de Educación el plan de estudios de las titulaciones de Grado en Maestro en Educación Infantil y Maestro en Educación Primaria, deberían tener 240 créditos ETCS e incluir unos bloques de materias con estructuras formativas

\footnotetext{
3 The key competencies in a knowledge-based economy: a first sep towards selection, definition and description.
} 
modulares: de formación básica, didáctico-disciplinar y de Practicum y Trabajo de Fin de Grado.

\subsection{Los Estudios del Grado en Maestro en Educación Infantil de la Universidad de} Salamanca

En la Universidad de Salamanca a partir del curso 2010-11, se ofertan los estudios de Grado en Maestro en Educación Infantil, además, desde el curso 2011-12 y hasta el 2014-15 se ofertó el Curso de Adaptación al Grado en Maestro de Educación Infantil para realizar la transformación de los Profesores de Educación General Básica especialidad Preescolar y de los Maestros Especialistas en Educación Infantil en Graduados en Maestro en Educación Infantil. ${ }^{4}$

El Grado en Maestro en Educación Infantil de la Universidad de Salamanca se imparte en los tres centros pertenecientes a un mismo distrito universitario: la Escuela Universitaria de Educación y Turismo de Ávila, la Facultad de Educación de Salamanca y la Escuela Universitaria de Magisterio de Zamora.

Los estudios de Grado de Maestro en Educación Infantil pertenecen a la rama de conocimiento de las Ciencias Sociales y Jurídicas. Su objetivo es preparar profesionalmente para el ejercicio de la profesión regulada de Maestro de Educación Infantil y sus distintas especialidades, con unos requisitos de formación establecidos por el Ministerio de Educación y Ciencia respecto a objetivos del título y planificación de las enseñanzas, que garantizarán la adquisición de las competencias necesarias para ejercer la profesión de acuerdo con lo regulado en la normativa aplicable.

Concretamente el Real Decreto 1594/2011, de 4 de noviembre, establece las especialidades docentes del Cuerpo de Maestros que desempeñarán sus funciones en las etapas de Educación Infantil y de Educación Primaria. Así el "Grado de Maestro en Educación Infantil o la titulación equivalente, cualifica al maestro que será el encargado de impartir todas las áreas del currículo en la etapa de Educación Infantil, tanto del primer ciclo, (0-3 años) como el segundo, (3-6 años)" (p. 17.630).

\footnotetext{
${ }^{4}$ El Real Decreto 1618/2011, de 14 de noviembre, estableció el reconocimiento de estudios en el ámbito de la educación superior para la realización de dichas adaptaciones.
} 


\subsubsection{El plan de estudios}

En la Memoria del Título de Grado en Maestro en Educación Infantil de la Universidad de Salamanca de 2014, aparece definido coma "una titulación con un modelo compatible con la mayoría de los países del Espacio Europeo de Educación Superior con una duración de cuatro años, organizado en colaboración con centros escolares, con objeto de reforzar los vínculos entre formadores de profesores, profesores en activo y el mundo del trabajo". (p.10)

El Plan de Estudios del Grado en Maestro en Educación Infantil asume las medidas políticas para mejorar la calidad de la formación del profesorado en la Unión Europea, y en consecuencia propone un plan capaz de impulsar programas de formación de profesores en los ciclos de master y de doctorado que completen el ciclo de la carrera docente de nuestros egresados.

La formación del profesorado de Educación Infantil ha de garantizar la adquisición de competencias profesionales que contribuyan a propiciar el desarrollo individual y social del alumnado de Educación Infantil y que permitan al estudiante el ejercicio de la actividad profesional conforme a las exigencias y estándares utilizados en el área ocupacional correspondiente.

Con el propósito de adquirir dicho objetivo, el Grado en Maestro en Educación Infantil de la Universidad de Salamanca contempla, de forma explícita, tres tipos de competencias:

1.- Las competencias generales para todos los títulos de Grado (definidas en el RD 1393/2007, de 29 de octubre, por el que se establece la ordenación de las enseñanzas universitarias oficiales):

1.-Que los estudiantes hayan demostrado poseer y comprender conocimientos en las áreas de estudio que parten de la base de la educación secundaria general, y se hayan completado hasta un nivel que, si bien se apoya en libros de texto avanzados, incluyen también algunos aspectos que implican conocimientos procedentes de la vanguardia del campo de la educación. 
2.-Que los estudiantes sepan aplicar sus conocimientos a su trabajo de una forma profesional y posean las competencias que suelen demostrarse por medio de la elaboración y defensa de argumentos y la resolución de problemas dentro del campo de la educación.

3.-Que los estudiantes tengan la capacidad de reunir e interpretar datos significativos del ámbito de la educación para emitir juicios que incluyan una reflexión sobre temas relevantes de índole social, científica o ética.

4.-Que los estudiantes puedan transmitir información, ideas, problemas y soluciones tanto a sus compañeros de profesión como a la sociedad en general y a los padres de sus alumnos en particular.

5.-Que los estudiantes hayan desarrollado aquellas habilidades de aprendizaje necesarias para emprender estudios posteriores con un alto grado de autonomía.

2.- Las competencias específicas señaladas en el Plan de Estudios de Grado en Maestro en Educación Infantil (responden a las exigidas en la Orden ECI/3854/2007, de 27 de diciembre, por la que se establecen los requisitos para la verificación de los títulos universitarios oficiales que habiliten para el ejercicio de la profesión de Maestro en Educación Infantil):

1. Conocer los objetivos, contenidos curriculares y criterios de evaluación de la Educación Infantil.

2. Promover y facilitar los aprendizajes en la primera infancia, desde una perspectiva globalizadora e integradora de las diferentes dimensiones cognitiva, emocional, psicomotora y volitiva.

3. Diseñar y regular espacios de aprendizaje en contextos de diversidad que atiendan a las singulares necesidades educativas de los estudiantes, a la igualdad de género, a la equidad y al respeto a los derechos humanos.

4. Fomentar la convivencia en el aula y fuera de ella y abordar la resolución pacífica de conflictos. Saber observar sistemáticamente contextos de aprendizaje y convivencia y saber reflexionar sobre ellos. 
5. Reflexionar en grupo sobre la aceptación de normas y el respeto a los demás. Promover la autonomía y la singularidad de cada estudiante como factores de educación de las emociones, los sentimientos y los valores en la primera infancia.

6. Conocer la evolución del lenguaje en la primera infancia, saber identificar posibles disfunciones y velar por su correcta evolución. Abordar con eficacia situaciones de aprendizaje de lenguas en contextos multiculturales y multilingües. Expresarse oralmente y por escrito y dominar el uso de diferentes técnicas de expresión.

7. Conocer las implicaciones educativas de las tecnologías de la información y la comunicación y, en particular, de la televisión en la primera infancia.

8. Conocer fundamentos de dietética e higiene infantiles. Conocer fundamentos de atención temprana y las bases y desarrollos que permiten comprender los procesos psicológicos, de aprendizaje y de construcción de la personalidad en la primera infancia.

9. Conocer la organización de las escuelas de Educación Infantil y la diversidad de acciones que comprende su funcionamiento. Asumir que el ejercicio de la función docente ha de ir perfeccionándose y adaptándose a los cambios científicos, pedagógicos y sociales a lo largo de la vida.

10. Actuar como orientador de padres y madres en relación con la educación familiar en el periodo 0-6 y dominar habilidades sociales en el trato y relación con la familia de cada estudiante y con el conjunto de las familias.

11. Reflexionar sobre las prácticas de aula para innovar y mejorar la labor docente Adquirir hábitos y destrezas para el aprendizaje autónomo y cooperativo y promoverlo en los estudiantes.

12. Comprender la función, las posibilidades y los límites de la educación en la sociedad actual y las competencias fundamentales que afectan a los colegios de Educación Infantil y a sus profesionales. Conocer modelos de mejora de la calidad con aplicación a los centros educativos.

3.- Las competencias específicas del título, recogidas en la Memoria del título, están relacionadas con las disciplinas propias de éste y que se dividen en cinco tipos: 
Competencias básicas de Educación Infantil: aquellas que los estudiantes deben adquirir durante sus estudios exigibles para conseguir el título de Grado.

Competencias didáctico disciplinares de educación Infantil: aquellas que se deben adquirir durante sus estudios exigibles para conseguir el título de Grado.

Competencias de Practicum: las que se deben adquirir para tener un conocimiento práctico del aula y de la gestión de la misma.

Competencias de las Menciones: las que contribuyen al desarrollo de competencias específicas de la mención.

Competencias de la optatividad: las elegidas entre un conjunto de asignaturas cuyas competencias inciden en aspectos de interés concreto de los estudiantes.

\subsubsection{Estructura del Plan de Estudios}

La ORDEN ECI/3854/2007, de 27 de diciembre, por la que se establecen los requisitos para la verificación de los títulos universitarios oficiales que habilitan para el ejercicio de la profesión de Maestro en Educación Infantil, define los Módulos requeridos para la formación del Grado en Maestros en Educación Infantil.

Cada uno de los módulos se subdivide agrupando conjuntos de competencias coherentes con el título del módulo. Estas competencias pueden corresponder al objeto de estudio de las Áreas de Conocimiento de los Departamentos Universitarios que imparten su docencia en el Grado. Por ello, el Plan de Estudios se estructura en Materias $^{5}$, que serán las que seleccionen, desarrollen y den coherencia a las competencias de los módulos de la Orden dentro del conjunto de la formación.

El Módulo Básico lo forman materias que se concretan en dieciséis asignaturas de 6 créditos ECTS, distribuidas a lo largo del primer y segundo curso. Son aquellas disciplinas básicas que el alumno tiene que conocer para llevar a cabo su labor en el aula, relacionadas con el conocimiento del centro escolar, el desarrollo psicológico de los alumnos, trastornos del aprendizaje, didáctica, teoría, etc. Se cursan a lo largo de toda la titulación.

\footnotetext{
5 Debemos distinguir entre materias y asignaturas. Una materia se puede impartir por varias asignaturas p.e. la práctica escolar se imparte en dos asignaturas: Practicum I y Practicum II.
} 
El Módulo Didáctico Disciplinar lo forman 9 materias de entre 6 y 12 ECTS, que se concretan en asignaturas de 4 o 6 créditos; proceden de la división de los tres submódulos de la Orden ECl/3854/2007: Aprendizaje de las Ciencias de la Naturaleza, de las Ciencias Sociales y de la Matemática; Aprendizaje de Lenguas y Lectoescritura, y Música, Expresión plástica y corporal. Se cursan a lo largo de segundo y tercer curso.

El Módulo de Optatividad y Menciones. Este Módulo ofrece asignaturas de 6 ECTS que los estudiantes deberán escoger en tercer y cuarto curso, superando un total de 30 ECTS, es decir, cursarán 5 asignaturas de las ofertadas. Están formadas por aquellas asignaturas ofertadas por los distintos Departamentos con docencia en el Grado y por aquellas que forman parte de una de las menciones ${ }^{6}$ de: Educación Especial, Educación Musical, Audición y Lenguaje, Lengua Extranjera: Francés, Lengua Extranjera: Inglés, y Lengua Extranjera: Alemán. En el caso que las 5 asignaturas cursadas sean de la misma mención, se obtendrá la mención correspondiente.

Las Menciones están repartidas entre los tres Centros de la Universidad de Salamanca en los que se imparte el Grado en Maestro en Educación Infantil. (Tabla 1)

Los alumnos podrán cursar las asignaturas de la mención que elijan en el centro en que se imparta con independencia de que su matrícula esté adscrita a otro centro. Para facilitar la movilidad de los estudiantes entre los centros, dichas clases se concentran en dos días (jueves y viernes para las asignaturas de 30 y lunes y martes para las de cuarto curso).

Tabla 1: Menciones ofertadas para el Grado de Infantil de la Universidad de Salamanca.

\begin{tabular}{|c|c|c|}
\hline $\begin{array}{c}\text { E. U. EDUCACIÓN Y TURISMO } \\
\text { ÁVILA }\end{array}$ & $\begin{array}{c}\text { FACULTAD DE EDUCACIÓN } \\
\text { SALAMANCA }\end{array}$ & $\begin{array}{c}\text { E. U. DE MAGISTERIO } \\
\text { ZAMORA }\end{array}$ \\
\hline $\begin{array}{c}\text { Lengua Extranjera: inglés } \\
\text { Audición y Lenguaje } \\
\text { Educación Musical }\end{array}$ & $\begin{array}{c}\text { Lengua Extranjera: francés } \\
\text { Educación Especial }\end{array}$ & $\begin{array}{c}\text { Lengua Extranjera: inglés } \\
\text { Lengua Extranjera: alemán }\end{array}$ \\
& & \\
\hline
\end{tabular}

Tabla de elaboración propia.

El Módulo Practicum y Trabajo de fin de Grado. Este Módulo engloba, por un lado, una materia de 44 ECTS, el Practicum, que se desarrollará en dos semestres

\footnotetext{
6 Las Menciones sirven para adquirir una especialización específica que se incorpora a la formación y cualificación atribuida al título de Grado correspondiente, para el reconocimiento de distintas Especialidades del Cuerpo de Maestros, y para cumplir con los requisitos específicos de cualificación y formación para impartir determinadas materias en Educación Infantil en los centros privados.
} 
distintos y lo forman dos asignaturas, una en tercero y otra en cuarto curso que se concretan en la realización de prácticas externas en centros de educación infantil. Permiten a los estudiantes iniciarse en la realidad docente directa y conocer los aspectos pedagógicos, organizativos y de funcionamiento de los centros, con el apoyo y bajo la tutela de maestros en ejercicio acreditados como maestros tutores de prácticas. Y por otro, el Trabajo de Fin de Grado (TFG), corresponde a un trabajo autónomo que cada estudiante realizará bajo la orientación de un tutor académico, quien actuará como dinamizador y facilitador del proceso de aprendizaje. El TFG permitirá al estudiante mostrar de forma integrada los contenidos formativos recibidos y las competencias adquiridas asociadas al título de Grado, mostrando con ello su capacidad para desempeñar una labor profesional acorde a su titulación. La presentación del TFG supone la superación previa de todos los créditos necesarios para obtener la titulación a excepción de los 6 ECTS que corresponden al TFG.

Por tanto, el plan de estudios tiene una duración de 4 años, en los que los alumnos deben completar los 240 créditos de los que consta el Título. Cada año han de completar 60 ECTS, cursando las materias correspondientes pertenecientes a los diferentes módulos mencionados. (Tablas 2,3 y4)

Tabla 2: Tipos de materias, créditos asignados y su correspondencia con los módulos

\begin{tabular}{|l|l|l|l|}
\hline Tipo de Materia & \multicolumn{2}{|l|}{ Créditos } & Correspondencia con Módulos \\
\hline Formación básica & 60 & 48 & $\begin{array}{l}\text { Módulo Básico común de los Grados de Maestro } \\
\text { Módulo Didáctico Disciplinar común de los Grados de Maestro }\end{array}$ \\
\hline Obligatorias & 100 & 12 & $\begin{array}{l}\text { Módulo Básico común de los Grados de Maestro } \\
\text { Módulo Básico de E. Infantil } \\
\text { Módulo Didáctico Disciplinar de E. Infantil }\end{array}$ \\
\hline Optativas y Menciones & 30 & 30 & $\begin{array}{l}\text { Módulo de optatividad del perfil generalista en E. Infantil y optativas de } \\
\text { las menciones de Educación Musical, Audición y lenguaje, Lengua } \\
\text { Extranjera: inglés, y Lengua Extranjera: alemán } \\
\text { Menciones de: Lengua Extranjera: Francés y Educación Especial. }\end{array}$ \\
\hline Practicum y Trabajo de Grado & 50 & 44 & $\begin{array}{l}\text { Módulo Practicum } \\
\text { Trabajo de fin de Grado }\end{array}$ \\
\hline
\end{tabular}

Fuente: Tabla adaptada de la memoria del Título de Graduado o Graduada en Maestro en Educación infantil. Universidad de Salamanca. 
Tabla 3. Distribución del plan de estudios tipo de módulos y materias (Orden ECI/3854/2007)

\begin{tabular}{|c|c|c|}
\hline TIPO DE MÓDULO & Créditos ECTS & MATERIAS \\
\hline Módulo de Formación Básica & 100 & $\begin{array}{l}\text {-Procesos educativos, aprendizaje y desarrollo de la personalidad. } \\
18 \text { ECTS } \\
\text {-Dificultades de aprendizaje y trastornos del desarrollo.12 ECTS } \\
\text {-Sociedad, familia y escuela.22 ECTS } \\
\text {-Organización del espacio escolar, materiales y habilidades } \\
\text { docentes.18 ECTS } \\
\text {-La escuela de educación infantil.12 ECTS } \\
\text {-Observación sistemática y análisis de contextos.6 ECTS }\end{array}$ \\
\hline $\begin{array}{l}\text { Módulo didáctico disciplinar de } \\
\text { Educación Infantil }\end{array}$ & 60 & $\begin{array}{l}\text {-Aprendizaje de las CC de la Naturaleza, de las CC Sociales, y de las } \\
\text { matemáticas. } 24 \text { ECTS } \\
\text {-Aprendizaje de lenguas y lectoescritura.18 ECTS } \\
\text {-Música, expresión plástica y corporal. } 18 \text { ECTS }\end{array}$ \\
\hline Módulo de optatividad y menciones & 30 & $\begin{array}{l}\text { - } 5 \text { asignaturas elegidas entre las optativas ofertadas por las } \\
\text { menciones o por el perfil generalista }\end{array}$ \\
\hline $\begin{array}{l}\text { Módulo Practicum: Prácticas externas y } \\
\text { Trabajo Fin de Grado }\end{array}$ & $44+6$ & $\begin{array}{l}\text { - Practicum. } 44 \text { ECTS } \\
\text { - Trabajo Fin de Grado.6ECTS }\end{array}$ \\
\hline TOTAL & 240 & \\
\hline
\end{tabular}

Fuente: Adaptación del Plan de estudios. Grado en Maestro en Educación Infantil. Universidad de Salamanca p.8: Módulos y materias.

Tabla 4. Distribución del plan de estudios (artículo 28 del Real Decreto 1393/2007 de 29 de octubre)

\begin{tabular}{|c|c|c|c|c|}
\hline Módulo & Asignatura & Carácter & $\begin{array}{l}\text { Créditos } \\
\text { ECTS }\end{array}$ & $\begin{array}{c}\text { Organización } \\
\text { Temporal }\end{array}$ \\
\hline \multirow{3}{*}{ Psicología I } & Psicología del desarrollo, infancia y adolescencia & Básica & 6 & Semestral \\
\hline & Psicología de la educación & Básica & 6 & Semestral \\
\hline & Psicología de las dificultades de aprendizaje & Obligatoria & 6 & Semestral \\
\hline \multirow{3}{*}{ Psicología II } & Psicología del desarrollo infantil de $0-6$ años. & Obligatoria & 6 & Semestral \\
\hline & Promoción del desarrollo personal y social & Obligatoria & 6 & Semestral \\
\hline & Desarrollo y aprendizaje en alumnos con n.e.e. & Obligatoria & 6 & Semestral \\
\hline \multirow{6}{*}{ Pedagogía I } & Procesos educativos & Básica & 6 & Semestral \\
\hline & Didáctica General & Básica & 6 & Semestral \\
\hline & Las tecnologías de la información y la comunicación en educación & Básica & 6 & Semestral \\
\hline & Organización del centro escolar & Básica & 6 & Semestral \\
\hline & Metodología de Investigación en educación & Básica & 6 & Semestral \\
\hline & Atención a la diversidad & Obligatoria & 6 & Semestral \\
\hline \multirow{3}{*}{ Pedagogía II } & Instituciones educativas. & Obligatoria & 6 & Semestral \\
\hline & Didáctica de la educación infantil & Obligatoria & 6 & Semestral \\
\hline & Organización de la escuela infantil & Obligatoria & 6 & Semestral \\
\hline Lengua Extranjera & Lengua inglesa / lengua francesa/ Lengua alemana & Básica & 6 & Semestral \\
\hline Sociología & Sociología & Básica & 6 & Semestral \\
\hline Comunicación en Educación & Comunicación Lingüística & Básica & 6 & Semestral \\
\hline $\begin{array}{l}\text { Aprendizaje de las Ciencias de la } \\
\text { Naturaleza }\end{array}$ & Ciencias de la naturaleza y su didáctica en educación infantil & Obligatoria & 6 & Semestral \\
\hline Aprendizaje de las Ciencias Sociales & Aprendizaje de las ciencias sociales en educación infantil & Obligatoria & 6 & Semestral \\
\hline \multirow{2}{*}{$\begin{array}{l}\text { Aprendizaje de Lenguas y } \\
\text { Lectoescritura }\end{array}$} & Desarrollo de habilidades lingüísticas & Obligatoria & 6 & Semestral \\
\hline & Literatura infantil y enseñanza de la literatura & Obligatoria & 6 & Semestral \\
\hline Aprendizaje de las Matemáticas & Matemáticas y su didáctica para educación infantil & Obligatoria & 6 & Semestral \\
\hline Expresión Corporal & Educación corporal a través del movimiento & Obligatoria & 6 & Semestral \\
\hline Expresión Plástica & Expresión plástica en la educación infantil & Obligatoria & 6 & Semestral \\
\hline Expresión Musical & Expresión musical en la educación infantil & Obligatoria & 6 & Semestral \\
\hline Infancia, Salud y Alimentación & Salud y alimentación en la infancia y su didáctica & Obligatoria & 4 & Semestral \\
\hline Optativa & Optativa o Mención & Optativa & 30 & Semestral \\
\hline \multirow{2}{*}{ Practicum } & Practicum I & $\begin{array}{l}\text { Prácticas } \\
\text { externas }\end{array}$ & 20 & Semestral \\
\hline & Practicum II & $\begin{array}{l}\text { Prácticas } \\
\text { externas }\end{array}$ & 24 & Semestral \\
\hline Trabajo Fin de Grado & Trabajo fin de Grado & TFG & 6 & Semestral \\
\hline
\end{tabular}

Fuente: Plan de estudios. Grado en Maestro en Educación Infantil. Universidad de Salamanca. 


\subsubsection{Las Menciones del Grado en Maestro en Educación Infantil}

Como ya se comentó en el apartado anterior, los estudiantes del grado a partir del tercer año pueden especializarse en un campo concreto de la docencia escolar a través de las menciones.

Las Menciones de los estudios de Grado de Maestro se establecen en consonancia con las Especialidades del Cuerpo de Maestros establecidas en el Real Decreto 1594/2011, de 4 de noviembre, por lo que se refiere a los centros públicos, y con los requisitos de cualificación y formación para el desempeño de la profesión de Maestro en los centros privados de Educación Infantil y Educación Primaria, establecidos en el RD 476/2013, de 21 de junio.

El Grado en Maestro en Educación Infantil de la Universidad de Salamanca ofrece la posibilidad de cursar Menciones cualificadoras adecuadas a los objetivos, ciclos y áreas de la Educación Infantil, de acuerdo con lo establecido en la LOE 2/2006, de 3 de mayo. (Art. 92). La Orden ECl/3854/2007, de 27 de diciembre, en su apartado 5 establece que "En estas enseñanzas podrán proponerse menciones cualificadoras, entre 30 y 60 créditos europeos, adecuadas a los objetivos, ciclos y áreas de la Educación Infantil que se establecen en los artículos 13 y 14 de la LOE 2/2006, de 3 de mayo".

Las menciones proporcionan una formación especializada en los siguientes ámbitos de conocimiento:

Audición y Lenguaje. Esta mención se cursará en la Escuela Universitaria de Educación y Turismo de Ávila. Trata de formar maestros que atiendan la educación de los niños con graves problemas de audición, del habla y/o que no han desarrollado adecuadamente el lenguaje, como personas con discapacidad intelectual, motórica con afectación del habla, trastornos del espectro autista y/o trastornos específicos del lenguaje.

Educación Especial. Esta mención se cursará en la Facultad de Educación. Trata de formar maestros que atiendan adecuadamente la educación de niños $\operatorname{con}^{7}$ retraso

\footnotetext{
${ }^{7}$ Terminología que viene definida en la ORDEN ECI/3854/2007, de 27 de diciembre, por la que se establecen los requisitos para la verificación de los títulos universitarios oficiales que habiliten para el ejercicio de la profesión de Maestro en Educación Infantil, BOE núm. 312. En este sentido, creemos
} 
intelectual, altas capacidades intelectuales, problemas de aprendizaje, deficiencia motora, sistemas de comunicación no verbales, deficiencias visuales, alteraciones de comportamiento y diferentes tipos de trastornos. ${ }^{8}$

Educación Musical. Esta mención se cursará en la Escuela Universitaria de Educación y Turismo de Ávila, y trata de formar a los maestros especialistas en educación musical para impartir la educación musical en la etapa de educación primaria tal como aparece regulada en el Capítulo II, Profesorado de las distintas enseñanzas, Artículo 93, Profesorado de educación primaria, de la L.O. 2/2006, de 3 de mayo, de Educación.

Lengua extranjera Inglés, Francés y Alemán. La realidad muestra la creciente demanda de programas escolares que integran los contenidos curriculares y las lenguas extranjeras desde la etapa más temprana, lo cual justifica plenamente el establecimiento de itinerarios formativos en este sentido.

Por otro lado, es necesario puntualizar que, aunque la Mención de la enseñanza de la religión escolar solo se oferta para el Grado en Maestro en Educación Primaria, los alumnos del Grado en Maestro en Educación Infantil podrán cursarla en su totalidad en régimen de asignaturas optativas para con ello, poder acceder a la posesión del título de la Declaración Eclesiástica de Competencia Académica (DECA), expedido por la CEE para el nivel de Educación Infantil.

\subsubsection{Las prácticas externas en el grado en maestro en educación infantil}

El Practicum, hace referencia a las materias que se cursan en el Grado en relación a la realización de las prácticas externas.

Estamos de acuerdo con González Sannamed y Fuentes Abeledo (2011) cuando señalan que

...el Practicum se ubica en la encrucijada del aprendizaje docente, la construcción del conocimiento y la socialización profesional. Encrucijada en

conveniente sustituir el término de necesidades educativas especiales, por el de barreras de aprendizaje, que se ha estado proponiendo desde 2002 por diferentes investigadores, colectivos y profesores.

${ }^{8}$ La necesidad de ambas menciones queda patente en el Título II de la LOE 2/2006, de 3 de mayo, que establece tanto el concepto de alumnos con necesidades específicas de apoyo como las condiciones en las que éstos han de ser atendidos. 
cuanto a las experiencias, acciones, conocimientos y sentimientos que el futuro profesor se ve obligado a procesar y, necesariamente, asimilar; y en cuanto a los modos de afrontarlos y aprovecharlos para dotarse de los saberes y destrezas que necesita (p. 59).

Dentro de la formación del maestro, el Practicum es la materia con mayor carga de créditos del plan de estudios, 44 ECTS. En ella, el estudiante pone en marcha todos los mecanismos docentes teóricos y prácticos que ha ido adquiriendo a través de las diferentes asignaturas cursadas en el Grado. Se divide en dos asignaturas a cursar respectivamente en tercer y cuarto curso: Practicum I y Practicum II. Este periodo de prácticas tiene un carácter progresivo y para cursarlas el estudiante tendrá que haber superado al menos 90 ECTS del Grado en el momento de realizar la matrícula.

El Practicum contempla, además de la estancia en los centros escolares acreditados de Educación Infantil, otras actividades como sesiones formativas y clases presenciales, que son planificadas, programadas, impartidas y evaluadas por el profesorado de la universidad.

Para el desarrollo de las prácticas, existe un convenio suscrito entre la Consejería de Educación de la Junta de Castilla y León y la Universidad de Salamanca a través del cual las Direcciones Provinciales proporcionan a los tres Centros una relación de centros educativos y maestros tutores donde los estudiantes del Grado pueden realizar sus prácticas. ${ }^{9}$

El período de prácticas que realiza el estudiante pretende ayudarle a enriquecer su formación teórico-práctica mediante un proceso guiado en la práctica docente, que garantice el apoyo emocional, estratégico y conceptual requerido en cada momento; así como la reflexión individual y colaborativa en aras de una mayor autonomía, madurez y responsabilidad. Por tanto, las finalidades generales que el alumno debe alcanzar, tal y como figura en la Guía del Practicum de los Grados de Maestro de la Universidad de Salamanca, (p.10) son:

- Iniciarse en el conocimiento práctico de la profesión docente.

- Ponerse a prueba como profesional de la educación.

\footnotetext{
9 Orden, de 25 de julio, por la que se regula la realización de las prácticas de las asignaturas del Practicum de las enseñanzas universitarias de Grado en Educación Infantil y Grado en Educación Primaria en centros docentes sostenidos con fondos públicos de la Comunidad de Castilla y León que imparten estas enseñanzas (BOCyL 31/7/2012).
} 
- Desarrollar la autonomía de pensamiento y de actuación.

- Potenciar la capacidad de trabajo en equipo.

- Integrar reflexiva y críticamente los contenidos estudiados.

- Identificarse con un determinado modelo profesional.

- Crear redes integradoras de trabajo y unión de fuerzas entre personas.

Estas, se han de traducir en la aplicación y consecución de las siguientes competencias específicas del Practicum (Anexo de las Órdenes ECl/3854/2007 y $\mathrm{ECl} / 3857 / 2007$, p. 53738) que son:

P 1. Adquirir un conocimiento práctico del aula y de la gestión de la misma.

P 2. Conocer y aplicar los procesos de interacción y comunicación en el aula y dominar las destrezas y habilidades sociales necesarias para fomentar un clima de aula que facilite el aprendizaje y la convivencia.

P 3. Controlar y hacer el seguimiento del proceso educativo y en particular el de enseñanza-aprendizaje mediante el dominio de las técnicas y estrategias necesarias.

P 4. Relacionar teoría y práctica con la realidad del aula y del centro.

P 5. Participar en la actividad docente y aprender a saber hacer, actuando y reflexionando desde la práctica.

P 6. Participar en las propuestas de mejora en los distintos ámbitos de actuación que se puedan establecer en un centro.

P 7. Regular los procesos de interacción y comunicación en grupos de estudiantes 6-12 años.

P 8. Conocer formas de colaboración con los distintos sectores de la comunidad educativa y del entorno social. 


\section{LA FORMACIÓN EN EXPRESIÓN MUSICAL EN EL GRADO EN MAESTRO EN EDUCACIÓN INFANTIL}

\subsection{La enseñanza de la música en los estudios de Maestro}

La enseñanza de la música en las Escuelas Normales de Salamanca se venía impartiendo en el currículum de maestro desde 1878 (García Herrera, 1994) bajo diferentes materias como Música y Canto $^{10}$ o Música ${ }^{11}$. A partir de 1970, con la Ley General de Educación, la enseñanza de la música empezó a formar parte de los contenidos del área de Expresión Dinámica y continuaría sin interrupción en los diferentes planes de estudios hasta la entrada en vigor de la Ley Orgánica 11/1983, de 25 de agosto, de Reforma Universitaria, (RLU) en la que se impartiría en las especialidades de Filología, Ciencias Humanas y Ciencias como área común y como materia específica en las especialidades de Preescolar y de Educación Especial formando parte del currículo de la materia de "Expresión plástica y dinámica".

A partir de la implantación de la LOGSE de 1990, se produce una renovación de los estudios universitarios relacionados con la música. Ley que, como hemos visto, formula un nuevo mapa del título de Maestro con siete especialidades, lo que trajo consigo la creación del Título de Maestro-Especialidad en Educación Musical ${ }^{12}$, además de la presencia de la asignatura de "Expresión Musical y su Didáctica" como una asignatura de 6 créditos troncal en las especialidades de Educación Primaria, Educación Especial, Educación Física y Lengua Extranjera y de dos asignaturas de 4,5 créditos cada una en la Titulación de Educación Infantil: "Expresión Musical y su Didáctica I" y "Expresión Musical y su Didáctica II".

La diplomatura de Maestro en Educación Musical tenía como objetivo general la formación de un maestro generalista de Primaria con especialización en educación

\footnotetext{
${ }^{10}$ RD 23 de septiembre de 1898 de reforma de las Escuelas Normales

${ }^{11} \mathrm{RD}$ de 30 de agosto de 1914. Decreto de 29 de septiembre de 1931, las normas relativas a la preparación del Magisterio primario. Decreto de 7 de Julio de 1950 por el que se aprueba el Reglamento para las Escuelas del Magisterio

12 RD 1140/1991 de 30 de agosto, por el que se establece el Título oficial de Maestro en sus diversas especialidades y las directrices generales propias de los planes de estudio conducentes a su obtención.
} 
artística-musical, enseñanzas que debían "proporcionar una formación orientada al desarrollo de la actividad docente en los correspondientes niveles del sistema educativo, integrando aspectos básicos con la preparación específica en la Especialidad de Educación Musical" (Real Decreto 1140/1991 de 30 de agosto p. 33013).

Antes de la implantación de los Grados, diversos autores entre los que se encontraba López de la Calle Sampedro, constataron en 2007, la escasa formación musical que recibían los alumnos de infantil en las diplomaturas, ofreciendo unas recomendaciones a tener en cuanta en los futuros estudios del Grado.

\subsection{La enseñanza de la música en el Grado en Maestro en Educación Infantil}

En las enseñanzas oficiales de la etapa de Educación Infantil, no se contempla la figura del Maestro Especialista en Educación Musical, ya que, como hemos visto, solo existe para las enseñanzas de la etapa de Educación Primaria, siendo, por tanto, el maestro generalista en Educación Infantil el encargado de impartir el currículum de música en esta etapa.

En la actual titulación del Grado en Maestro en Educación Infantil, la formación musical básica que reciben los alumnos, se ha reducido a una asignatura que se imparte en tercer curso: "Expresión Musical en la Educación infantil", con una carga de 6 ECTS, lo que supone, una disminución respecto a los anteriores planes de formación que constituían las antiguas diplomaturas.

Por otro lado, los alumnos que cursan el Grado en Maestro en Educación Infantil, pueden elegir entre las asignaturas optativas ofertadas por las menciones de Educación Musical, Educación Especial, o generales del Grado relacionadas con la música, como un intento de fortalecer su formación musical. Estas se muestran en la Tabla 5: 
Tabla 5. Relación de asignaturas optativas ofertadas por el área de Didáctica de la Expresión Musical para el Grado en Maestro en Educación Infantil.

\begin{tabular}{|c|c|c|c|}
\hline Curso & Titulación & Asignatura & Tipología \\
\hline 40 & Men. E. Especial & Educación Musical en los niños con N.E.E. & Optativa Mención \\
\hline 40 & Grado E. Infantil & Taller de actividades musicales & Optativa Grado \\
\hline 30 & Menc. E. Musical & Formación vocal & Optativa Mención \\
\hline $4 \stackrel{0}{4}$ & Menc. E. Musical & Formación rítmica y danza & Optativa Mención \\
\hline 40 & Menc. E. Musical & Formación instrumental & Optativa Mención \\
\hline 40 & Menc. E. Musical & Creación y selección de repertorio musical para el aula. & Optativa Mención \\
\hline 40 & Menc. E. Musical & Educación auditiva. & Optativa Mención \\
\hline
\end{tabular}

Fuente. Elaboración propia

Como se puede comprobar, resulta escasa la formación musical que reciben nuestros alumnos, pues si no cursaran ninguna asignatura optativa relacionada con la música, recibiría a lo largo del Grado una formación musical de 6 créditos ECTS, lo que resulta insuficiente para poder impartir adecuadamente el currículum en Expresión musical en la etapa de infantil. López de la Calle Sampedro (2007) señala esta carencia en una investigación realizada en las Escuelas de Formación Universitaria de la comunidad gallega:

...en la valoración que los profesores le conceden a su propia preparación en diversos ámbitos decisivos de la formación en educación musical en los estudios de maestro en educación infantil, los resultados obtenidos apuntaron que los profesores en general percibían todos los ámbitos propuestos como deficientes o regulares (p.497).

O la llevada a cabo en la Universidad de Burgos por Ruíz Palomo y Santamaría Conde (2013) sobre la formación musical del profesorado en Educación Infantil, que afirmaban que:

...lo deseable sería que los maestros del nivel educativo infantil, tengan una sólida formación musical que les permita realizar un trabajo estructurado, con planteamientos y objetivos claros y adecuados a las capacidades de los niños de cara a integrar la música en sus prácticas (p.447).

La formación musical básica resulta insuficiente para adquirir las competencias de carácter didáctico-disciplinar que los estudiantes deben conseguir en educación 
artística $^{13}$, dentro de la que forma parte la expresión musical, recogidas en la Orden $\mathrm{ECl} / 3854 / 2007$, enunciadas de la siguiente forma (p. 53738):

DI.21. Conocer los fundamentos musicales, plásticos y de expresión corporal del currículo de esta etapa, así como las teorías sobre la adquisición y desarrollo de los aprendizajes correspondientes.

DI.22. Conocer y utilizar canciones para promover la educación auditiva, rítmica y vocal.

DI.23. Saber utilizar el juego como recurso didáctico, así como diseñar actividades de aprendizaje basadas en principios lúdicos.

DI.24. Elaborar propuestas didácticas que fomenten la percepción y expresión musicales, las habilidades motrices, el dibujo y la creatividad.

DI.25. Analizar los lenguajes audiovisuales y sus implicaciones educativas.

DI.26. Promover la sensibilidad relativa a la expresión plástica y a la creación artística.

Es una realidad que constatamos cada año, que la formación inicial del profesorado respecto a su formación artística y en concreto a la educación musical, con tan pocas horas de formación se sigue limitando, tal como ya señalaba Giráldez (2009) a unas pocas horas de música centradas en la cualificación a base de técnicas y rudimentos básicos, sin proporcionar unas bases teóricas y metodológicas adecuadas lo que repercutirá más tarde, en los maestros y maestras en ejercicio que, cuando se dispongan a integrar los distintos lenguajes artísticos en el aula se encuentran, entonces, con una gran desorientación a la hora de acometer la tarea (p.14).

\footnotetext{
${ }^{13}$ En el currículo de Educación Infantil (RD 1630/2006, de 29 de diciembre, por el que se establecen las enseñanzas mínimas del segundo ciclo de Educación Infantil), la educación artística forma parte de un área más amplia, denominada Lenguajes: Comunicación y Representación, que incluye el lenguaje verbal, el lenguaje artístico, el lenguaje corporal, el lenguaje audiovisual y de las tecnologías de la información y la comunicación.
} 


\section{LA FORMACIÓN EN EDUCACIÓN INCLUSIVA EN EL GRADO EN MAESTRO EN EDUCACIÓN INFANTIL}

La diversidad de alumnos que integran las aulas escolares, ha producido una serie de cambios curriculares en nuestros sistemas educativos especialmente en la formación de los futuros encargados de recibir en el aula a todo tipo de alumnos, sean cual sean sus características.

\subsection{La educación inclusiva en los estudios de Maestro}

Como hemos visto, la primera vez que se introducen en la historia del magisterio estudios relacionados con las enseñanzas especiales fue durante la proclamación de la Segunda República, en concreto con la promulgación del Decreto de 29 de septiembre de 1931.

Por entonces, estas enseñanzas se entendían, como hemos comentado en palabras de Escolano (1982) aquellas dirigidas a los párvulos, retrasados, superdotados, etc., que requerían una escolarización diferente a la ordinaria.

La reforma educativa de 1970 de la Ley General de Educación, empieza a contemplar la idea de la integración de los alumnos que presenten "deficiencias leves" en aulas especiales dentro de los centros ordinarios, aunque debido a deficiencias presupuestarias no se llevó a cabo, y hasta 1977, con el Plan de Perfeccionamiento del Profesorado de EGB, no se crearían en los títulos de maestro, las especialidades de Preescolar y de Educación Especial.

Con la publicación del Real Decreto 334/1985, de 6 de marzo, de ordenación de la educación especial, se establece un currículum general para todo el alumnado, quedando reflejado en los planes de estudio del magisterio, por el Real Decreto 1297/1987, de 27 de noviembre, donde se establecieron las directrices comunes generales de los planes de estudio de los títulos universitarios de carácter oficial con validez en todo el territorio nacional. Para la formación inicial y oficial de los futuros profesores de EGB se ofertaban cinco especialidades: Ciencias, Ciencias Humanas y Sociales, Educación Especial, Filología y Educación Preescolar. 
Después de la Constitución Española de $1978^{14}$ y del fuerte cambio políticosocial de España, se publica la Ley 13/1982, de 7 de abril, de Integración Social de los Minusválidos (LISMI). En sus artículos 23 al 31 reflejan el planteamiento educativo de las personas con discapacidad, en los cuales ya se afirma y se insiste con rotundidad en que el alumno "se integrará en el sistema ordinario de educación general" (Casanova, 2011).

Por ello, cuando se publica la LOGSE, en 1990, ya se establece como norma la escolarización del alumnado con necesidades educativas especiales en la escuela ordinaria.

Para atender a estas demandas se dictamina el RD 1440/1991 de 30 de agosto, por el que se establece el Título Oficial de Maestro en sus diversas especialidades y las directrices generales propias de los planes de estudio conducentes a su obtención, dando lugar, como ya se ha mencionado, a una nueva titulación de Maestro especialista en Educación Especial.

\subsection{La educación inclusiva en los estudios del Grado en Maestro en Educación} Infantil

En los estudios del Grado en Maestro en Educación Infantil, se adquiere una formación generalista con algunas asignaturas en relación a la educación inclusiva, y los alumnos cuentan con la opción de profundizar en la Educación Especial cursando dicha mención, o asignaturas optativas de la mención ${ }^{15}$, de cara a formarse en el campo de la educación inclusiva.

Como materias obligatorias, en segundo curso se imparte "Atención a la diversidad", donde se parte del tratamiento a la diversidad para reforzar especialmente conceptos, procedimientos y valores inclusivos. En tercero, "Desarrollo y aprendizaje de alumnos con necesidades educativas especiales", asignaturas de 6 ECTS enmarcadas dentro de la atención a la diversidad de todo el alumnado. Como materias optativas en

\footnotetext{
${ }^{14}$ El artículo 27 reconoce el derecho a la educación de todos los ciudadanos

${ }^{15}$ El estudiante, que no desee cursar una mención deberá escoger y superar un total de 30 ECTS distribuidos en cinco asignaturas optativas de 6 ECTS de entre todas las ofertadas pertenecientes a una mención sin cursarla completa cuando la disponibilidad de plazas lo permita. (Plan de estudios de Graduado o graduada en Educación Infantil. p. 45)
} 
la mención en Educación Especial y también con una carga de 6 ECTS, se ofertan las asignaturas que aparecen en la siguiente tabla:

Tabla 6: Relación de asignaturas ofertadas para cursar la mención en Educación Especial

\begin{tabular}{|c|c|c|c|}
\hline Curso & Titulación & Asignatura & Tipología \\
\hline 30 & Grado infantil & Psicología de la discapacidad & $\begin{array}{l}\text { Obligatoria- } \\
\text { Mención. Optativa }\end{array}$ \\
\hline 30 & Grado infantil & Trastornos psicológicos infantiles & $\begin{array}{l}\text { Obligatoria- } \\
\text { Mención. Optativa }\end{array}$ \\
\hline 40 & Grado infantil & $\begin{array}{l}\text { Necesidades y respuestas educativas en alumnos } \\
\text { con discapacidad }\end{array}$ & $\begin{array}{c}\text { Obligatoria- } \\
\text { Mención. Optativa }\end{array}$ \\
\hline 40 & Grado infantil & Educación Musical en las N.E.E. & Optativa Mención \\
\hline 40 & Grado infantil & $\begin{array}{l}\text { Intervención educativa en la comunicación y el } \\
\text { lenguaje }\end{array}$ & Optativa Mención \\
\hline 40 & Grado infantil & Educación motriz en alumnos con N.E.E. & Optativa Mención \\
\hline
\end{tabular}

Tabla de elaboración propia.

En la Orden ECl/3857/2007, de 27 de diciembre, por la que se establecen los requisitos para la verificación de los títulos universitarios oficiales que habiliten para el ejercicio de la profesión de Maestro en Educación Infantil, se establecen las competencias que los estudiantes deben adquirir. En el grado de Maestro de Educación Infantil, de un total de 88, 37, tienen que ver con adquirir competencias para abordar una escuela inclusiva (León Guerrero, 2011).

En concreto, algunas competencias de tipo disciplinar y profesional específica que los alumnos deben adquirir son y que recoge la mencionada orden (pp. 53735 a 53738), son:

- Conocer los fundamentos psicológicos, pedagógicos y sociales de los procesos de desarrollo y aprendizaje en los diversos contextos educativos.

- Diseñar y gestionar espacios e intervenciones educativas en contextos de diversidad que atiendan a la igualdad de género, la equidad y el respeto a los derechos humanos como valores de una sociedad plural.

- Diseñar y regular espacios de aprendizaje en contextos de diversidad que atiendan a las singulares necesidades educativas de los estudiantes, a la igualdad de género, a la equidad y al respeto a los derechos humanos. 
- Promover la autonomía y la singularidad de cada estudiante como factores de educación de las emociones, los sentimientos y los valores en la primera infancia.

- Conocer los fundamentos de atención temprana.

- Adquirir recursos para favorecer la integración educativa de estudiantes con dificultades.

- Conocer y aplicar los procesos de interacción y comunicación en el aula.

- Dominar las destrezas y habilidades sociales necesarias para fomentar un clima de aula que facilite el aprendizaje y la convivencia

En un estudio realizado sobre las actitudes de los estudiantes del Grado de Magisterio y del Máster de Educación Especial de la Universidad de Valencia sobre la Inclusión educativa, todos los estudiantes mostraron una actitud favorable, pero, los alumnos de 2 o tras cursar la asignatura de formación básica, "Necesidades educativas especiales", relacionada con contenidos de educación especial, e incluso los de 3 o matriculados en la especialidad de Educación Inclusiva o del postgrado en Educación Especial eran de la misma opinión, pues se consideraban con formación insuficiente en para hacer frente a una inclusión educativa. (Tárraga, Grau, Peirats, 2013). Lo mismo recogían investigadores como Boer, Pijl, y Minnaert, (2011) que indicaban que los estudiantes ni los maestros se sienten suficientemente formados, ni competentes para llevar a cabo la inclusión, aunque tienen una actitud positiva, por lo que, en nuestra opinión, creemos que los estudiantes reciben una formación insuficiente en este sentido.

La realidad de las aulas apunta a que la falta de capacitación del profesorado, bloquea la inclusión, pues representa una tarea difícil para los maestros todavía no dimensionada de forma clara (Santos Jara, 2006). Los profesores deben contar con los conocimientos teóricos y prácticos que les permitan atender a la gran variedad de necesidades educativas de sus alumnos, siendo vital la formación inicial de un profesorado inclusivo.

La Agencia Europea para el Desarrollo de las Necesidades Educativas Especiales, (2011), analizó como debería ser la formación del profesorado para que este fuera 
inclusivo. Durante tres años, se revisaron 29 informes nacionales sobre la formación inicial del profesorado, con la finalidad de elaborar un perfil de competencias del profesorado inclusivo para darlo a conocer en las Facultades de Educación y centros de Formación del Profesorado como punto de partida para todos los formadores de maestros (Echeita, 2011) El perfil, estaría estructurado alrededor de cuatro valores nucleares:

1. Valorar la diversidad del alumnado. Las diferencias en el aprendizaje son consideradas un recurso y un valor educativo.

2. Apoyar a todos los aprendices. El profesorado tiene altas expectativas sobre el rendimiento de todo su alumnado.

3. Trabajar con otros: la colaboración y el trabajo en equipo son esenciales para el trabajo que todos los profesores deben desarrollar

4. Cuidar el desarrollo profesional personal: la enseñanza es una actividad de aprendizaje constante y el profesorado debe tomar la responsabilidad de su formación permanente, a lo largo de su vida profesional.

En este sentido, en la Universidad de Salamanca las competencias de formación básicas que los alumnos adquieren relacionadas con la escuela inclusiva que vienen recogidas en el plan de estudios son:

BI.2. Conocer los desarrollos de la psicología evolutiva de la infancia en los periodos 0-3 y 3-6.

Bl.3. Conocer los fundamentos de atención temprana. Reconocer la identidad de la etapa y sus características cognitivas, psicomotoras, comunicativas, sociales, afectivas.

Bl.4. Saber promover la adquisición de hábitos en torno a la autonomía, la libertad, la curiosidad, la observación, la experimentación, la imitación, la aceptación de normas y de límites, el juego simbólico y heurístico.

BI.5. Conocer la dimensión pedagógica de la interacción con los iguales y los adultos y saber promover la participación en actividades colectivas, el trabajo cooperativo y el esfuerzo individual.

BI.6. Identificar dificultades de aprendizaje, disfunciones cognitivas y las relacionadas con la atención.

BI.7. Saber informar a otros profesionales especialistas para abordar la colaboración del centro y del maestro en la atención a las necesidades educativas especiales que se planteen. 
Bl.8. Adquirir recursos para favorecer la integración educativa de estudiantes con dificultades.

BI.12. Analizar e incorporar de forma crítica las cuestiones más relevantes de la sociedad actual que afectan a la educación familiar y escolar: impacto social y educativo de los lenguajes audiovisuales y de las pantallas; cambios en las relaciones de género e intergeneracionales; multiculturalidad e interculturalidad; discriminación e inclusión social y desarrollo sostenible.

BI.15. Identificar trastornos en el sueño, la alimentación, el desarrollo psicomotor, la atención y la percepción auditiva y visual.

BI.16. Colaborar con los profesionales especializados para solucionar dichos trastornos.

BI.17. Detectar carencias afectivas, alimenticias y de bienestar que perturben el desarrollo físico y psíquico adecuado de los estudiantes.

¿Es suficiente esta formación para, como dice la LOMCE atender a aquellos alumnos que requieran una atención diferente a la ordinaria? Estas competencias, ¿̇e adquieren cursando las asignaturas relacionadas con la Formación Básica? 


\section{Capitulo 2. LA EDUCACIÓN MUSICAL}

En este capítulo se presenta el tratamiento que la educación musical ha recibido, por una parte, en el currículo de las distintas etapas de la educación obligatoria española en las diferentes leyes educativas hasta la actual Ley Orgánica de Mejora de la Calidad Educativa (LOMCE) por otra, el currículum de música en la etapa de la educación infantil en nuestra comunidad de Castilla y León.

\section{LA EDUCACIÓN MUSICAL TEMPRANA}

Las corrientes de pensamiento que más han influido en la educación obligatoria en nuestro país, han tenido como base las teorías cognitivas desarrolladas en psicología en la segunda mitad del S. XX. Desde la LOGSE, los sistemas educativos españoles se han fundamentado en las teorías de Bruner (1915-2016), Piaget (1896-1980) y Vygotsky (1898-1934) representantes entre otros, del cognitivismo al constructivismo y en los principios pedagógicos de la Escuela Nueva ${ }^{16}$. Este movimiento, que surge en el S.XIX. subrayaba el valor educativo de las distintas artes, otorgando a la música un lugar destacado. Sus raíces, se encuentran entre otros, en las pedagogías sensoriales de Comenio (1592-1670) o Rameau (1638-1764) quienes defendieron las capacidades musicales como patrimonio universal, y en Rousseau (1712-1778) para quien la experimentación musical debía ser antes que alfabetización musical y que continuaron con Decroly (1871-1932), Freinet (1896-1966) y María Montessory (1870-1952). Esta autora otorgaba a la música un valor formativo, la comparaba con el lenguaje hablado considerándola como algo natural en el desarrollo humano. Ideas que tuvieron una gran repercusión en la legislación educativa sobre todo en la educación infantil (Ibarretxe, 2011) pues resaltaban la importancia de comenzar la educación musical a una edad temprana proponiendo su introducción en los programas escolares.

Todas estas aportaciones tuvieron su continuidad durante el siglo XX, con una serie de métodos y propuestas pedagógicas que en Europa se realizaron por parte de

\footnotetext{
${ }^{16}$ La Escuela Nueva plantea un modelo didáctico y educativo completamente diferente a la tradicional, el paidocentrismo que va a convertir al niño en el centro del proceso de enseñanza y aprendizaje, mientras que el profesor dejará de ser el punto de referencia fundamental para convertirse en un dinamizador de la vida en el aula, al servicio de los intereses y necesidades de los alumnos.
} 
músicos, pedagogos, compositores y profesores que se dedicaron a la búsqueda de nuevos caminos para resaltar la importancia de la educación musical en la enseñanza temprana y a hacer de la música un lenguaje fácil y atractivo.

Algunos de los más destacados fueron: Jacques Dalcroze (1865-1950) pionero en la educación rítmica corporal, defensor con su rítmica del desarrollo del sentimiento musical; Belá Bartók (1881-1945) quien junto con Zoltan Kodaly (1882-1967) realizaron una recopilación de canciones folklóricas que constituyó la base del método pedagógico musical KODALY implantado en Hungría; Maurice Martenot (1898-1980) para quien la formación musical debe estar al servicio de la educación general; Edgar Willems (18901978) quien diseñó una metodología musical para los niños a partir de los 3 años; Justine Ward (1879-1975) quien desarrolló una metodología para todos sin exclusión; Carl ORFF (1895-1982) quien consideró la palabra como la célula generadora de la música, adaptando para los niños una serie de instrumentos para tocar en al aula o Paul Hindemith (1895-1963) quien diseñó un sistema completo de educación musical, desde el nivel de escuela primaria hasta la formación de maestros encargado por el gobierno Turco. Luego continuarían de la mano, entre otros, de Murray Schafer (1933) para quien el sonido y el silencio constituyeron una inagotable fuente de creatividad musical o de John Paynter (1931-2010) en Estados Unidos cuyo objetivo fue Incluir la música en el sistema total de la educación recuperando así el concepto de "educación por el arte", desarrollando las grafías no convencionales, acercando así la música contemporánea a la escuela.

Debido a esta gran proliferación de propuestas pedagógicas, al siglo XX se le ha llamado "el siglo de oro de la pedagogía musical" (Angulo, 1999). A estos métodos se les conoce como Métodos de educación musical ACTIVA, ya que parten de actividades que tienen interés y significado para los niños desde los primeros años escolares. A pesar de que cada uno de ellos pueda aparecer distantes en sus propuestas, sigue unos principios o fundamentos muy próximos y comparten muchos de sus objetivos. (Alsina, 2007).

Paralelamente, se difunden las teorías de John Dewey (1859-1942), filósofo y educador americano quien defendió la necesidad de una educación para todos y que influyó notablemente en el psicólogo y educador musical James Mursellk (1893-1963), 
cuyas obras influenciaron la educación musical de este país y sentaron las bases de la educación musical, tal y como las entendemos hoy ${ }^{17}$ (Hemsy de Gainza, 2004).

En España, estas propuestas vinieron de un grupo de pedagogos "cuya preocupación fue difundir la enseñanza de la música en la educación general, bien, impulsando los métodos creados en estos países o creando métodos propios". (Oriol, 2000, p.240). A este respecto destacamos las figuras, entre otros, de Joan Llongueras (1880-1953), Irineu Segarra I Malla (1917-2005), Rosa Font Fuster (1931), Montserrat Sanuy Simón (1935), Luis Elizalde (1940) o Mạ de los Ángeles Cosculluela (1943-2002). Para todos estos autores la educación musical es accesible a todos los niños, especialmente a partir de los tres o cuatro años de edad. Promueve, gracias a sus bases ordenadas y vivas, un desarrollo del oído musical y del sentido rítmico con unos principios válidos en todas las etapas gracias a la práctica continuada de la improvisación rítmica, melódica y armónica (Willems, 1981).

\section{LA IMPORTANCIA DE LA EDUCACIÓN MUSICAL EN LA EDUCACIÓN INFANTIL.}

La importancia de las enseñanzas artísticas ha estado muy reconocida por diferentes organismos internacionales. Basta mencionar la Declaración Universal de los Derechos Humanos de la UNESCO de 1948, donde en su artículo 27, se establecía que "toda persona tiene derecho a tomar parte libremente en la vida cultural de la comunidad, a gozar de las artes...", o en la Convención sobre los Derechos del Niño (UNICEF, 1989), donde en su artículo 31.2 establece que "Los Estados respetarán y promoverán el derecho del niño a participar plenamente en la vida cultural y artística y propiciarán oportunidades apropiadas, en condiciones de igualdad, de participar en la vida cultural, artística, recreativa y de esparcimiento" (p. 19) o en La Conferencia Mundial sobre Educación Artística (UNESCO, 2006), cuyo objetivo fue el de consolidar la posición de la educación artística y musical, para el desarrollo integral de las personas y su rol dentro de una educación de calidad.

Las investigaciones realizadas en el campo de la educación musical por Bermell y Alonso $^{18}$ (2012), Campbell ${ }^{19}$ (1998), Gardner ${ }^{20}$ (1994), Hargreaves ${ }^{21}$ (2001), Swanwick ${ }^{22}$

\footnotetext{
${ }^{17}$ Nos referimos principalmente a Music in American Schools y a The Psychology of music, publicados en Nueva York en 1943 y 1948 respectivamente.
} 
(1999), entre otros, ponen de manifiesto la necesidad de que esta se inicie lo antes posible. Por eso la función de la educación infantil ha de consistir en ofrecer a los niños la mayor estimulación sensorial posible. Así lo expresa Lacárcel Moreno (1995) al afirmar que "la música enriquece la vida, y por este motivo es necesario que rodee al niño un ambiente musical rico y controlado en estímulos, puesto que esta experiencia sensorial es lo que le va a proporcionar un desarrollo emocional, psicofisiológico y social equilibrado" (p.9).

La enseñanza de la música, es un medio de expresión y comunicación en la que interviene el tiempo, los sonidos, el ritmo y el movimiento. Como recurso pedagógico, enriquece la formación integral del niño, no solo por su aspecto formativo sino también por su aporte en el sano desarrollo del individuo y en la formación de su personalidad. Entre sus ventajas más significativas se encuentran el desarrollo de los siguientes aspectos (Conejo Rodríguez, 2012):

- En el aspecto intelectual, la música favorece la atención, observación, concentración, memorización, experimentación, la agilidad mental y la creatividad, permite evaluar resultados, mide capacidades, ayuda al conocimiento de sí mismo, y enseña a pensar.

- En el aspecto psicomotor, la música condiciona el cuerpo, desarrolla la psicomotricidad fina y gruesa, la agilidad corporal y la autonomía.

- En el aspecto relativo al crecimiento personal desarrolla el sentido de la justicia, promueve la libertad, alivia el temor y la timidez, canaliza la agresión, desarrolla voluntad y autocontrol.

- En el desarrollo socio-afectivo, enseña al niño a diferenciar roles y definir responsabilidades, lo capacita para una mayor y mejor participación en el aula, en la relación con los compañeros y hasta con los mismos adultos al compartir o

\footnotetext{
${ }^{18}$ Sus estudios sobre las agrupaciones musicales escolares van en la línea de la neurociencia para quienes la práctica musical transforma la organización cerebral incentivando los procesos cognitivos.

${ }^{19}$ Una de sus líneas de estudio es la investigación musical escolar. Consideró la respuesta física de los niños como una de las más importantes para su desarrollo, recomendando estimularla y potenciarla a través de las actividades musicales como ritmo en movimiento y las danzas.

20 Desarrolla las teorías de las inteligencias múltiples. Considera las habilidades musicales como inteligencia musical, otorgándoles un estatus propio en el desarrollo cognitivo integral del ser humano.

${ }^{21}$ Sus obras demuestran la importancia de la investigación psicológica en los procesos relacionados con la percepción musical de los niños y su conocimiento e interpretación de la música.

${ }^{22}$ Sus investigaciones confirman la existencia de aptitudes musicales innatas en el ser humano que se deben potenciar por la educación lo antes posible.
} 
interactuar con ellos a través de juegos y actividades musicales (canto, actividades de movimiento, ejecución instrumental), dirigidas fundamentalmente a ejercitar destrezas. El niño experimenta emociones y espontaneidad, así como también el crecimiento de sus sentimientos estéticos reforzados, por ejemplo, por los juegos con canciones que motivan al contacto físico.

- Facilita la integración grupal al compartir cantando y tocando los instrumentos con los compañeros, lo que refuerza, a su vez, la noción de trabajo cooperativo y otros indicadores de buena convivencia, como el respeto a la diversidad y el amor a sus semejantes.

- Sensibiliza ante el arte y la naturaleza: el niño descubre un nuevo medio de expresión y comunicación, fortalece su autoestima, conoce y expresa sus capacidades, demuestra su perseverancia en el alcance de metas; se motiva a superar dificultades al participar en producciones artísticas.

- Ayuda a relajarse, expresar sentimientos y canalizar sus energías de una manera apropiada, le sirve como medio para expresar el respeto hacia la vida de los demás y la suya.

Sin embargo y a pesar de todas las contribuciones de la formación musical en el desarrollo de los niños, nos preguntamos si se tiene en cuenta la importancia de comenzar una educación musical en nuestro país en la etapa de educación infantil.

Para responder a esta pregunta realizaremos un breve recorrido por la educación musical en nuestro sistema educativo, haciendo referencia también a la educación musical en esta etapa.

\section{LA MUSICA EN LA EDUCACIÓN ESPAÑOLA}

La educación musical en nuestro país, no adquiere una importancia real dentro de las enseñanzas del régimen general de nuestro sistema educativo hasta la llegada de la LOGSE. Autores como Embrid (2000) y Pérez (2004) consideran que siempre ha estado muy infravalorada y que no existió ni en la teoría ni en la práctica durante prácticamente todo el siglo XX, aunque, como veremos a continuación la educación musical se venía impartiendo desde mucho antes. 


\subsection{La Ley General de Educación (LGE)}

La asignatura de "Música" se empezó a impartir en nuestro sistema educativo obligatorio a partir de la LGE 14/1970 del 4 de agosto, si bien, anteriormente existieron una serie de decretos y leyes que la contemplaron en otros niveles educativos ${ }^{23}$. En dicha ley, la enseñanza de la música se contempla por primera vez en todas las etapas educativas integrada con otras materias como Plástica o Educación Física en un área denominada Expresión Dinámica.

Concretamente, en la Educación Preescolar ${ }^{24}$, etapa que correspondía con la actual educación infantil, la música, en teoría, aparece formando parte de la Educación Dinámica, y pretendía el desarrollo de la expresión dinámica, rítmica y musical, (esta última de manera explícita desde los cuatro años de edad) a través de la expresión corporal, vocal e instrumental, con el desarrollo de los juegos. En la práctica, la música en esta etapa no obligatoria, ni aparecía, pero la mayoría de los centros privados ofrecían educación musical a su alumnado, ya que como reseña Alsina (1997): “En esta etapa siempre ha habido un profesorado muy sensibilizado por los recursos educativos que ofrece la música, en parte porque ha observado el papel de seducción sobre el alumnado" (p.22).

En la Educación General Básica (EGB) se desarrollaría a través de un área artística en la que no se mencionaba expresamente la música y en el Bachillerato la asignatura que enseñaba estos conocimientos aparecía con el nombre de "Música y actividades artístico-musicales". Su propósito era ofrecer a los alumnos un conocimiento general del hecho artístico y educar su formación para la sensibilidad estética. El plan de estudios concedía a la asignatura un carácter eminentemente teórico.

\footnotetext{
${ }^{23}$ Véase: El Decreto de 29 de septiembre de 1931 que desarrolla el Plan de Formación de Maestros en el que figura la educación musical bajo el nombre de Música y canto, o el Reglamento de las escuelas normales, promulgado el 17 de abril de 1933, en el que la asignatura de Música aparece en primero y segundo curso, el comienzo de la guerra civil en 1936 supuso un retroceso en el sistema educativo español en ese sentido hasta 1970; La ley de julio de 1945 sobre Educación Primaria establece la materia de Música y canto adscrita al grupo de conocimientos complementarios, no contemplándose como asignatura en el calendario escolar.

${ }^{24}$ Las orientaciones para la Educación Preescolar aparecieron en la Orden de 27 de julio de 1973 con las referencias a la educación musical. B.O.E. de 4 de agosto de 1973.
} 
La LGE, supuso la incorporación progresiva del profesorado de la especialidad de música a los institutos de bachillerato, lo que condujo a la equiparación por RD 1198/1982 de licenciados y poseedores del título superior de conservatorio.

\subsection{La renovación de las enseñanzas musicales a partir de 1981}

En la Orden de 17 de enero de 1981, por la que se regulan las enseñanzas de Educación Preescolar y del Ciclo Inicial de la Educación General Básica, aparecen las áreas de Educación Artística y Educación Física formando parte del currículum de estos niveles educativos. Esta Orden desarrolló los contenidos y horarios por áreas para el ámbito de competencias del MEC, para los niveles de Educación Preescolar y Ciclo Inicial de la EGB, incluyendo los correspondientes a la educación musical. El Ministerio publicó en febrero de ese año una Resolución de la Dirección General de Educación Básica en la que se ofrecían criterios y orientaciones metodológicas generales y específicas para cada materia, así como un repertorio de actividades adecuado a los objetivos de los programas. Estos se conocerían como los "Programas Renovados de Preescolar, Ciclo inicial, Medio y Superior de la Educación General Básica” ${ }^{25}$. Las artes plásticas y la música contaban con una carga lectiva de cinco horas semanales en Preescolar y de tres en Ciclo Inicial. Estas asignaturas se desarrollaban a través de los siguientes bloques temáticos: Expresión y comunicación a través de la música; la música tradicional y colectiva; fuentes de sonido y comportamiento del sonido en el lenguaje musical.

Aunque señalaron los objetivos a conseguir en cada curso, sugiriendo las actividades a realizar, proponiendo los medios y recursos didácticos más adecuados para realizar las actividades planteadas, sin embargo, todo quedó en teoría debido a dos causas: la deficiente formación musical de los profesores de EGB, y los problemas de financiación para dotar de profesores especialistas (Coello y Plata, 2000) y la realidad es que la asignatura de música, se impartió casi en exclusividad en los centros privados como muestra de innovación pedagógica y señas de prestigio. (Rodríguez Pérez, 2015).

\footnotetext{
25 Los programas Renovados de la E.G.B. (Real Decreto 69/1981, de 9 de enero y Real Decreto 710/1982 de 12 de febrero) respondieron a un intento por parte del Ministerio de Educación de dar una orientación y ordenar las enseñanzas de la EGB en ciclos (Inicial-Medio-Superior).
} 


\subsection{La Ley Orgánica de Ordenación General del Sistema Educativo (LOGSE)}

En 1990, con la aprobación de la LOGSE, se definió un profesorado específico en primaria para la impartición de la música ${ }^{26}$. Estas medidas subsanaron, hasta cierto punto, la escasa importancia que hasta ese momento se le había concedido a la música en el ámbito de la enseñanza general y se dio respuesta a la necesidad de una norma legal que contemplara las enseñanzas musicales en el conjunto de la legislación educativa. Lo relevante, respecto a estas enseñanzas, fue la creación de un espacio curricular independiente y la dotación de los recursos necesarios para estar al mismo nivel que el resto de las áreas curriculares (Martos Sánchez, 2013).

La oferta musical se consolidó en tres niveles: enseñanzas de régimen general, enseñanzas musicales regladas y enseñanzas no regladas; por primera vez una ley abordaba una regulación amplia de la enseñanza de la música, pues hasta ese momento no existía la figura del maestro especialista en Música.

La música adquiere con la LOGSE un papel destacado también en la educación infantil (0-6 años). En esta etapa, aparece en el currículo dentro del Área de Comunicación y Representación ${ }^{27}$ pretendiendo "que el niño adquiera una progresiva capacidad para servirse de este procedimiento de comunicación y representación al servicio de los objetivos educativos generales"; con este fin programaba una serie de contenidos conceptuales, procedimentales y actitudinales centrados en la expresión corporal, vocal e instrumental de iniciación. Aunque no se mencionaba la música como área específica también podemos encontrarla referenciada en las Áreas de Identidad y Autonomía Personal y Medio Físico y Social. La música, en la mayoría de los centros educativos se impartía por los Maestros generalistas de Educación Infantil, ya que no se contemplaba la figura del especialista en esta etapa.

\footnotetext{
${ }^{26}$ El Real Decreto 1440/1991, de 30 de agosto, establece el título universitario oficial de Maestro de Educación Primaria Especialista en Educación Musical.

${ }^{27}$ Real Decreto 1333/91 de 6 de septiembre, BOE de 9 de septiembre.
} 
En la educación primaria (6-12 años) la música era obligatoria, se impartió en una sesión semanal y se contemplaba en el currículo como parte del Área Artística junto con la plástica, la dramatización, las artes y la cultura, pero impartida por un Maestro Especialista en Educación Musical ${ }^{28}$.

En la etapa de la Educación Secundaria Obligatoria (12-16 años), se incluyó un Área de Música con contenidos independientes de las otras áreas artísticas. Era obligatoria en los tres primeros cursos y en 4 으 curso se ofrecía como optativa denominada "Canto Coral". En todos los cursos con una carga lectiva de dos horas semanales. Se organiza en seis bloques temáticos en los que primaba la práctica sobre la teoría: expresión instrumental, movimiento y danza, lenguaje musical, música en el tiempo, expresión vocal y canto, y música y comunicación. El profesorado encargado de impartir estas enseñanzas en la ESO y en el Bachillerato tenía que ser licenciado o equivalente y estar en posesión también del Título de Capacitación Pedagógica (CAP).

En Bachillerato, etapa postobligatoria (16-18 años), se establecieron cuatro modalidades: Artes, Ciencias de la Naturaleza y de la Salud, Humanidades y Ciencias Sociales y Tecnología. La música se ofertaba como asignatura optativa para todas ellas en 1 으 o 2 으 o en ambos cursos y tenía una carga lectiva de 4 horas semanales.

La novedad más importante que se dio en la reforma de la LOGSE respecto al área de música se encuentra en sus objetivos y contenidos pues priorizaba en lo artístico "la percepción y la expresión" de diversos aspectos de la realidad exterior y del mundo interior a través de "la comunicación" mediante los propios lenguajes y los lenguajes del mundo, lo que obligó a tratar la música de una forma muy diferente a como se venía desarrollando (Alsina, 1997).

\footnotetext{
${ }^{28}$ A partir de 1991, se crea la diplomatura de Maestro-Especialidad de Educación Musical, figura que imparte estas enseñanzas hasta nuestros días.
} 


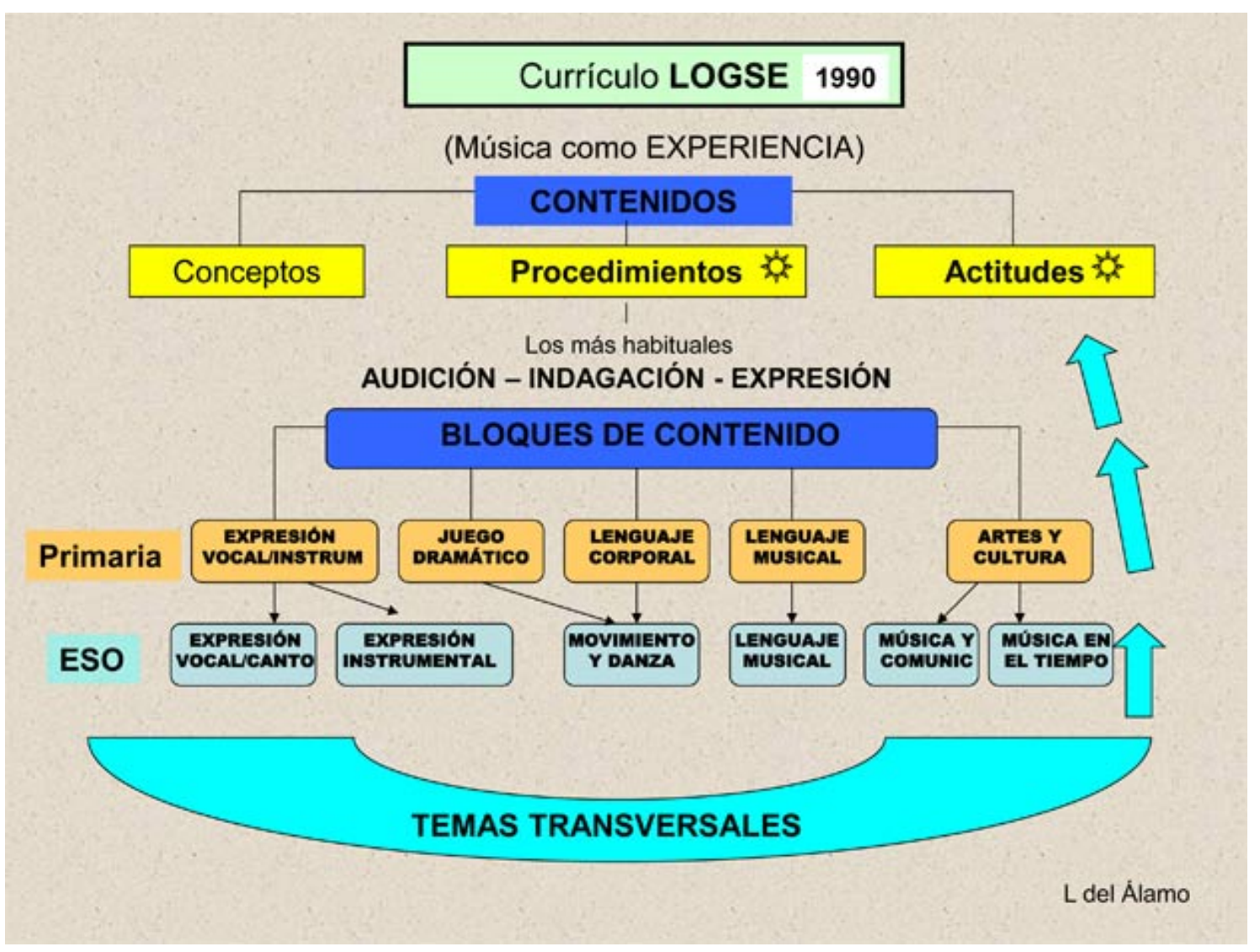

Fuente: Del Álamo Caballero (2013, p.12).

\subsection{La Ley Orgánica de Calidad de la Educación (LOCE)}

En el año 2002 aparece la LOCE $^{29}$. Esta ley modifica parcialmente la LOGSE. En lo que a nuestro tema afecta, se reducen los contenidos y las horas de enseñanza del área de Educación Artística.

Según el RD 114/2004, de 23 de enero por el que se establecía el currículum de Educación Infantil, la educación musical, junto con la expresión plástica y la expresión corporal formó parte de una nueva área curricular denominada Expresión artística y la creatividad, cuyo objetivo general era que el niño se expresara por medio de la utilización de diferentes técnicas e instrumentos. Sería impartida por maestros con la especialidad de educación infantil con una formación musical básica.

\footnotetext{
${ }^{29} \mathrm{~A}$ penas llegará a aplicarse pues se paraliza su implantación por la llegada al poder del gobierno socialista.
} 
En la Educación Primaria, sigue teniendo una presencia muy importante en los 6 cursos en los que se estructura esta etapa, apareciendo en el currículo como parte integrante del Área Artística y será impartida por Maestros Especialistas en Educación Musical.

En la ESO la asignatura de Música desaparece de primer curso y solo se imparte en segundo.

En el Bachillerato, cambia el carácter de la asignatura y deja de ser optativa en todas las modalidades para delimitarse como troncal en la modalidad de Humanidades y Ciencias Sociales, pasando a llamarse "Historia de la Música".

Para impartir estas enseñanzas tanto en la ESO como en el Bachillerato, se necesitaba estar en posesión del título de Licenciado, Doctor, Ingeniero o Arquitecto, además del título de Especialidad Didáctica (Art. 32 y 36).

Esquema 3. Currículum de la música en la LOCE

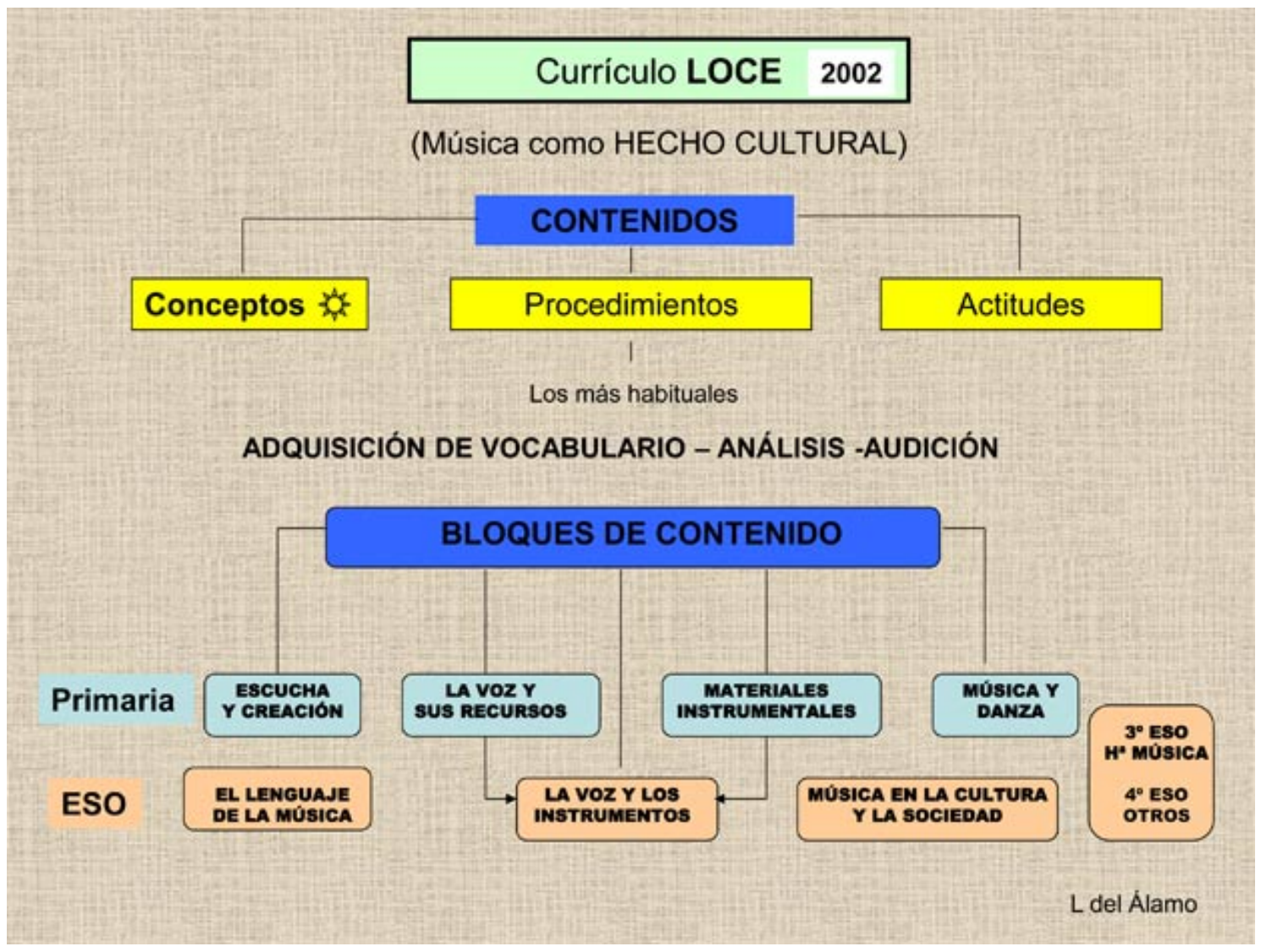

Fuente: Del Álamo Caballero (2013, p.13). 


\subsection{La Ley Orgánica de Educación (LOE)}

En 2006 se aprueba la LOE. Respecto al currículo aparece la novedad de lograr una serie de competencias básicas ${ }^{30}$ que se unen a otros elementos más conocidos por el profesorado, como los objetivos, los contenidos o los criterios de evaluación. Estas competencias se desarrollan a lo largo de todas las etapas educativas y el alumnado las debe alcanzar al finalizar la ESO, ya que están relacionadas con la preparación para su inserción laboral. A su desarrollo se debe contribuir desde todas las áreas y asignaturas de la enseñanza obligatoria, por lo que focaliza su aplicación tanto en la etapa de Educación Primaria como en Educación Secundaria Obligatoria. En el caso de la música, en estas etapas, está ligada a la adquisición y desarrollo de la "competencia cultural y artística":

La materia de música contribuye de forma directa a la adquisición de la competencia cultural y artística en todos los aspectos que la configura, ya que fomenta la capacidad de apreciar, comprender y valorar críticamente diferentes manifestaciones culturales y musicales, a través de experiencias perceptivas y expresivas y del conocimiento de músicas de diferentes culturas, épocas y estilos, potenciando actitudes abiertas y respetuosas respecto a las distintas manifestaciones culturales (RD 1630/ 2006, p.43045).

En la LOE los contenidos para la educación Infantil, están organizados en Áreas de conocimientos. Para este ciclo se plantearon 3 áreas: Área de Conocimiento de sí mismo y autonomía personal; Área de conocimiento del entorno y Área de Lenguajes: Comunicación y representación, donde el lenguaje musical se integra junto con el lenguaje plástico configurando el bloque de lenguaje artístico.

Igualmente ocurrirá en la Educación Primaria, la música se articulará en dos ejes: expresión y percepción, y se integrará junto con Plástica en el Área de Expresión Artística. Se impartirá en todos los cursos por un Maestro Especialista en Educación Musical con una hora semanal.

\footnotetext{
${ }^{30}$ La Unión Europea propuso ocho competencias básicas o competencias clave para el alumnado de las etapas obligatorias: 1. Competencia en comunicación lingüística. 2. Competencia matemática. 3. Competencia en el conocimiento y en la interacción con el mundo físico. 4. Tratamiento de la información y competencia digital. 5. Competencia social y ciudadana. 6. Competencia cultural y artística. 7. Competencia para aprender a aprender. 8. Autonomía e iniciativa personal.
} 
En ESO, la asignatura de música aparece como materia obligatoria en primer y segundo curso, no aparece en tercero y en cuarto, como optativa y sus contenidos será una continuación de lo adquirido en la etapa anterior.

Con la LOE, el Bachillerato se ofertaba en tres modalidades ${ }^{31}$ : Artes, Ciencias y Tecnología, y Humanidades y Ciencias Sociales. La modalidad de Artes se organizaba en dos vías: una de ellas referidas a Artes Plásticas, Diseño e Imagen, y la otra a Artes Escénicas, Música y Danza. En esta última, las asignaturas específicas de música a cursar eran: “Análisis musical I", "Análisis musical II", "Historia de la Música y de la Danza” y "Lenguaje y Práctica Musical". En el resto de modalidades aparece como optativa a cursar en segundo curso de la modalidad de Humanidades y Ciencias Sociales con el nombre de "Historia de la Música y la Danza".

Esquema 4. Currículum de la música en la $L O E$

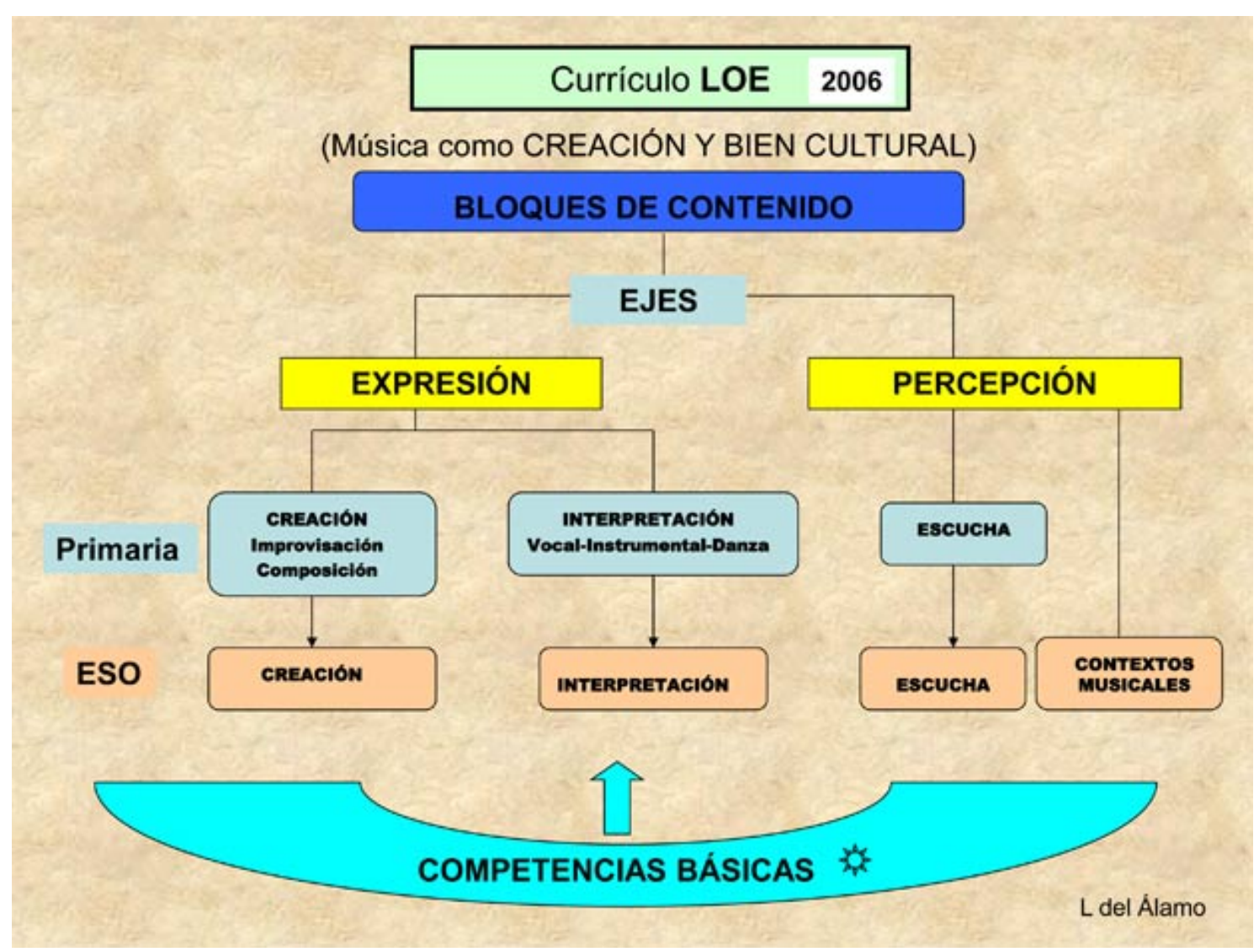

Fuente: Del Álamo Caballero (2013, p.14).

\footnotetext{
${ }^{31}$ Real Decreto 1467/2007, de 2 de noviembre, por el que se establece la estructura del bachillerato y se fijan sus enseñanzas mínimas.
} 


\subsection{La Ley Orgánica para la Mejora de la Calidad Educativa (LOMCE)}

La LOMCE, ${ }^{32}$ introduce una serie de cambios con respecto a la LOE en cuanto a la organización del currículo obligatorio común y la optatividad curricular, aunque al ser un modelo educativo del Estado descentralizado, confiere a las Comunidades Autónomas un margen de decisión respecto a la implementación de la ley o a cierto tipo de asignaturas.

Establece tres tipos de asignaturas:

- Troncales: las que dan una formación general al alumnado. Algunas son obligatorias y otras varían en función de la modalidad del bachillerato.

- Específicas: aquellas que profundizan en la modalidad del bachillerato elegido. Su oferta depende del centro y de las administraciones educativas.

- Libre Configuración Autonómica: son asignaturas de ampliación de contenidos u otras determinadas por las administraciones educativas. Su oferta depende del centro.

En lo que a nuestro tema se refiere, en la Educación infantil, la música no sufre ningún cambio, ya que la LOMCE no modifica esta etapa.

En Primaria, la música deja de ser una asignatura troncal. Con la materia de "Plástica" forman parte del área de Educación Artística y su oferta es decisión de cada Comunidad Autónoma. Los contenidos a impartir en Castilla y León, corresponden a tres bloques: el primero referido a la "escucha", donde el alumno indagará en las posibilidades del sonido. El segundo bloque comprende el desarrollo de habilidades para la "interpretación musical", y el tercero destinado al desarrollo de capacidades expresivas y creativas desde el conocimiento y práctica de la danza: "la música, el movimiento y la danza" ${ }^{33}$.

En Secundaria, pasa a ser una asignatura específica para todos los cursos. En el caso de Castilla y León, en segundo curso se cursará "Música y cultura clásica" ${ }^{34}$ y en tercero se oferta la asignatura de "Música" que se podrá elegir entre otras. Además, en tercer

\footnotetext{
32 La LOMCE comenzó a implantarse en el curso 2014-15 para infantil y 1으, 3ㅇy y 50 de primaria, y, en el curso 2015-16 para 2으, 4ㅇ y 6을 de primaria, Secundaria y Bachillerato.

${ }^{33}$ Decreto 26/2016, de 21 de junio por el que se establece el currículo de la Educación Primaria en Castilla y León.

${ }^{34}$ ORDEN EDU/362/2015, de 4 de mayo, por el que se establece el currículo de la ESO en la comunidad de Castilla y León.
} 
curso se oferta una materia de Libre Configuración Autonómica:"Taller de Expresión Musical" ${ }^{35}$ a escoger en función de la oferta de los centros docentes.

Puede darse el caso de que un alumno, termine su escolarización obligatoria sin haber cursado ninguna asignatura de música.

En la etapa de Bachillerato, la LOMCE establece tres modalidades: Artes, Ciencias y Humanidades, y Ciencias Sociales, con dos itinerarios para esta última: Humanidades y Ciencias Sociales ${ }^{36}$. Para la comunidad de Castilla y León ${ }^{37}$, se oferta la asignatura de "Historia de la Música y de la Danza" para segundo curso en las modalidades de Ciencias, Humanidades y Ciencias Sociales. Y para la modalidad de Artes, en primer curso "Análisis Musical I", y para segundo curso "Análisis Musical II", e "“Historia de la Música y de la Danza".

Además, el panorama autonómico en el tratamiento de la música en los planes de estudios es muy disperso. Domínguez Noray (2015) recoge esa dispersión y considera que no puede ser buena tanta disparidad. Así, para la Educación Primaria, la Comunidad Valenciana se ha comprometido a dar un trato relevante a las materias musicales (se ha llegado a hablar de "troncales autonómicas") (p.50) y en La Rioja, se va a incrementar media hora semanal para la educación artística. Mientras, en la Comunidad de Madrid el área de Educación Artística solo será obligatoria de 1 a 3 de Primaria, quedando como optativa de 4ㅇ a 6o junto a Segundo Idioma. Andalucía, Asturias, Castilla y León, Extremadura, Galicia, Murcia y Navarra han asegurado una hora de Música y otra de Plástica para toda la Educación Primaria.

En este sentido y a pesar de que el Parlamento Europeo incluyó la competencia cultural y artística entre las competencias básicas ${ }^{38}$ a adquirir para el desarrollo integral

\footnotetext{
${ }^{35}$ ORDEN EDU/589/2016, de 22 de junio, por a que se regula la oferta de materias de libre configuración autonómica para tercero y cuarto de la ESO en la comunidad de Castilla y león.

36 Artículo 1.24 que modifica el artículo 34 de la LOE

${ }^{37}$ ORDEN EDU/363/2015, de 4 de mayo por el que se establece el currículum del bachillerato en la comunidad de Castilla y León.

38 La Educación Musical y Artística es la base fundamental de la Competencia cultural y artística, una de las ocho competencias establecidas en la Recomendación de 18 de diciembre de 2006 del Parlamento Europeo y del Consejo como las competencias clave para el aprendizaje permanente de todo ciudadano de la Unión Europea. Dicha recomendación dice expresamente que "las competencias clave se consideran igualmente importantes, ya que cada una de ellas puede contribuir al éxito en la sociedad del
} 
de los alumnos, o que la propia $\mathrm{LOMCE}^{39}$ en su Preámbulo establece "nuestras personas y sus talentos son lo más valioso que tenemos como país", de manera que "el reto de una sociedad democrática es crear las condiciones para que todos los alumnos y alumnas puedan adquirir y expresar sus talentos" ${ }^{140}$, la música, según lo anteriormente expuesto, tiende a desaparecer.

\section{LA MÚSICA EN EL CURRÍCULO ACTUAL DE EDUCACIÓN INFANTIL}

\subsection{La legislación actual en educación infantil}

La educación en nuestro sistema educativo a nivel nacional se encuentra regulado por dos leyes orgánicas, la LOE y la LOMCE. Esta última no ha modificado la Educación Infantil, por tanto, se rige por lo que se establece la LOE.

Para la LOE, la educación infantil es una etapa educativa con identidad propia que atiende a niños desde el nacimiento hasta los seis años de edad.

Esta etapa se ordena en dos ciclos. El primero comprende hasta los tres años y el segundo desde los tres hasta los seis años de edad. Tiene carácter voluntario y su finalidad es la de contribuir al desarrollo físico, afectivo, social e intelectual de los niños. El segundo ciclo es gratuito.

El currículo de esta etapa está regulado por el Real Decreto 1630/2006, de 29 de diciembre, por el que se establecen las Enseñanzas Mínimas del Segundo Ciclo de Educación Infantil.

Los objetivos marcados para la etapa son muy generales y quedan recogidos en el artículo 13, y aunque ninguno de ellos se refiere de manera concreta a la música, destacamos por su relación con ella, los objetivos de "Desarrollar habilidades comunicativas en diferentes lenguajes y formas de expresión", e "Iniciarse en las

conocimiento". Así mismo, la UNESCO subraya, desde 1999, la efectividad pedagógica de las materias artísticas y del uso del pensamiento creativo en la resolución de problemas.

${ }^{39}$ Con la LOMCE las competencias clave que sustituyen a las ocho competencias básicas de la LOE, pasan a siete: 1. Comunicación lingüística. 2. Competencia matemática y competencias básicas en ciencia y tecnología. 3. Competencia digital. 4. Aprender a aprender. 5.․Competencias sociales y cívicas. 6.ำ Sentido de iniciativa y espíritu emprendedor. 7. Conciencia y expresiones culturales.

${ }^{40}$ Ley Orgánica 8/2013, de 9 de diciembre, para la Mejora de la Calidad Educativa. Preámbulo, apartado I. 
habilidades lógico-matemáticas, en la lecto-escritura y en el movimiento, el gesto y el ritmo".

En cuanto a principios pedagógicos se sitúa muy cerca de la LOGSE, por ejemplo, en la necesidad de atender progresivamente al desarrollo afectivo, la psicomotricidad, los hábitos de control, la comunicación, el lenguaje, la convivencia y la relación social; también en conocer el entorno en que viven, todo ello en busca de una imagen positiva y equilibrada de sí mismos, con el objetivo de alcanzar la autonomía personal.

Los contenidos con los que se trabaja en esta etapa se organizan igual que anteriormente en áreas de conocimiento que se corresponden con los ámbitos propios de la experiencia y del desarrollo infantil desde un enfoque que recoge actividades globalizadas de interés y significado para los alumnos.

\subsection{Las Áreas de conocimiento en Segundo ciclo de Educación Infantil}

La LOE, en el Real Decreto 1630/2006, de 29 de diciembre, estableció las enseñanzas mínimas del segundo ciclo de Educación infantil, articulándolas en Áreas de conocimiento, que quedan enunciadas para este ciclo en las siguientes (Art. 6, p. 1):

a. Conocimiento de sí mismo y autonomía personal. Durante estos años se produce un significativo avance en el nivel de autonomía personal y en la independencia con respecto a los adultos. El niño adquiere hábitos de salud, higiene, nutrición, seguridad y prevención que contribuyen al cuidado del propio cuerpo y de los espacios en los que transcurre la vida cotidiana, y a la progresiva autonomía.

b. Conocimiento del entorno. A lo largo de esta etapa se dan avances significativos en el ámbito social. La vida escolar conlleva el establecimiento de numerosas experiencias que amplían su conocimiento acerca de las organizaciones sociales que le son próximas, modifican el significado que tienen de pertenencia a otros grupos sociales y exige pautas de comportamiento diferentes en nuevas situaciones de relación.

c. Lenguajes: Comunicación y representación. A través del lenguaje el niño estructura su pensamiento, amplía sus conocimientos sobre la realidad y establece relaciones con sus iguales y con el adulto, lo cual favorece su desarrollo afectivo y social. 
Estas áreas deben entenderse como ámbitos de actuación, como espacios de aprendizajes de todo orden: actitudes, procedimientos y conceptos, que contribuirán al desarrollo de los niños y propiciarán su aproximación a la interpretación del mundo, otorgándole significado y facilitando su participación activa en él. De igual modo, las administraciones educativas implantarán el currículo de este ciclo teniendo en cuenta las enseñanzas mínimas fijadas en el RD.

De las tres áreas mencionadas, nos vamos a detener en la última de ellas por su relación con nuestro trabajo Las diferentes formas de comunicación y representación que se integran en ella son los lenguajes verbal, artístico, corporal, audiovisual y el lenguaje de las tecnologías de la información y la comunicación.

Con el desarrollo del lenguaje artístico, se pretende estimular la adquisición de nuevas habilidades y destrezas que permitan la producción, uso y comprensión de sonidos de distintas características con un sentido expresivo y comunicativo y favorezcan un despertar de la sensibilidad estética frente a manifestaciones musicales de distintas características.

Los objetivos de esta área ${ }^{41}$ vienen marcados por el desarrollo de las siguientes capacidades (p. 481):

1. Utilizar la lengua como instrumento de comunicación, de representación, aprendizaje y disfrute, de expresión de ideas y sentimientos, y valorar la lengua oral como un medio de relación con los demás y de regulación de la convivencia.

2. Expresar emociones, sentimientos, deseos e ideas mediante la lengua oral y a través de otros lenguajes, eligiendo el que mejor se ajuste a la intención y a la situación.

3. Comprender las intenciones y mensajes de otros niños y adultos, adoptando una actitud positiva hacia la lengua, tanto propia como extranjera.

4. Comprender, reproducir y recrear algunos textos literarios mostrando actitudes de valoración, disfrute e interés hacia ellos.

5. Iniciarse en los usos sociales de la lectura y la escritura explorando su funcionamiento y valorándolas como instrumento de comunicación, información y disfrute.

\footnotetext{
${ }^{41}$ Real Decreto 1630/2006, de 29 de diciembre, por el que se establecen las enseñanzas mínimas del segundo ciclo de Educación Infantil.
} 
6. Acercarse al conocimiento de obras artísticas expresadas en distintos lenguajes y realizar actividades de representación y expresión artística mediante el empleo de diversas técnicas.

7. Iniciarse en el uso oral de una lengua extranjera para comunicarse en actividades dentro del aula, y mostrar interés y disfrute al participar en estos intercambios comunicativos.

Los contenidos del área de Lenguaje: comunicación y representación, está divididos en cuatro bloques (RD 1630/2006, p.481):

Bloque 1: lenguaje verbal.

Bloque 2: lenguaje visual, tecnologías de la información y la comunicación.

Bloque 3: lenguaje artístico: lenguaje plástico y lenguaje musical.

Bloque 4: lenguaje corporal.

El bloque 3 corresponde al lenguaje artístico y hace referencia tanto al plástico como al musical. El lenguaje musical posibilita el desarrollo de capacidades vinculadas con la percepción, el canto, la utilización de objetos sonoros e instrumentos, el movimiento corporal y la creación que surgen de la escucha atenta, la exploración, la manipulación y el juego con los sonidos y la música. A este bloque le corresponden los siguientes contenidos (p.481):

- Experimentación y descubrimiento de algunos elementos que configuran el lenguaje plástico (línea, forma, color, textura, espacio).

- Expresión y comunicación de hechos, sentimientos y emociones, vivencias, o fantasías a través del dibujo y de producciones plásticas realizadas con distintos materiales y técnicas.

- Interpretación y valoración, progresivamente ajustada, de diferentes tipos de obras plásticas presentes en el entorno.

- $\quad{ }^{42}$ Exploración de las posibilidades sonoras de la voz, del propio cuerpo, de objetos cotidianos y de instrumentos musicales.

- Utilización de los sonidos hallados para la interpretación y la creación musical.

- Reconocimiento de sonidos del entorno natural y social, y discriminación de sus rasgos distintivos y de algunos contrastes básicos (largo-corto, fuerte-suave, agudo-grave).

\footnotetext{
${ }^{42}$ Aparece en azul aquellas relacionadas con el lenguaje musical.
} 
- Audición atenta de obras musicales presentes en el entorno. Participación activa y disfrute en la interpretación de canciones, juegos musicales y danzas.

Como se puede observar, son los cuatro últimos contenidos los que corresponden a la educación musical.

Los criterios de evaluación ${ }^{43}$ vienen enunciados, para el lenguaje artístico de la siguiente forma (p.482):

Expresarse y comunicarse utilizando medios, materiales y técnicas propios de los diferentes lenguajes artísticos y audiovisuales, mostrando interés por explorar sus posibilidades, por disfrutar con sus producciones y por compartir con los demás las experiencias estéticas y comunicativas.

Con este criterio se evalúa el desarrollo de las habilidades expresivas por medio de diferentes materiales, instrumentos y técnicas propios de los lenguajes musical, audiovisual, plástico y corporal. Se observará el gusto por experimentar y explorar las posibilidades expresivas del gesto, los movimientos, la voz y también, el color, la textura o los sonidos. Se valorará el desarrollo de la sensibilidad estética y de actitudes positivas hacia las producciones artísticas en distintos medios, junto con el interés por compartir las experiencias estéticas.

\subsection{La expresión musical en el currículo del segundo ciclo de educación infantil} en Castilla y León

A partir de lo dispuesto en el RD que acabamos de analizar, las Comunidades Autónomas promulgan sus correspondientes Decretos de desarrollo. En el caso de nuestra comunidad, es el Decreto 122/2007, de 27 de diciembre el que establece el currículo del segundo ciclo de la Educación Infantil en la Comunidad de Castilla y León.

Los Objetivos que marca para la etapa infantil se encuentran indicados en su Artículo 4. Destacamos por su relación con nuestra temática (Art 4, p. 7):

\footnotetext{
${ }^{43}$ Orden ECl/734/2008, de 5 de marzo, de evaluación de Educación Infantil.
} 
La Educación Infantil contribuirá a desarrollar en las niñas y niños las capacidades que les permitan:

f) Desarrollar habilidades comunicativas en diferentes lenguajes y formas de expresión.

g) Iniciarse en las habilidades lógico-matemáticas, en la lectoescritura y en el movimiento, el gesto y el ritmo.

Además, concretamente para el área de lenguajes, el Decreto establece como objetivos relacionados con la música (p. 14):

1. Expresar ideas, sentimientos, emociones y deseos mediante la lengua oral y otros lenguajes, eligiendo el que mejor se ajuste a la intención y a la situación.

10. Acercarse al conocimiento de obras artísticas expresadas en distintos lenguajes, realizar actividades de representación y expresión artística mediante el empleo creativo de diversas técnicas, y explicar verbalmente la obra realizada.

11. Demostrar con confianza sus posibilidades de expresión artística y corporal.

12. Descubrir e identificar las cualidades sonoras de la voz, del cuerpo, de los objetos de uso cotidiano y de algunos instrumentos musicales. Reproducir con ellos juegos sonoros, tonos, timbres, entonaciones y ritmos con soltura y desinhibición.

13. Escuchar con placer y reconocer fragmentos musicales de diversos estilos.

14. Participar en juegos sonoros, reproduciendo grupos de sonidos con significado, palabras o textos orales breves en la lengua extranjera.

Formando parte de esta área se encuentra, de igual forma que en el RD, el bloque 3 “lenguaje artístico", formado por la expresión musical y la expresión plástica.

En cuanto a los contenidos a impartir, respecto al RD, son prácticamente iguales, pero aparece uno novedoso: curiosidad por las canciones y danzas de nuestra tradición popular y de otras tradiciones. 


\begin{tabular}{|c|c|}
\hline $\begin{array}{l}\text { REAL DECRETO 1630/2006 } \\
\text { Contenidos lenguaje Musical }\end{array}$ & $\begin{array}{l}\text { DECRETO 122/2007 } \\
\text { Contenidos Expresión Musical }^{44}\end{array}$ \\
\hline $\begin{array}{l}\text { Exploración de las posibilidades sonoras de la voz, del propio } \\
\text { cuerpo, de objetos cotidianos y de instrumentos musicales. }\end{array}$ & $\begin{array}{l}\text { Exploración de las posibilidades sonoras de la voz, del propio } \\
\text { cuerpo, de objetos cotidianos y de instrumentos musicales. }\end{array}$ \\
\hline $\begin{array}{l}\text { Utilización de los sonidos hallados para la interpretación y la } \\
\text { creación musical. }\end{array}$ & $\begin{array}{l}\text { Utilización de los sonidos hallados para la interpretación y la } \\
\text { creación musical. }\end{array}$ \\
\hline $\begin{array}{l}\text { Reconocimiento de sonidos del entorno natural y social, y } \\
\text { discriminación de sus rasgos distintivos y de algunos contrastes } \\
\text { básicos (largo-corto, fuerte-suave, agudo-grave). }\end{array}$ & $\begin{array}{l}\text { Ruido, sonido, silencio y música. Reconocimiento de sonidos } \\
\text { del entorno natural y social, y discriminación de sus rasgos } \\
\text { distintivos y de algunos contrastes básicos (largo-corto, fuerte- } \\
\text { suave, agudo-grave). }\end{array}$ \\
\hline \multirow[t]{2}{*}{$\begin{array}{l}\text { Audición atenta de obras musicales presentes en el entorno. } \\
\text { Participación activa y disfrute en la interpretación de canciones, } \\
\text { juegos musicales y danzas. }\end{array}$} & $\begin{array}{l}\text { Audición atenta de obras musicales presentes en el entorno. } \\
\text { Actitud de escucha e interés por la identificación de lo que } \\
\text { escuchan }\end{array}$ \\
\hline & $\begin{array}{l}\text { Curiosidad por las canciones y danzas de nuestra tradición } \\
\text { popular y de otras culturas. }\end{array}$ \\
\hline $\begin{array}{l}\text { Participación activa y disfrute en la interpretación de canciones, } \\
\text { juegos musicales y danzas }\end{array}$ & $\begin{array}{l}\text { Participación activa y disfrute en la interpretación de canciones, } \\
\text { juegos musicales y danzas (p.16) }\end{array}$ \\
\hline
\end{tabular}

Fuente: elaboración propia.

Por último, en lo que respecta a los criterios de evaluación, de los 38 que desarrolla el Decreto, seis tienen que ver con la expresión musical:

\section{Reproducir canciones y ritmos aprendidos.}

31. Reconocer algunos instrumentos musicales por su sonido y reproducir ritmos con ellos.

32. Reproducir aspectos sonoros, de ritmo, acentuación y entonación, característicos de la lengua extranjera, en canciones o rimas.

33. Desplazarse por el espacio con distintos movimientos ajustados a las acciones que realiza.

35. Realizar sin inhibición representaciones dramáticas, danzas, bailes y desplazamientos rítmicos y ajustar sus acciones a las de los demás en actividades de grupo.

36. Mostrar curiosidad por las manifestaciones artísticas y culturales de su entorno (p.16).

\footnotetext{
${ }^{44}$ En la Comunidad de Castilla y León los aspectos referidos a la educación musical reciben el tratamiento de Expresión musical en vez de lenguaje musical.
} 


\subsection{La impartición del currículo de expresión musical}

Aunque la educación musical se ha ido incorporando en la Educación Infantil, en el currículo de segundo ciclo, en nuestra comunidad, como hemos visto, desaparece todo enunciado relacionado no solo con la educación musical, sino también con el lenguaje musical, pasando a denominarse expresión musical, lo que implica una reducción de los contenidos musicales a favor de la utilización instrumental de la música. Este hecho, nos preocupa especialmente, pues consideramos que no se le da la importancia que debe tener en esta etapa educativa y que, como ocurre en otros niveles educativos, la educación musical sigue siendo una materia infravalorada respecto al resto de las materias:

Estamos, por tanto, ante una materia que debería formar parte del currículo de la educación infantil -tanto en su primer como segundo ciclo- de una forma activa y lúdica, tomando como referencia las características, intereses y motivaciones de los educandos a los que va destinado este propósito, para así favorecer el desarrollo de la libre expresión y creatividad, contribuyendo a una formación más integral del individuo (Bernal y Calvo, 2000, p. 9)

El maestro de Educación Infantil, es el encargado de impartir todas las áreas que forman parte del currículo de la Educación Infantil, incluidas las relacionadas con la educación artística y en concreto con la expresión musical. Hasta ahora, ninguna de las leyes educativas implantadas en nuestro país ha considerado ninguna especialización para impartir estos contenidos, dado el carácter global de esta etapa.

El tiempo lectivo dedicado a impartirlos depende de la importancia que le otorgue el maestro generalista y el centro educativo, ya que no hay reglamentación alguna al respecto. Así, hay centros escolares que cuentan con el Especialista de Música de Educación Primaria para impartir estos contenidos generalmente en una sesión semanal, tiempo que resulta insuficiente para impartir el currículo, ya que, entre otros López de la Calle, 2007, Mairet y Malvicini de Benini, 2012, recomiendan tres sesiones 
semanales de cuarenta minutos, pero en la mayoría de los centros educativos, es el maestro generalista el encargado de impartirlos.

Sin embargo, de nada valen los estudios científicos (Bermell y Alonso 2012, Bernal, 2000, Díaz 2004, Giráldez 2011, López de la Calle 2007, Oriol 2003, Ruiz Palomo, 2013, Ruiz, Palomero y Baños, 2015) que avalan la importancia de formar profesionales competentes para impartir estas enseñanzas.

Los contenidos que propone el Decreto 122/2007, se estructuran dentro de tres áreas íntimamente relacionadas denominadas educación vocal, educación rítmica y educación auditiva (Pascual Mejía, 2006). La primera, desarrolla las posibilidades de la voz como instrumento de expresión y como instrumento musical; ayuda al niño en el desarrollo de las habilidades de respiración, vocalización y articulación necesarios para la interpretación de canciones; desarrolla su memoria, su repertorio lingüístico y favorece la comprensión del entorno. La educación rítmica, contribuye al desarrollo del esquema corporal y a las nociones espacio-temporal mediante la participación en las danzas y en las actividades instrumentales y de movimiento, y, por último, la educación auditiva, mediante la percepción, reconocimiento y discriminación del entorno sonoro desarrolla la escucha atenta y el gusto por el repertorio musical.

Por tanto, para impartirlos de manera correcta, el maestro debe contar con una formación previa en educación vocal, auditiva y rítmica para desarrollar en sus alumnos capacidades que les permitan percibir, expresar y crear a través del lenguaje musical y adquirir una serie de cualidades, habilidades y destrezas.

Las características básicas que debería reunir un maestro para poder impartir una adecuada educación musical, a las que hace referencia autores como, Hemsy de Gainza 1982, Orff 1964, Pascual Mejía 2006, Willems 1980, entre otros, las podemos resumir en:

. Buen oído musical sensible y cultivado con capacidad de discernir la melodía, la armonía y el ritmo.

. Conocimiento del lenguaje musical elemental tanto en la parte teórica como práctica, que comprende tanto el aspecto melódico (notación y entonación musical que le permita realizar una lectura entonada a primera vista) como el rítmico (pulso, acento, compás, valores rítmicos, etc.). 
. Conocimiento del aparato vocal, que le permita una correcta emisión de la voz para el canto, para corregir defectos de emisión vocal que presenten los alumnos.

- Conocimiento de la técnica y manejo de los instrumentos escolares, tanto de la metodología Willems, o de Orff, como de la flauta dulce, que constituye un buen recurso para la entonación y acompañamiento del repertorio infantil.

- Conocimientos de expresión rítmico-corporal y danzas para dirigir sesiones de movimiento con los alumnos y así expresarse a través del cuerpo.

Sin embargo, esta reducción del número de créditos en los planes de formación musical en el Grado en Maestro en Educación Infantil, tal y como lo expresan Ruiz, Palomero y Baños (2015) y que, compartimos plenamente, está obligado a reajustar los contenidos de la materia lo que, supone una selección de aquellos considerados más relevantes y un cambio en el enfoque metodológico que conjugue teoría y su aplicación práctica, tarea sumamente difícil.

Por lo tanto, y como se ha expuesto en el capítulo anterior, la formación musical básica que reciben los estudiantes que cursan el grado en Maestro en Educación Infantil, se limita a solo una asignatura de 6 ECTS, tiempo que se limita a adquirir rudimentos musicales básicos sin proporcionar bases teóricas y metodológicas adecuadas, lo que hace que, en la práctica del aula los maestros generalistas en Educación Infantil, "releguen estas enseñanzas a un papel secundario y casi testimonial debido a una marcada falta de confianza en sus propias capacidades para hacer frente a este cometido" (Giráldez, 2009, p. 106) lo que da lugar a una desorientación a la hora de impartir estos contenidos. 


\section{CAPÍTULO 3. LA EDUCACIÓN INCLUSIVA}

A las aulas asisten alumnos con diferentes ritmos de aprendizaje, capacidades, expectativas que requieren una atención educativa adecuada respetando la igualdad de oportunidades. Alcanzar este objetivo demanda, entre otras cosas, la implicación de la Administración educativa, de los centros escolares y de los docentes de cara a conseguir la inclusión como modelo educativo que dé cabida y atienda las necesidades de todo el alumnado. En este contexto, en el presente capítulo, expondremos las reformas educativas que se han llevado a cabo para intentar conseguir una educación para todos, el tratamiento que recibe en la comunidad castellano leonesa, el papel importantísimo de los maestros como agentes fundamentales de la educación inclusiva y el recurso que constituyen las actividades musicales para la atención a todos los alumnos en el aula de segundo ciclo de Educación infantil.

\section{1. ¿Qué es la educación inclusiva?}

Los diferentes enfoques que se dan a la hora de definir la educación inclusiva dependen de la perspectiva de los autores e instituciones a los que hagamos referencia. Unas definiciones dan más peso a los aspectos prácticos y a las acciones y cambios en las orientaciones de los sistemas educativos.

Así, en opinión de Barton (1998):

La educación inclusiva no es algo que tenga que ver meramente con facilitar el acceso a las escuelas ordinarias a los alumnos que han sido previamente excluidos. No es algo que tenga que ver con terminar con un inaceptable sistema de segregación y con lanzar a todo ese alumnado hacia un sistema ordinario que no ha cambiado. El sistema escolar que conocemos, tendrá que cambiar. Y ello porque Educación Inclusiva es participación de todos los niños y jóvenes y remover para conseguirlo, todas las prácticas excluyentes (p. 85).

Arnaiz (2004) se enfoca más en los principios y derechos:

La educación inclusiva es ante todo una cuestión de derechos humanos, ya que defiende que no se puede segregar a ninguna persona como consecuencia de su 
discapacidad o dificultad de aprendizaje, género o pertenencia a una minoría étnica (p.17).

Otras definiciones, engloban el conjunto del alumnado. Así lo pone de manifiesto, entre otros, Echeita (2002):

Las escuelas deben acoger a todos los niños, independientemente de sus condiciones físicas, intelectuales, sociales, emocionales, lingüísticas u otras (...) todas estas condiciones plantean una serie de retos para los sistemas escolares (...) las escuelas tienen que encontrar la manera de educar con éxito a todos los niños, incluidos a aquellos con discapacidades graves (p. 59).

O como en el caso de Caprile (2015), la definen como un proceso de construcción continua:

Educación inclusiva es aquella que dejó de sorprenderse ante la diversidad porque entiende y acepta que las diferencias son expresión de la vida de una sociedad libre; sin desatender el riesgo de exclusión, una amenaza real, agazapada detrás de argumentos y políticas que ven la diferencia como desventaja (p.96).

Así, la educación inclusiva no es un estado, ni es un fin en sí misma, sino un medio para alcanzar el establecimiento de una sociedad democrática que se basa en el principio de que cada niño tiene características, intereses, capacidades y necesidades de aprendizaje distintas, que tienen su origen en las diferencias culturales, sociales, de género y personales (Sabatella Riccardi, 2008) inherentes a la condición y que es el sistema educativo quien debe garantizar la plena participación y rendimiento de todos los alumnos en su proceso de enseñanza-aprendizaje.

\section{Antecedentes}

Desde hace décadas, autores sensibles al tema como Ainscow (2001), Booth (2006) o Echeita (2011) entre otros, abogaban por la necesidad de conseguir la participación de todas las personas en la sociedad, en la escuela o en la comunidad de forma simultánea, procurando disminuir y eliminar aquellas barreras sociales, culturales, actitudinales, etc., que impiden el aprendizaje y la participación de todos aquellos externos a las clases dominantes. 
El derecho a la educación para todos, es adoptado y proclamado por la Organización de las Naciones Unidas (ONU) en La Declaración Universal de los Derechos Humanos de 1948, donde por primera vez los Estados miembros la reconocen internacionalmente:

Toda persona tiene derecho a la educación. La educación debe ser gratuita, al menos en lo concerniente a la instrucción elemental y fundamental. La instrucción elemental será obligatoria. La instrucción técnica y profesional habrá de ser generalizada; el acceso a los estudios superiores será igual para todos, en función de los méritos respectivos (ONU, 1948, Art. 26).

A partir de esta Declaración, se generaron una serie de Foros internacionales que, aunque no hacen referencia a la educación inclusiva como tal, "son el antecedente que dieron soporte a las actuales propuestas en materia de atención a los niños con necesidades educativas especiales (NEE) asociadas a discapacidad u otros factores" (Meza, 2010, p. 41) y que sentaron las bases para el establecimiento de las normativas que impulsaron el tránsito de la perspectiva de la integración a la de la inclusión. Entre ellas destacamos:

- La Convención de los derechos de los niños de 1989 donde en la Asamblea General de las Naciones Unidas, celebrada en Nueva York el 20 de noviembre, se reconocía el derecho de todo niño a recibir una educación sin ningún tipo de discriminación.

- La Declaración Mundial sobre educación: Satisfacción de las necesidades básicas sobre el aprendizaje, celebrada en 1990 en Jomtien, Tailandia, donde se puso de manifiesto la idea de universalizar el acceso a la educación para que "los seres humanos puedan sobrevivir, desarrollar plenamente sus capacidades, vivir y trabajar con dignidad, participar plenamente en el desarrollo, mejorar la calidad de su vida, tomar decisiones fundamentadas y continuar aprendiendo" (UNESCO, 1990, Art. 1).

- La Declaración de Salamanca y Marco de acción sobre Necesidades Educativas Especiales, que en 1994 marcó sin duda el punto de inflexión. En ella se enfatizó la urgencia de impartir la enseñanza a todos los niños y niñas, jóvenes y adultos, con y sin necesidades educativas especiales, dentro de un mismo sistema 
común de educación. Se generalizó la inclusión como principio central que debía guiar la política y la práctica de la construcción de una educación para todas las personas. "Las escuelas deben acoger a todos los niños, independientemente de sus condiciones físicas, intelectuales, sociales, emocionales, lingüísticas u otra... las escuelas tienen que encontrar la manera de educar a todos los niños, incluidos aquellos con discapacidades graves" (UNESCO, 1994, p. 6).

- El Marco de Acción del Foro Mundial sobre la Educación (Dakar, Senegal, 2000) afirmó en su Informe final, que "la educación es una tarea de todos" y se fijaron cumplir unos compromisos comunes, entre ellos "velar por que antes del año 2015 todos los niños, y sobre todo las niñas y los niños que se encuentran en situaciones difíciles, tengan acceso a una enseñanza primaria gratuita y obligatoria de buena calidad y la terminen" (p. 43).

- La Convención sobre los Derechos de las Personas con Discapacidad (2007), donde organizaciones civiles se reunieron con diversos colectivos de personas con discapacidad e influyeron en la elaboración de la "Clasificación Internacional del funcionamiento de la discapacidad y de la salud" (2001) de la Organización Mundial para la Salud (OMS) (Pantano, 2003). "Con miras a hacer efectivo el derecho de las personas con discapacidad a la educación sin discriminación y sobre la base de igualdad de oportunidades, los estados parte asegurarán un sistema de educación inclusivo a todos los niveles, así como la enseñanza a lo largo de la vida" (ONU, 2007, Art. 24).

- La Conferencia Internacional de la Educación: "Educación inclusiva: un camino hacia el futuro", celebrada en Ginebra en 2008 (UNESCO) donde se enunciaron unas orientaciones para lograrla y se hizo hincapié, entre otras cosas, en la formación del profesorado como la clave para el desarrollo futuro de la educación inclusiva.

- La Conferencia mundial sobre Educación Inclusiva "Volviendo a Salamanca: Afrontando el reto: Derechos, retórica y Situación actual"(Salamanca 2009), en ella se presentó el informe mundial "Mejor educación para todos cuando se nos incluya también" en el que se revisó el progreso realizado y el estado de la Educación Inclusiva quince años después de la Declaración de Salamanca, 
proponiendo recomendaciones a los gobiernos e instituciones internacionales para hacer inclusivos los sistemas educativos (Casanova, 2011).

- El Comunicado de la Comisión Europea de noviembre de 2010, elaboró la "Estrategia Europea sobre Discapacidad 2010-20: un compromiso renovado para una Europa sin barreras" donde se establecía que "se deberá promover una educación y aprendizaje permanente inclusivo para todos los alumnos con discapacidad" (CE, 2010, p. 8).

En todos estos foros, queda plasmado:

- El derecho de una educación para todos y no solo para los que tienen necesidades especiales.

- Una educación que atienda a las necesidades de todos los educandos a través de una mayor participación en el aprendizaje y en las actividades culturales.

- Una educación que se contemple como un proyecto para conseguir una sociedad más democrática y participativa.

- Una educación inclusiva donde los maestros y estudiantes se sientan cómodos ante la diversidad y la perciban no como un problema, sino como una oportunidad para enriquecer el entorno de aprendizaje.

- Una educación que logre transformar los sistemas educativos y otros entornos de aprendizaje, con el fin de responder a la diversidad de todos los alumnos.

\section{La educación inclusiva en la legislación española}

En nuestro país, se ha ido realizando una serie de reformas en el sistema educativo para alcanzar una educación inclusiva que no siempre se han traducido en políticas coherentes con los principios en los que ésta se sustenta.

La Constitución Española de 1978, en el artículo 27 reconoce el derecho a la educación de todos los ciudadanos sin excepciones, quedando patente que el objetivo primero y fundamental de la educación debe ser el de proporcionar a los alumnos una formación plena que les permita desarrollar al máximo sus capacidades, conformar su 
propia identidad personal y configurar su comprensión de la realidad, integrando la dimensión cognitiva, la socio-afectiva y la motora. Quedaba reflejado en su Artículo 49, la necesidad de atención específica de aquel alumnado que estando en la escolarización obligatoria, precisa de más ayuda para la consecución de dicho derecho fundamental. En este contexto apareció el término normalización, definido en aquel momento como "la posibilidad de que el deficiente mental desarrolle un tipo de vida tan normal como sea posible" (Fernández González, 1993, p. 89).

La Ley de 1985 planteó explícitamente los beneficios y la necesidad de escolarizar en centros ordinarios a todas aquellas personas "con deficiencias psíquicas y sensoriales" a través de apoyos individuales específicos. En el RD 334/1985 de 6 de marzo sobre Ordenación de la Educación Especial, apareció un nuevo concepto de Educación Especial definiéndola como parte integrante del sistema educativo, y la concreta como un conjunto de apoyos y adaptaciones para que estos alumnos puedan hacer efectivo su derecho a la educación. Los artículos del 23 al 31 reflejaban el planteamiento educativo para las personas con discapacidad, en los cuales ya se afirmaba e insistía con rotundidad en que el alumno "se integrará en el sistema ordinario de educación general" recibiendo los apoyos necesarios que prevé la misma ley y señalando que sólo cuando las características del alumno no hacían posible su inserción en el sistema educativo convencional, se debería recurrir a centros de educación especial.

Casanova (2011) concluye que, a partir de esta norma, comienza a ser un hecho cierto la integración de los alumnos con necesidades educativas especiales en las aulas ordinarias, lo que supuso un cambio en la configuración estructural del sistema educativo, que se empezó a plantear la integración de niños con discapacidades en centros ordinarios.

Pero la primera ley que se manifiesta en términos de necesidades educativas especiales $^{45}$ (como alternativa a los deficientes, disminuidos, discapacitados y minusválidos) y de diversidad del alumnado, es con la Ley Orgánica 1/1990, de 3 de octubre, de Ordenación General del Sistema Educativo (LOGSE). En ella, se introduce por primera vez el concepto de alumno con necesidades educativas especiales

\footnotetext{
${ }^{45}$ Este concepto de necesidades educativas especiales surgió en el informe Warnock elaborado en 1978. En España no se introduce el concepto hasta esta ley.
} 
(ACNEES) y se estableció que la escolarización en centros específicos de educación especial se llevaría a cabo sólo en casos excepcionales (Casanova, 2011). Esta inclusión al Sistema Educativo Español "se seguirá y regirá por los principios de normalización y de integración social" (LOGSE, Art. 36, p.3).

Se instaba ya en aquel momento a todos los centros para que asumieran las diferencias individuales de los alumnos y planificaran a partir de la diversidad su respuesta educativa (MEC, 1992). De este modo, la atención a las necesidades educativas especiales se circunscribe en el marco de atención a la diversidad. Pero al utilizar este término, muchos alumnos analizados en términos de deficiencias fueron clasificados con N.E.E. y se les supuso una discapacidad sin tenerla. (Vlachou, 1999).

Este enfoque puso de manifiesto que la escuela no estaba realmente preparada para atender a la diversidad del alumnado en general (Martín Pastor, 2012) pues se mantenía una separación entre la enseñanza que recibía un alumno con necesidades educativas especiales y la del resto de sus compañeros.

Posteriormente, en el Real Decreto 696/1995, de 28 de abril, de ordenación de la educación de los alumnos con necesidades educativas especiales, se perfilan los distintos tipos de n.e.e. en función del contexto social y cultural, la historia educativa y escolar o las condiciones personales de sobredotación, de discapacidad psíquica, motora o sensorial o trastornos graves de conducta. Se ofreció garantía de calidad educativa para este alumnado a través de la organización de todos los elementos relativos a la planificación de recursos, a la ordenación y a la organización de la atención educativa a estos estudiantes, incorporando ésta al Proyecto Curricular de los centros y aumentando los recursos, medidas y apoyos complementarios que garantizaran una educación óptima para todos los alumnos (Martín Pastor, 2012).

Con la Ley Orgánica 10/2002, de 23 de diciembre de calidad de la Educación (LOCE) se introdujeron nuevos conceptos. Definió con más precisión el concepto de ACNEE (Art. 44) como alumnos que a lo largo de su escolarización requieran determinados apoyos y atenciones educativas específicas por padecer discapacidades físicas, psíquicas, sensoriales o por manifestar graves trastornos de la personalidad y de la conducta, y contempló cuatro modalidades de escolarización: en grupos ordinarios, en aulas especializadas en centros ordinarios, en centros de educación especial o en escolarización combinada (Art. 45). 
La Ley Orgánica 2/2006, de 3 de mayo de 2006, de Educación (LOE) concibe la respuesta educativa a todos los alumnos a partir del concepto de inclusión, entendiendo así que se garantizaba el desarrollo de todos y se favorecía la equidad.

También reconoció el derecho de todos los estudiantes a una educación adaptada a las necesidades y características de cada uno. "La atención a la diversidad en el principio de inclusión educativa es un derecho de todos los estudiantes, en todas las etapas de educación obligatoria, y con independencia de si se trata de un centro privado, público o concertado" (Arts. 1b, 4.3, 71.3 y 121.2).

En su Capítulo 1 utilizó una categorización más amplia para definir al alumnado con necesidades específicas de apoyo educativo: alumnos que presentan n.e.e. (discapacidades, trastorno generalizado del desarrollo, trastorno del espectro autista, trastorno emocional y trastorno de conducta), alumnos con altas capacidades intelectuales y alumnos con integración tardía al sistema educativo.

Además, a la hora de clasificar en grupos y establecer tipologías, las distintas Comunidades Autónomas adaptaron sus actuaciones, estableciendo otras divisiones ${ }^{46}$.

Al establecer tantas categorías en función de las necesidades, el planteamiento de la LOE es contrario a los principios de la inclusión, por eso, una de las críticas que recibió fue que resultaba poco coherente con los principios en los que se basa el modelo de la educación inclusiva (Muntaner, Forteza, Roselló, Verger y De la Iglesia, 2016) ya que la categorización del alumnado que presenta necesidades específicas de apoyo educativo y las subdivisiones que realizaba en determinadas categorías, llevaba a la infravaloración de ciertos alumnos en relación al resto; otra fue que, en general, se trataba de una ley que se conformaba con un planteamiento reduccionista de la inclusión.

La actual Ley Orgánica, 8/2013, de 9 de diciembre para la Mejora de la Calidad Educativa (LOMCE) no supone ningún avance significativo en relación a la inclusión escolar.

En el Preámbulo I, especifica que solo un sistema educativo de calidad, inclusivo, integrador y exigente garantiza la igualdad de oportunidades y hace efectiva la

\footnotetext{
${ }^{46}$ ORDEN EDU/571/2005, de 26 de abril, por la que se crea fichero automatizado de datos de carácter personal denominado «Datos relativos al alumnado con Necesidades Educativas Específicas» de la Consejería de Educación de la Junta de Castilla y León.
} 
posibilidad de que cada alumno o alumna desarrolle el máximo de sus posibilidades.

Amplía de nuevo el término de alumnos con necesidades específicas de apoyo educativo, abarcando a un grupo más amplio y recogiendo en él al siguiente alumnado: alumnos con necesidades educativas especiales (ACNEEs); alumnado con altas capacidades intelectuales; alumnado de Integración tardía al Sistema Educativo Español y alumnado con dificultades específicas de aprendizaje.

Desde la perspectiva de la inclusión educativa, pretende ofrecer oportunidades reales de aprendizaje a todo el alumnado, sin embargo, diversos sectores relacionados con la educación consideran que solo hace una declaración de intenciones, porque en su desarrollo habla más de integración que de inclusión. Así, en opinión de López Melero (2015):

La LOMCE, institucionalmente, desmonta un modelo comprensivo e inclusivo de escuela que hablaba de solidaridad, cooperación, respeto, justicia, democracia, etc., por un modelo elitista, segregador y discriminatorio. En lo personal mata las ilusiones de aquellas personas que confiábamos en que era posible construir una escuela sin exclusiones. Para ello utiliza los recortes como pretexto, lo que significa menos oportunidades para los colectivos más pobres y para los que tienen más dificultades, y la creación de itinerarios para segregar, porque no sólo se hacen recortes económicos sino recortes de derechos y de democracia. Es una ley que beneficia a las élites y clases sociales altas y castiga y margina al resto, especialmente a las clases populares y a los colectivos más desfavorecidos (p. 165).

\section{La educación inclusiva en la legislación de la Comunidad de Castilla y León}

En los últimos años, la comunidad de Castilla y León ha adoptado Planes Órdenes, Resoluciones y Decretos que, bajo el supuesto compromiso de responder a la diversidad de su alumnado, ha centrado principalmente en la atención a los alumnos con necesidades específicas de apoyo educativo. A continuación, destacamos las más relevantes:

- La ORDEN EDU/965/2009, de 16 de abril, por la que se regula la evaluación del alumnado con necesidades educativas especiales 
escolarizado en el segundo ciclo de Educación Infantil, Educación Primaria, Educación Secundaria Obligatoria y Bachillerato, en la Comunidad de Castilla y León.

- La Resolución de mayo de 2010, de la Dirección General de Planificación, Ordenación e Inspección Educativa de Castilla y León, por la que se organiza la atención educativa al alumnado con incorporación tardía en el sistema educativo y al alumnado en situación de desventaja socioeducativa, escolarizado en el segundo ciclo de Educación Infantil, Educación Primaria y Educación Secundaria Obligatoria.

- La ORDEN EDU/1152/2010, de 3 de agosto, por la que se regula la respuesta educativa al alumnado con necesidad específica de apoyo educativo escolarizado en el segundo ciclo de Educación Infantil, Educación Primaria, Educación Secundaria Obligatoria, Bachillerato y Enseñanzas de Educación Especial, en los centros docentes de la Comunidad. En su artículo 3, enumera los principios generales de actuación: "mayor grado de normalización, inclusión, integración, compensación, calidad y equidad en su proceso educativo, en sus interacciones personales y sociales, en el aula y en el centro, con el objeto de garantizar la igualdad de oportunidades en el acceso, la permanencia y la promoción en el sistema educativo" (p. 64452).

- La ORDEN EDU/1152/2010, de 3 de agosto, desarrolla en su art. 9 el Plan de Atención a la Diversidad, documento en el que se recoge el conjunto de actuaciones y medidas educativas y organizativas que un centro docente diseña y desarrolla para adecuar la respuesta a las necesidades educativas del alumnado en él escolarizado.

- Ley $3 / 2013$, de 28 de mayo, de la integración de los inmigrantes en la sociedad de Castilla y León.

- INSTRUCCIÓN, de 9 de Julio de 2015, de la Dirección General de Innovación Educativa y Formación del profesorado, por el que se establece el procedimiento de recogida y tratamiento de los datos relativos al alumnado con necesidades específicas de apoyo educativo escolarizado en centros docentes de Castilla y León, que dejó sin efectos 
las Instrucciones conjuntas de 21 de octubre de 2005, y de 12 de junio de 2007 de la Dirección General de Formación Profesional e Innovación Educativa y de la Dirección General de la Coordinación, Inspección y Programas Educativos, y de 7 d enero de 2009 de las Direcciones Generales de Planificación, Ordenación e Inspección Educativa y de Calidad, innovación y Formación del Profesorado.

- El II Plan de Atención a la Diversidad (2015), donde se establecieron las líneas estratégicas de actuación desde una perspectiva inclusiva de la educación. Un aspecto importante a destacar en la elaboración de este nuevo plan fue que se contó con un análisis DAFO (debilidades, amenazas, fortalezas y oportunidades), llevado a cabo en el sistema educativo de Castilla y León en relación a la atención a la diversidad, encaminado a detectar y consolidar los puntos fuertes y minimizar los débiles, teniendo en cuenta las valoraciones realizadas por los agentes más representativos: el profesorado, el alumnado de Educación Secundaria, las familias y la administración.

\section{La formación del profesorado como agente fundamental de la educación} inclusiva

Unos de los puntos analizados en el II Plan de Atención a la Diversidad que acabamos de mencionar fue el de la "Formación en educación inclusiva para todos los docentes", destacando como debilidades "la poca formación inicial del profesorado en principios básicos de atención a la diversidad por su escasa presencia en el currículo universitario" (p.22) y la presencia de actividades complementarias y extraescolares no accesibles ni adaptadas a las características de todo el alumnado, pues no contemplan el "diseño para todos".

Para que la educación inclusiva sea una realidad, el profesorado debe adquirir la actitud, capacidad y los conocimientos necesarios para enseñar a todos los alumnos.

Sin embargo, en el Grado en Maestro en Educación Infantil, solo se cursan 2 asignaturas de 6 ECTS relacionadas con la educación inclusiva: "Atención a la diversidad" y "Desarrollo y aprendizaje con alumnos con necesidades educativas 
especiales"; en raras ocasiones, se contempla como algo transversal dentro de la formación en el resto de disciplinas. En el enfoque que se da en las materias y asignaturas que forman parte del currículo de la titulación, en general, a la hora de planificar las actividades docentes para aplicar en el aula, no se contempla la diversidad como algo característico del quehacer educativo, por lo que a la hora de desarrollar la práctica los maestros no están preparados para abordar con éxito una educación para todos. Pensamos por ello que la formación en educación inclusiva no se aborda en profundidad en los planes de estudio de la formación de los maestros.

Las dificultades que se encuentran los profesores en el aula para poder formar y atender a todo el alumnado, en palabras de López Melero (2015), no se encuentran en las personas diferentes, sino en las barreras que nos existentes en los procesos de enseñanza y aprendizaje, el currículo y en los profesores. Así, debemos formar al profesorado en estrategias metodológicas que le permitan dar respuesta a estas peculiaridades donde las actividades que se realicen en el aula se organicen no de forma individual ni competitiva, sino cooperativa:

...una buena práctica docente no se aprende memorizando teorías sin conexión con la realidad escolar, sino desarrollando un conocimiento práctico riguroso que sirva para tomar decisiones fundamentadas sobre para qué enseñar, qué enseñar, con qué metodología actuar y de qué manera evaluar (López Melero, 2015, p.179).

En este sentido, un estudio (González-Gil, Martín-Pastor, Flores, Jenaro, Poy, Gómez-Vela, 2013) Ilevado a cabo con 400 profesores de nuestra comunidad castellano leonesa mostró que las necesidades formativas en los profesores estaban relacionadas fundamentalmente con aspectos metodológicos y curriculares que permitan la transformación de sus escuelas en centros educativos inclusivos.

Lo mismo puso de manifiesto la investigación de Contreras (2015) cuando afirmaba que, aunque el profesorado demanda formación relacionada con las necesidades de los alumnos, lo que genera problema al trabajar con todo el alumnado en el aula no son las diferencias personales, sino la metodología. De esta forma, es fundamental formar un profesorado cualificado para abordar con éxito una educación inclusiva. 
En las declaraciones y conferencias internacionales que hemos ido mencionando a lo largo de este capítulo se destaca la formación del profesor como uno de los aspectos básicos clave para el desarrollo futuro:

Que formen a los docentes, dotándoles de las capacidades y los materiales necesarios para enseñar a distintas poblaciones estudiantiles y satisfacer las distintas necesidades de aprendizaje de las diferentes categorías de educandos, mediante métodos como el desarrollo profesional a nivel de la escuela, la formación inicial sobre inclusión y una instrucción en la que se tenga en cuenta el desarrollo y los puntos fuertes de cada educando (UNESCO, 2008, p. 17).

En la misma línea pensamos que la formación del profesorado, tanto inicial como permanente, debería ayudarle en todo momento para ser el motor del cambio hacia una educación inclusiva, empezando por la etapa de Educación Infantil, descrita por Casanova (2011) como el segundo entorno de socialización de una persona, donde debemos ofrecer un modelo de educación en el que todos los niños tengan cabida y donde los maestros estén preparados para responder a las necesidades de todos sus alumnos y para planificar una enseñanza adaptada a sus necesidades.

La formación que proponemos viene a recoger los enfoques de Booth y Ainscow (2011), González-Gil et. al (2013), López Melero (2015) y las recomendaciones del II Plan de atención a la diversidad de Castilla y León:

- Una formación inicial del profesorado en valores, tal como se recoge en el Index for inclusion (Booth y Ainscow, 2002, 2011; Booth, Ainscow y Kingston, 2006) para llegar a analizar hasta qué punto nuestras acciones serán coherentes con esos valores.

- Una mayor formación en metodología y estrategias que permita una planificación donde participe todo el alumnado (por ejemplo, aprendizaje cooperativo o grupos interactivos) y en procesos de enseñanza-aprendizaje que respondan a la diversidad, tanto en lo referido a la formación inicial como permanente del profesorado. 
- Apoyar la formación permanente de los maestros en los centros educativos para que aprendan a estructurar las tareas con diferentes enfoques para que todo el alumnado pueda participar en ellas.

- Mejorar la formación del profesorado sobre cómo aprenden los alumnos, cómo interpretar las diferencias individuales y cómo planificar su enseñanza teniendo en cuenta esas diferencias.

- Revisar la rigidez del currículo y convertirlo en uno más flexible.

- Fomentar la participación de los estudiantes en formación en proyectos educativos vinculados con la educación inclusiva realizados por maestros en ejercicio.

Por tanto, pensamos que la formación para la inclusión tiene ante todo como metas ayudar al profesorado a aceptar la responsabilidad del aprendizaje de todos los alumnos y ayudarle a entender sus dificultades de aprendizaje como oportunidades para mejorar la práctica educativa (Rouse, 2010).

\section{La música como recurso para la educación inclusiva}

La educación inclusiva implica modificar sustancialmente la estructura, funcionamiento y propuesta pedagógica de las escuelas para dar respuesta a las necesidades educativas de todos y cada uno de los alumnos, de forma que todos tengan éxito en su aprendizaje y participen en igualdad de condiciones. En este contexto, sabemos que el uso de la música contribuye a generar prácticas conducentes a la inclusión escolar o social (Fernández Carrión, 2011).

En el terreno musical existen proyectos que trabajan en esa línea y que tienen en común establecer un objetivo para todos y un trabajo conjunto que fomente la relación igualitaria entre todos sus integrantes.

Así, José Antonio Abreu (1939) utilizó la educación musical dentro de su proyecto "El sistema"para el desarrollo comunitario, la integración social y la solidaridad en Venezuela. Comenzó un proyecto revolucionario que partía de la música como medio de inclusión social con niños de pueblos y barrios con un índice de pobreza muy elevado, que aprendían a tocar un instrumento. 
Mary Ruth McGinn, defensora de la enseñanza a través de la música, creó en Inglaterra una compañía de ópera en un centro de Educación Primaria donde el 78\% del alumnado procedía de familias azotadas por la pobreza; trabajaba la ópera como medio de motivación y desarrollo integral y no sólo musical. En 2001, desarrolló "Creating original Opera", un programa para desarrollar el potencial creativo de los niños en el Metropolitan de Nueva York, y a partir de 2007 ha desarrollado en el con la Fundación SaludArte en el Teatro Real de Madrid su proyecto LÓVA (la ópera un vehículo de aprendizaje) en colaboración con diferentes centros y maestros, cuyo objetivo es el desarrollo emocional, social y cognitivo de todos los niños que participan.

Además, por las múltiples funciones que cumple la música y por su influencia decisiva en la conducta humana, es considerada esencialmente una experiencia multidimensional (Elliot, 1994). Se reconoce y consolida a través de la práctica la acción reparadora de la música como herramienta privilegiada de intervención social que evita que el alumnado con algún tipo de dificultad se sienta excluido socialmente.

La contribución de la experiencia musical en esta dirección (Carabeta, 2011; Ibarretxe, 2010; Lotova, 2009) muestra que en la diferencia del ser humano está la riqueza de la integración, al tiempo que favorece la reflexión y el respeto, gracias a actividades como el trabajo en grupos musicales, que crea vínculos emocionales destinados a mejorar la socialización y la prevención de la exclusión.

Cuando hablamos de la música como medio para conseguir la inclusión escolar, se hace inevitable vincularla con la educación intercultural, debido a que la música tiene un gran poder de enculturación. Así, en opinión de Giráldez (1998):

Basar el aprendizaje musical en un repertorio plural contribuye al desarrollo de una conciencia multicultural que tiene como cimientos la tolerancia y la comprensión, promueve un mayor diálogo de entendimiento y aceptación entre personas de diferentes culturas, desarrollando una mentalidad más abierta y ayudando a erradicar prejuicios raciales y generacionales (p. 225).

Las actividades musicales que se realizan en el aula de infantil son un buen recurso para trabajar la inclusión de todos alumnos, ya que hace posible establecer una buena relación y una buena comunicación entre todos, cantando, bailando, tocando 
instrumentos, escenificando un cuento sonoro, dramatizando una historia, pues permite la participación de todos.

Para Rodríguez Quiles (2013) entre los beneficios que reporta a los niños la práctica continuada de la música en la escuela se encuentra que experimentan por sí mismos su propia capacidad de expresión, favorece el aumento de las competencias sociales gracias a la práctica en grupo y facilita el significado de la forma y el orden. Pensamos que es necesaria una formación inicial en ese sentido que, como hemos visto, en el Grado en Maestro en Educación Infantil resulta escasa.

Siguiendo los principios de la Educación Inclusiva, Sabattela Riccardi, desarrolla en 2008 el concepto de Educación Musical Inclusiva (EMI) y la define como

"el conjunto de estrategias y recursos utilizados para facilitar el acceso a la educación musical de todos los individuos atendiendo a sus características, intereses, capacidades y necesidades de aprendizaje (diferencias culturales, sociales, de género y personales) en contextos formales y no formales" (p. 258).

Este enfoque de aprendizaje musical implica modificar las propuestas pedagógicas en sus aspectos metodológicos a fin de dar respuesta a las necesidades educativas de todos y cada uno de los niños, de forma que todos tengan éxito en su aprendizaje y participen en igualdad de condiciones. 
PARTE II: ESTUDIO EMPÍRICO 


\section{CAPITULO 4. INVESTIGACIÓN}

\section{INTRODUCCIÓN}

La metodología elegida en esta investigación, es de carácter cuantitativa con una finalidad descriptiva no experimental, puesto que se han estudiado grupos naturales ya formados de estudiantes y maestros en ejercicio.

Pretende informar, en primer lugar, acerca de la formación musical de los alumnos que cursan el Grado en Maestro en Educación Infantil en la Universidad de Salamanca y en segundo, de la utilización que se está haciendo de la música en las aulas de segundo ciclo de educación infantil. Todo ello, con el fin de diseñar propuestas de mejora de la formación musical tanto para los estudiantes como para los maestros en ejercicio que repercutan en una mejor educación en la etapa de educación infantil.

A lo largo de la investigación, utilizaremos la siguiente terminología para referirnos a los protagonistas de nuestro estudio:

- El término estudiantes, se usa en referencia a los alumnos que cursan el Grado en Maestro en Educación Infantil de la Universidad de Salamanca.

- El término maestros, se emplea para referirse a los maestros-tutores con los que los estudiantes realizaron las prácticas educativas.

- El término alumnos, se refiere a los niños escolarizados en las aulas del segundo ciclo de educación infantil. 


\section{OBJETIVOS}

Esta investigación plantea tres objetivos generales de los que se derivan siete específicos:

1.- Analizar la formación musical de los estudiantes que cursan el Grado en Maestro en Educación Infantil en la Universidad de Salamanca.

1.1- Diseñar un instrumento que permita, por un lado, autoevaluar la formación musical previa de los estudiantes de magisterio y por otro, las percepciones respecto a su dominio de habilidades y destrezas musicales.

1.2- Evaluar la formación y la actuación musical de los estudiantes en prácticas por los maestros, después de haber cursado las asignaturas de Expresión musical en educación infantil y de Practicum I.

2.- Evaluar la utilización de la música en la etapa de educación infantil en los centros educativos de Castilla y León.

2.1 -Diseñar un instrumento para analizar el empleo de la música en el segundo ciclo de educación infantil.

2.2- Evaluar el uso de la música en la práctica educativa en la etapa de educación infantil.

2.3- Analizar la contribución de la música a la mejora de la respuesta educativa a la diversidad.

3.-Diseñar propuestas para mejorar la formación de los maestros y futuros maestros en competencias musicales para la puesta en marcha de prácticas inclusivas.

3.1.- Elaborar propuestas para mejorar la formación inicial de los estudiantes del Grado en Maestro en Educación Infantil.

3.2.- Elaborar propuestas de formación permanente para los maestros de segundo ciclo de Educación Infantil. 


\section{HIPÓTESIS}

A partir de la revisión de las investigaciones realizadas sobre nuestra temática (Arriaga, Madariaga y Morentín, 2012; Carrillo Aguilera y Vilar Monmany, 2016; López de la Calle San Pedro, 2007; Oriol, 2001, Ruiz Palomo, 2013 y Ruiz Palomo, Palmero Cámara y Baños Martínez, 2015), se plantearon las siguientes hipótesis:

Hipótesis 1: La formación musical de los estudiantes del Grado es insuficiente para un uso adecuado de la música en su práctica educativa.

1.1: La formación musical recibida por los estudiantes del Grado en sus anteriores etapas educativas, es insuficiente para continuar su formación en Expresión musical en el Grado en Maestro en Educación infantil.

1.2: A pesar de haber recibido formación musical en las anteriores etapas educativas los estudiantes no se consideran musicalmente formados para continuar con su formación musical en el Grado.

1.3: Existen diferencias en las destrezas y habilidades musicales y en la adquisición de recursos en la formación musical del Grado entre aquellos estudiantes que han recibido formación musical extraescolar previa y los que no.

Hipótesis 2: La formación musical recibida en el Grado es insuficiente para dotar a los estudiantes de las competencias necesarias para integrar la música en su futura práctica profesional.

2.1: La formación básica del Grado en educación musical no es suficiente para impartir el currículo de Expresión musical.

2.2: Los maestros consideran que los estudiantes no tienen formación musical suficiente para desempeñar su trabajo en el segundo ciclo de Educación infantil.

2.3: Hay diferencia de percepción y de valoración entre los estudiantes y los maestros sobre la valoración de la formación en contenidos procedimentales referidos a la expresión, percepción, creación y representación gráfica de la música necesarios para impartir el currículo de música en segundo ciclo de educación infantil. 
Hipótesis 3: No se hace un uso ni adecuado ni suficiente de la música en la etapa de segundo ciclo de educación infantil.

3.1: Las sesiones de música en las aulas de 2o ciclo de educación infantil son insuficientes para desarrollar los contenidos del currículo de Expresión musical.

3.2: Los maestros consideran que la participación en las actividades musicales en la etapa de educación infantil contribuye a la inclusión de todos los alumnos.

3.3: Hay diferencia de valoración entre los estudiantes y los maestros sobre la importancia de la música en la Educación. Los estudiantes consideran menos importante que los maestros la educación musical en la etapa de educación infantil. 


\section{MÉTODO}

\section{PARTICIPANTES}

Los participantes de este trabajo se dividen en dos muestras diferenciadas: por un lado, los estudiantes matriculados en el tercer curso del Grado en Maestro en Educación Infantil de la Universidad de Salamanca; por otro, los maestros de segundo ciclo de educación infantil que han sido tutores de los estudiantes durante sus prácticas en centros educativos de Ávila, Zamora y Salamanca.

En lo que respecta a los estudiantes, la muestra fue conformada en dos cursos académicos 2013-14 y 2014-15 y estuvo compuesta por un total de 191 estudiantes, la mayoría mujeres (97,4\%), con media de 22,4 años de edad. Un 66\% estudió previamente en centros públicos y un 31,9\% en centros concertados. De todos ellos, el $83,5 \%$ realizaron sus prácticas educativas en centros de la provincia de Salamanca, del resto, un $5,8 \%$ las realizaron en centros educativos de Ávila y un $12 \%$ en centros de Zamora. Estos datos concuerdan con el porcentaje mayoritario de estudiantes de nuestra muestra (82,2\%) que, en su origen, están adscritos a la Facultad de Educación de Salamanca.

La diferencia de la muestra entre los tres centros que imparten el Grado en Maestro en Educación Infantil en la Universidad de Salamanca, viene justificada, por una parte, porque el índice de matrícula de los centros periféricos es inferior al de la Facultad de Educación y otra causa que justifica el porcentaje relativamente bajo de respuestas es que los datos que se facilitaron en los centros de Ávila y Zamora, no se correspondieron con los datos reales de los alumnos de esos cursos, lo que dificultó la recogida de información.

En lo referente a los maestros, la muestra estuvo compuesta por 41 tutores de los diferentes centros educativos donde los estudiantes cursaron sus prácticas. La mayoría de ellos eran mujeres $(87,8 \%)$ con edad media de 43,2 años. En lo que se refiere a la figura profesional que desempeñaban, 36 tenían el puesto de tutores, 4 el de coordinadores de segundo ciclo de educación infantil y 1 el de profesor de apoyo. Respecto a su formación, además de haber cursado la Diplomatura de Maestro, 5 contaban con formación en Audición y Lenguaje, 2 en Logopedia y 1 en Ciencias Humanas. En cuanto a sus años de experiencia docente en la etapa de educación 
Infantil, 17 llevan menos de 10 años en ejercicio; 13 tutores entre 10 y 20 años; 10 entre 21 y 30 años y 1 maestro más de 30 años de docencia. En lo que concierne a la titularidad de los centros, $58,5 \%$ trabajan en centros públicos y el resto en centros concertados $(41,5 \%)$.

Por último, en lo que respecta al volumen de estudiantes en prácticas que los maestros han tutorizado, los datos indican que casi la mitad $(46,2 \%)$ han tenido durante sus prácticas a 1 estudiante, un 38,5\% a 2 estudiantes y un 15,4\% de los maestros a 3, lo que conforma un total de 66 estudiantes.

\section{INSTRUMENTOS DE EVALUACIÓN}

Para la recogida de datos en nuestro estudio utilizamos cuatro cuestionarios, los dos primeros de elaboración propia y los dos siguientes basados en el "Cuestionario dirigido al profesorado de educación infantil 3-6 años de los Centros educativos de Galicia" (López de la Calle Sampedro, 2007) ${ }^{47}$ del que se ha tomado unos ítems de las secciones A-C-E-F ajustándolos a la actual ley educativa y al tipo de información que queríamos recopilar.

A continuación, describimos las principales características de cada uno de ellos.

1) El "Cuestionario sobre la formación musical de los estudiantes" (Anexo I) pretende recoger información sobre la formación musical de los estudiantes del Grado en Maestro en Educación Infantil recibida en las anteriores etapas educativas y/o en centros musicales específicos. Consta de seis secciones, cada una de ellas referidas a un nivel educativo:

- la primera sección nos aporta datos sobre la formación musical de todos los estudiantes en la etapa educativa obligatoria de Educación Primaria,

- la segunda indaga en la formación musical recibida por todos los estudiantes en la Educación Secundaria Obligatoria (E.S.O.)

\footnotetext{
${ }^{47}$ El cuestionario consta de las siguientes secciones: A: Desarrollando el currículum de música en su escuela. B: Evaluación y supervisión del progreso musical de los niños. C: Ayudando a los niños con diversas necesidades. D: Uso de las TIC (tecnologías de información y de comunicación) para la enseñanza y el aprendizaje de la música. E: Analizando la formación en educación musical en los Centros Universitarios de Formación del Profesorado. F: Diseñando un currículum equilibrado y ajustado para la formación del maestro especialista en educación infantil. G: Guía, formación y ayuda en la enseñanza.
} 
- la tercera, corresponde a la recibida por los estudiantes que han cursado el Bachillerato,

- la cuarta destinada a los alumnos que realizaron algún Ciclo Formativo de Grado Medio,

- la quinta a los que cursaron el nivel de Técnico Superior en Educación Infantil y

- la sexta a aquellos alumnos que recibieron otro tipo de formación musical.

En todas estas secciones nos interesa conocer, la disponibilidad de los espacios donde recibieron la formación musical, el uso de los materiales empleados y el tipo de conocimientos musicales que recibieron respecto a la formación vocal, formación instrumental, formación auditiva, formación en movimiento y danza, lenguaje musical e historia de la música. ${ }^{48}$

En relación a la tipología y caracterización de las preguntas, el cuestionario está formado por una combinación de preguntas con diversos formatos de respuesta: dicotómicas con opciones mutuamente excluyentes y de elección múltiple, con varias opciones de respuesta donde tienen que elegir solo una de las opciones.

2) El "Cuestionario sobre conocimientos /habilidades y destrezas musicales", (Anexo II) está formado por un total de 9 ítems que pretenden recabar información, por un lado, sobre la percepción de los estudiantes respecto a su formación musical en cuanto a: habilidades, destrezas y conocimientos musicales, necesarios para poder impartir en currículo de expresión musical en la Educación Infantil y por otro, sobre la percepción de los aspectos que necesitarían mejorar.

Este cuestionario se les pasó inicialmente a todos los alumnos matriculados en la asignatura "Expresión musical en la educación infantil" antes que esta se impartiera y posteriormente se les pasa a los estudiantes que cursaron la asignatura "Practicum I" porque la investigación continuó solo con los alumnos que realizaron las prácticas.

En relación a la tipología y categorización de las preguntas, estas son de elección múltiple y están ordenadas para representar el mayor/menor grado de aquello que se mide (por ejemplo, en el caso los conocimientos musicales desde nada hasta mucho).

\footnotetext{
${ }^{48}$ Contenidos, que como se mencionó en el capítulo 2 forman parte del currículo de estas etapas educativas y que se estructuran dentro de las áreas denominadas: educación vocal, educación rítmica y educación auditiva.
} 
3) Con el tercero, "Cuestionario sobre el uso de la música en los centros de Educación Infantil “, adaptado de López de la Calle, 2007 (Anexo III) destinado a los estudiantes, se pretendía recopilar información sobre la utilización de la música en la etapa de educación infantil en los centros educativos de Castilla y León donde realizaron sus prácticas educativas. La tipología de las preguntas utilizadas ha sido: de elección múltiple con varias opciones de respuestas, de opinión (desde en contra a favor, de acuerdo o no), de escala tipo Lickert donde tienen que mostrar su grado de acuerdo en cuatro niveles (desde totalmente en contra a totalmente a favor) y termina con preguntas abiertas donde el encuestado expresa libremente sus opiniones sin tener que ajustarse a unas respuestas preestablecidas.

Para ello, dividimos este cuestionario en cuatro secciones:

- La sección I, indagaba sobre las características del centro y de los alumnos que integraban el aula de educación infantil donde los estudiantes cursaron las prácticas.

- La sección II, está formada por 6 ítems que nos aportan información sobre el uso de la música en el aula de infantil, del currículo de música y de quien lo imparte. Para su elaboración se han utilizado cuatro ítems de la sección A “Desarrollando el currículum de música en su escuela", del mencionado cuestionario: A2, frecuencia de utilización de los contenidos musicales; $A 3$, utilización de instrumentos en clase; A5, frecuencia de utilización de las actividades musicales y A6, tiempo semanal de horas dedicadas a la expresión musical en la programación.

- La sección III, Música e Inclusión, está formada por 8 ítems destinados a conocer la opinión de los estudiantes sobre el grado en que la música mejora la respuesta educativa que se proporciona a todos los alumnos. Para su elaboración se han utilizado dos ítems de la sección C "Ayudando a los niños con diversas necesidades", del citado cuestionario: C1, Descripción de los niños que presentan n.e.e. y C2, identificación de aquellos que la música les puede proporcionar un apoyo afectivo. 
- Por último, la sección IV está formada por 5 ítems que indagan sobre la opinión de los estudiantes acerca de los contenidos aprendidos en el Grado relativos a la Percepción, la Expresión, la Creatividad y la Representación gráfica de la música (aspectos clave que forman el currículo de Expresión Musical) tras cursar la asignatura de Expresión musical de segundo ciclo de educación infantil. Para su elaboración se han utilizado 4 ítems de la sección F " Diseñando un currículum equilibrado y ajustado para la formación del maestro especialista en educación infantil": F1, valoración de los contenidos procedimentales para la formación del maestro de infantil en la Percepción de la música; F2, valoración de los contenidos procedimentales para la formación del maestro de infantil en la Expresión de la música; F3, valoración de los contenidos procedimentales para la formación del maestro de infantil en la Creatividad de la música) y F4 (Valoración de los contenidos procedimentales para la formación del maestro de infantil en la representación gráfica de la música.

4) Por último el "Cuestionario sobre competencias y currículo de expresión musical en Educación infantil”, adaptado de López de la Calle, 2007 (Anexo IV), está dirigido a los maestros-tutores de educación infantil de los centros educativos donde los estudiantes del Grado realizaron sus prácticas.

Consta de siete secciones y de una combinación de preguntas cerradas y abiertas de distintos tipos. Las preguntas cerradas: dicotómicas con dos opciones mutuamente excluyentes; de elección múltiple con varias opciones de respuesta donde tienen que elegir solo 1; en otros casos las opciones de respuesta están ordenadas para representar el mayor/menor grado de aquello que se mide: de conocimientos (desde nada hasta mucho); de opinión (desde en contra a favor). Estas últimas han sido consideradas como escalas de tipo Likert. En las preguntas abiertas el encuestado expresa libremente sus opiniones.

Secciones:

- La sección I inicia el cuestionario con 8 preguntas que recogen datos de tipo sociodemográfico y de los alumnos que integran las aulas de infantil.

- La sección II está compuesta por 7 ítems que nos proporcionan información sobre cómo aplican los estudiantes el currículum de música en la práctica 
educativa; de forma más específica se centra en los procedimientos musicales que utilizan en su clase y la frecuencia de utilización de las actividades propiamente musicales. Para su elaboración se han utilizado cuatro ítems de la sección A “Desarrollando el currículum de música en su escuela, del mencionado cuestionario": A2, frecuencia de utilización de los contenidos musicales; A3, utilización de instrumentos en clase; A5, frecuencia de utilización de las actividades musicales; A6, tiempo semanal de horas dedicadas a la Expresión musical en la programación y G1, ayuda de un especialista.

- La sección III, compuesta por 8 ítems, pretende conocer la opinión de los maestros sobre si la música mejora la respuesta educativa a sus alumnos y si favorece la inclusión. Para su elaboración se ha utilizado dos ítems de la sección C "Ayudando a los niños con diversas necesidades" del cuestionario: C1 Descripción de los niños que presentan n.e.e. y C2, identificación de aquellos que la música les puede proporcionar un apoyo afectivo.

- En la sección IV recogemos, a través de 4 ítems, la valoración que los maestros hacen sobre determinados contenidos de la formación musical relacionados con aspectos fundamentales del currículo acerca de la percepción, expresión, creatividad y la representación gráfica de la música que, como estudiantes, recibieron en sus estudios universitarios. Para su elaboración se han utilizado 4 ítems de la sección F "Diseñando un currículum equilibrado y ajustado para la formación del maestro especialista en educación infantil”: F1, valoración de los contenidos procedimentales para la formación del maestro de infantil en la Percepción de la música; F2, Valoración de los contenidos procedimentales para la formación del maestro de infantil en la Expresión de la música; F3, valoración de los contenidos procedimentales para la formación del maestro de infantil en la Creatividad de la música y F4, valoración de los contenidos procedimentales para la formación del maestro de infantil en la representación gráfica de la música.

- En la sección $V$ formada por 6 ítems, recoge la valoración que los maestros hacen de la actuación de los estudiantes del Grado en Maestro en Educación 
Infantil durante el periodo de prácticas y su opinión sobre la preparación que tienen para impartir el currículum de música. Para su elaboración se han utilizado los siguientes ítems del apartado E "Analizando la formación en educación musical en los Centros Universitarios de Formación del Profesorado", del citado cuestionario, en concreto E1, opinión sobre la formación en destrezas y comprensión musical durante su formación universitaria; E4: Indagación sobre la formación musical que reciben los estudiantes de Educación Infantil y E5, valoración de los estudios musicales recibidos en los estudios de maestro en educación Infantil.

- En la sección VI obtenemos a través de 6 ítems, datos sobre carencias y necesidades en formación musical que tienen ellos en su práctica diaria y el interés que tienen en asistir a actividades de formación.

- En la sección VII, formada por preguntas abiertas se incluyen todo tipo de reflexiones, experiencias, consideraciones que los maestros-tutores quieran aportar para elevar la calidad de la enseñanza de la música en la educación infantil.

PROCEDIMIENTO

El desarrollo de la investigación se ha llevado a cabo en tres etapas comprendidas entre el curso académico 2013-14 donde se inicia la investigación y el curso 2016-17 donde se elaboran las conclusiones.

La primera etapa de diseño de la investigación, comienza durante el curso 201314 con la definición del problema, la elaboración de los cuestionarios y la selección de la muestra tanto de los estudiantes que cursan el Grado en Maestro en Educación Infantil en la Universidad de Salamanca, como de los maestros-tutores. En este sentido, como ya se comentó en la descripción de los participantes, la muestra la conformaron por un lado los estudiantes de tercer curso del Grado en Maestro en Educación Infantil de la USAL, matriculados en las asignaturas "Expresión Musical en la Educación Infantil" y "Practicum I" y por otro, los maestros-tutores de los centros educativos donde los estudiantes realizaron las prácticas. 
La segunda etapa de trabajo de campo. El contacto con los estudiantes se hizo a partir de la figura del Coordinadora del Grado de la titulación en la Facultad de Educación y a través de las Coordinadoras de Prácticas en los centros de Ávila y Zamora.

En primer lugar, y antes de cursar las asignaturas de "Expresión musical en educación infantil" y "Practicum I", los estudiantes debían de cumplimentar de manera on-line los cuestionarios 1 y 2 . Una vez finalizado su periodo de prácticas, se contactó solo con aquellos estudiantes que habían realizado las prácticas para que rellenaran de nuevo el cuestionario 2 y el cuestionario 3. Estos los han realizado desde sus ordenadores personales fuera del horario lectivo de clases, solicitándoles su participación voluntaria y garantizándoles el anonimato.

A los maestros-tutores se les contacta a través de una carta dirigida a los directores de los centros educativos donde trabajaban. En ella, se les presenta el estudio y se solicita autorización para la participación en el mismo de los maestrostutores de 2 o ciclo de educación infantil con quienes nuestros estudiantes habían realizado sus prácticas educativas (Anexo V). Además, se escribió a cada maestro-tutor, otra carta informativa del estudio (Anexo $\mathrm{VI}$ ) con el enlace on-line para cumplimentar el cuestionario 4.

La tercera etapa de análisis de resultados, comienza con la recogida y revisión de los cuestionarios, la clasificación, descripción y análisis de los resultados obtenidos y la elaboración de las conclusiones y discusión del estudio. 


\section{RESULTADOS}

Los datos obtenidos a partir de la aplicación de los cuatro instrumentos de evaluación empleados se analizaron con el programa IBM SPSS Statistics, v.22.

Previamente al análisis de los resultados, se realizó una comparativa de los resultados de los cursos académicos 2013-14 y 2014-15 por si el momento en que se pasó el cuestionario afectaba a los resultados. Al comprobar que en ninguno de los resultados las diferencias eran significativas, se procedió a considerarse a los estudiantes de ambos cursos como un solo grupo. ${ }^{49}$

A partir de ahora vamos a analizar los resultados en base a las hipótesis formuladas al principio de la metodología en el apartado 3.

Hipótesis 1: La formación musical de los estudiantes del Grado es insuficiente para un uso adecuado de la música en su práctica educativa. Para responderla nos planteamos tres sub-hipótesis:

1.1. La formación musical recibida por los estudiantes del Grado en sus anteriores etapas educativas, es insuficiente para continuar su formación en expresión musical en el Grado en Maestro en Educación infantil.

Comenzamos mostrando los resultados sobre la formación musical recibida por los estudiantes en las etapas de educación obligatoria.

En primer lugar, se realizó un análisis de frecuencias con el fin de saber la edad media de los estudiantes participantes y así conocer la legislación educativa vigente a lo largo de la escolarización obligatoria. Se sitúa en torno a los 22,4 años. El momento en que cursaban la Educación Primaria correspondía a la LOGSE (2000-2006) en ella, la música se cursaba como asignatura obligatoria y era impartida por un Maestro especialista en Educación Musical. En las etapas de E.S.O. y Bachillerato la legislación

\footnotetext{
${ }^{49}$ En el anexo VII se muestran las tablas comparativas de ambos cursos donde se pueden comprobar estas afirmaciones. En todos los casos el nivel de significación fijado es el $5 \%$ (significativo si $P<.05$ ) excepto la prueba de Kolmogorov-Smirnov o test KS de bondad de ajuste, donde seremos más exigentes y optaremos por una significación fijada en el 1\% $(P<.01)$.
} 
vigente era la LOE (2006-2013) y la música pasa a ser materia de carácter optativo, aunque igualmente impartida por un profesor especialista.

Respecto a la etapa educativa de Educación Primaria, los datos reflejan que 154 (81\%) estudiantes recibieron 2 horas semanales de música y 20 (10\%) recibieron 3h. En lo que se refiere al desarrollo de sus clases, el 82,7\% recibía las clases impartidas por un maestro especialista en educación musical. Un 69,1\% seguía en sus clases un libro de texto de música, aunque en algo más de la mitad de los casos $(58,1 \%)$ el profesor elaboraba su propio material; contaban con un aula de música en el 62,3\% de los casos.

Sobre la formación en contenidos musicales recibida en esta etapa, al 94\% de los estudiantes se les enseñó educación rítmica, en concreto a tocar la flauta dulce y aunque un 78\% disponía en clase de otros instrumentos solo recibieron formación para tocarlos un 56,6\%. Casi la mitad (49,2\%) les enseñaron danzas o coreografías. Un 47,1\% recibieron educación auditiva y solo el 36,6\% recibió educación vocal. En la Tabla 1 se recoge esta información.

En la Educación Secundaria Obligatoria, la mayoría de los encuestados (77\%) recibían 2 horas semanales de formación musical en lo que se refiere al desarrollo de sus clases.

En la mayoría de los casos $(91,1 \%)$ las clases eran impartidas por un profesor especialista. Un 68,6\% utilizaba en sus clases un libro de texto de música y contaban con un aula específica de música un $71,2 \%$.

En este nivel educativo hay que destacar que la formación musical del $88 \%$ de los estudiantes consistió en recibir nociones de Historia de la música, es decir formación teórica y que un 73,3\% realizaban audiciones (educación auditiva). Respecto a la educación rítmico instrumental, aunque un $82,2 \%$ contaban con instrumentos en sus aulas, sólo a un poco más de la mitad $(59,2 \%)$ se les enseñó a tocarlos. Como estamos comprobando, este dato se repite también en este nivel educativos. De igual forma que en la etapa anterior, el aspecto en el que menos formación han recibido, sigue siendo la educación vocal, pues solo a un 33\% se les ha enseñado a cantar (Tabla 1). 
Tabla 1. Descriptiva la enseñanza de la música en la enseñanza obligatoria.

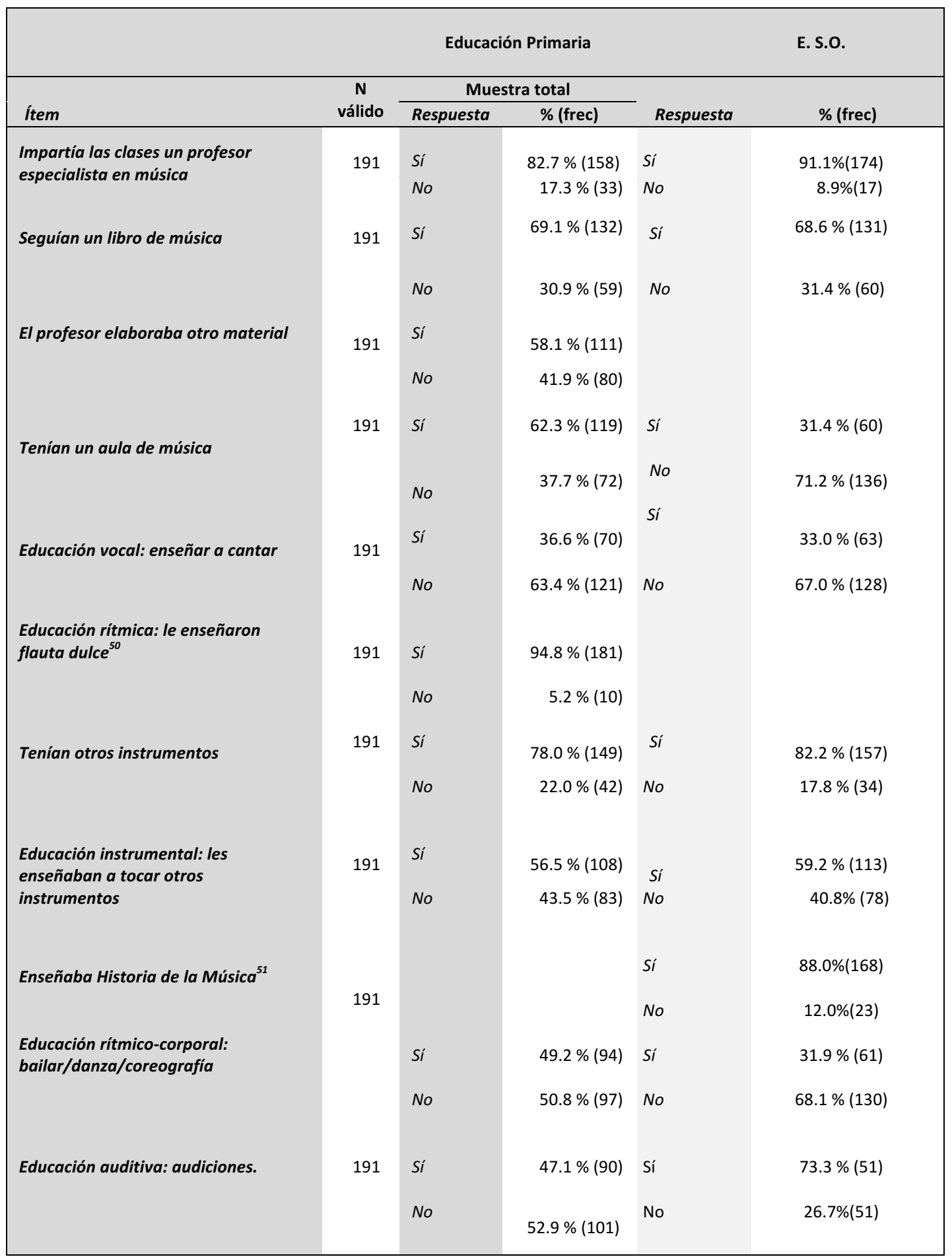

${ }^{50}$ Contenidos relativos Educación Primaria.

${ }^{51}$ Contenidos relativos a la E.S.O. 
Respecto a la etapa educativa de Bachillerato, la cursaron un total de 171 estudiantes y de ellos un 23,8\% eligió una asignatura optativa con contenido musical en uno de los dos cursos.

En la mayoría de los casos (75\%) las clases eran impartidas por un profesor especialista, algo menos de la mitad $(48,2 \%)$ seguían un libro de texto y un $68 \%$ contaba con un aula específica de música.

En relación a los contenidos musicales, como en el ciclo anterior, predominaron los contenidos relacionados con Historia de la música. Mejoran los datos en educación rítmico- instrumental pues la recibieron más de la mitad, 40 estudiantes y los aspectos más deficitarios siguen siendo la educación vocal y la rítmico- corporal, ya que solo 24 estudiantes recibieron formación en estos contenidos. (Tabla 2)

\begin{tabular}{|c|c|c|c|}
\hline \multirow[b]{2}{*}{ Ítem } & \multirow{2}{*}{$\begin{array}{c}\mathbf{N} \\
\text { válido }\end{array}$} & \multicolumn{2}{|c|}{ Muestra total } \\
\hline & & Respuesta & $\%$ (frec) \\
\hline \multirow[t]{2}{*}{ Educación vocal: enseñar a cantar } & 74 & Sí & $32.4 \%(24)$ \\
\hline & & No & $67.6 \%(50)$ \\
\hline \multirow{2}{*}{$\begin{array}{l}\text { Educación rítmico- instrumental: les enseñaban a } \\
\text { tocar Instrumentos }\end{array}$} & 74 & Sí & $54.1 \%(40)$ \\
\hline & & No & $45.9 \%(34)$ \\
\hline \multirow[t]{2}{*}{ Historia de la Música } & 74 & Sí & $75.7 \%(56)$ \\
\hline & & No & $24.3 \%(18)$ \\
\hline \multirow[t]{2}{*}{ Educación rítmico-corporal: Danza/coreografía } & 74 & Si & $32.4 \%(24)$ \\
\hline & & No & $67.6 \%(50)$ \\
\hline \multirow{2}{*}{ Educación auditiva: audiciones } & 74 & Si & $56.8 \%(42)$ \\
\hline & & No & $43.2 \%(32)$ \\
\hline
\end{tabular}

Respecto a los 43 estudiantes que realizaron el nivel de Técnico Superior en Educación Infantil, ${ }^{52}$ la formación musical recibida fue más práctica que los alumnos que cursaron el Bachillerato pues todos aprendieron a cantar canciones infantiles, 42 a contar cuentos, 32 a bailar alguna danza/coreografía y 14 aprendieron a tocar instrumentos. Es de resaltar que 41 de estos estudiantes realizaron prácticas en primer

\footnotetext{
52 Estas enseñanzas se organizan por Módulos. En los contenidos básicos del módulo de Expresión y Comunicación se imparten recursos relacionados con la Expresión musical. RD 1394/2007, de 29 de octubre, por el que se establece el título de Técnico Superior de Educación infantil fijan sus enseñanzas mínimas.
} 
ciclo (0-3) en centros educativos donde un $79,1 \%$ realizaron actividades musicales con niños.

Los estudiantes que recibieron otro tipo de formación musical fueron 40. De ellos, 37 han pertenecido a un coro, 15 formaron parte de una rondalla, tuna, pasacalle o grupo de danza, 12 a un grupo musical, 24, recibieron clases en una Academia de música y 11 en un Conservatorio. De estos estudiantes, 32 recibieron formación para tocar un instrumento.

En base a todo lo expuesto, podemos concluir que todos los estudiantes han recibido algún tipo de educación musical en las etapas de enseñanza obligatoria. En estos niveles educativos la educación vocal ha sido la más reducida junto con la educación rítmico-corporal, pero casi todos (95\%) han recibido nociones de educación rítmico-instrumental de flauta dulce, lo que supone que han aprendido nociones básicas de lenguaje musical para leer e interpretar partituras.

Respecto al resto de las etapas, solo un $23,8 \%$ ha cursado la música en bachillerato como optativa, con una formación predominantemente teórica en Historia de la Música. Hay que destacar que un 22,5\% estudiantes ha estudiado el Ciclo Formativo Superior de Educación Infantil, donde se han formado en contenidos musicales con un enfoque más práctico y que han realizado prácticas educativas en el primer ciclo de esta etapa.

Por lo tanto, los estudiantes cuando llegan a cursar la asignatura de "Expresión musical en educación infantil" en el Grado, aunque han recibido formación musical previa no es suficiente para continuar sus estudios en el Grado debido principalmente a sus carencias formativas en educación vocal y educación rítmica (tanto en su aspecto instrumental como corporal) formación imprescindible para continuar con los estudios del Grado.

1.2. A pesar de haber recibido formación musical en las anteriores etapas educativas los estudiantes no se consideran musicalmente formados para continuar con su formación musical en el Grado. 
Quisimos saber cómo se percibían musicalmente formados y a este respecto, se les pidió que evaluaran el grado de conocimientos musicales que creían tener. Un 77,5\% afirma que tienen pocos conocimientos musicales (Tabla 3).

Tabla 3. Descriptiva conocimientos musicales.

\begin{tabular}{|rlr|}
\hline \multirow{2}{*}{ N válido } & \multicolumn{2}{c|}{ Muestra total } \\
\cline { 2 - 3 } & Respuesta & \multicolumn{1}{c|}{$\%$ (frec) } \\
\hline \multirow{2}{*}{191} & Nada & $3.7 \%(7)$ \\
& Poco & $77.5 \%(148)$ \\
& Bastante & $17.3 \%(33)$ \\
& Mucho & $1.6 \%(3)$ \\
\hline
\end{tabular}

Profundizando en los conocimientos musicales de educación rítmica, tal como aparecen en la Tabla 4, los datos nos muestran respecto a las nociones de lenguaje musical adquiridas para interpretar instrumentos que la mitad de los estudiantes $(50,3 \%)$ se considera con pocas nociones para tocar canciones infantiles con flauta dulce ni para tocar otros instrumentos escolares (50\%) y mucho más de la mitad se consideran con poca formación en movimiento y danzas (68,3\%).

Respecto a la educación auditiva, tal como aparece reflejado en la Tabla 4, solo el $16 \%$ se considera bastante formado respecto a las audiciones musicales frente a un $66 \%$ que se considera con poca formación. Por último, respecto a los contenidos de educación vocal, más de la mitad se consideran que aunque conocen bastantes canciones infantiles $(53,7 \%$ bastante y $11,2 \%$ mucho) respecto a las nociones de lenguaje musical necesarios para interpretar partituras, encontramos un porcentaje casi similar entre los estudiantes que se consideran con pocas nociones $(38,2 \%)$ y los que se consideran con bastantes (39,3\%). 
Tabla 4. Descriptiva conocimientos musicales.

\begin{tabular}{|c|c|c|c|c|}
\hline \multirow[b]{2}{*}{ Ítems. } & \multirow[b]{2}{*}{ NS/NC } & \multirow{2}{*}{$\begin{array}{c}\mathbf{N} \\
\text { válido }\end{array}$} & \multicolumn{2}{|c|}{ Muestra total } \\
\hline & & & Respuesta & $\%$ (frec) \\
\hline \multirow[t]{4}{*}{ Canciones infantiles } & 3 & 188 & Nada & $0.5 \%(1)$ \\
\hline & & & Росо & $34.6 \%(65)$ \\
\hline & & & Bastante & $53.7 \%(101)$ \\
\hline & & & Mucho & $11.2 \%(21)$ \\
\hline \multirow[t]{4}{*}{ Movimiento y Danzas infantiles } & 2 & 189 & $N a d a$ & $16.9 \%(32)$ \\
\hline & & & Росо & $68.3 \%(129)$ \\
\hline & & & Bastante & $13.8 \%(26)$ \\
\hline & & & Mucho & $1.1 \%(2)$ \\
\hline \multirow[t]{4}{*}{ Audiciones } & 4 & 187 & Nada & $16.6 \%(31)$ \\
\hline & & & Poco & $66.3 \%(124)$ \\
\hline & & & Bastante & $16.0 \%(30)$ \\
\hline & & & Mucho & $1.1 \%(2)$ \\
\hline \multirow[t]{4}{*}{ Dramatizaciones } & 4 & 187 & Nada & $15.5 \%(29)$ \\
\hline & & & Poco & $55.1 \%(103)$ \\
\hline & & & Bastante & $27.3 \%(51)$ \\
\hline & & & Mucho & $2.1 \%(4)$ \\
\hline \multirow[t]{5}{*}{ Cuentos, narraciones } & & 10 & & \\
\hline & 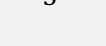 & 100 & Nada & $5.4 \% 10)$ \\
\hline & & & Poco & $37.1 \%(69)$ \\
\hline & & & Bastante & 46. \% (86) \\
\hline & & & Mucho & $11.3 \%(21)$ \\
\hline \multirow[t]{4}{*}{$\begin{array}{l}\text { Nociones para tocar flauta } \\
\text { dulce }\end{array}$} & 0 & 191 & Nada & 13. \% (25) \\
\hline & & & Росо & $46.1 \%(88)$ \\
\hline & & & Bastante & $34.6 \%(66)$ \\
\hline & & & Mucho & $6.3 \%(12)$ \\
\hline \multirow{4}{*}{$\begin{array}{l}\text { Nociones para leer } \\
\text { partituras sencillas }\end{array}$} & 0 & 191 & Nada & $12.0 \%(23)$ \\
\hline & & & Росо & 38. \% (73) \\
\hline & & & Bastante & $39.3 \%(75)$ \\
\hline & & & Mucho & $10.5(20)$ \\
\hline \multirow{4}{*}{$\begin{array}{l}\text { Nociones para tocar } \\
\text { instrumentos escolares }\end{array}$} & 0 & 191 & Nada & $11.5(22)$ \\
\hline & & & Poco & 50. \% (96) \\
\hline & & & Bastante & $31.4(60)$ \\
\hline & & & Mucho & $6.8 \%(13)$ \\
\hline
\end{tabular}

Quisimos conocer su valoración respecto a las destrezas y habilidades musicales necesarias para continuar con su formación musical sobre todo respecto a la entonación para cantar canciones, movimiento para interpretar una danza y coordinación para tocar los instrumentos (Tabla 5). 
Tabla 5. Descriptiva destrezas y habilidades musicales.

\begin{tabular}{|c|c|c|c|c|}
\hline \multirow[b]{2}{*}{ ítem } & \multirow[b]{2}{*}{$\mathrm{NS} / \mathrm{NC}$} & \multirow{2}{*}{$\begin{array}{c}\mathbf{N} \\
\text { válido }\end{array}$} & \multicolumn{2}{|c|}{ Muestra total } \\
\hline & & & Respuesta & $\%$ (frec) \\
\hline \multirow[t]{5}{*}{ Cantar bien } & \multirow[t]{5}{*}{1} & \multirow[t]{5}{*}{190} & Muy mal & $8.9 \%(17)$ \\
\hline & & & Mal & $\begin{array}{r}28.9 \% \\
(55)\end{array}$ \\
\hline & & & Regular & $\begin{array}{r}41.1 \% \\
(78)\end{array}$ \\
\hline & & & Bien & $\begin{array}{r}20.0 \% \\
(38)\end{array}$ \\
\hline & & & Muy bien & $1.1 \%(2)$ \\
\hline \multirow[t]{5}{*}{ Coordinación motora } & \multirow[t]{5}{*}{0} & \multirow[t]{5}{*}{191} & Muy mal & $3.1 \%(6)$ \\
\hline & & & Mal & $\begin{array}{r}13.6 \% \\
(26)\end{array}$ \\
\hline & & & Regular & $\begin{array}{r}35.6 \% \\
(68)\end{array}$ \\
\hline & & & Bien & $\begin{array}{r}36.6 \% \\
(70)\end{array}$ \\
\hline & & & Muy bien & $\begin{array}{r}11.0 \% \\
(21)\end{array}$ \\
\hline \multirow[t]{5}{*}{ Bailar } & \multirow[t]{5}{*}{1} & \multirow[t]{5}{*}{190} & Muy mal & $1.1 \%(2)$ \\
\hline & & & Mal & $\begin{array}{r}12.6 \% \\
(24)\end{array}$ \\
\hline & & & Regular & $\begin{array}{r}37.9 \% \\
(72)\end{array}$ \\
\hline & & & Bien & $\begin{array}{r}38.4 \% \\
(73)\end{array}$ \\
\hline & & & Muy bien & $\begin{array}{r}10.0 \% \\
(19)\end{array}$ \\
\hline \multirow[t]{5}{*}{ Buen oído } & \multirow[t]{5}{*}{1} & \multirow[t]{5}{*}{183} & Muy mal & $2.1 \%(4)$ \\
\hline & & & Mal & $\begin{array}{r}12.6 \% \\
(24)\end{array}$ \\
\hline & & & Regular & $\begin{array}{r}30.0 \% \\
(57)\end{array}$ \\
\hline & & & Bien & $\begin{array}{r}41.6 \% \\
(79)\end{array}$ \\
\hline & & & Muy bien & $\begin{array}{r}13.7 \% \\
(26) \\
\end{array}$ \\
\hline
\end{tabular}

Los datos que nos facilitan los entrevistados nos muestran que solo $21,1 \%$ cantan bien o muy bien, un 47,6\% poseen una buena coordinación motora, un 48,4\% baila bien o muy bien y un 55,3\% tiene buen oído. Resultados muy similares a los anteriores se han encontrado sobre su destreza en el baile o en los movimientos.

También se les preguntó si consideraban que debían comenzar su formación musical desde "cero". Los que creen que sí, son algo más de la mitad del grupo, 104 estudiantes $(54,4 \%)$.

Por lo tanto, los datos demuestran que, aunque todos han recibido formación musical en las anteriores etapas educativas, más de la mayoría no se consideran 
musicalmente formados en educación vocal, auditiva o rítmica ni con destrezas ni habilidades suficientes para continuar con la formación musical en el Grado y una amplia mayoría cree que necesitaría comenzar de nuevo esta formación.

1.3: Existen diferencias en las destrezas y habilidades musicales y en la adquisición de recursos en la formación musical del Grado entre aquellos estudiantes que han recibido formación musical extraescolar previa y los que no.

Puesto que 40 estudiantes (21\%) habían recibido otro tipo de formación musical quisimos saber si se percibían aventajados respecto al resto en cuanto a conocimientos musicales o destrezas y habilidades musicales adquiridas o si consideraban que tenían más recursos musicales que les facilitara cursar la asignatura del Grado "Expresión musical en la educación infantil”.

Para conocer la respuesta ${ }^{53}$, comparamos tres aspectos:

En primer lugar, las nociones musicales referentes a: Teoría musical, Lenguaje musical para leer partituras sencillas y Formación rítmica para tocar instrumentos escolares (Tabla 6).

\footnotetext{
${ }^{53}$ Para responderlas, las técnicas y test estadístico utilizado ha sido el Test de contraste de diferencias entre medias en medidas de grupos independientes entre sí: T Student. El nivel de significación fijado es el habitual 5\% (significativo si $\mathrm{P}<.05$ ). Puesto que las categorías están ordenadas se han considerado como numéricas (en una escala desde: nada 0 hasta mucho=4) y se han calculado las medias de los dos grupos generados por el factor comparación. Lo mismo para las tablas 7 y 8.
} 
Tabla 6: Nociones musicales básicas en función de la formación extraescolar.

\begin{tabular}{|c|c|c|c|c|c|c|}
\hline \multirow{2}{*}{$\begin{array}{l}\text { Ítem: Conocimientos } \\
\text { sobre }\end{array}$} & \multirow{2}{*}{$\begin{array}{c}\mathrm{N} \\
\text { válido }\end{array}$} & \multirow[b]{2}{*}{ Respuesta } & \multirow{2}{*}{$\begin{array}{c}\begin{array}{c}\text { sí Formación } \\
\text { extraescolar }\end{array} \\
\% \text { (frec) }\end{array}$} & \multirow{2}{*}{$\begin{array}{c}\text { NO formación } \\
\text { extraescolar }\end{array}$} & \multicolumn{2}{|c|}{ T de Student } \\
\hline & & & & & Valor & P-sig \\
\hline \multirow[t]{5}{*}{ Teoría musical } & 108 & O.Nada & $9.1 \%$ (7) & $14.7 \%(5)$ & & \\
\hline & & 1.Poco & $50.6 \%$ (39) & $55.9 \%$ (19) & & \\
\hline & & 2.Bastante & $33.8 \%(26)$ & $26.5 \%(9)$ & & \\
\hline & & 3. Mucho & $6.5 \%(5)$ & $2.9 \%(1)$ & & \\
\hline & & Media (D.E.) & $1.38(0.74)$ & $1.18(0.72)$ & 1.32 & 189 \\
\hline \multirow[t]{5}{*}{$\begin{array}{l}\text { Lenguaje musical para } \\
\text { leer partituras sencillas }\end{array}$} & 109 & O.Nada & $11.7 \%$ (9) & $14.7 \%(5)$ & & \\
\hline & & 1.Poco & $44.2 \%$ (34) & $38.2 \%(13)$ & & \\
\hline & & 2.Bastant & $31.2 \%$ (24) & $44.1 \%$ (15) & & \\
\hline & & 3.Mucho & $13.0 \%(10)$ & $2.9 \%(1)$ & & \\
\hline & & Media (D.E.) & $1.45(0.87)$ & $1.35(0.77)$ & 0.59 & .558 \\
\hline \multirow{5}{*}{$\begin{array}{l}\text { Ritmo para tocar } \\
\text { instrumentos escolares }\end{array}$} & 108 & O.Nada & $10.4 \%(8)$ & $14.7 \%(5)$ & & \\
\hline & & 1.Poco & $55.8 \%$ (43) & $55.9 \%$ (19) & & \\
\hline & & 2.Bastante & $26.0 \%(20)$ & $26.5 \%$ (9) & & \\
\hline & & 3.Mucho & $7.8 \%(6)$ & $2.9 \%(1)$ & & \\
\hline & & Media (D.E.) & $1.31(0.76)$ & $1.18(0.72)$ & 0.88 & .384 \\
\hline
\end{tabular}

Los resultados obtenidos, desvelan que no hay diferencias estadísticamente significativas ( $p>$.05) en las destrezas, habilidades musicales con respecto a los estudiantes que recibieron algún tipo de formación musical extraescolar y los que no, aunque se observan mejores puntuaciones en las medias de los estudiantes que si han recibido formación extraescolar.

En segundo lugar, analizamos los recursos musicales adquiridos respecto a: canciones, danzas, audiciones, dramatizaciones, cuentos musicales, etc.

Como se puede comprobar en la tabla 7, en las variables que se evalúan no se han encontrado diferencias entre los grupos que se puedan considerar como estadísticamente significativas, aunque se observa una tendencia a mayor puntuación en los alumnos con que no han recibido formación musical extraescolar en los siguientes aspectos: canciones infantiles, danzas, dramatizaciones y cuentos musicales. 
Tabla 7: Grado de conocimientos sobre recursos musicales en función de la formación extraescolar.

\begin{tabular}{|c|c|c|c|c|c|c|}
\hline \multirow{2}{*}{$\begin{array}{c}\text { Ítem: Conocimientos } \\
\text { sobre }\end{array}$} & \multirow{2}{*}{$\begin{array}{c}\mathbf{N} \\
\text { válido }\end{array}$} & \multirow[b]{2}{*}{ Respuesta } & \multirow{2}{*}{$\begin{array}{c}\begin{array}{c}\text { sí Formación } \\
\text { extraescolar }\end{array} \\
\% \text { (frec) }\end{array}$} & \multirow{2}{*}{$\begin{array}{c}\text { NO formación } \\
\text { extraescolar }\end{array}$} & \multicolumn{2}{|c|}{ T de Student } \\
\hline & & & & & Valor & P-sig \\
\hline \multirow[t]{5}{*}{ Canciones infantiles } & 108 & O.Nada & $1.3 \%(1)$ & --- & & \\
\hline & & 1.Poco & $36.8 \%(28)$ & $21.9 \%(7)$ & & \\
\hline & & 2.Bastante & $48.7 \%$ (37) & $65.6 \%(21)$ & & \\
\hline & & 3.Mucho & $13.2 \%(10)$ & $12.5 \%(4)$ & & \\
\hline & & Media (D.E.) & $1.74(0.70)$ & $1.91(0.59)$ & -1.20 & .232 \\
\hline \multirow[t]{5}{*}{ Danzas } & 109 & O.Nada & $22.1 \%(17)$ & $9.4 \%(3)$ & & \\
\hline & & 1.Poco & $58.4 \%$ (45) & $78.1 \%(25)$ & & \\
\hline & & 2.Bastante & $18.2 \%(14)$ & $12.5 \%(4)$ & & \\
\hline & & 3.Mucho & $1.3 \%(1)$ & --- & & \\
\hline & & Media (D.E.) & $0.99(0.68)$ & $1.03(0, .47)$ & -0.34 & .738 \\
\hline \multirow[t]{5}{*}{ Audiciones } & 109 & O.Nada & $16.9 \%(13)$ & $25.0 \%(8)$ & & \\
\hline & & 1.Poco & $63.6 \%$ (49) & $53.1 \%$ (17) & & \\
\hline & & 2. Bastante & $16.9 \%(13)$ & $21.9 \%$ (7) & & \\
\hline & & 3.Mucho & $2.6 \%(2)$ & --- & & \\
\hline & & Media (D.E.) & $1.05(0.67)$ & $0.97(0.70)$ & 0.59 & .559 \\
\hline \multirow[t]{5}{*}{ Dramatizaciones } & 109 & O.Nada & $18.2 \%(14)$ & $9.4 \%(3)$ & & \\
\hline & & 1.Poco & $57.1 \%$ (44) & $56.3 \%$ (18) & & \\
\hline & & 2.Bastante & $20.8 \%(16)$ & $31.3 \%(10)$ & & \\
\hline & & 3.Mucho & $3.9 \%(3)$ & $3.1 \%(1)$ & & \\
\hline & & Media (D.E.) & $1.10(0.74)$ & $1.28(0.68)$ & -1.17 & .245 \\
\hline \multirow[t]{5}{*}{$\begin{array}{l}\text { Cuentos musicales, } \\
\text { narraciones,... }\end{array}$} & 108 & O.Nada & $10.4 \%(8)$ & $3.2 \%(1)$ & & \\
\hline & & 1.Poco & $29.9 \%(23)$ & $41.9 \%(13)$ & & \\
\hline & & 2.Bastante & $50.6 \%$ (39) & $41.9 \%(13)$ & & \\
\hline & & 3.Mucho & $9.1 \%(7)$ & $12.9 \%(4)$ & & \\
\hline & & Media (D.E.) & $1.58(0.80)$ & $1.65(0.76)$ & -0.36 & .718 \\
\hline
\end{tabular}

En tercer lugar, respecto a destrezas y habilidades y competencias generales musicales, los resultados nos muestran que, en general, no se han encontrado diferencias que se puedan considerar estadísticamente significativas, pero comparando medias, en la tabla 6, son mejores las capacidades en los estudiantes que sí se han formado extraescolarmente pues las medias son de 102 puntos más arriba. En cambio, en "saberse mover/bailar bien" y "Se le da bien la música" las diferencias son prácticamente nulas. 
Tabla 8: Valoración de las capacidades musicales en función de la formación extraescolar.

\begin{tabular}{|c|c|c|c|c|c|c|}
\hline \multirow[b]{2}{*}{ Capacidades musicales } & \multirow{2}{*}{$\begin{array}{c}\mathbf{N} \\
\text { válido }\end{array}$} & \multirow[b]{2}{*}{ Respuesta } & \multirow{2}{*}{$\begin{array}{c}\begin{array}{c}\text { Sí Formación } \\
\text { extraescolar }\end{array} \\
\% \text { (frec) }\end{array}$} & \multirow{2}{*}{$\begin{array}{c}\text { NO formación } \\
\text { extraescolar }\end{array}$} & \multicolumn{2}{|c|}{ T de Student } \\
\hline & & & & & Valor & P-sig \\
\hline \multirow[t]{7}{*}{ Sabe cantar bien } & \multirow[t]{6}{*}{110} & 1.Muy mal & $7.9 \%(6)$ & $17.6 \%(6)$ & & \\
\hline & & 2.Mal & $25.0 \%(19)$ & $29.4 \%(10)$ & & \\
\hline & & 3. Regular & $39.5 \%(30)$ & $32.4 \%(11)$ & & \\
\hline & & 4.Bien & $25.0 \%(19)$ & $20.6 \%(7)$ & & \\
\hline & & 5.Muy bien & $2.6 \%(2)$ & --- & & \\
\hline & & Media (D.E.) & $2.89(0.96)$ & $2.56(1.02)$ & 1.66 & .099 \\
\hline & \multirow[t]{6}{*}{111} & 1.Muy mal & $2.6 \%(2)$ & $5.9 \%(2)$ & & \\
\hline \multirow[t]{5}{*}{ Coordinación motora } & & 2.Mal & $13.0 \%(10)$ & $8.8 \%(3)$ & & \\
\hline & & 3. Regular & $29.9 \%(23)$ & $41.2 \%(14)$ & & \\
\hline & & 4.Bien & $37.7 \%(29)$ & $35.3 \%(12)$ & & \\
\hline & & 5.Muy bien & $16.9 \%(13)$ & $8.8 \%(3)$ & & \\
\hline & & Media (D.E.) & $3.53(1.01)$ & $3.32(0.98)$ & 1.02 & .312 \\
\hline Sabe moverse / bailar & \multirow[t]{6}{*}{111} & 1.Muy mal & $1.3 \%(1)$ & --- & & \\
\hline \multirow[t]{5}{*}{ bien } & & 2.Mal & $15.6 \%(12)$ & $8.8 \%(3)$ & & \\
\hline & & 3. Regular & $28.6 \%(22)$ & $35.3 \%(12)$ & & \\
\hline & & 4.Bien & $36.4 \%(28)$ & $47.1 \%(16)$ & & \\
\hline & & 5.Muy bien & $18.2 \%(14)$ & $8.8 \%(3)$ & & \\
\hline & & Media (D.E.) & $3.55(1.01)$ & $3.56(0.79$ & -0.07 & .945 \\
\hline \multirow[t]{6}{*}{ Tiene buen oído } & \multirow[t]{6}{*}{111} & 1.Muy mal & $2.6 \%(3)$ & --- & & \\
\hline & & 2.Mal & $9.1 \%(7)$ & $20.6 \%(7)$ & & \\
\hline & & 3. Regular & $29.9 \%(23)$ & $38.2 \%(13)$ & & \\
\hline & & 4.Bien & $39.0 \%(30)$ & $35.3 \%(12)$ & & \\
\hline & & 5.Muy bien & $19.5 \%(15)$ & $5.9 \%(2)$ & & \\
\hline & & Media (D.E.) & $3.64(0.99)$ & $3.26(0.86)$ & 1.90 & .109 \\
\hline \multirow[t]{6}{*}{ Se le da bien la música } & \multirow[t]{6}{*}{107} & 1.Muy mal & $4.0 \%(3)$ & --- & & \\
\hline & & 2.Mal & $12.0 \%(9)$ & $12.5 \%(4)$ & & \\
\hline & & 3. Regular & $41.3 \%(31)$ & $46.9 \%(15)$ & & \\
\hline & & 4.Bien & $33.3 \%(25)$ & $37.5 \%(12)$ & & \\
\hline & & 5.Muy bien & $9.3 \%(7)$ & $3.1 \%(1)$ & & \\
\hline & & Media (D.E.) & $3.32(0.95)$ & $3.31(0.74)$ & 0.04 & .968 \\
\hline \multirow{6}{*}{$\begin{array}{l}\text { Tocar } \\
\text { instrumentos }\end{array}$} & \multirow[t]{6}{*}{111} & 1.Muy mal & $33.8 \%(26)$ & $47.1 \%(16)$ & & \\
\hline & & 2.Mal & $36.4 \%(28)$ & $20.6 \%(7)$ & & \\
\hline & & 3. Regular & $13.0 \%(10)$ & $26.5 \%$ (9) & & \\
\hline & & 4.Bien & $11.7 \%(9)$ & $5.9 \%(2)$ & & \\
\hline & & 5.Muy bien & $5.2 \%(4)$ & --- & & \\
\hline & & Media (D.E.) & $2.18(1.18)$ & $1.91(1.00)$ & 1.16 & .247 \\
\hline
\end{tabular}

Por lo tanto, podemos concluir que los estudiantes que han recibido formación musical extraescolar, bien por pertenecer a un coro, por cursar estudios de conservatorio o por tocar algún instrumento, no se perciben significativamente mejor formados que el resto de sus compañeros en contenidos musicales ni en recursos 
musicales para continuar con sus estudios de Grado, pero si se consideran con más destrezas o habilidades musicales que el resto de los participantes.

A la vista de los resultados se confirma la hipótesis 1: La formación musical de los estudiantes del grado es insuficiente para un uso adecuado de la música en sus prácticas educativas.

A continuación, mostramos los resultados obtenidos correspondiente a la segunda hipótesis, sobre la valoración que los estudiantes y los maestros hacen de las competencias musicales adquiridas en el Grado necesarios para integrar la música en su práctica profesional para lo que también analizaremos las sub-hipótesis correspondientes.

Hipótesis 2: La formación musical recibida en el Grado es insuficiente para dotar a los estudiantes de las competencias necesarias para integrar la música en su futura práctica profesional.

En educación infantil, las actividades musicales que se realizan pueden ser de carácter instrumental y estar presentes en la mayoría de los momentos del día (en las rutinas, como refuerzo de otras disciplinas, presentes en temas transversales) o tener un carácter curricular, donde trabajan los contenidos de la Expresión musical. Este último se realiza a través de las tres áreas denominadas: educación vocal, por medio de las canciones infantiles y de los cuentos musicales ${ }^{54}$, educación rítmica por medio de las danzas, el movimiento o de los instrumentos y educación auditiva, mediante el trabajo con las cualidades del sonido, del entorno sonoro y las audiciones.

Por lo tanto, una vez que los estudiantes cursaron en el Grado las asignaturas de "Expresión musical en educación infantil" y "Practicum I", quisimos saber si la formación recibida era suficiente para adquirir las competencias musicales necesarias para impartir el currículum de Expresión musical o para realizar actividades musicales en segundo ciclo de educación infantil. Para ello, recogimos la opinión, por un lado, de los

\footnotetext{
54 Los cuentos musicales son relatos que incluyen la audición y ejecución de la música, canciones, movimientos, juegos rítmicos y auditivos. Estas historias sencillas no necesitan tener un argumento propiamente dicho donde intervienen todo tipo de personajes- humanos, animales, animados e inanimados- que se mueven, juegan, cantan con los que los niños se identifican. (Hemsy de Gainza, 1964)
} 
estudiantes sobre los conocimientos adquiridos y por otro, de los maestros acerca de su actuación durante las prácticas educativas que se muestran en las siguientes subhipótesis:

2.1: La formación básica del Grado en educación musical no es suficiente para adquirir las competencias necesarias para impartir el currículo de Expresión musical.

La formación musical básica que reciben los estudiantes en el Grado, como se comentó en el Capítulo 1, se traduce en la asignatura "Expresión musical en la Educación Infantil" de 6ECTS impartida en tercer curso y así conseguir las competencias necesarias que les habiliten a impartir el currículo de Expresión musical ${ }^{55}$.

Para analizar esta cuestión comparamos los resultados de los estudiantes sobre la formación musical adquirida en el Grado antes de haber cursado la asignatura "Expresión Musical en la Educación Infantil" con los resultados de los alumnos que realizaron las prácticas educativas. La diferencia de la muestra de estos grupos se debe a que no todos los alumnos matriculados en la asignatura realizaron sus prácticas pues los estudiantes que han cursado el Ciclo formativo Superior en Educación Infantil, las tienen convalidadas). Nos interesaba conocer si la formación recibida en las tres áreas: educación rítmica, educación vocal y educación auditiva mejoraba las competencias musicales de los estudiantes tras haber cursado esta asignatura. Los resultados se encuentran en la Tabla 9.

\footnotetext{
${ }^{55}$ Las competencias de carácter didáctico-disciplinar que los estudiantes deben conseguir en educación artística, aparecen recogidas en la Orden ECI/3854/2007. Las competencias específicas a conseguir con la asignatura "Expresión musical en la Educación Infantil" publicadas en la ficha de la asignatura que forma parte de la Guía didáctica de la USAL son las siguientes: CE 1 Conocer los fundamentos musicales y de expresión corporal del currículo de esta etapa, así como las teorías sobre la adquisición y desarrollo de los aprendizajes correspondientes. CE 2 Conocer y utilizar canciones para promover la educación auditiva, rítmica y vocal. CE 3 Saber utilizar el juego como recurso didáctico, así como diseñar actividades de aprendizaje basadas en principios lúdicos. CE 4 Elaborar propuestas didácticas que fomenten la percepción y expresión musicales, las habilidades motrices y la creatividad. CE 5 Analizar los lenguajes audiovisuales y sus implicaciones educativas. CE 6 Promover la sensibilidad relativa a la expresión musical y a la creación artística.
} 
Tabla 9. Comparativa. Conocimientos musicales adquiridos antes de cursar Expresión musical y después de cursarla. ${ }^{56}$

\begin{tabular}{|c|c|c|c|c|c|c|c|}
\hline \multirow{2}{*}{ Ítems } & \multicolumn{3}{|c|}{ Antes de cursar Expresión musical } & \multicolumn{2}{|c|}{ Después de cursarla } & \multicolumn{2}{|c|}{ Test de contraste } \\
\hline & $\begin{array}{c}\mathrm{N} \\
\text { válido }\end{array}$ & Respuesta & $\%$ (frec) & $\begin{array}{c}\mathrm{N} \\
\text { válido }\end{array}$ & $\%$ (frec) & Valor & P-Sig \\
\hline \multirow{4}{*}{$\begin{array}{l}\text { Educación rítmico - } \\
\text { instrumental: } \\
\text { Tocar la flauta dulce }\end{array}$} & \multirow[t]{4}{*}{191} & Nada & $13.1 \%(25)$ & \multirow[t]{4}{*}{139} & $17.3 \%(24)$ & \multirow{4}{*}{3.14} & \multirow{4}{*}{$.002 * *$} \\
\hline & & Poco & $46.1 \%(88)$ & & $29.5 \%(41)$ & & \\
\hline & & Bastante & $34.6 \%(66)$ & & $46.8 \%(65)$ & & \\
\hline & & Mucho & $6.3 \%(12)$ & & $6.5 \%(9)$ & & \\
\hline \multirow{4}{*}{$\begin{array}{l}\text { Educación rítmico - } \\
\text { corporal: actividades } \\
\text { de movimiento. }\end{array}$} & \multirow[t]{4}{*}{189} & Nada & $16.9 \%(32)$ & \multirow[t]{4}{*}{139} & $4.3 \%(6)$ & \multirow{4}{*}{31.87} & \multirow{4}{*}{$.000 * *$} \\
\hline & & Poco & $68.3 \%(129)$ & & $5.0 \%(7)$ & & \\
\hline & & Bastante & $13.8 \%(26)$ & & $53.2 \%(74)$ & & \\
\hline & & Mucho & $1.1 \%(2)$ & & $37.4 \%(52)$ & & \\
\hline \multirow{4}{*}{$\begin{array}{l}\text { Educación auditiva: } \\
\text { Cuentos musicales }\end{array}$} & \multirow[t]{4}{*}{186} & Nada & $16.6 \%(31)$ & \multirow[t]{4}{*}{139} & $7.9 \%(11)$ & \multirow{4}{*}{24.83} & \multirow{4}{*}{$.000 * *$} \\
\hline & & Poco & $66.3 \%(124)$ & & $17.3 \%(24)$ & & \\
\hline & & Bastante & $16.0 \%(30)$ & & $38.1 \%(53)$ & & \\
\hline & & Mucho & $1.1 \%(2)$ & & $36.7 \%(51)$ & & \\
\hline \multirow{4}{*}{$\begin{array}{l}\text { Educación rítmico - } \\
\text { instrumental: } \\
\text { instrumentos de } \\
\text { percusión Off }\end{array}$} & \multirow[t]{4}{*}{191} & Nada & $13.1 \%(25)$ & \multirow[t]{4}{*}{139} & $18.0 \%(25)$ & \multirow{4}{*}{6.24} & \multirow{4}{*}{$.000 * *$} \\
\hline & & Poco & $46.1 \%(88)$ & & $28.1 \%$ (39) & & \\
\hline & & Bastante & $34.6 \%(66)$ & & $28.8 \%(40)$ & & \\
\hline & & Mucho & $6.3 \%(12)$ & & $25.2 \%(35)$ & & \\
\hline \multirow{4}{*}{$\begin{array}{l}\text { Educación auditiva: } \\
\text { actividades con el } \\
\text { sonido, parámetros, } \\
\text { audiciones } \\
\text { musicales... }\end{array}$} & \multirow[t]{4}{*}{187} & Nada & $16.6 \%(31)$ & & $8.6 \%(12)$ & \multirow{4}{*}{24.35} & \multirow{4}{*}{$.000^{* *}$} \\
\hline & & Poco & $66.3 \%(124)$ & & $17.3 \%(24)$ & & \\
\hline & & Bastante & $16.0 \%(30)$ & & $37.4 \%(52)$ & & \\
\hline & & Mucho & $1.1 \%(2)$ & & $36.7 \%(51)$ & & \\
\hline \multirow{4}{*}{$\begin{array}{l}\text { Educación vocal: } \\
\text { Aprender un amplio } \\
\text { repertorio de } \\
\text { canciones infantiles }\end{array}$} & \multirow[t]{4}{*}{188} & Nada & $0.5 \%(1)$ & \multirow[t]{4}{*}{139} & $2.2 \%(3)$ & \multirow{4}{*}{24.24} & \\
\hline & & Poco & $34.6 \%(65)$ & & $7.9 \%(11)$ & & $.000 *$ \\
\hline & & Bastante & $53.7 \%(101)$ & & $21.6 \%(30)$ & & \\
\hline & & Mucho & $11.2 \%(21)$ & & $68.3 \%(95)$ & & \\
\hline
\end{tabular}

A la vista de los resultados, todos los aspectos referidos a las tres áreas evaluadas han reflejado diferencias significativas, lo que supone que ha habido mejoras en la formación musical pero aún hay un porcentaje de alumnos que no se consideran nada formados (18\%) en educación rítmico-instrumental para tocar canciones con flauta dulce o con instrumental Orff, y en educación auditiva (8,6\%).

Lo que muestra que, aunque la formación musical recibida no es suficiente, sí que contribuye a mejorar las competencias musicales adquiridas por los estudiantes, no

\footnotetext{
${ }^{56}$ Para realizar esta comparativa se ha utilizado Test de Contrate ya que los grupos no estaban formados por los mismos sujetos de forma que se han tratado como grupos independientes utilizándose Chicuadrado. Lo mismo ocurre en las tablas 12, 13, 14, 15 y 21.
} 
obstante, si se ofreciera una mejor formación musical básica, con más horas de formación, mejorarían más en todos los aspectos y así evitar, que dependa de la elección de los alumnos (cursando las materias optativas) tener una buena formación musical.

2.2: Los maestros consideran que los estudiantes no tienen formación musical suficiente para desempeñar su trabajo en el segundo ciclo de Educación infantil.

Para analizar este aspecto, partimos de la información proporcionada por los maestros (41) que tutelaron a 60 estudiantes.

Respecto a formación musical que tienen los estudiantes para impartir los contenidos del currículo de expresión musical, más de la mitad (68\%) consideran que no siempre demuestran tener una formación suficiente. En concreto, como vemos en la Tabla 10:

- Los consideran con falta de formación en educación rítmico-corporal en concreto para realizar danzas y coreografías $(57,1 \%)$ y en formación rítmicoinstrumental para tocar instrumentos musicales escolares o con objetos sonoros (42,7\%). Sin embargo, un porcentaje superior (49\%) destaca la buena formación de los estudiantes en prácticas en el uso del cuerpo humano como instrumento con el que se puede hacer música.

- En lo que se refiere a los contenidos relacionados con la educación auditiva, los maestros consideran que los estudiantes en lo que mejor están formados son en los contenidos relacionados con la percepción del sonido, discriminación del entorno sonoro, trabajo con los parámetros del sonido (50\%) mientras que consideran las actividades de audiciones musicales con formación más deficitaria (68\%).

- En relación a los contenidos relacionados con la educación vocal, los maestros consideran que los estudiantes tienen una formación escasa en entonación para cantar canciones infantiles $(69,4 \%)$ y para usar la voz en la realización de cuentos musicales (72\%) no obstante, el $42 \%$ afirmaron que 
los estudiantes enseñaron canciones y danzas a los alumnos para trabajar diferentes contenidos del currículo de Educación Infantil.

Tabla 10. Nivel de preparación para el uso curricular de las actividades musicales.

\begin{tabular}{|c|c|c|}
\hline \multirow[b]{2}{*}{ Ítem } & \multicolumn{2}{|c|}{ Total } \\
\hline & Respuesta & $\%$ (frec) \\
\hline \multirow[t]{4}{*}{ La percepción del sonido y de sus cualidades } & Nada formado & $0 \%(--)$ \\
\hline & Poco & $50.0 \%(25)$ \\
\hline & Bastante & $46.0 \%(23)$ \\
\hline & Muy formado & $4.0 \%(2)$ \\
\hline \multirow[t]{4}{*}{ La entonación } & Nada formado & $0 \%(--)$ \\
\hline & Poco & $69.4 \%$ (34) \\
\hline & Bastante & $28.6 \%(14)$ \\
\hline & Muy formado & $2.0 \%(1)$ \\
\hline \multirow[t]{4}{*}{ Los cuentos musicales } & Nada formado & $0 \%(--)$ \\
\hline & Poco & $72.0 \%(36)$ \\
\hline & Bastante & $24.0 \%(12)$ \\
\hline & Muy formado & $4.0 \%(2)$ \\
\hline \multirow{4}{*}{$\begin{array}{l}\text { El cuerpo humano como un instrumento } \\
\text { musical }\end{array}$} & Nada formado & $2.0 \%(1)$ \\
\hline & Poco & $49.0 \%(24)$ \\
\hline & Bastante & $44.9 \%(22)$ \\
\hline & Muy formado & $4.1 \%(2)$ \\
\hline \multirow[t]{4}{*}{ Los instrumentos musicales y objetos sonoros } & Nada formado & $42.7 \%(35)$ \\
\hline & Poco & $36.6 \%(30)$ \\
\hline & Bastante & $19.5 \%(16)$ \\
\hline & Muy formado & $1.2 \%(1)$ \\
\hline \multirow{4}{*}{$\begin{array}{l}\text { La formación rítmica: El movimiento como } \\
\text { medio de expresión }\end{array}$} & Nada formado & $0 \%(--)$ \\
\hline & Poco & $57.1 \%(28)$ \\
\hline & Bastante & $34.7 \%(17)$ \\
\hline & Muy formado & $8.2 \%(4)$ \\
\hline \multirow{4}{*}{$\begin{array}{l}\text { La formación rítmica: las danzas y } \\
\text { coreografías }\end{array}$} & Nada formado & $0 \%(--)$ \\
\hline & Poco & $60.4 \%$ (29) \\
\hline & Bastante & $35.4 \%$ (17) \\
\hline & Muy formado & $4.2 \%(2)$ \\
\hline \multirow[t]{4}{*}{ La audición de pequeñas obras musicales } & Nada formado & $2.1 \%(1)$ \\
\hline & Poco & $68.8 \%(33)$ \\
\hline & Bastante & $22.9 \%(11)$ \\
\hline & Muy formado & $6.3 \%(3)$ \\
\hline
\end{tabular}

Por otro lado, en lo que se refiere al uso funcional que los estudiantes realizaron de las actividades musicales, estos, han sido mejor valorados. Como se puede ver en los resultados de la Tabla 11, los maestros destacan que los estudiantes han cantado canciones infantiles para acompañar momentos especiales de la vida, tales como en los cumpleaños o en navidad en un porcentaje bastante elevado (56,3\% bastante y $31,3 \%$ mucho) también para reforzar actividades transversales, como educación moral o 
ambiental o el día de La Paz (58,3\% bastante) y también para trabajar diferentes rutinas (bastante 66.3\%). Las actividades musicales que menos han utilizado han sido para reforzar otras materias (matemáticas, lengua) utilizado por un 30\%.

Tabla 11. Uso funcional de las actividades musicales.

\begin{tabular}{|c|c|c|}
\hline \multirow[b]{2}{*}{ Ítem } & \multicolumn{2}{|c|}{ Total } \\
\hline & Respuesta & $\%$ (frec) \\
\hline \multirow{4}{*}{$\begin{array}{l}\text { Utiliza canciones en las actividades } \\
\text { transversales (educación moral, ambiental...) }\end{array}$} & Nada & $2.1 \%(1)$ \\
\hline & Poco & $31.3 \%(28)$ \\
\hline & Bastante & $58.3 \%(15)$ \\
\hline & Mucho & $8.3 \%(4)$ \\
\hline \multirow{4}{*}{$\begin{array}{l}\text { Canta canciones en momentos especiales } \\
\text { (cumpleaños, navidad...) }\end{array}$} & Nada & $2.1 \%(1)$ \\
\hline & Росо & $10.4 \%(5)$ \\
\hline & Bastante & $56.3 \%(27)$ \\
\hline & Mucho & $31.3 \%(15)$ \\
\hline \multirow{4}{*}{$\begin{array}{l}\text { Realizar actividades musicales } \\
\text { en diferentes rutinas }\end{array}$} & Nada & $8.3 \%(4)$ \\
\hline & Poco & $33.3 \%(16)$ \\
\hline & Bastante & $56.3 \%(27)$ \\
\hline & Mucho & $2.1 \%(1)$ \\
\hline \multirow{4}{*}{$\begin{array}{l}\text { Realizar actividades musicales como refuerzo de } \\
\text { otras materias (lengua, matemáticas...) }\end{array}$} & Nada & $36.5 \%(27)$ \\
\hline & Poco & $33.8 \%(25)$ \\
\hline & Bastante & $21.6 \%(16)$ \\
\hline & Mucho & $8.1 \%(6)$ \\
\hline \multirow{4}{*}{$\begin{array}{l}\text { Realiza actividades musicales en momentos de } \\
\text { relajación, siesta... }\end{array}$} & Nada & $10.7 \%(10)$ \\
\hline & Poco & $28.6 \%(16)$ \\
\hline & Bastante & $42.9 \%(24)$ \\
\hline & Mucho & $17.9 \%(6)$ \\
\hline
\end{tabular}

La explicación que dieron los maestros en las preguntas abiertas por las que algunos alumnos no han realizado actividades musicales reside en la "falta de programación por parte de los estudiantes para para vincular la música al desarrollo de otras actividades dentro del aula".

En conclusión a todo lo expuesto, podemos afirmar que los estudiantes han mejorado en general en su formación musical después de haber cursado la asignatura “Expresión musical en la educación infantil", durante el Grado pero que los maestros consideran que, aunque con diferencias entre unas competencias y otras, en general no tienen adquiridas las competencias suficientes que les capaciten para desarrollar de manera adecuada el currículo de Expresión musical para el segundo ciclo de Educación Infantil, pero si para hacer un uso funcional de las actividades musicales en el aula de infantil en diferentes momentos del horario escolar. 
2.3: Hay diferencia de percepción y de valoración entre los estudiantes y los maestros sobre la formación en procedimientos referidos a la expresión, percepción, creación y representación gráfica de la música necesarios para impartir el currículo de música en segundo ciclo de educación infantil.

Para el contraste de esta hipótesis, se analizó la valoración que los maestros y los estudiantes realizaron de su formación en los distintos aspectos de la música.

En lo que se refiere a la PERCEPCIÓN, como se observa en la tabla 12, ambos colectivos consideran esta formación en contenidos procedimentales muy importante en sus distintas dimensiones o aspectos, pero hay diferencias significativas en el aspecto relacionado con Distinguir los ritmos y las melodías en fragmentos musicales ya que los estudiantes han valorado más estos contenidos relacionados con la discriminación auditiva de los elementos del lenguaje musical.

Tabla 12. Comparativa. Valoración de la formación en procedimientos referidos a la PERCEPCIÓN de la música.

\begin{tabular}{|c|c|c|c|c|c|c|c|}
\hline \multirow{2}{*}{ ítems } & \multicolumn{3}{|c|}{ Maestros } & & Estudiantes & \multirow{2}{*}{ Test de } & \multirow{2}{*}{$\begin{array}{l}\text { contraste } \\
\text { P-Sig }\end{array}$} \\
\hline & $\begin{array}{c}\mathbf{N} \\
\text { válido }\end{array}$ & Respuesta & $\%$ (frec) & válid & $\%$ (frec) & & \\
\hline $\begin{array}{l}\text { Discriminar el } \\
\text { entorno sonoro que } \\
\text { nos rodea para } \\
\text { realizar escuchas } \\
\text { activas }\end{array}$ & 38 & $\begin{array}{l}\text { Poco Importante } \\
\text { Algo } \\
\text { Bastante } \\
\text { Muy importante }\end{array}$ & $\begin{array}{c}0 \%(--) \\
2.6 \%(1) \\
34.2 \%(13) \\
63.2 \%(24)\end{array}$ & 135 & $\begin{array}{c}0 \%(--) \\
6.7 \%(9) \\
28.1 \%(38) \\
65.2 \%(88)\end{array}$ & 0.07 & $.947^{\mathrm{NS}}$ \\
\hline $\begin{array}{l}\text { Distinguir y } \\
\text { reproducir la } \\
\text { duración, la altura, } \\
\text { el timbre y la } \\
\text { intensidad del } \\
\text { sonido }\end{array}$ & 38 & $\begin{array}{l}\text { Poco Importante } \\
\text { Algo } \\
\text { Bastante } \\
\text { Muy importante }\end{array}$ & $\begin{array}{c}0 \%(--) \\
7.9 \%(3) \\
44.7 \%(17) \\
47.4 \%(18)\end{array}$ & 135 & $\begin{array}{c}0 \%(--) \\
3.7 \%(5) \\
38.5 \%(52) \\
57.8 \%(78)\end{array}$ & 1.62 & $.105^{\mathrm{NS}}$ \\
\hline $\begin{array}{l}\text { Distinguir los ritmos } \\
\text { y las melodías en } \\
\text { fragmentos } \\
\text { musicales }\end{array}$ & 37 & $\begin{array}{l}\text { Poco Importante } \\
\text { Algo } \\
\text { Bastante } \\
\text { Muy importante }\end{array}$ & $\begin{array}{c}0 \%(--) \\
16.2 \%(6) \\
37.8 \%(14) \\
45.9 \%(17)\end{array}$ & 134 & $\begin{array}{c}0 \%(--) \\
6.0 \%(8) \\
29.1 \%(39) \\
64.9 \%(87)\end{array}$ & 2.94 & $.003 * *$ \\
\hline $\begin{array}{l}\text { Identificar obras } \\
\text { musicales }\end{array}$ & 38 & $\begin{array}{l}\text { Poco Importante } \\
\text { Algo } \\
\text { Bastante } \\
\text { Muy importante }\end{array}$ & $\begin{array}{c}2.6 \%(1) \\
15.8 \%(6) \\
36.8 \%(14) \\
44.7 \%(17)\end{array}$ & 135 & $\begin{array}{c}2.2 \%(3) \\
15.6 \%(21) \\
29.6 \%(40) \\
52.6 \%(71)\end{array}$ & 0.95 & $.341^{\text {NS }}$ \\
\hline
\end{tabular}

Respecto a la EXPRESIÓN, como se observa en la Tabla 13, aunque ambos grupos consideran importante la formación de estos contenidos, los estudiantes les 
otorgan mayor valoración a dos aspectos: Tocar instrumentos musicales como medio de expresión para acompañar canciones y bailes y Bailar danzas infantiles y coreografías sencillas. Es decir, valoran más todos los aspectos relacionados con la expresión otorgando mayor importancia a los contenidos relacionados con el área de educación rítmica en concreto con la formación corporal y de movimientos y la formación instrumental.

Tabla 13. Comparativa . Formación en procedimientos referidos a la EXPRESIÓN de la música.

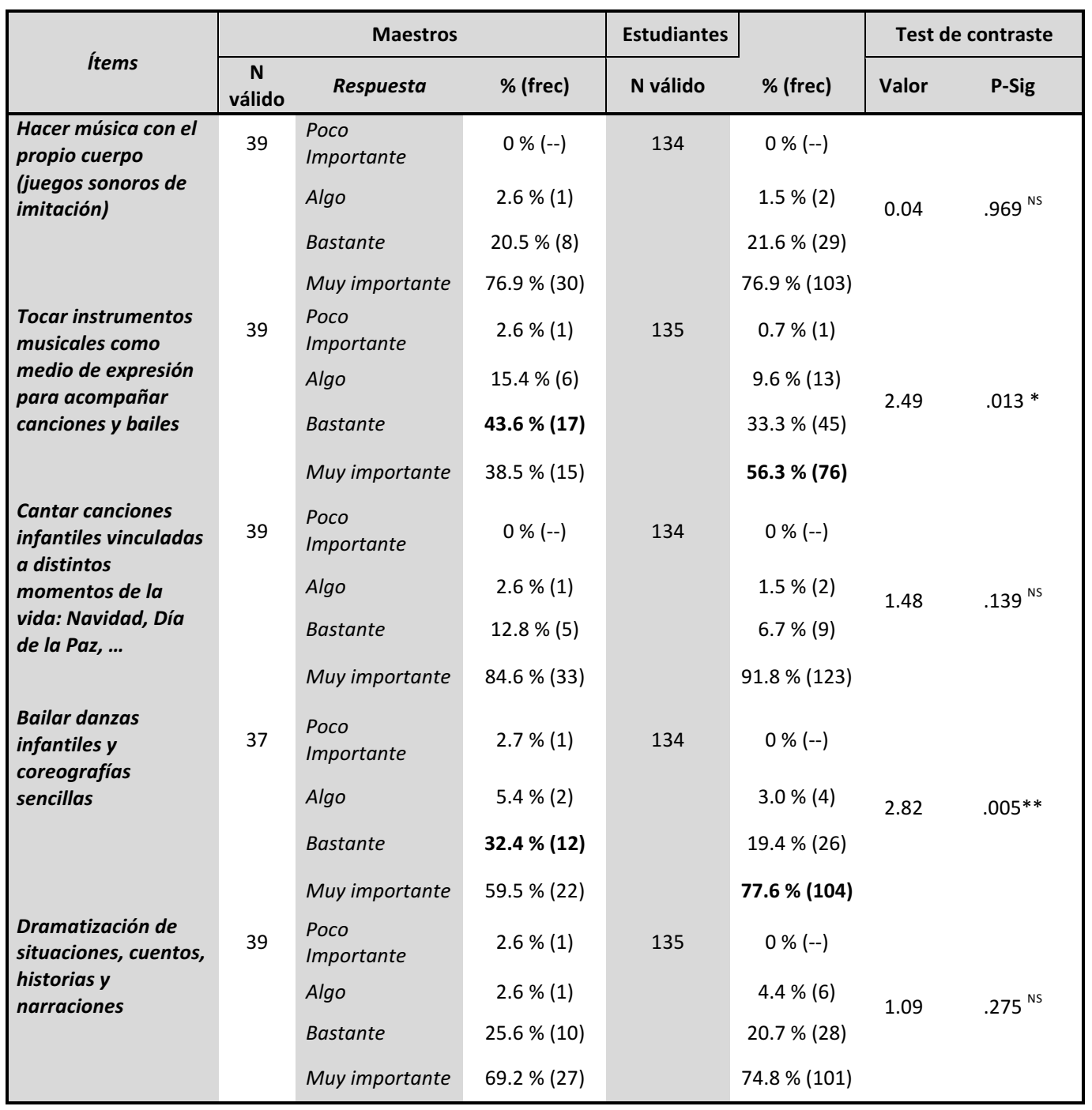

A continuación, valoraron la formación en contenidos relacionados con la CREATIVIDAD de la música. Tal como se describe en la Tabla 14, los resultados manifestados indican que todos estos aspectos relacionados con la creatividad son altamente importantes, pero de nuevo, los estudiantes valoran más la Experimentación 
con gestos y movimientos, es decir los aspectos relacionados con la improvisación corporal como fundamental de la creatividad. Como estamos observando, los estudiantes están otorgando mucha importancia al trabajo con el cuerpo.

Tabla 14. Comparativa. Valoración de los contenidos procedimentales respecto a la CREATIVIDAD de la música.

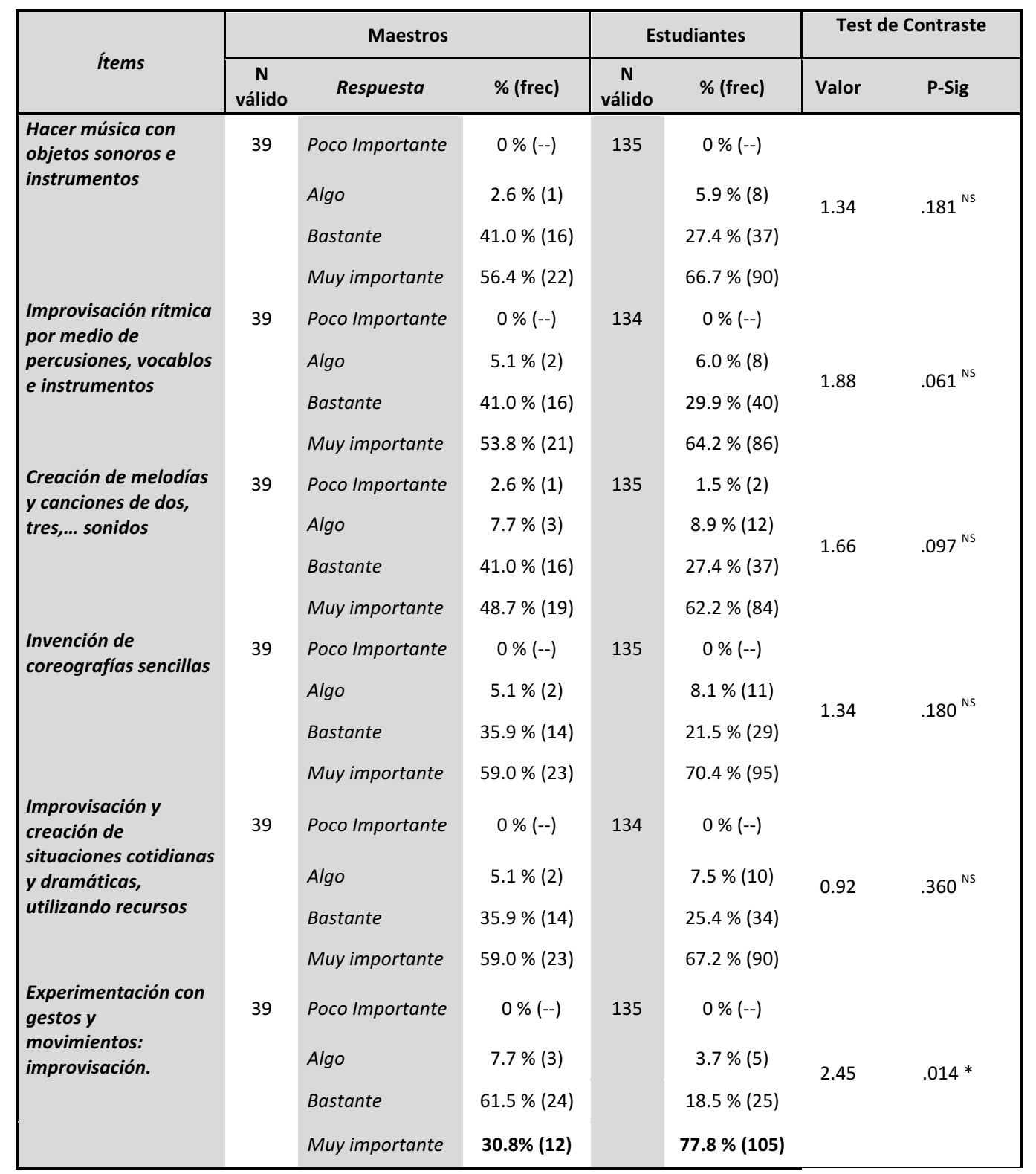

El último aspecto que nos interesaba conocer era la valoración de los siguientes contenidos procedimentales relacionados con la representación gráfica de la música, esto es, con la lectura y escritura musical: leer y escribir rítmos, partituras, grafías. Como veremos en la Tabla 15, todos estos contenidos, han sido mejor valorado por los 
estudiantes que por los maestros, sobre todo la lectura y escritura musical con grafía convencional (pentagrama) y no convencional, así como el diseño de musicogramas para representar las audiciones.

Tabla 15. Comparativa. Valoración de los contenidos procedimentales relacionados con la lectoescritura musical.

\begin{tabular}{|c|c|c|c|c|c|c|c|}
\hline \multirow{2}{*}{ Ítems } & \multicolumn{3}{|c|}{ Maestros } & \multicolumn{2}{|c|}{ Estudiantes } & \multicolumn{2}{|c|}{$\begin{array}{c}\text { Test de } \\
\text { contraste }\end{array}$} \\
\hline & $\begin{array}{c}\mathbf{N} \\
\text { válido }\end{array}$ & Respuesta & $\%$ (frec) & $\begin{array}{c}\mathbf{N} \\
\text { válido }\end{array}$ & $\%$ (frec) & Valor & P-Sig \\
\hline $\begin{array}{l}\text { Leer y escribir los } \\
\text { elementos de la } \\
\text { música con grafías no } \\
\text { convencionales }\end{array}$ & 37 & $\begin{array}{l}\text { Poco Importante } \\
\text { Algo } \\
\text { Bastante } \\
\text { Muy importante }\end{array}$ & $\begin{array}{r}2.7 \%(1) \\
48.6 \%(18) \\
32.4 \%(12) \\
16.2 \%(6)\end{array}$ & 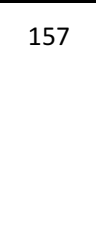 & $\begin{array}{c}3.7 \%(5) \\
28.1 \%(38) \\
42.2 \%(57) \\
35.9 \%(57)\end{array}$ & 3.48 & $.001^{* *}$ \\
\hline $\begin{array}{l}\text { Diseñar } \\
\text { musicogramas } \\
\text { Para representar las } \\
\text { audiciones }\end{array}$ & 38 & $\begin{array}{l}\text { Poco Importante } \\
\text { Algo } \\
\text { Bastante } \\
\text { Muy importante }\end{array}$ & $\begin{array}{r}13.2 \%(5) \\
42.1 \%(16) \\
31.6 \%(12) \\
13.2 \%(5)\end{array}$ & 135 & $\begin{array}{c}5.2 \%(7) \\
35.6 \%(48) \\
33.3 \%(45) \\
25.9 \%(35)\end{array}$ & 2.66 & $.008^{* *}$ \\
\hline Representar ritmos & 38 & $\begin{array}{l}\text { Poco Importante } \\
\text { Algo } \\
\text { Bastante } \\
\text { Muy importante }\end{array}$ & $\begin{array}{r}2.6 \%(1) \\
36.8 \%(14) \\
26.3 \%(10) \\
34.2 \%(13)\end{array}$ & 134 & $\begin{array}{c}2.2 \%(3) \\
15.7 \%(21) \\
41.0 \%(55) \\
41.0 \% 55)\end{array}$ & 2.39 & $.017^{*}$ \\
\hline $\begin{array}{l}\text { Leer y escribir las } \\
\text { notas con grafía } \\
\text { convencional } \\
\text { pentagrama. }\end{array}$ & 37 & $\begin{array}{l}\text { Poco Importante } \\
\text { Algo } \\
\text { Bastante } \\
\text { Muy importante }\end{array}$ & $\begin{array}{r}18.9 \%(7) \\
40.5 \%(15) \\
27.0 \%(10) \\
13.5 \%(5)\end{array}$ & 135 & $\begin{array}{c}5.9 \%(8) \\
25.2 \%(34) \\
34.1 \%(46) \\
34.8 \%(47)\end{array}$ & 4.51 & $.000 * *$ \\
\hline
\end{tabular}

Como se puede observar, aunque los maestros y los estudiantes conceden gran importancia a los contenidos procedimentales relacionados con la percepción, la expresión, la creatividad y la representación gráfica de la música, los estudiantes han considerado formarse en todos estos aspectos más importantes que los maestros. En concreto, referente a los contenidos del lenguaje musical, han destacado la importancia de formarse en la lectoescritura de la música tanto con grafías convencionales como no convencionales, aspecto que consideramos muy importante para poder interpretar y aprender canciones infantiles presentes en los cancioneros tradicionales o en las metodologías musicales. En relación con la creatividad musical, han destacado la importancia del trabajo con el cuerpo y a la improvisación corporal. No olvidemos que todos los pedagogos musicales. Dalcroze, Willems, Orff, proponen que los elementos musicales, principalmente el ritmo y la melodía, tienen que ser primero vivenciados a 
través del cuerpo que se mueve, siente e improvisa para luego adquirir las nociones teóricas. Por otro lado, es uno de los aspectos más difíciles de trabajar en el aula y que estamos constatando que menos se usa. En relación con expresión de la música, manifiestan la necesidad de tener una formación instrumental que les permita acompañar canciones y bailes, pues es fundamental tener un apoyo instrumental para conseguir una buena entonación. En relación con la percepción de la música, apuntan al trabajo auditivo de la discriminación del ritmo y la melodía. Enseñar a descubrir el mundo sonoro que nos rodea, las características del sonido y del ruido, son los pilares básicos para conseguir una educación auditiva que nos permita identificar los elementos del ritmo (pulso, acento, compás...) de la melodía (intervalos, escalas ascendentes y descendentes, tonalidades...) y de los instrumentos (comenzando por los instrumentos escolares determinados e indeterminados para continuar con los orquestales y tradicionales) y disfrutar así del repertorio musical. Por tanto, los estudiantes consideran necesaria contar con una formación en educación vocal, auditiva y rítmica para desarrollar en sus alumnos capacidades que les permitan percibir, expresar y crear a través del lenguaje musical.

Una de las razones que podemos atribuir a la valoración inferior realizada por los maestros puede deberse a que el programa de la "Expresión Musical en Educación Infantil" que se imparten actualmente en los estudios del Grado, tiene un componente menos teórico y más vivencial y más orientado a la práctica que en los programas de "Didáctica de la Expresión musical" de las anteriores Diplomaturas con una orientación más teórica, sin apenas haberse formado en aspectos como la improvisación con el cuerpo o con los instrumentos, por lo que no pueden valorar este aspecto.

Como hemos visto los estudiantes valoran más que los maestros la formación en los contenidos procedimentales relacionados con la percepción, expresión, creación y de representación gráfica de los elementos musicales.

A la vista de los resultados, corroboramos la hipótesis 2 al confirmar que La formación musical recibida en el Grado es insuficiente para dotar a los estudiantes de las competencias necesarias para integrar la música en su futura práctica profesional. 
A continuación, presentamos los principales resultados que nos permiten conocer el grado de implementación del currículo de Expresión musical en segundo ciclo de educación infantil y la importancia otorgada por los maestros a los distintos procedimientos musicales según la frecuencia de utilización de los mismos, tal como planteamos en la tercera hipótesis.

Hipótesis 3: No se hace un uso ni adecuado ni suficiente de la música en la etapa de segundo ciclo de educación infantil. Para responderla nos planeamos las siguientes sub-hipótesis:

3.1: Las sesiones de música en las aulas de 2o ciclo de educación infantil son insuficientes para desarrollar los contenidos del currículo de Expresión musical.

En primer lugar, en lo que se refiere a contar con la ayuda de un Maestro Especialista en Educación musical ${ }^{57}$, la mayoría de los maestros participantes (61,5\%), afirman no contar con la ayuda de este profesional, siendo ellos los únicos encargados de impartir la Expresión musical en esta etapa. Para hacernos idea de esta situación en la pregunta abierta han respondido "La música en educación infantil no está reglada por el ministerio, quiere decir que no es obligatorio que el especialista de música imparta en educación infantil. Viene al aula de forma voluntaria. Si un especialista de música se niega a ir a Educación Infantil nadie le puede obligar".

Con respecto al tiempo semanal que dedican en su programación para trabajar los contenidos musicales, varía, por un lado, el 28,9\% afirma que cada día dedica una sesión; el 34,2\% una sesión a la semana y el 13,2\% realizan alguna sesión ocasional. Estos resultados se justifican en la pregunta abierta de a siguiente forma: "contar con apoyo de un especialista es el motivo para no programar este tipo de contenidos"; "en mi época, el especialista en Música daba una sesión a la semana en Educación Infantil.

\footnotetext{
${ }^{57}$ Figura que solo existe para la Enseñanza primaria, aunque como veremos, algunos centros cuentan con su ayuda para impartir el currículo de música en la etapa de educación Infantil.
} 
Ahora, es el mismo tutor quien debe proporcionar al alumnado esas clases. Sería conveniente que los tutores recibiéramos formación en ese sentido urgentemente";

"mis carencias formativas y la premura de otros aprendizajes me hacen relegar estas actividades a situaciones puntuales en lugar de un proceso continuado de enseñanza aprendizaje. Una pena."; "Este curso al tener un apoyo musical no realizo actividades musicales propiamente dichas".

Respecto a la utilización de los contenidos musicales del currículo, se les pidió que comentaran la frecuencia de utilización de cada una de las tres áreas, educación auditiva, educación vocal y educación rítmica. (Tabla 16)

Los contenidos más utilizados por los maestros, son los que tienen que ver con la educación vocal, ya que cantar canciones lo emplean prácticamente todos los maestros (97\%) y hacer sonidos con la voz lo ponen en práctica bastantes (75\%).

Le sigue la educación auditiva, pues excepto un maestro que nunca realiza contenidos relacionados con la discriminación y la identificación de los sonidos y ruidos del entorno, el resto ponen en práctica todos estos contenidos en mayor o menor medida (siempre $25 \%$, casi siempre $25 \%$ ) y más de la mitad realizan audiciones musicales (62\%).

Respecto a los contenidos relacionados con la educación rítmica, si analizamos las respuestas agrupadas en "casi siempre y siempre" encontramos que bailar y realizar coreografías lo desarrollan más de la mitad (59\%). Si nos fijamos en la respuesta "nunca" observamos que el 37,5\% no ha realizado ningún trabajo rítmico- instrumental, aunque todos han hecho alguna vez sonidos y ritmos con el cuerpo, por lo que consideramos que este tipo de formación es la que menos se desarrolla. 


\begin{tabular}{|c|c|c|c|}
\hline \multirow[b]{2}{*}{ Variable } & \multirow{2}{*}{$\begin{array}{c}\mathrm{N} \\
\text { válido }\end{array}$} & \multicolumn{2}{|c|}{ Total participantes $=41$} \\
\hline & & Respuesta & $\%$ (frec) \\
\hline \multirow{4}{*}{$\begin{array}{l}\text { Discriminar/identificar sonidos y ruidos de la vida } \\
\text { cotidiana }\end{array}$} & \multirow[t]{4}{*}{40} & Nunca & $2.5 \%(1)$ \\
\hline & & A veces & $47.5 \%(19)$ \\
\hline & & Casi siempre & $25.0 \%(10)$ \\
\hline & & Siempre & $25.0 \%(10)$ \\
\hline \multirow{4}{*}{$\begin{array}{l}\text { Hacer sonidos y ritmos con el cuerpo (juegos sonoros de } \\
\text { imitación) }\end{array}$} & \multirow[t]{4}{*}{40} & Nunca & -- \\
\hline & & A veces & $40.0 \%(16)$ \\
\hline & & Casi siempre & $37.5 \%(15)$ \\
\hline & & Siempre & $22.5 \%(9)$ \\
\hline \multirow[t]{4}{*}{ Hacer sonidos con la voz, vocalizaciones, imitación... } & \multirow[t]{4}{*}{40} & Nunca & -- \\
\hline & & A veces & $20.0 \%(8)$ \\
\hline & & Casi siempre & $55.0 \%(22)$ \\
\hline & & Siempre & $25.0 \%(10)$ \\
\hline \multirow[t]{4}{*}{ Tocar instrumentos para acompañar canciones } & \multirow[t]{4}{*}{40} & Nunca & $37.5 \%(15)$ \\
\hline & & A veces & $45.0 \%(18)$ \\
\hline & & Casi siempre & $12.5 \%(5)$ \\
\hline & & Siempre & $5.0 \%(2)$ \\
\hline \multirow[t]{4}{*}{ Cantar canciones } & \multirow[t]{4}{*}{39} & Nunca & -- \\
\hline & & A veces & $2.6 \%(1)$ \\
\hline & & Casi siempre & $30.8 \%(12)$ \\
\hline & & Siempre & $66.7 \%(26)$ \\
\hline \multirow[t]{4}{*}{ Hacer juegos musicales siguiendo distintas melodías } & \multirow[t]{4}{*}{40} & Nunca & $15.0 \%(6)$ \\
\hline & & A veces & $47.5 \%(19)$ \\
\hline & & Casi siempre & $27.5 \%(11)$ \\
\hline & & Siempre & $10.0 \%(4)$ \\
\hline \multirow[t]{4}{*}{ Bailar o realizar coreografías sencillas } & \multirow[t]{4}{*}{40} & Nunca & -- \\
\hline & & A veces & $40.0 \%(16)$ \\
\hline & & Casi siempre & $37.5 \%(15)$ \\
\hline & & Siempre & $22.5 \%(9)$ \\
\hline \multirow{4}{*}{$\begin{array}{l}\text { Audiciones musicales: escuchar breves obras } \\
\text { instrumentales y vocales }\end{array}$} & \multirow[t]{4}{*}{40} & Nunca & -- \\
\hline & & A veces & $37.5 \%$ (15) \\
\hline & & Casi siempre & $35.0 \%$ (14) \\
\hline & & Siempre & $27.5 \%$ \\
\hline
\end{tabular}

A fin de tener una idea más visual de estas respuestas, se ha diseñado un gráfico donde se ha considerado las respuestas a esta pregunta como valores numéricos, desde: nunca $=0$ hasta: siempre $=3$, se han calculado las medias de la frecuencia de utilización de estos recursos. En el gráfico 5, se muestran los resultados. 
Figura 5: Gráfico de medias. Frecuencia de utilización de contenidos

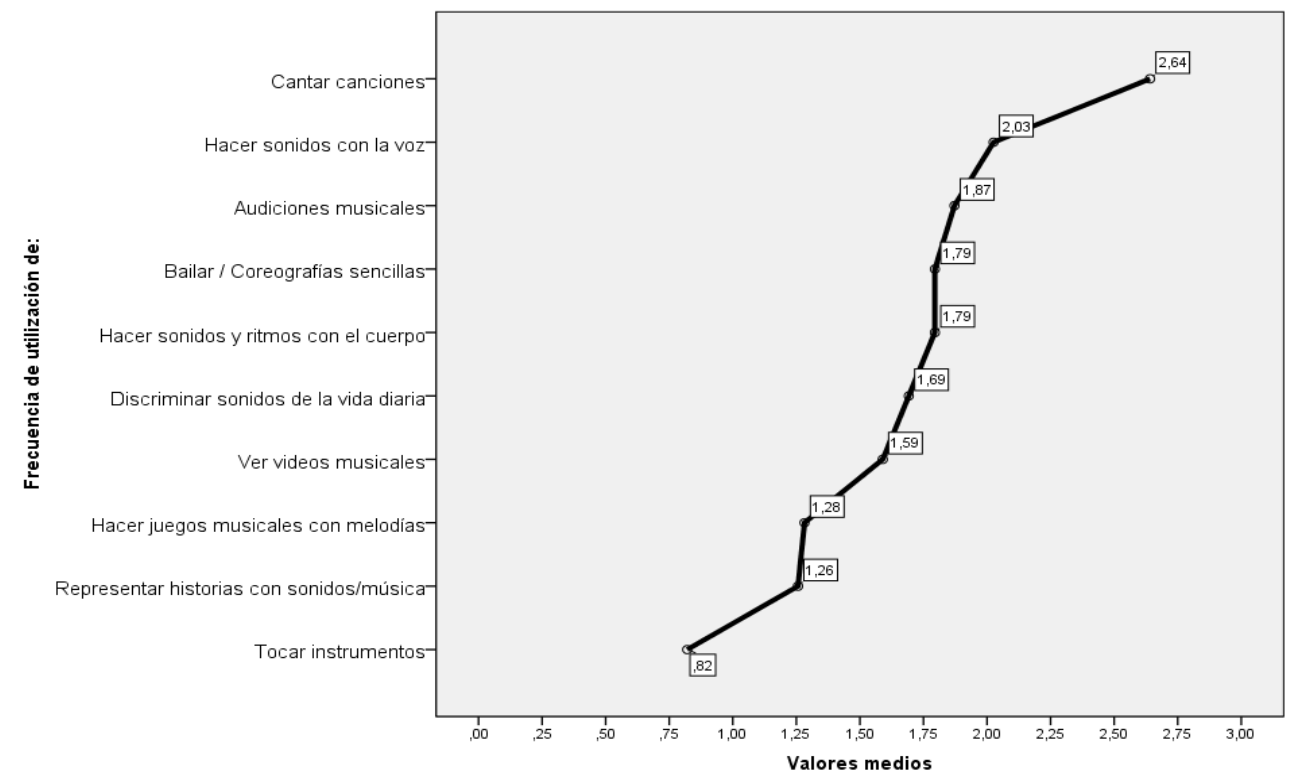

Elaboración propia mediante IBM SPSS Statistics 22

Preguntamos a los maestros la presencia que la música (bien por cantar canciones o por utilizar audiciones) tiene en las rutinas ${ }^{58}$ en las que se organiza la programación diaria de un aula de infantil. En la tabla 17, se muestra información al respecto. El momento en que más cantan los maestros con sus alumnos (89\%) es para "los buenos días" y un 84,2\% cantan como refuerzo en otras materias. También un 86,1\% emplea la música en momentos de "relajación", sobre todo durante la siesta o como estrategia didáctica para alcanzar momentos de calma. Para conocer "el nombre del día" es utilizada por el 69\% de los maestros y una amplia mayoría (84\%) la utilizan en "otros momentos" no contempladas en las respuestas propuestas.

\footnotetext{
${ }^{58}$ Las actividades que se realizan diariamente de forma periódica, regular y sistemática en el aula de infantil se conocen como "rutinas". Por medio de ellas, el alumno establece una estructuración mental de la organización de las actividades que le ofrece seguridad, estabilidad, referencia y organización espacial. Marcan la pauta a la hora de desarrollar los acontecimientos de la jornada escolar.
} 


\begin{tabular}{|c|c|c|c|}
\hline \multirow[b]{2}{*}{ Variable } & \multirow{2}{*}{$\begin{array}{c}\mathbf{N} \\
\text { válido }\end{array}$} & \multicolumn{2}{|c|}{ Total participantes $=41$} \\
\hline & & Respuesta & $\%$ (frec) \\
\hline \multirow{2}{*}{ En la entrada al Centro } & \multirow[t]{2}{*}{36} & Sí & $61.1 \%(22)$ \\
\hline & & No & $38.9 \%(14)$ \\
\hline \multirow[t]{2}{*}{ En los buenos días } & \multirow[t]{2}{*}{37} & Sí & $89.2 \%(33)$ \\
\hline & & No & $10.8 \%(4)$ \\
\hline \multirow[t]{2}{*}{ En el nombre del día } & \multirow[t]{2}{*}{29} & Sí & $69.0 \%(20)$ \\
\hline & & No & $31.0 \%(9)$ \\
\hline \multirow[t]{2}{*}{ En el tiempo de hoy } & \multirow[t]{2}{*}{40} & Sí & $30.0 \%(12)$ \\
\hline & & No & $70.0 \%(28)$ \\
\hline \multirow{2}{*}{$\begin{array}{l}\text { En otras materias como } \\
\text { refuerzo }\end{array}$} & \multirow[t]{2}{*}{38} & Sí & $84.2 \%$ (32) \\
\hline & & No & $15.8 \%(6)$ \\
\hline \multirow[t]{2}{*}{ En la asamblea } & \multirow[t]{2}{*}{32} & Sí & $78.1 \%(25)$ \\
\hline & & No & $21.9 \%(7)$ \\
\hline \multirow[t]{2}{*}{ En el aseo/higiene } & \multirow[t]{2}{*}{32} & Sí & $34.4 \%$ (11) \\
\hline & & No & $65.6 \%(21)$ \\
\hline \multirow[t]{2}{*}{ En la siesta/relajación } & \multirow[t]{2}{*}{36} & Sí & $86.1 \%(31)$ \\
\hline & & No & $13.9 \%(5)$ \\
\hline \multirow[t]{2}{*}{ En la salida } & \multirow[t]{2}{*}{31} & Si & $58.1 \%(18)$ \\
\hline & & No & $41.9 \%(13)$ \\
\hline \multirow[t]{2}{*}{ Otros } & \multirow[t]{2}{*}{25} & Si & $84.0 \%(21)$ \\
\hline & & No & $16.0 \%$ \\
\hline
\end{tabular}

A este respecto en la pregunta abierta se reflejan dos opiniones que ilustran estos resultados: "Yo puedo utilizar una canción tanto para comenzar una actividad, para hacer un cambio de actividad o para rematarla"; "A diario, intento integrar técnicas de relajación que, combinadas con la música, ayuden a los niños de hoy en día a estar más serenos y alejarlos en algunos momentos de las "máquinas" para ayudarlos a disfrutar de la música".

Como se puede observar, la música está presente en gran parte de las rutinas escolares. Los maestros cantan con sus alumnos en muchos momentos de la jornada escolar y utilizan música de fondo durante la siesta o en las relajaciones. También han manifestado todos, el empleo de las canciones en momentos especiales de la vida de 
los alumnos y la cotidianidad del aula, como por ejemplo para felicitar los cumpleaños, en las actividades transversales como en el día de la paz o en las fiestas navideñas. Es decir, la música se utiliza de manera funcional sobre todo en las rutinas, pero no se usa de forma curricular pues se programan pocas sesiones semanales, bien porque algunos cuentan con ayuda de un especialista o porque reconocen sus carencias formativas para desarrollar los contenidos propiamente musicales.

Podemos concluir que, a la vista de los resultados, las sesiones de música son insuficientes para desarrollar los contenidos del currículo de Expresión musical ya que la mayoría de las veces se hace un uso de la música exclusivamente funcional.

3.2: Los maestros consideran que la participación en las actividades musicales en la etapa infantil contribuye a la inclusión de todos los alumnos.

Además de valorar el uso que los maestros han hecho en sus clases de la música, en cuanto a tipo de actividades, momentos empleados y tiempo de utilización, quisimos conocer su opinión si realizar actividades musicales constituye un recurso para mejorar la inclusión de todos los alumnos. La mayoría (91\%) así la consideran. También les preguntamos si consideran que estas, contribuyen a proporcionar apoyo afectivo, a enriquecer los procesos cognitivos y a la adquisición de habilidades comunicativas en aquellos alumnos que presentan mayores dificultades en las aulas porque sus necesidades no se han cubierto.

Para ello, pedimos información sobre las características de sus alumnos siguiendo las categorizaciones que sigue la ATDI en función de las necesidades específicas de apoyo educativo que presentaban sus alumnos ${ }^{59}$.

En la Tabla 18, se muestran las principales necesidades específicas de apoyo educativo que los maestros participantes tenían en sus aulas.

\footnotetext{
${ }^{59}$ Se tomaron como referencia las categorías de la ATDI vigente en aquel momento. INSTRUCCIÓN CONJUNTA, de 7 de enero de 2009 de las Direcciones Generales de Planificación, Ordenación e Inspección Educativa y de Calidad, Innovación y Formación del Profesorado, por la que se establece el procedimiento de recogida y tratamiento de los datos relativos al alumnado con necesidad específica de apoyo educativo escolarizado en centros docentes de Castilla y León.
} 


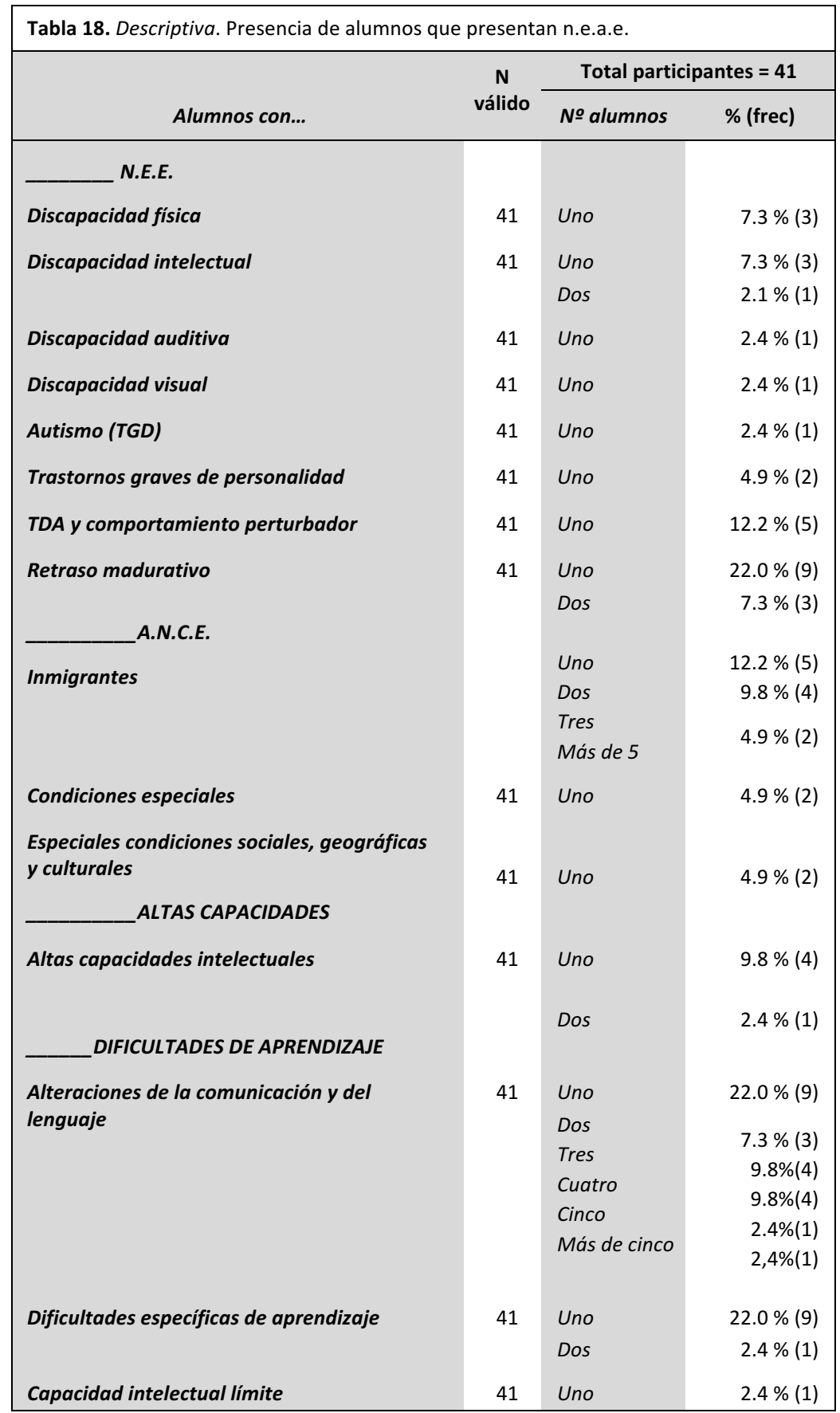

Como podemos observar, una gran mayoría de maestros, tienen en sus aulas alumnos con necesidades específicas de apoyo educativo. Entre las más frecuentes están 53 alumnos que presentan alteraciones de la comunicación y del lenguaje, 23 inmigrantes, 15 con retraso madurativo, 10 con dificultades de aprendizaje, 5 con altas capacidades y 5 con TDA. Del resto de categorías hay uno o dos. Por lo tanto, quisimos 
saber a qué alumnos las actividades musicales contribuyen a la adquisición de habilidades comunicativas, a enriquecer los procesos cognitivos y a proporcionar apoyo afectivo. Estas respuestas se especifican en la Tabla 19.

Tabla 19. Descriptiva. Alumnos a los que las actividades musicales proporcionan apoyo afectivo, ayuda a enriquecer los procesos cognitivos y contribuyen a la adquisición de habilidades comunicativas y de interacción

\begin{tabular}{|c|c|c|c|c|c|}
\hline $\begin{array}{c}\text { Alumnos con... } \\
\text { N.E.E. }\end{array}$ & N válido & Respuesta & $\begin{array}{l}\text { Apoyo } \\
\text { Afectivo } \\
\% \text { (frec) }\end{array}$ & $\begin{array}{l}\text { Procesos } \\
\text { Cognitivos } \\
\% \text { (frec) }\end{array}$ & $\begin{array}{l}\text { Habilidades } \\
\text { comunicativas } \\
\% \text { (frec) }\end{array}$ \\
\hline \multirow[b]{2}{*}{ Discapacidad física } & \multirow[t]{2}{*}{12} & $A$ veces & $10.0 \%(1)$ & $18.2 \%(2)$ & $25.0 \%(3)$ \\
\hline & & Casi siempre & $30.0 \%(3)$ & $72.7 \%(8)$ & $8.3 \%(1)$ \\
\hline & & Siempre & $60.0 \%(6)$ & $9.1 \%(1)$ & $66.7 \%(8)$ \\
\hline \multirow[t]{2}{*}{ Discapacidad intelectual } & \multirow[t]{2}{*}{16} & A veces & $16.7 \%(2)$ & $15.4 \%(2)$ & $12.5 \%(2)$ \\
\hline & & Casi siempre & $33.3 \%(4)$ & $69.2 \%$ (9) & $25.0 \%(4)$ \\
\hline \multirow[t]{5}{*}{ Discapacidad auditiva } & & Siempre & $50.0 \%(6)$ & $15.4 \%(2)$ & $62.5 \%(10)$ \\
\hline & \multirow[t]{3}{*}{12} & $A$ veces & $25.0 \%(2)$ & $40.0 \%(4)$ & $50.0 \%(6)$ \\
\hline & & Casi siempre & $25.0 \%(2)$ & $40.0 \%(4)$ & $8.3 \%(1)$ \\
\hline & & Siempre & $50.0 \%(4)$ & $20.0 \%(2)$ & $41.7 \%(5)$ \\
\hline & 13 & $A$ veces & $10.0 \%(1)$ & $10.0 \%(1)$ & $7.7 \%(1)$ \\
\hline \multirow[t]{3}{*}{ Discapacidad visual } & & Casi siempre & $30.0 \%(3)$ & $80.0 \%(8)$ & $23.1 \%(3)$ \\
\hline & & Siempre & $60.0 \%(6)$ & $10.0 \%(1)$ & $69.2(9)$ \\
\hline & 13 & A veces & $10.0 \%(1)$ & $41.7 \%(5)$ & $15.4 \%(2)$ \\
\hline \multirow[t]{2}{*}{ Autismo (TGD) } & & Casi siempre & $30.0 \%(3)$ & $41.7 \%(5)$ & $23.1 \%(3)$ \\
\hline & & Siempre & $60.0 \%(6)$ & $16.7 \%(2)$ & $61.5 \%(8)$ \\
\hline \multirow[t]{3}{*}{ Trastornos graves de personalidad } & 13 & A veces & $10.0 \%(1)$ & $18.2 \%(2)$ & $15.4 \%$ \\
\hline & & Casi siempre & $30.0 \%(3)$ & $63.6 \%(7)$ & $15.4 \%(2)$ \\
\hline & & Siempre & $60.0 \%(6)$ & $18.2 \%(2)$ & $69.2 \%(9)$ \\
\hline \multirow[t]{3}{*}{ TDA y comportamiento perturbador } & 40 & A veces & $8.3 \%()$ & $6.7 \%(1)$ & $58.5 \%(24)$ \\
\hline & & Casi siempre & $25.0 \%(3)$ & $80.0 \%(12)$ & $25.0 \%(3)$ \\
\hline & & Siempre & $66.7 \%(8)$ & $13.3 \%(2)$ & $24.4 \%(10)$ \\
\hline \multirow[t]{2}{*}{ Retraso madurativo } & 22 & A veces & $18.2 \%(2)$ & $15.4 \%(2)$ & $10.5 \%(2)$ \\
\hline & & Casi siempre & $18.2 \%(2)$ & $76.9 \%(10)$ & $26.3 \%(5)$ \\
\hline \multirow[t]{5}{*}{ Inmigrantes } & & Siempre & $63.6 \%(7)$ & $7.7 \%(1)$ & $63.2 \%(12)$ \\
\hline & 21 & Nunca & $11.8 \%(2)$ & & $9.5 \%(2)$ \\
\hline & & A veces & $11.8 \%(2)$ & $5.9 \%(1)$ & $9.5 \%(2)$ \\
\hline & & Casi siempre & $17.6 \%(3)$ & $88.2 \%(15)$ & $14.3 \%(3)$ \\
\hline & & Siempre & $58.8 \%(10)$ & $5.9 \%(1)$ & $66.7 \%(14)$ \\
\hline \multirow[t]{3}{*}{ Condiciones especiales } & 13 & A veces & $22.2 \%(2)$ & $15.4 \%(2)$ & $15.4 \%(2)$ \\
\hline & & Casi siempre & $11.1 \%(1)$ & $69.2 \%$ (9) & $30.8 \%$ (4) \\
\hline & & Siempre & $66.7 \%(6)$ & & $53.8 \%(7)$ \\
\hline \multirow{2}{*}{$\begin{array}{l}\text { Especiales condiciones sociales, } \\
\text { geográficas y culturales }\end{array}$} & 16 & A veces & $16.7 \%(2)$ & $14.3 \%(2)$ & $12.5 \%(2)$ \\
\hline & & Casi siempre & $16.7 \%(2)$ & $85.7 \%(12)$ & $12.5 \%(2)$ \\
\hline
\end{tabular}




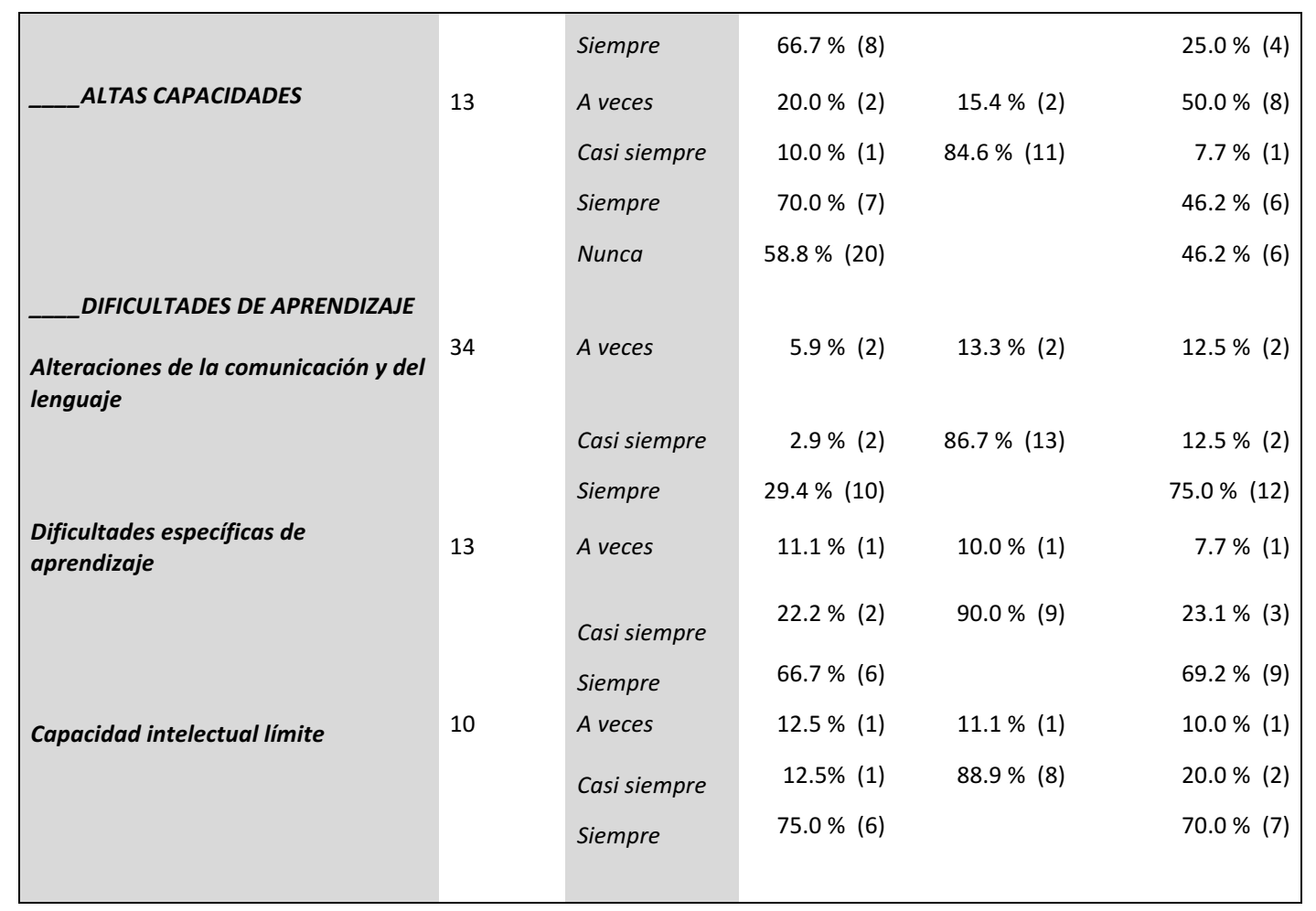

Como se puede observar en la Tabla 19, los docentes opinan que a los alumnos que la música contribuye a proporcionarles apoyo afectivo es a aquellos que presentan capacidad intelectual límite (75\%), altas capacidades intelectuales (70\%), dificultades específicas de aprendizaje $(66,7 \%)$ y alumnos que presentan condiciones especiales $(66,7 \%)$.

Cuando abiertamente preguntamos a los maestros las razones por las que consideraban que las actividades musicales pueden proporcionar apoyo afectivo, estas fueron:

- La música nos acerca, nos comunica y con el baile nos tocamos.

- La música puede tratar sentimientos que a lo mejor con otras técnicas cuesta más.

- Al estar en contacto en las diferentes actividades con los compañeros

-Con estas actividades los niños van ganando confianza en sí mismos, lo que hace que se sientan seguros a la hora de interactuar con sus iguales y adultos.

-Con las actividades musicales pueden expresar como se sienten e incluso pueden traer a su mente y cuerpo recuerdos y sensaciones afectivas que les pueden hacer sentir muy bien. 
- La música es un recurso que nos ayuda a relacionarnos y puede ser un buen vehículo para demostrar sentimientos, que en estas edades no siempre tiene capacidad para expresar de forma oral.

- La música trasmite alegría

-Porque con la música se desarrolla un ambiente acogedor y afectivo, relajante y divertido, que hace que el niño se sienta a gusto y querido.

-Porque les ayuda a relacionarse con los demás y así poder sentirse más queridos.

Al preguntarles su opinión respecto a si realizar actividades musicales proporciona estímulos para enriquecer los procesos cognitivos de estos alumnos, los maestros además de estar de acuerdo con esta afirmación mostraron que a los alumnos que la música contribuye a la mejora de estos procesos son los que presentan dificultades específicas de aprendizaje (90\%), capacidad intelectual límite (88,9\%), altas capacidades intelectuales $(84,6 \%)$ y retraso madurativo $(76,9 \%)$.

Cuando les preguntamos las razones por las que consideraban que realizar actividades musicales era importante para desarrollar y enriquecer los procesos cognitivos, comentaron:

- Es una manera divertida y estimulante en la que están implicados objetivos encaminados a desarrollar todos los procesos cognitivos.

- Favorece la estimulación y la educación integral

- La diversidad de músicas nos puede ayudar en cada caso a un mejor desarrollo de cada niño.

- La música es un estímulo importantísimo para el desarrollo integral del niño. Al ser la mayoría de las actividades lúdicas, la música es un elemento del movimiento y ritmo natural del niño.

- La repetición de las canciones o juegos ayuda a ampliar el vocabulario pues se les presentan de forma repetitiva atractiva y en forma de juego.

-Las actividades musicales son beneficiosas para nuestros alumnos permitiendo un desarrollo más integral.

-Las actividades musicales pueden aportarles a los distintos alumnos un montón de estímulos que les pueden ayudar a superar las dificultades que puedan tener.

-Porque por medio de la música se pueden transmitir todo tipo de conceptos, así como ampliar conocimientos y estimular procesos lógicos. 
Por último, los maestros consideran además que a los alumnos que más contribuye a la adquisición de habilidades comunicativas y de interacción, son a aquellos que presentan alteraciones de la comunicación y del lenguaje (75\%) a los alumnos con capacidad intelectual límite (70\%) y a los escolares con trastornos graves de personalidad o con dificultades específicas de aprendizaje $(69,2 \%)$

Las razones por las que los maestros consideraban que la música era importante para adquirir estas habilidades comunicativas, fueron:

-Porque de una manera u otra mejora su nivel de comunicación y relación.

-Porque es una forma de integración y de comunicación con sus iguales y adultos y a todos les encanta.

-Porque la música admite y contiene muchos matices que en cada caso pueden ayudar. -Porque es otra forma de expresión.

-Cuando se hacen este tipo de actividades siempre se incorporan al ritmo normal de la clase, rutinas, etc.

-Este tipo de actividades siempre se hacen en grupo, por los que les viene muy bien para mejorar las habilidades sociales y aprender a trabajar en gran grupo.

-Favorece la integración.

- Las actividades musicales pueden ayudar a todos los tipos de alumnos que podemos encontrarnos en las aulas a superar cualquiera de sus dificultades, por sus propiedades artísticas, motivadoras, estimulantes, calmantes, de concentración, de expresividad...

- Le facilita el acceso al lenguaje, les sociabiliza, etc.

- Mejora todas las capacidades y habilidades.

- Las actividades de música y danza actúan "'"como elemento socializador"'" y los resultados son asombrosos.

Por otro lado, quisimos conocer las actividades musicales en las que más participaban todos los alumnos. Como podemos comprobar en la Tabla 20, por encima de las demás destacan ver videos musicales $(67,6 \%)$ y cantar canciones $(65,8 \%)$, siendo, por el contrario, la menos participativa representación de cuentos musicales (29.7\%). 
Tabla 20. Descriptiva. Grado de participación de los alumnos de la clase, en las actividades musicales

\begin{tabular}{|c|c|c|c|}
\hline \multirow[b]{2}{*}{ Variable } & \multirow{2}{*}{$\begin{array}{c}\mathrm{N} \\
\text { válido }\end{array}$} & \multicolumn{2}{|c|}{ Total participantes = 41} \\
\hline & & Respuesta & $\%$ (frec) \\
\hline \multirow[t]{3}{*}{ Discriminar/identificar sonidos y ruidos de la vida cotidiana } & 39 & Algunos & $7.7 \%(3)$ \\
\hline & & Casi todos & $41.0 \%(16)$ \\
\hline & & Todos & $51.3 \%(20)$ \\
\hline \multirow{3}{*}{$\begin{array}{l}\text { Hacer sonidos y ritmos con el cuerpo (juegos sonoros de } \\
\text { imitación) }\end{array}$} & 38 & Algunos & $7.9 \%(3)$ \\
\hline & & Casi todos & $42.1 \%(16)$ \\
\hline & & Todos & $50.0 \%(19)$ \\
\hline \multirow[t]{3}{*}{ Hacer sonidos con la voz, vocalizaciones, imitación... } & 38 & Algunos & $7.9 \%(3)$ \\
\hline & & Casi todos & $47.4 \%(18)$ \\
\hline & & Todos & $44.7 \%(17)$ \\
\hline \multirow[t]{3}{*}{ Tocar instrumentos para acompañar canciones } & 35 & Algunos & $22.9 \%(8)$ \\
\hline & & Casi todos & $20.0 \%(7)$ \\
\hline & & Todos & $57.1 \%(20)$ \\
\hline \multirow[t]{3}{*}{ Cantar canciones } & 38 & Algunos & $5.3 \%(2)$ \\
\hline & & Casi todos & $28.9 \%(11)$ \\
\hline & & Todos & $65.8 \%(25)$ \\
\hline \multirow[t]{3}{*}{ Hacer juegos musicales siguiendo distintas melodías } & 37 & Algunos & $13.5 \%(5)$ \\
\hline & & Casi todos & $37.8 \%(14)$ \\
\hline & & Todos & $48.6 \%(18)$ \\
\hline \multirow[t]{3}{*}{ Bailar o realizar coreografías sencillas } & 38 & Algunos & $2.6 \%(1)$ \\
\hline & & Casi todos & $55.3 \%(21)$ \\
\hline & & Todos & $42.1 \%(16)$ \\
\hline \multirow{3}{*}{$\begin{array}{l}\text { Audiciones musicales: escuchar breves obras instrumentales } \\
\text { y vocales }\end{array}$} & 37 & Algunos & $5.4 \%(2)$ \\
\hline & & Casi todos & $40.5 \%(15)$ \\
\hline & & Todos & $54.1 \%(20)$ \\
\hline \multirow[t]{3}{*}{ Representar cuentos musicales } & 37 & Algunos & $16.2 \%(6)$ \\
\hline & & Casi todos & $54.1 \%(20)$ \\
\hline & & Todos & $29.7 \%(11)$ \\
\hline \multirow[t]{3}{*}{ Ver vídeos musicales } & 37 & Algunos & $10.8 \%(4)$ \\
\hline & & Casi todos & $21.6 \%(8)$ \\
\hline & & Todos & $67.6 \%(25)$ \\
\hline
\end{tabular}

3.3 Hay diferencia de valoración entre los estudiantes y los maestros sobre la importancia de la música en la educación.

Según valoren la importancia de la música se hará un uso de ella en las aulas de infantil. Para saberlos comparamos los resultados de ambos grupos (Tabla 21). 
Tabla 21: Comparativa de la importancia de la música en la educación.

\begin{tabular}{|c|c|c|c|c|c|c|c|}
\hline \multirow{2}{*}{ ítems } & \multicolumn{3}{|c|}{ Estudiantes } & \multicolumn{2}{|c|}{ Maestros } & \multicolumn{2}{|c|}{ Test de contraste } \\
\hline & Respuesta & $\begin{array}{c}\mathbf{N} \\
\text { válido }\end{array}$ & $\%$ (frec) & N válido & $\%$ (frec) & Valor & P-Sig \\
\hline $\begin{array}{l}\text { Aumenta la memoria, atención } \\
\text { y concentración }\end{array}$ & $\begin{array}{l}\text { Poco } \\
\text { Bastante } \\
\text { Mucho }\end{array}$ & 139 & $\begin{array}{r}0.7 \%(1) \\
43.9 \%(61) \\
55.4 \%(77)\end{array}$ & 39 & $\begin{array}{l}10.3 \%(4) \\
33.3 \%(13) \\
56.4 \%(22)\end{array}$ & 0.35 & $.723^{\mathrm{NS}}$ \\
\hline $\begin{array}{l}\text { Mejora la habilidad para } \\
\text { resolver problemas } \\
\text { matemáticos y de } \\
\text { razonamiento complejos }\end{array}$ & $\begin{array}{l}\text { Nada } \\
\text { Poco } \\
\text { Bastante } \\
\text { Mucho }\end{array}$ & 138 & $\begin{array}{r}2.2 \%(3) \\
37.7 \%(52) \\
45.7 \%(63) \\
14.5 \%(20)\end{array}$ & 39 & $\begin{array}{r}0 . \%(0) \\
28.2 \%(11) \\
48.7 \%(19) \\
23.1 \%(9)\end{array}$ & 2.04 & $.042 *$ \\
\hline $\begin{array}{l}\text { Introduce a los sonidos y } \\
\text { significados de las } \\
\text { palabras y fortalece el } \\
\text { aprendizaje }\end{array}$ & $\begin{array}{l}\text { Poco } \\
\text { Bastante } \\
\text { Mucho }\end{array}$ & 138 & $\begin{array}{r}2.2 \%(3) \\
44.9 \%(62) \\
52.9 \%(73)\end{array}$ & 38 & $\begin{array}{r}0 . \%(0) \\
44.7 \%(17) \\
55.3 \%(21)\end{array}$ & 0.41 & $.683^{\mathrm{NS}}$ \\
\hline $\begin{array}{l}\text { Desarrolla la creatividad y la } \\
\text { imaginación infantil }\end{array}$ & $\begin{array}{l}\text { Nada } \\
\text { Poco } \\
\text { Bastante } \\
\text { Mucho }\end{array}$ & 139 & $\begin{array}{r}0.7 \%(1) \\
1.4 \%(2) \\
22.3 \%(31) \\
75.5 \%(105)\end{array}$ & 39 & $\begin{array}{r}0 . \%(0) \\
0 . \%(0) \\
46,2 \%(18) \\
53.8 \%(21)\end{array}$ & 3.11 & $.002 * *$ \\
\hline $\begin{array}{l}\text { Combinada con el baile } \\
\text { estimula los sentidos y } \\
\text { el equilibrio }\end{array}$ & $\begin{array}{l}\text { Poco } \\
\text { Bastante } \\
\text { Mucho }\end{array}$ & 139 & $\begin{array}{r}0.7 \%(1) \\
18.0 \%(25) \\
81.3 \%(113)\end{array}$ & 41 & $\begin{array}{r}9,7 \%(4) \\
31.7 \%(13) \\
58.5 \%(24)\end{array}$ & 3.66 & $.000^{* *}$ \\
\hline $\begin{array}{l}\text { Provoca evocación de } \\
\text { recuerdos e imágenes; } \\
\text { enriquece el intelecto }\end{array}$ & $\begin{array}{l}\text { Nada } \\
\text { Poco } \\
\text { Bastante } \\
\text { Mucho }\end{array}$ & 139 & $\begin{array}{r}0.7 \%(1) \\
18.7 \%(26) \\
46.8 \%(65) \\
33.8 \%(47)\end{array}$ & 38 & $\begin{array}{r}0 . \%(0) \\
5.3 \%(2) \\
52.6 \%(20) \\
42.1 \%(16)\end{array}$ & 2.24 & $.025^{*}$ \\
\hline $\begin{array}{l}\text { Estimula el desarrollo integral } \\
\text { al actuar sobre las } \\
\text { áreas del desarrollo }\end{array}$ & $\begin{array}{l}\text { Nada } \\
\text { Poco } \\
\text { Bastante } \\
\text { Mucho }\end{array}$ & 138 & $\begin{array}{r}0.7 \%(1) \\
5.1 \%(7) \\
52.9 \%(73) \\
41.3 \%(57)\end{array}$ & 38 & $\begin{array}{r}0 . \%(0) \\
2.6 \%(1) \\
39.5 \%(15) \\
57.9 \%(22)\end{array}$ & 2.39 & $.017^{*}$ \\
\hline $\begin{array}{l}\text { Mejora la comunicación con } \\
\text { todo el grupo }\end{array}$ & $\begin{array}{l}\text { Nada } \\
\text { Poco } \\
\text { Bastante } \\
\text { Mucho }\end{array}$ & 138 & $\begin{array}{r}0.7 \%(1) \\
10.9 \%(15) \\
38.4 \%(53) \\
50.0 \%(69)\end{array}$ & 38 & $\begin{array}{r}0 . \%(0) \\
2.6 \%(1) \\
39.5 \%(15) \\
57.9 \%(22)\end{array}$ & 1.53 & $.126^{\mathrm{NS}}$ \\
\hline $\begin{array}{l}\text { Ayuda el desarrollo a resolver } \\
\text { problemas de relación }\end{array}$ & $\begin{array}{l}\text { Nada } \\
\text { Poco } \\
\text { Bastante } \\
\text { Mucho }\end{array}$ & 139 & $\begin{array}{r}1.4 \%(2) \\
19.4 \%(27) \\
45.3 \%(63) \\
33.8 \%(47)\end{array}$ & 41 & $\begin{array}{r}7.3 \%(3) \\
4.9 \%(2) \\
51.2 \%(21) \\
36.6 \%(15)\end{array}$ & 0.83 & $.409^{\mathrm{NS}}$ \\
\hline
\end{tabular}


Como se puede observar, tanto los estudiantes como los maestros consideran que la música contribuye a mejorar todas las competencias, habilidades y a desarrollar los diferentes aspectos presentados en cada uno de los ítems. En relación a los resultados obtenidos y la significatividad de las diferencias, los estudiantes le dan una importancia significativamente mayor al papel o la ayuda que la música combinada con el baile estimula los sentidos y el equilibrio (81,3\% estudiantes - 58,5\% maestros) y contribuye a desarrollar la imaginación y la creatividad infantil (75\% estudiantes - 53.3\% maestros), no obstante si agrupamos las respuestas de los maestros que consideran bastante y mucho, arrojan un índice más bien elevado, con lo cual no se aprecian diferencias.

En cambio, los maestros otorgan mayor importancia a que la música estimula el desarrollo integral al actuar sobre las áreas de desarrollo y provoca la evocación de recuerdos e imágenes, enriqueciendo el intelecto (57,9\% maestros-52,9\% estudiantes).

Por lo tanto, la tendencia de los estudiantes es que dan más importancia al aspecto creativo y vivencial de la música a través del cuerpo y lo vinculan con el desarrollo de la imaginación y de la creatividad, mientras que la tendencia de los maestros apuntan más a cuestiones cognitivas para estimular el intelecto y con el desarrollo integral del alumno.

En función de los datos obtenidos, se confirma la hipótesis 3 pues no se hace un uso ni adecuado ni suficiente de la música en la etapa de segundo ciclo de educación infantil. 


\section{CAPÍTULO 5. CONCLUSIONES Y DISCUSIÓN}

\section{VALORACIÓN DEL GRADO DE CONSECUCIÓN DE LOS OBJETIVOS}

En el presente estudio nos plantemos tres objetivos generales. A partir de los resultados presentados es posible afirmar que hemos conseguido el primero de ellos, Analizar la formación musical de los estudiantes que cursan el Grado en Maestro en Educación Infantil en la Universidad de Salamanca, al haber diseñado un instrumento que nos ha permitido evaluar, por una parte, la formación en educación musical recibida en los diferentes niveles educativos y, por otra, su actuación en el aula de segundo ciclo de Educación Infantil, desde la perspectiva de los maestros de prácticas. Los resultados obtenidos, nos servirán para adecuar nuestra práctica profesional, dentro de los planes de estudios del Grado, a la realidad de las aulas de segundo ciclo de Educación Infantil, ofreciendo a los estudiantes una formación en competencias musicales básicas necesarias para utilizarla de una manera segura y con garantías de calidad.

En lo que respecta al segundo objetivo, Evaluar la utilización de la música en la etapa de infantil en los centros educativos de Castilla y León, también lo hemos conseguido, ya que hemos obtenido información, no lo suficientemente amplia pero sí lo suficientemente significativa, para conocer el uso que se está haciendo de la música en la práctica educativa en la etapa infantil.

Respecto al tercer objetivo que nos propusimos, diseñar propuestas de mejora tanto en la formación musical inicial como permanente para los maestros de educación infantil, se presentan a continuación como resultado de las necesidades reflejadas en los objetivos anteriores. 


\section{ANÁLISIS Y DISCUSIÓN DE LOS RESULTADOS}

A continuación, se contrastan los resultados obtenidos en nuestra investigación con los referentes teóricos y con resultados de otras investigaciones, centrándonos en la discusión de los siguientes apartados: la formación musical en la enseñanza obligatoria impartida en las últimas décadas en nuestro país, la formación musical básica que se imparte en el Grado en Maestro en la Universidad de Salamanca y el uso que se hace de la música en segundo ciclo de Educación Infantil. Intentamos dar respuesta a las hipótesis iniciales y presentamos algunas propuestas de futuro para mejorar la formación musical tanto para los estudiantes como para los maestros de Educación Infantil en ejercicio.

\section{La formación musical recibida por los estudiantes en la enseñanza obligatoria}

En nuestra investigación se ha constatado que todos los estudiantes que cursan el Grado en Maestro en Educación Infantil si bien, han recibido en las etapas de Educación Primaria, Secundaria y en Bachillerato o Ciclos Formativos, un número de horas, a nuestro juicio, adecuadas para estar musicalmente formados, no se ha traducido en una formación suficiente para continuarla durante el Grado y así poder enfocarla al trabajo con niños de la etapa de segundo ciclo de Educación Infantil. Los datos mostraron que en la enseñanza obligatoria de Educación Primaria un 95\% ha recibido formación referente al lenguaje musical para leer e interpretar partituras a través de la Flauta dulce y en ESO, nociones teóricas de Historia de la Música (88\%). No obstante, en estos niveles educativos hemos constatado que se ha recibido más formación teórica que práctica y que los aspectos en los que menos formación han recibido han sido los relacionados con la educación vocal y educación rítmica, es decir, la parte práctica y vivencial de la música. Estos datos concuerdan con los presentados por Oriol (2004), quien concluía que la enseñanza musical recibida durante la Educación Primaria y la ESO por los alumnos que cursaban Magisterio en la Universidad Complutense de Madrid fue más teórica que práctica en un 53,25\% de los casos, con contenidos teóricos que se repetían en ambas etapas y recomendaba una "revisión en profundidad de la secuenciación en contenidos de las mismas" (p.48).

En nuestro estudio, los estudiantes que cursaron Música en Bachillerato, manifiestan en su mayoría la misma tendencia anterior: haber recibido una formación 
teórica orientada a la Historia de la Música con alguna ligera formación en audiciones. Respecto a los estudiantes que han cursado un Ciclo Formativo de Formación Profesional, debemos resaltar que la formación musical recibida por los que optaron por el nivel de Técnico Superior en Educación Infantil ha sido más práctica que para los que cursaron el Bachillerato, sobre todo respecto al aprendizaje de canciones infantiles y que haber realizado prácticas educativas en primer ciclo de educación infantil (0-3 años) donde han desarrollado actividades musicales, les capacita a nuestro juicio, más que al resto, para continuar con los estudios musicales del Grado, pues no solo han recibido más formación práctica en recursos musicales sino que han tenido contacto con la realidad educativa durante sus prácticas. Datos que también coinciden con investigaciones de Gimeno Romero (2014) y Ramos (2009) sobre los contenidos musicales cursados por los alumnos de la ESO, quienes mostraron que el libro de texto seguía siendo la herramienta didáctica de máximo consumo en estos niveles con un enfoque eminentemente teórico en las clases.

En cambio, los 40 estudiantes que habían recibido formación musical extraescolar, aunque no mostraron diferencias estadísticamente significativas en cuanto a la adquisición de conocimientos o recursos musicales, sí presentaron mejores puntuaciones respecto a la valoración de sus capacidades musicales y a la adquisición de destrezas y habilidades musicales: en concreto, en saberse mover, bailar, en formación en educación vocal e instrumental y buena coordinación motórica, lo que nos permite decir que en este aspecto la formación extraescolar les ha permitido lograr capacidades suficientes para interpretar las piezas vocales e instrumentales sencillas que se utilizan en la educación musical de segundo ciclo de Educación Infantil. Es decir, en la medida en que han vivenciado los elementos musicales por formar parte de un coro, una rondalla, grupo musical o han recibido formación para tocar algún instrumento, cambia su autovaloración, lo que pone de manifiesto que la formación musical, cuando está resultando realmente eficaz, a juicio de los estudiantes, es cuando se ha cursado extraescolarmente.

Ante estos resultados, en principio podríamos suponer que, con el número de horas de música recibidas, los estudiantes se deberían considerar con formación musical suficiente para continuarla durante sus estudios del Grado; sin embargo, cuando les pedimos que autoevaluaran su formación musical, los datos nos mostraron que más de la mitad de los estudiantes encuestados consideraban que necesitarían comenzar esta 
formación desde cero, lo que demuestra que para casi la mayoría, dicha formación, no ha sido eficaz.

En el II Congreso de la Unesco sobre Pedagogía Musical celebrado en 1958, una serie de músicos, pedagogos y compositores, entre los que se encontraban Dalcroze, Martenot y Orff, sentaron las bases sobre las que se fundamentan los diferentes currículos de la educación musical y que Oriol y Parra (1979) difundieron en nuestro país en un manual de referencia para todos los profesionales interesados en impartir la educación musical, La expresión musical en la educación básica. Estos se resumían de la siguiente forma:

La Educación Musical ha de tener un carácter progresivo, y debe acompañar al niño a lo largo de todo su proceso evolutivo, desde la Educación Infantil hasta la Educación Secundaria, siempre teniendo presente sus capacidades e intereses [...] La Educación Musical ha de tener un carácter integral, por lo que en los programas educativos deberá aparecer con un contenido formativo más que como una asignatura especial, puesto que no tiene por fin la formación de artistas, sino hacer que nazcan en el niño emociones y vivencias de naturaleza estética [...] La Educación Musical no ha de revestir la forma de una disciplina sometida a una calificación estricta de los resultados a nivel individual [...] En la metodología utilizada se atenderá en primer lugar a familiarizar al alumnado con la realidad musical y con los hechos musicales por vía experimental y participativa, antes que abordar la representación conceptual y gráfica de los sonidos [...] La Educación Musical que se lleve a cabo en las instituciones escolares debe abordar todos y cada uno de sus aspectos: educación vocal, educación instrumental, educación auditiva, historia de la música, etc. $(p, 14-16)$.

Llegados a este punto, sobre los resultados obtenidos se nos plantea un serio interrogante ¿como ha sido este tipo de formación recibida por los estudiantes en las etapas de enseñanza obligatoria?, ¿sobre qué base han fundamentado los diferentes currículos de la educación musical para que los estudiantes no se consideren musicalmente formados?

Si queremos que los estudiantes continúen con su formación musical en el Grado, se debe revisar el planteamiento de esta formación en la Enseñanza Obligatoria, aunque, tal como comentamos en el Capítulo 1, la actual LOMCE, considera la Educación 
Musical en estas etapas como materia optativa a ofertar por las diferentes Comunidades Autónomas y puede llegar a ocurrir que la formación musical que reciban los futuros alumnos, solo se imparta en etapa de la Educación Infantil, enseñanza no obligatoria.

\section{La formación musical básica de los estudiantes recibida en el Grado en Maestro en educación Infantil}

Para adquirir en el Grado las competencias musicales necesarias para impartir adecuadamente el currículo de Expresión musical para la etapa de segundo ciclo de Educación Infantil se requiere, por parte de los estudiantes, unos conocimientos musicales previos de lenguaje musical, formación rítmica (instrumental y de movimiento) y formación vocal, que en la mayoría de los casos no tienen.

Ante este panorama, la mayoría de los profesores que impartimos esta formación en el Grado nos vemos en la necesidad de formar musicalmente a los estudiantes en nociones básicas, dificultando en gran parte profundizar en la didáctica y en las metodologías musicales activas, a pesar de que, como señala Oriol, "La Universidad está concebida para desarrollar estudios superiores, pero no, para alfabetizar a los estudiantes" (2003, p, 57).

En relación a la formación musical básica recibida por los estudiantes en el Grado tras cursar la asignatura de "Expresión musical en la Educación Infantil" los datos reflejan que, aunque ha habido mejoras en la adquisición de todos los conocimientos relacionados con la educación vocal, educación auditiva y educación instrumental mejorando las competencias necesarias para integrar la música en su futura práctica profesional, todavía resulta insuficiente para poder impartir el currículo de expresión musical en el segundo ciclo de Educación Infantil.

En este sentido, la mayoría de los maestros opinan que los alumnos del Grado en Educación Infantil que han realizado con ellos sus prácticas educativas, no reciben en su etapa universitaria ni formación ni conocimientos musicales suficientes para hacer uso de la música en esta etapa educativa. Datos similares a los recogidos en anteriores investigaciones por Carrillo Aguilera y Vilar Monmany (2016), Ruiz Palomo (2013), Zabalza (2011) y López de la Calle (2009), al comprobar que la formación musical del Maestro en 
Educación Infantil continúa siendo insuficiente para adquirir las competencias que se necesitan para impartir la expresión musical en su práctica profesional.

Así, los contenidos musicales que deben adquirir los estudiantes del Grado para poder desarrollar el currículo de Expresión Musical, se resumen en tres apartados: 1) los referentes a la audición, discriminación auditiva, las cualidades del sonido, el entorno sonoro y en las audiciones; 2) los relacionados con el ritmo, tanto a nivel corporal, de movimiento y a nivel instrumental y 3) los relacionados con la formación vocal, que desarrollan el sentido melódico a través de las canciones infantiles y de los juegos con la voz.

La valoración que han hecho los maestros de los contenidos musicales adquiridos por los estudiantes ha sido que les consideran poco formados, sobre todo respecto a la formación recibida en educación rítmica, aunque mejora respecto a la educación auditiva y a la educación vocal.

A pesar de esto, nos parece un dato positivo que casi la mitad de los maestros, un $41.7 \%$, considera que los estudiantes estaban bastante/muy preparados para realizar actividades musicales, comentando literalmente en las preguntas abiertas que "...mis estudiantes se expresaban mucho musicalmente" (...) "realizaban practicas musicales" (...) "utilizaban las nuevas tecnologías" (...) "enseñaron canciones y danzas a los alumnos" por lo que su valoración ha sido positiva. Para el otro 58\%, no están formados porque no han realizado estas actividades, literalmente "mis estudiantes no han desarrollado ningún tipo de actividades musicales, porque no las hemos contemplado en la programación de aula". Este comentario nos lleva a reflexionar sobre el hecho de que si los maestros no programan este tipo de contenidos ¿cómo los van a realizar los estudiantes que hicieron con ellos las prácticas educativas?

En las preguntas abiertas, los motivos que los maestros consideran que los estudiantes no realizan prácticas musicales, son "porque los estudiantes no han mostrado iniciativa" (...) "porque su timidez lo impedía" (...) "porque tienen poca experiencia al ser su primer año de prácticas". Comentarios que nos parecen muy significativos y explican, en gran medida, estos resultados. Esta afirmación, de nuevo concuerda con la señalada por López de la Calle (2009) para quien un 86\% de los maestros gallegos entrevistados afirmaba que los "futuros profesores no estaban preparados para la implementación de la música en la práctica educativa" (p. 228). 
Creemos, por lo tanto, que la formación musical básica recibida en el Grado mejora las competencias de los estudiantes, ya que los que realizaron actividades musicales durante las prácticas han sido bien valorados, pero no están formados suficientemente en todos los contenidos para hacer un uso adecuado de la música en esta etapa.

Esta investigación pretendía conocer también la valoración que hacen tanto los estudiantes como los maestros sobre la formación en procedimientos recibida en el Grado en Maestro en Educación Infantil y su relevancia para impartir el currículo musical en esta etapa. En este sentido, se presentaron para valorar la importancia por ambos grupos, los contenidos procedimentales para la formación del Maestro en relación a la Percepción, Expresión, Creatividad y Representación gráfica de la música (contenidos de Expresión musical que para Educación Infantil aparecen publicados en el Bocyl ${ }^{60}$ ) y, aunque todos son percibidos como relevantes, las valoraciones presentan ligeras diferencias.

A la vista de los resultados, podemos afirmar que, tanto los maestros como los estudiantes conceden gran importancia a estar formados en estos procedimientos y habilidades. No obstante, los estudiantes han concedido una relevancia significativamente mayor a los aspectos relacionados con la percepción de la música, la expresión y representación gráfica de la música, destacando la lectura y escritura de la notación musical, aspectos clave para la formación musical del maestro, necesarios para poder interpretar un amplio repertorio de piezas instrumentales, canciones infantiles, diseñar musicogramas y leer y representar ritmos para introducirlos en las grafías convencionales.

En cuanto a la valoración que los estudiantes hacen de la utilidad en la práctica de los conocimientos musicales aprendidos en el Grado, los que más útiles les han resultado fueron aprender un amplio repertorio de canciones, seguido de actividades de

\footnotetext{
60 Percepción musical. - Exploración de las posibilidades sonoras de la voz, del propio cuerpo, de objetos cotidianos y de instrumentos musicales. Expresión musical. - Utilización de los sonidos hallados para la interpretación y la creación musical. Juegos sonoros de imitación. - Ruido, sonido, silencio y música. Discriminación de sonidos y ruidos de la vida diaria, de sus rasgos distintivos y de algunos contrastes básicos (largo-corto, fuerte-suave, agudo-grave). - Audiciones musicales que fomenten la creatividad. Actitud de escucha e interés por la identificación de lo que escuchan. - Creatividad musical. - Aprendizaje de canciones y juegos musicales siguiendo distintos ritmos y melodías, individualmente o en grupo. Curiosidad por las canciones y danzas de nuestra tradición popular y de otras culturas.
} 
ritmo y movimiento. Esto pone de manifiesto una vez más que la canción infantil sigue siendo el recurso musical más utilizado en la educación infantil, ya que, como hemos visto, se utiliza continuamente formando parte de las rutinas diarias o para reforzar otros aprendizajes. Datos que coinciden con los de Ruiz Palomo, Palmero Cámara y Baños Martínez (2015), quien recogieron la gran relevancia que le concedían a la canción infantil tantos los maestros como los estudiantes.

Los maestros, en cambio, han destacado las actividades de ritmo y movimiento como las más útiles, aunque como veremos a continuación, los datos nos indican que las más utilizada por ellos son cantar canciones.

Ambos grupos coinciden en que el aspecto menos utilizado ha sido tocar la flauta dulce. Creemos que es porque no se hace un uso adecuado del mismo, ya que es considerado en todas las metodologías musicales, Orff, Kodaly, Ward y en investigaciones recientes (Capriles, 2016) como un recurso inmejorable para trabajar la educación auditiva, al poner en práctica los contenidos del lenguaje musical y realizar numerosas aplicaciones en el aula, sobre todo para entonar adecuadamente las canciones. Coincidimos totalmente con Oriol (2002) cuando afirma que "Hemos comprobado que el desconocimiento de la utilización de este instrumento, hace que no se siga enseñando en los diferentes centros universitarios" $(p, 47)$.

En las preguntas abiertas, los maestros perciben que a los estudiantes se les "sigue enseñando teoría desconectada de la aplicación práctica" por lo que sugieren que se les enseñen "actividades prácticas que puedan desarrollar en el aula, concretándolas en: audiciones, canciones infantiles, dramatizaciones, técnica instrumental con instrumentos de percusión escolar y, sobre todo, en recursos para trabajar en el aula". Esta afirmación coincide con la manifestada por López de la Calle donde recogía la necesidad de "realizar una formación práctica y aplicada" (p.229).

También señalan "la necesidad de formarse en contenidos musicales, sobre todo, en formación vocal", lo que pone de manifiesto de nuevo que en este aspecto es en el que consideran que están menos formados. 
En lo que se refiere al uso adecuado y suficiente de la música en la etapa de educación infantil, hemos encontrado una discrepancia entre la percepción de la importancia de la música en la educación y el uso que se hace de ella en la práctica diaria, lo que pone de manifiesto que la teoría camina en una dirección y la práctica en otra.

Los datos recogidos manifiestan como un hecho a destacar que el tiempo asignado para trabajar los contenidos de la expresión musical, en general, sigue siendo escaso, aunque un $28,9 \%$ de maestros han manifestado que dedican un tiempo diario para trabajar estos contenidos y solo un 23,1\% programa salidas didácticas relacionadas con la música. El porcentaje de maestros que imparte tres sesiones semanales o más, tiempo mínimo recomendable para desarrollar estos contenidos (López de la calle, 2008, Mairet y Malvicini de Benini, 2012) es del 31,5\% frente al 68,5\% que dedica una sola sesión semanal. Aun así, encontramos porcentajes más elevados que en anteriores investigaciones como la de López de la Calle (2007), quien constató que solo el 20\% del profesorado encuestado dedicaba entre una y dos sesiones semanales; en nuestro caso el $55,3 \%$ solo dedica entre una y dos sesiones semanales.

Aunque en Educación Infantil, no existe la figura de Especialista en Educación Musical, un 38,5 \% de maestros cuenta con esta ayuda, siendo para alguno "el motivo para no programar este tipo de contenidos". Un 77,7\% ha manifestado que necesitaría su ayuda para trabajar con más recursos musicales y así incluir más prácticas musicales en su programación didáctica, lo que nos lleva a decir que, en un alto porcentaje, todavía se depende de la ayuda de un especialista de música para desarrollar estos contenidos.

Otra de las razones por las que los maestros no programan este tipo de actividades es porque no se sienten formados, "... aunque utilizo de vez en cuando canciones para realizar algún cambio de actividad, mis carencias formativas y las premuras de otros aprendizajes, hacen que relegue estas actividades a situaciones puntuales en lugar de hacer un proceso continuado".

En cuanto a sus carencias formativas (aquello en lo que les hubiera gustado formarse en sus estudios universitarios), la mayoría (86,9\%) hace referencia a los aspectos prácticos, en concreto, la educación vocal (para enseñar a cantar un amplio repertorio de canciones), la educación rítmico-corporal (conocer coreografías y danzas infantiles) y la educación auditiva (acostumbrar al oído a una escucha activa) y un 98\% hace referencia a 
formarse en metodologías musicales (que proporcionen recursos para trabajar la música en educación infantil). Estos datos concuerdan con los de anteriores investigaciones de Ruiz Palomo y Santamaría Conde (2013) recogidos de los maestros de Educación infantil de la capital de Burgos, quienes resaltaron en sus carencias formativas las estrategias metodológicas; López de la Calle (2007) también manifestaba la falta de formación en los estudios de magisterio respecto a los conocimientos de sonido, melodía, ritmo, formación vocal y movimiento.

Los datos han reflejado que todos los maestros realizan actividades musicales con sus alumnos, aunque la mayor parte hace un uso más instrumental que curricular y que el recurso más utilizado por los maestros es cantar canciones, sobre todo cuando forma parte de las "rutinas". La mayoría las emplea para "dar los buenos días" o para "conocer el nombre del día". También "en la asamblea", para reforzar "apoyo en determinados aprendizajes", aprender los números, las letras, el vocabulario y "en momentos especiales", navidad y "en las actividades transversales", día de la paz, etc., por lo que concluimos que las canciones son el recurso musical más empleado para apoyar las rutinas y reforzar y apoyar otros aprendizajes. Es decir, cumple con una función instrumental pero no curricular, pues no se usa para desarrollar una educación rítmica, ni vocal, ni auditiva: hacer juegos musicales siguiendo una melodía, que es uno de los recursos utilizados para trabajar la educación vocal propiamente dicha, el 15\% de los maestros ha manifestado que no lo ha empleado nunca.

Lo mismo ocurre con los contenidos relacionados con la educación auditiva, pues las audiciones musicales son utilizadas por la mayoría como música ambiental en la siesta o para relajar, una vez más con carácter funcional, usadas de música de fondo y no para desarrollar aspectos curriculares de audiciones musicales activas propiamente dichas.

Respecto a los contenidos relacionados con el desarrollo rítmico-instrumental, un $37 \%$ nunca ha utilizado los instrumentos escolares para acompañar canciones infantiles, pero un porcentaje algo superior $(51,3 \%)$ afirma que sus alumnos sí tocan instrumentos en clase, sobre todo los de percusión de altura indeterminada. 


\section{. Las actividades musicales como recurso para la inclusión}

Las actividades musicales que se realizan en el aula de infantil (cantar, bailar, tocar instrumentos, realizar cuentos sonoros, escuchar, etc.) pueden convertirse en inclusivas si los maestros aprovechan las funciones sociales que reconocemos en la música potenciando en los niños el deseo de participar mediante los procesos de imitación e identificación, básicos para el desarrollo de la expresión musical y que junto al refuerzo positivo, contribuirán a lograr los objetivos de inclusión que se persiguen.

Ante la diversidad del alumnado que encontramos en las aulas de segundo ciclo de Educación Infantil, preguntamos la valoración del uso de la música para mejorar la inclusión de todos los alumnos en la práctica educativa, cuestión considerada por todos ellos de gran valor. Apenas ponen de manifiesto la existencia de problemas asociados a la realización de actividades musicales con todos los alumnos, aunque excepcionalmente hemos encontrado la respuesta de un maestro para quien realizar este tipo de actividades con todos sus alumnos "crea problema en la dinámica de clase, pues produce falta de concentración".

Cuando pedimos su opinión sobre la participación de todos los alumnos en las actividades musicales, sorprende que, aunque la mayoría responden que siempre es bueno que participen todos, a la hora de que describan el tipo de actividades en las que todos participan, no hay ninguna respuesta, siendo la más puntuada ver videos musicales, actividad que, a nuestro entender, no tiene mucho que ver con los contenidos de la expresión musical.

El uso de la música en relación a la atención a la diversidad lleva implícita una adecuada preparación por parte de los maestros. Esta es una carencia que constatamos frecuentemente y que ha quedado reflejada por todos ellos cuando han manifestado "necesidad de formarse en recursos musicales para trabajar con todos los alumnos" (...) "formación musical en atención a la diversidad "(...) "metodologías musicales para trabajar con niños con necesidades educativas especiales" como principales necesidades formativas. Este tipo de formación apenas se tiene en cuenta en la impartición de la asignatura de "Expresión musical en la Educación Infantil" que, como hemos visto, es la única formación musical básica que reciben los estudiantes del Grado en Maestro en Educación Infantil en nuestra universidad. Los estudiantes que realizan la Mención en 
Educación Especial adicionalmente, deben cursar la asignatura optativa "La música en alumnos con necesidades educativas especiales". Consideramos una gran carencia formativa para los estudiantes que no se contemplen en los Planes de estudio del Grado conocimientos musicales básicos que incluyan formación musical como herramienta de inclusión y de atención a la diversidad y que esta formación quede relegada a cursar asignaturas optativas o realizar cursos y talleres de formación donde sólo se dan a conocer técnicas basadas en experiencia con la musicoterapia, visión bastante reducida del uso de la música.

Basándonos en diferentes estudios que recogen las investigaciones acerca del papel educativo de la música (Caprile, 2006; Mir y Ferrer, 2014) y en la diversidad de emociones, sentimientos y afectos que se experimentan al vivir la experiencia musical y que potencian todas las facetas del ser humano (Campbell, 1998; Leiva y Mates, 1998; Ramírez, 2006) quisimos conocer la opinión de los maestros sobre los alumnos que consideran que demandan una mayor atención educativa.

Los datos recogidos indicaron que, para los maestros, los alumnos en los que la música contribuye al desarrollo de diferentes capacidades son los que presentan necesidades educativas especiales, pero no consideran que en todos los alumnos la música favorezca una educación integral. Y así indicaron que:

- Los alumnos a los que las actividades musicales contribuyen a la adquisición de las habilidades comunicativas (donde el empleo de canciones favorece la expresión oral, la articulación, la fluidez y aspectos afectivos de la comunicación) y de interacción (fomenta la conciencia del logro y la valoración de los otros) son en aquellos que presentan trastornos de comunicación y lenguaje, capacidad intelectual límite y dificultades específicas de aprendizaje, porque mejora sus niveles de comunicación y de relación al facilitar la interacción con los otros y porque crea un ambiente lúdico que favorece el aprendizaje y la integración.

- A los alumnos a los que realizar actividades musicales les proporciona estímulos para enriquecer los procesos cognitivos (estimular la memoria, la atención y la creatividad) son los que presentan discapacidad auditiva y alteraciones de comunicación y del lenguaje, porque les aporta gran 
cantidad de estímulos, favorece su desarrollo integral y amplía el vocabulario, ayudándoles a superar dificultades de lenguaje.

- Los alumnos a los que las actividades musicales pueden proporcionar apoyo afectivo (donde ayuda a encauzar los sentimientos y emociones para reconocer los sentimientos propios y ajenos, desarrollando la confianza y la autoestima) son aquellos con alteraciones de la comunicación y del lenguaje, porque les ayuda a expresarse y a relacionarse con los demás. Bailar o cantar les ayuda a comunicarse y así acceder a un tipo de sensaciones que de lo contrario sería difícil poder experimentar.

Por lo tanto, aunque a priori parece que los maestros son conscientes de los beneficios de utilizar actividades musicales con todo el alumnado, sin embargo, no contribuyen a esta mejora porque en ellas no participan todos los alumnos y porque consideran que solo algunos (aquellos con necesidades específicas de apoyo educativo) son susceptibles de trabajarlas.

Ello pone de manifiesto una doble carencia formativa: por un lado, no conocen el concepto de inclusión ni sus implicaciones y, por lo tanto, desconocen las ventajas que el uso de la música proporciona a todos sus alumnos.

\section{. La importancia de la música en segundo ciclo de infantil}

Por último, quisimos conocer las valoraciones que los estudiantes y los maestros hacen sobre la importancia de la música en la educación. Ante las afirmaciones presentadas, referidas a estimular la creatividad y los sentidos o a aumentar las capacidades intelectuales o mejorar la comunicación, podemos afirmar que todos les conceden gran valor y no se destacan grandes diferencias, aunque los maestros valoran más, en general, todos los aspectos evaluados, destacando que la música combinada con el baile estimula los sentidos, el equilibrio y el desarrollo musical, la creatividad y la imaginación infantil.

Si la valoración de la música en la educación es tan alta, nos preguntamos ¿por qué no se programan más actividades musicales? ¿por qué no se realizan actividades musicales para todos los alumnos? La respuesta solo puede orientarse a que se hace un uso más 
funcional que curricular de la expresión musical en esta etapa. Así, en teoría los maestros conceden gran valor a la música en la educación, es insuficiente el tiempo que le dedican en su programación, además de no plantear actividades musicales para todos por necesitar la ayuda de un especialista. Todo ello pone de manifiesto sus grandes carencias formativas.

\section{CONCLUSIONES}

En base a todo lo expuesto y a modo de síntesis las principales conclusiones de la presente investigación son las siguientes:

1. La formación musical recibida por los estudiantes universitarios que cursan el Grado en Maestro en Educación Infantil en sus anteriores etapas educativas ha sido pobre y deficiente, con una formación totalmente teórica. Llegan a la Universidad con una formación insuficiente que no les permite adquirir las competencias necesarias para impartir la Expresión Musical en Segundo ciclo de Educación infantil.

2. La formación musical básica recibida por los estudiantes durante el Grado en Maestro en Educación Infantil, aunque mejora la adquisición de competencias y contenidos musicales relacionados con la educación vocal, educación rítmica y educación auditiva, es insuficiente para poder desarrollar los contenidos de la expresión musical en educación infantil, pues con 6 ECTS no se puede impartir una formación musical de calidad en contenidos y metodologías didácticas que se adecúen a la práctica real del aula de infantil.

3. La formación musical básica que se imparte en el Grado en Maestro en educación Infantil, debe formar a los estudiantes en contenidos musicales relacionados con la educación musical inclusiva, EMI (Sabatella Riccardi, 2008), es decir con el uso de la música en relación a la diversidad.

4. El número excesivo de estudiantes matriculados en la asignatura de Expresión Musical en los estudios del Grado en Maestro en Educación Infantil resulta excesivo para ofrecer una enseñanza musical de calidad.

5. Los maestros de los centros de educación infantil demandan una formación didáctico-musical para poder integrar las actividades musicales en su práctica diaria, ya 
que dependen de la ayuda de un Especialista en Educación Musical para impartir estos contenidos.

6. Los estudiantes del Grado y los maestros en educación infantil demandan una formación específica en EMI, para poder integrar la música en las prácticas educativas.

7. Los maestros opinan que el empleo de actividades musicales mejora de la respuesta educativa de todos los alumnos, afirmación que se contradice el uso que realizan de la música al no incluir a todos sus alumnos en la realización de estas actividades.

8. A juicio de los maestros, es necesario contar con un asesoramiento de un especialista en educación musical en la etapa de Educación infantil si se quiere formar musicalmente a los alumnos de segundo ciclo de esta etapa, pero a nuestro juicio, si abogamos en una mejora y profundización en la formación musical en los estudios del Grado en Maestro en Educación Infantil, el especialista solamente debería asumir tareas de asesoramiento.

9. Es necesario ampliar el número de sesiones semanales dedicadas a desarrollar los contenidos del currículo de expresión musical en las programaciones de los centros educativos de Educación Infantil

10. Aunque los maestros valoran la importancia y los beneficios de la música en la educación, no programan este tipo de actividades, en parte, por no estar formados para ello, relegando la música a un papel secundario.

11. Se necesita integrar la educación musical, de una vez por todas, en las aulas infantiles, orientando acciones destinadas a la formación permanente de los profesionales.

\section{PROPUESTAS DE MEJORA}

Después de analizar la formación musical de los estudiantes del Grado en Maestro en Educación Infantil, su actuación en las prácticas educativas y el uso de la expresión musical en el segundo ciclo de Educación Infantil, es hora de desarrollar nuestras propuestas en base a los resultados obtenidos.

Estas obedecen, por una parte, a las necesidades de formación expresadas por los estudiantes y por los maestros y, por otra, a la necesidad de revisar tanto los planes de estudios para ofertar una formación musical básica de calidad a los estudiantes del Grado 
de Maestro en Educación Infantil como los planes de formación permanente para los maestros de esta etapa.

Respecto a la formación inicial de los estudiantes del Grado en Maestro en Educación Infantil, nuestra investigación ha reflejado que existe una gran carencia de conocimientos musicales adquiridos en sus anteriores etapas educativas, lo que dificulta adquirir las competencias necesarias en los estudios del Grado para realizar una práctica profesional adecuada.

Cuando las anteriores Diplomaturas de Maestro dieron paso a los Grados, algunos estudios compararon la formación musical de nuestras universidades con la del resto de los países europeos, en un intento de dar unas directrices para abordar seriamente una formación musical de calidad para integrarse al Espacio Europeo de Educación Superior. Estas fueron publicadas en el "Informe de evaluación de la Enseñanza de las titulaciones de Maestros" realizado por varios profesores de la universidad del País Vasco (2003) y recogidos por López de la Calle (2008, p. 236) donde se recomendaba:

- un aumento de horas de formación musical en los nuevos planes de estudio

- una mayor coordinación e implicación del profesorado universitario para incrementar la calidad de la enseñanza

- una oferta de formación didáctico-musical y especializada y acordes con las competencias docentes de los especialistas de la etapa infantil y

- una mayor investigación seria y profunda en al área educativo musical que ayude a una orientación de los programas de didáctica musical acorde con el perfil de la titulación y con las investigaciones realizadas.

La realidad ha sido muy diferente. En los Grados, no sólo se ha reducido el número de créditos dedicados a la formación musical ${ }^{61}$ (en los estudios de Grado tiene una carga de 6 ECTS) y ha desaparecido cualquier tipo de formación en competencias de carácter didáctico-disciplinar ${ }^{62}$, sino que ha aumentado el número de estudiantes por curso ${ }^{63}$, dificultando realizar una formación de calidad tanto en la adquisición de destrezas

\footnotetext{
${ }^{61}$ En nuestra Universidad, en las antiguas Diplomaturas de Maestro en Educación Infantil se cursaban dos asignaturas de 4,5 créditos cada una "Desarrollo de la Expresión Musical y su didáctica I y II."

62 Desaparecido del enunciado de la asignatura, sino del programa de la asignatura.

${ }^{63}$ Este es el caso de la Facultad de Educación, donde la matrícula en esta asignatura supera los 88 estudiantes, pese a estar aprobado en su Plan de Estudios inicial 44 estudiantes por curso.
} 
musicales (tales como formación auditiva, vocal, corporal o instrumental), como en un trabajo didáctico encaminado a adquirir las competencias necesarias para impartir los contenidos musicales del currículum para la etapa de Educación infantil.

Así, en los planes de estudio de la Universidad de Salamanca no se dedica suficiente atención a la formación musical básica de los futuros maestros, responsables de impartir el currículo musical a los alumnos de segundo ciclo de Educación Infantil. La poca que se dedica impide realizar una formación vocal, rítmica y auditiva de calidad, limitándose a adquirir, en el mejor de los casos, un repertorio de canciones infantiles y unos recursos musicales básicos, insuficiente para dotar a los estudiantes de las competencias necesarias para integrar la música en su futura práctica profesional.

Por lo tanto, si queremos impartir una enseñanza de calidad, es necesario poner en marcha tres actuaciones. En primer lugar, formar adecuadamente a los estudiantes, ampliando el número de horas de formación musical en el Grado, con una atención más individualizada, donde se puedan adquirir los conocimientos en contenidos musicales, didáctico-disciplinar, metodologías musicales activas y recursos musicales para la mejora de la inclusión, necesarios para una correcta aplicación del currículo musical en el aula de infantil. En segundo lugar, ampliar la dedicación de asesoramiento por parte del especialista de educación musical a los maestros de la etapa de Educación Infantil, lo que contribuirá a una mejora del desarrollo del currículo de expresión musical en esta etapa. Y en tercero, poner en marcha una Mención en educación musical para la etapa de Educación Infantil. Con ello consideramos que se podría mejorar la calidad de la formación musical lo que repercutiría en una auténtica educación musical temprana en los alumnos de segundo ciclo de Educación Infantil.

Respecto a la primera actuación, ha quedado en evidencia que el aspecto más deficitario en formación musical en las etapas de enseñanza obligatoria es el relacionado con la formación vocal. Cuando los estudiantes continúan sus estudios musicales en el Grado, arrastran esta carencia formativa. Datos que concuerdan con las investigaciones de Ruiz Palomo, Palmero Cámara y Baños Martínez (2015). Cantar en la etapa infantil es una actividad que se realiza continuamente y el Maestro debe saber hacerlo adecuadamente. En este sentido, creemos que es necesario plantearse y contemplar la educación vocal como aspecto prioritario en la formación de nuestros estudiantes. 
El maestro que canta canciones no puede ser sustituidos por una grabación y si, además, las acompaña con algún instrumento, constituirá un estímulo para que los alumnos aprendan a cantar y a tocar. Recordemos que Willems (1987) incide en que cantar crea vínculos afectivos con todos los alumnos, lo que constituye un recurso de primer orden para la mejora de la inclusión.

En este sentido, una herramienta necesaria para ayudar a entonar adecuadamente el repertorio vocal es formarse en un instrumento tan sencillo como la flauta dulce, pues cumple con una doble finalidad, ya que al tocar un instrumento didáctico como este se facilita a los estudiantes y a los maestros la entonación en su práctica educativa y les ayuda a conceptualizar y a desarrollar los elementos del lenguaje musical, principalmente el ritmo y la melodía. En esta línea, Coromoto Capriles (2016) opina algo similar: "Incorporar el estudio del guitarró, o instrumentos similares de acceso fácil y económico puede convertirse en una estrategia atractiva para lograr los objetivos más básicos e imprescindibles en la formación musical del maestro de infantil y primaria" ( $p, 267)$.

El "Temario Abierto sobre Educación Inclusiva”, publicado en 2004 por la UNESCO, apunta que "Los curricula más inclusivos exigen más de los Maestros, por lo que necesitan apoyo para implementarlos con efectividad" $(p, 107)$. Y este apoyo pasa por una formación también en recursos donde, como en el caso de la música, se puedan desarrollar actividades colectivas donde participan todos: cantando, bailando o tocando instrumentos.

Por todo ello, en base a las actuaciones propuestas, podemos resumir nuestras recomendaciones en:

- Crear la Mención de Educación Musical para el Grado en Maestro en Educación Infantil.

- Mayor carga en créditos, horas y asignaturas de formación musical en el Grado en Maestro en educación Infantil.

- Grupos con un número de estudiantes más reducido para una mejor formación especializada en los aspectos auditivo, vocal, corporal e instrumental.

- Programas de las asignaturas con formación en contenidos, metodologías y recursos didácticos que se puedan poner en práctica en el aula de infantil, con mayor carga de horas prácticas que teóricas sin olvidar el principio de "actividad," donde la formación de los contenidos disciplinares se realice desde el uso de la voz, el movimiento y la práctica instrumental. 
- Formación musical inclusiva que facilite los recursos necesarios para atender a la diversidad del alumnado de Educación Infantil que promueven la socialización, la comunicación y la inclusión de todo el alumnado.

- Dar prioridad a los contenidos en formación vocal en los programas de las asignaturas del Grado y a la enseñanza de la flauta dulce o de otro instrumento sencillo como recurso inmejorable para reforzar esa educación vocal.

Respecto a la formación permanente para los maestros de educación infantil, ha quedado patente el interés y la necesidad que manifiestan de seguir formándose musicalmente, ya que la mayoría no aplica los contenidos del currículum de música por carecer de esta formación.

Además, como hemos visto en nuestro estudio, no se realiza un uso ni adecuado de la música en la práctica educativa en la etapa infantil, ni suficiente, pues la mayoría de los maestros, a pesar de realizar y estar interesados en los cursos de formación musical, siguen demandando la ayuda de un especialista para impartir estos contenidos porque no se consideran competentes para ello, lo que hace que la expresión musical, no se integre debidamente en las programaciones. Pero no todos los centros educativos de la comunidad de Castilla y León que han participado en este estudio cuentan con un especialista en educación musical, situación que no ocurre en otras comunidades autónomas, en el País Vasco, se ha incorporado desde hace años la educación musical en segundo ciclo de educación infantil en la mayoría de los centros, impartiéndose una hora semanal por un especialista en Educación musical (Díaz, 2004).

Así, las propuestas que realizamos recogen en parte los aspectos que demandan los maestros de esta etapa y que quedarían resumidos en:

- Asesoramiento de un especialista en educación musical para desarrollar adecuadamente el currículo de expresión musical en el segundo ciclo de Educación Infantil.

- Incrementar en todos los centros de educación infantil las horas semanales de expresión musical (al menos a tres sesiones semanales de cuarenta minutos).

- Creación de Talleres o cursos de formación permanente en:

- Formación musical específica para educación infantil y en EMI. 
- Recursos y metodologías musicales activas para aplicar en el aula de educación infantil.

- Educación vocal que aporte un amplio repertorio de canciones infantiles, con una metodología que repercuta en la manera de trabajar correctamente la educación vocal.

- Educación rítmico-corporal que aporte recursos para trabajar en el aula de infantil.

- Técnicas musicales básicas para poder acompañar y entonar las actividades musicales.

\section{LIMITACIONES DE NUESTRO ESTUDIO}

Para terminar, es necesario considerar las limitaciones de nuestra investigación y los nuevos enfoques surgidos desde los resultados obtenidos.

En primer lugar, es necesario mencionar algunos elementos relativos a la metodología. Así, respecto a las características de la muestra de estudio, será conveniente en futuros estudios, ampliar el número de participantes de ambos colectivos, tanto de los estudiantes como de los maestros tutores. En relación con ello, también resultaría interesante ampliar el estudio a otras universidades con el fin de poder conocer si las limitaciones encontradas en este trabajo en relación con la formación inicial y permanente en música de los maestros y futuros maestros de educación infantil, persisten en otras provincias, comunidades y en otros planes de estudio. Lo anterior nos permitirá obtener un mayor volumen de información con la que poder establecer conclusiones más generalizables en cuanto al dominio de competencias y habilidades para la enseñanza de la música en la etapa de educación infantil.

En segundo lugar, se deberán tener en cuenta las limitaciones de los instrumentos de evaluación utilizados. Será necesario realizar una revisión de la estructura y los ítems que constituyen los cuestionarios empleados ya que, a lo largo del desarrollo del estudio, nos hemos dado cuenta de que no se ha recogido información que podría haber 
contribuido a explicar los resultados encontrados. De este modo, en el caso de los cuestionarios dirigidos a los estudiantes, habrá que reformular y ampliar los contenidos del segundo Cuestionario sobre conocimientos /habilidades y destrezas musicales sobre las competencias adquiridas en el Grado. Además, sería conveniente aplicar el cuestionario antes y después de que los estudiantes hayan cursado las asignaturas de "Expresión musical en la educación infantil" y "Practicum I", lo que permitirá analizar el impacto de ambas asignaturas en la mejora de la formación de los estudiantes en las variables estudiadas y valorar si ese período de aprendizaje realmente se ha traducido en mejoras en cuanto a la adquisición de las competencias estudiadas.

En cuanto a la revisión de la estructura del cuestionario dirigido a los estudiantes, será conveniente revisar y eliminar aquellos ítems que, una vez analizados los resultados obtenidos no han proporcionado información relevante a nuestro estudio, tales como el tipo de centros donde estudiaron, la Comunidad Autónoma al que pertenecía, el año de finalización de los estudios, etc.

De todo lo presentado, se deduce que, si bien hay muchas carencias formativas en educación musical, también existe una gran motivación por parte de todos los implicados en superarlas. Ello abre líneas interesantes para futuras investigaciones y, sobre todo, para profundizar en la mejora de la formación de los maestros lo que repercutirá a su vez en una mejora en la formación que reciban los alumnos de segundo ciclo de Educación Infantil. 
REFERENCIAS BIBLIOGRÁFICAS 
Acedo, C. (2011). Preparing teachers for inclusive education. Prospects, 41, 301-302.

Ainscow, M. (2001). Desarrollo de escuelas inclusivas. Madrid: Narcea.

Akoschky, J., Alsina, P., Díaz, M. y Girádez, A. (2008). La música en la educación infantil. Barcelona: Graó.

Álamo Caballero, L. (2013). Música y Lomce. Recuperado el 22 abril de 2016 de http://www.sineris.es/musica_y_lomce_punto_final.html

Alsina, P. (1997). El área de educación musical. Propuestas para aplicar en el aula. Barcelona: Graó.

Alsina, P. (2007). Música. Investigación, innovación y buenas prácticas. Barcelona: Graó.

Alvin, J. (1993). Música para el niño disminuido. Buenos Aires: Ricordi.

ANECA (2005). Libro Blanco Título de Grado en Magisterio (vol.1). Madrid: Aneca.

Angulo, M. (1999). La educación musical: nuevas alternativas. Música y Educación, 37, 69-70.

Arnaiz, P. (2004). Hacia una educación eficaz para todos: la escuela inclusiva. Educar para el 2000. Revista de Educación para el profesorado, 15, 15-19.

Arnaiz, P., y Guirao, J.M. (2015). La autoevaluación de centros en España para la atención a la diversidad desde una perspectiva inclusiva: ACADI, Revista Electrónica Interuniversitaria de Formación del profesorado, 18 (1), 45-101. DOI:

http://dx.doi.org/10.6018/reifop.18.1.214341

Arriaga, C., Madariaga, J.M., Moretin, M. (2012). La música como medio de expresión en un trabajo multidisciplinar en el grado de maestro de educación infantil. Eufonía. Didáctica de la Música, 55, 26-39.

Arús Leita, E. y Muñoz, J.R (2017). Música y emociones. Eufonía. Didáctica de la música, $71,17-21$.

Ávila Fernández, A. y Holgado Barroso, J.A. (Coords.) (2008) Formación del magisterio en España. La legislación normalista como instrumento de poder y control (1834-2007). Madrid: Ministerio de Educación, Política Social y Deporte.

Bachmann, M-L. (1998). La rítmica de Jaques-dalcroze. Una educación por la música y para la música. Madrid: Pirámide.

Balsera, F.J., Nadal, I. y Fernández Amat, C. (2017). Pedagogía musical y música. Eufonía. Didáctica de la música, 71, 22-29.

Barton, L. (1998). Discapacidad y sociedad. Madrid: Morata. 
Benenzon, R. (1985) Manual de Musicoterapia Barcelona: Paidós.

Bermell, Mạ. Á. y Alonso, V. (2012). La educación musical y la sociedad del futuro. Música y Educación, 92, 50-59.

Bernard M. (2013) Necesidades de información de los usuarios de servicios sanitarios de atención primaria de Salamanca. (Tesis inédita de doctorado). Universidad de Salamanca, Salamanca.

Bernal, J. (1999). La formación musical del maestro especialista en la educación infantil. Eufonía Didáctica de la Música, 15, 23-32.

Bernal, J. y Calvo, M.L. (2000) Didáctica de la música: la expresión musical en la educación infantil. Madrid: Aljibe.

Blanco, R. (2008). Construyendo las bases de la inclusión y de la calidad de la educación en la primera infancia. Revista de educación, 347, 33-54.

Blasco Magraner, J. y Bernabé, G (2016). La musicoterapia como herramienta de integración en el ámbito escolar. Eufonía. Didáctica de la música, 67,35-38.

Boer, A., Pijl, S.J. y Minnaert, A.E. (2011). Regular primary schoolteachers' attitudes towards inclusive education: A review of the literature. International Journal of Inclusive Education, 15 (3), 331-353.

Booth, T. y Ainscow, M. (2002). Index for inclusion. Developing leaning and participation in schools (2ªed.). Manchester: CSIE [Traducción al castellano de A.L. López, D. Durán, G. Echeita, C. Giné, E. Miquel y M. Sandoval (2002). Guía para la evaluación y mejora de la educación inclusiva. Madrid: Consorcio Universitario para la Educación Inclusiva].

Booth, T. y Ainscow, M. (2011). Index for Inclusion. Developing learning and participation in schools (3aed.). Manchester: CSIE [Traducción al castellano de G. Echeita, Y. Muñoz, C. Simón y M. Sandoval (2015). Guía para la educación inclusiva. Desarrollando el aprendizaje y la participación en los centros escolares. Madrid: Fuhem y OEI].

Booth, T., Ainscow, M. y Kingston, D. (2006). Index for Inclusion: developing play, learning and participation in early years and childcare. Bristol, UK: CSIE [Taducción y adaptación al castellano de F. González-Gil, M. Gómez-Vela y C. Jenaro (2007). Index para la Inclusión: Desarrollo del juego, el aprendizaje y la participación en Educación Infantil. Salamanca: Universidad de Salamanca].

Booth, T., Simón, C., Sandoval, M., Echeita, G y Muñoz, Y. (2015). Guía para la Educación Inclusiva. Promoviendo el Aprendizaje y la Participación en las Escuelas: Nueva edición Revisada y Ampliada. Revista Iberoamericana sobre Calidad, Eficacia y Cambio en Educación, 13 (3),5-19.

Cabedo-Mas, A. (2016). Educar en valores a través de la música. Eufonía. Didáctica de la 
música, 69, 7-12.

Cabreizo, J. y Rubio, M. J. (2007) Atención a la diversidad. Teoría y práctica. Madrid: Pearson.

Calafell López, M.E. (2017). La música en infantil a partir de Pistoia.Eufonía.Didáctica de la Música, 72, 25-31.

Campbell, P.S. (1998). Songs in their heads. Music and its meaning in children's Lives. New York: Oxford University Press.

Campbell, P.S. (1999). En búsqueda de la cultura y el significado musical en la vida infantil. Recuperado de http://www.ejournal.unam.mx/cem/vol01-01/CEM01105.pdf

Campbell, P.S. (2004).Teaching music globally: Experiencing music, expressing culture. New York: Oxford University Press.

Capriles, I. (2016). El "guitarró" en el aula de educación infantil y primaria: una herramienta para la inclusión a través de la música. (Tesis inédita de doctorado). Universidad de las Islas Baleares, Islas Baleares.

Carabeta, M.C (2011). Educación musical y diversidad. Eufonía. Didáctica de la Música, $53,15-24$.

Carrillo, C. (2015). Competencias profesionales del profesorado de música: de los referentes teóricos a la concreción de una propuesta. Revista internacional de educación Musical, 3, 11-21.

Carrillo Aguilera, C. y Vilar Monmany, M. (2016). Percepciones del profesorado de música sobre competencias profesionales necesarias para la práctica. Opción, Año 32, No. Especial 7,358-382.

Carrillo Aguilera, C. y Vilar Monmany, M. (2017). Las competencias profesionales del profesorado de música opiniones de una muestra de docentes. Cultura y educación, 24, 319-335. Recuperado de http://dx.doi.org/10.1174/113564012802845668

Casanova, M.A. (2011). Educación inclusiva: un modelo de futuro. Madrid: Wolters Kluwer.

Cartón, C. (1994). Educación Musical "Médtodo Kodály". Valladolid: Ediciones Castilla.

Coello, J.R. y Plata, J. (2000). Educación musical y bandas de música. Granada: Grupo Editorial Universitario.

Comisión Europea (2010). Estrategia Europea sobre Discapacidad 2010-20: un compromiso renovado para una Europa sin barreras. Bruselas: COM 2010, 636 final. Recuperado 
https://www.msssi.gob.es/ssi/discapacidad/docs/estrategia_europea_discapacidad_20 10_2020.pdf

Comisión Europea (2014). La estructura de los sistemas educativos europeos 2014/15: Diagramas. Bruselas: Comisión Europea/ Portal Eurydice. Recuperado de http://eacea.ec.europa.eu/Education/eurydice/documents/facts_and_figures/educatio $\underline{\text { n_ES.pff }}$

Conejo Rodriguez, P.A. (2012). El valor formativo de la música para la educación en valores. Dedica. Revista de educação e humanidades, 2 (2), 263-278.

Constitución Española de $1978 . \quad$ Recuperado de https://www.boe.es/legislacion/documentos/ConstitucionCASTELLANO.pdf

Contreras Molina, A. (2015). La formación del profesorado en ejercicio para atender a la diversidad. (Trabajo de Fin de Máster no publicado). Universidad de Jaén, Jaén. Recuperado de http://tauja.ujaen.es/handle/10953.1/2259

Council of the European Union (2010). Council conclusions on the social dimension of education and training, 3013 Meeting of the Education, Youth and Culture Council Meeting.Brussels: Council of the EU. Recuperado de htpp://www.europeanagency.org/news-files/Council-Conclusions-May-2010-Social-Dimension.pdf/wiew

Cuadrado Méndez, F.J. (2016). Enseñar a través de la música Formación docente en el grado de primaria. Eufonía. Didáctica de la música, 69, 39-45.

Decreto 122/2007, de 27 de diciembre, por el que se establece el currículo del segundo ciclo de la Educación Infantil en la Comunidad de Castilla y León, BOCyL núm 1 de 2 de enero de 2007, 677-773.

Delgado López-Cortázar, J. (1992). La reforma de las enseñanzas universitarias en España: unas nuevas directrices para el Título de Diplomado en Biblioteconomía y Documentación. Boletín de la Asociación Andaluza de Bibliotecarios, 8(28), 5-22.

Díaz, M. (2004). La educación musical en la etapa 0-6 años. Léeme, Lista Europea de Música en la Educación, 14, 1-6.

Díaz, M. (2005): La educación musical en la escuela y el espacio europeo de educación superior. Revista Interuniversitaria de Formación del Profesorado, 19, 23-27.

Díaz, M. y Giráldez, A. (2007). Aportaciones teóricas y metodológicas a la educación musical. Barcelona: Graó.

Díaz, M. y Riaño, M.E. (2010). Fundamentos musicales y didácticos en Educación Infantil. Santander: Universidad de Cantabria. 
DuK, C. y Murillo, J. (2016). La inclusión como dilema. Revista latinoamericana de educación Inclusiva, 10 (1), 11.14.

Echeita, G. y Verdugo, M. A. (Eds.). (2004). La Declaración de Salamanca sobre Necesidades Educativas Especiales diez años después. Valoración y prospectiva. Salamanca: Publicaciones del INICO.

Echeita, G., Verdugo, M.A., Sandoval, M., Simón, C., López, M. González-Gil, F. y Calvo, I. (2008). La opinión de FEAPS sobre el proceso de inclusión educativa. Siglo Cero, 39 (4), 26-50.

Echeita, G. y Ainscow, M. (2011). La educación inclusiva como derecho: marco de referencia y pautas de acción para el desarrollo de una revolución pendiente. Tejuelo: Revista de Didáctica de la Lengua y la Literatura 12, 26-46.

Echeita, G. (2013). Inclusión y exclusión educativa. De nuevo "voz y quebranto". Revista Iberoamericana sobre Calidad, Eficacia y Cambio en Educación,11(2), 99-118.

Elliott, D. J. (1995). Music Matters: A New Philosophy of Music Educacion. New York: Oxford University Press.

Embrid Irujo, A. (2000). La enseñanza en España en el umbral del siglo XXI. Madrid: Tecnos.

Escolano, A. (1982). Las Escuelas Normales. Siglo y medio de perspectiva histórica. Revista de Educación, 269, 57-77.

Espinosa, J. y Valdebenito, V. (2016). Explorar las Concepciones de los Docentes respecto al Proceso de Evaluación Inclusiva para la Mejora Institucional. Revista Latinoamericana de Educación Inclusiva, 10 (1), 195-213.

Fernández González, G. (Coord.) (1993). La evolución de la Educación Especial. Asturias: Ediurno.

Fernández, A. y Holgado Barroso, J. A. (2008). Formación del magisterio en España. La legislación normalista como instrumento de poder y control (1834-2007). Madrid: MEC

Fernández-Carrión, M. (2011). Proyectos musicales inclusivos. Tendencias pedagógicas, $17,74-82$.

Fielding, M. (2011). La voz del alumnado y la inclusión educativa: una aproximación democrática radical para el aprendizaje intergeneracional. Revista Interuniversitaria de Formación del Profesorado, 70, (1), 31-61.

Fuentes, F. (2017). Puentes en educación. Hacia una didáctica para el S XXI. Eufonía. Didáctica de la música 70, 7-12. 
Frega, A., Fuertes C., Martínez, J.M., Téllez, E., Busquets, F., Lorenzo, T. y Amusategui, C. (1996). Música y nuevas tecnologías. Eufonía. Didáctica de la Música, 12, (23-29).

Frega, A. (1996). Música para maestros. Barcelona: Graó.

García Herrera, A. (1994). La enseñanza de la música en la Escuela Normal de maestros de Salamanca desde 1899 hasta 1970. Aula. Revista de Enseñanza e Investigación Educativa, 6, 207-227.

García Herrera, A. (1997) La educación de la expresividad musical en el niño de educación infantil. Aula. Revista de Enseñanza e Investigación Educativa, 7, 102-105.

Gardner, H. (1993). Multiple intelligences. The theory in practice. Nueva York: Basic Books.

Gardner, H. (2000). La educación de la mente y el conocimiento de las disciplinas. Barcelona: Paidós.

Gardner, H., Feldman, D.H. y Krechevsky, M. (2000). Proyecto Spectrum. Madrid: Morata.

Gimeno Romero J.V. (2014). La audición musical en la educación secundaria obligatoria en la provincia de Valencia: análisis de su tratamiento curricular en los libros de texto. (Tesis inédita de doctorado). Universidad de Valencia, Valencia. Recuperado de http://roderic.uv.es/handle/10550/42774

Giráldez, A. (2010a). Didáctica de la música. Barcelona: Graó.

Giráldez, A. (2010b). Música. Complementos de formación disciplinar. Barcelona: Graó.

Giráldez, A (2012). Motivación, práctica y estrategia para el autoaprendizaje musical. Eufonía Didáctica de la Música, 54,56-61.

Gómez Espinosa, J. (2015). Didáctica de la música. Manual para maestros de Infantil y primaria. Logroño: Unir.

Gómez Rodríguez de Castro, F. (1986). El currículo de la formación del maestro. España: Ediciones Universidad de Salamanca.

González-Gil, F., Gómez-Vela, M. y Jenaro, C. (2009). Traducción y Adaptación al castellano del Index para la Inclusión. Desarrollo del juego, el aprendizaje y la participación en Educación Infantil. En Verdugo, M. A., Nieto, T., Jordán de Urríes, B. y Crespo, M. (Coords.), Mejorando resultados personales para una vida de calidad (p. 577-590). Salamanca: Amarú.

González-Gil, F. (2011). Inclusión y atención al alumnado con necesidades educativas 
especiales en España. Participación Educativa, 18, 60-78.

González Gil, F., Martín Pastor, E., Flores, N., Jenaro, C., Poy Castro, R. y Gómez-Vela, M. (2013). Inclusión y convivencia escolar: análisis de la formación del profesorado. European Journal of Investigation in Health, Psychology and Education, 2 (3), 125-135.

González Sannamed, M. y Fuentes Abeledo, J. (2011). El Practicum en el aprendizaje de la profesión docente. Revista de Educación, 354 (1), 47-70.

Haerdgreaves, D.J. (1998). Música y desarrollo psicológico. Madrid: Morata.

Hargreaves, A. (2001). Aprender a cambiar. La enseñanza más allá de las materias y niveles. Octaedro: Barcelona.

Haya, I. y Calvo, A. (2010). Mejorar la escuela "dando voz" al alumnado en la etapa de Educación Infantil. Una investigación en curso. En Susinos, T. (Coord.), La Educación Inclusiva hoy: escenarios y protagonista (pp.1026-1041). Santander: Universidad de Cantabria.

Hemsy de Gainza,V. (1964). La iniciación musical del niño. Buenos Aires: Ricordi.

Hemsy de Gainza, V. (1977). Fundamentos, materiales y técnicas de la educación musical. Buenos Aires: Ricordi.

Hemsy de Gainza,V.(1999). La transformación de la educación musical a las puertas del siglo XXI. Buenos Aires: Editorial Guadalupe.

Hemsy de Gainza (2004). La educación musical en el siglo XX. Revista Musical Chilena, 201, 74-81.

Hindemith, P. (1971). Adiestramiento elemental para músicos. Buenos Aires: Ricordi.

Holgado Barroso, J.A. (2014). Los grados de magisterio y el modelo competencial. Un estudio crítico desde la educación personalizada. Revista digital de investigación educativa, 9, 80-105.

Ibarretxe, G. (2010), En Díaz, M. Fundamentos psicopedagógicos. En Díaz, M. y Riaño, M.E. (Coords.) Fundamentos musicales y didácticos en Educación Infantil. Santander: Universidad de Cantabria.

Ivanova Lotova, A. (2009). La educación musical en la educación infantil de España y Bulgaria: análisis comparado entre centros de Bulgaria y centros de la Comunidad Autónoma de Madrid. (Tesis inédita de doctorado). Universidad Complutense de Madrid, Madrid. Recuperado de http://eprints.ucm.es/9661/1/T31040.pdf 
Jiménez, L., Ramos, F. J. y Ávila, M. (2012). Las Universidades Españolas y EEES: Un Estudio Sobre los Títulos de Grado de Maestro en Educación Primaria. Formación Universitaria, 5 (1) 33-44.

Labajos, S., y Arroyo, M. J. (2013). Los Planes de Acogida en la Comunidad de Castilla y León: evaluación, análisis y propuestas de mejora desde la educación inclusiva. Revista de educación inclusiva, 6 (2), 1-20.

Lacarcel Moreno, J. (1995). Musicoterapia en educación especial. Murcia: Universidad de Murcia.

Lata Doporto, S. y Castro Rodriguez, M. (2015). El Aprendizaje Cooperativo, un camino hacia la inclusión cooperativa.Revista Complutense de Educación, 27 (3) 1085-1101.

Leiva, M.A. y Mates, E. (1998). Importancia de la educación musical en la formación integral del hombre. Música y educación, 33, 27-40.

Ley de 17 de julio, de 15 de julio sobre Educación Primaria, BOE, núm. 199, de 18 de Julio de 1945, 385 a 416.

Ley de Instrucción Pública de 9 de septiembre de 1857. Recuperado de http://www.filosofia.org/mfa/e1857ley.htm

Ley 14/1970, de 4 de agosto, General de Educación y Financiamiento de la Reforma Educativa, (LGE), BOE núm. 187 de 6 de agosto de 1970, 12525 a 12546.

Ley 13/1982, de 7 de abril, de Integración Social de los Minusválidos (LISMI), BOE núm. 103, de 30 de abril de 1982, 2314 a 2325.

Ley Orgánica 11/1983, de 25 de agosto, de Reforma Universitaria (LRU), BOE núm. 209, de 1 de septiembre de 1983, 24034 a 24042.

Ley Orgánica 1/1990, de 3 de octubre, de Ordenación General del Sistema Educativo (LOGSE), BOE núm. 238, de 4 de octubre de 1990, 28927 a 28942.

Ley Orgánica 6/2001, de 21 de diciembre, de Universidades (LOU), BOE núm.307, de 24 de diciembre de 2001, 49400 a 49425.

Ley Orgánica 2/2006, de 3 de mayo, de Educación (LOE), BOE núm. 106, de 4 de mayo de 2006, 17158-17207.

Ley Orgánica 8/2013, de 9 de diciembre, para la mejora de la calidad educativa (LOMCE), BOE núm. 295, de 10 de diciembre de 2013, 97858 a 97921.

Mairet, S. y Malvicini de Benini, K. (2012). Didáctica de la música en el nivel inicial. Buenos Aires: Bonum. 
Malbrán, S. S. (2006). Investigación musical cuantitativa: un recorrido desde la práctica. En Díaz, M. (Coord.), Introducción a la investigación en educación musical (pp.59-61). Madrid: Enclave Creativa.

Martenot, M. (1979). Método Martenot. Solfeo. Formación y desarrollo musical. Guía didáctica del maestro. Buenos Aires: Ricordi.

Martín, D. (2010). La banda sonora en las producciones audiovisuales infantiles y su aplicación en educación infantil, primaria y secundaria: una propuesta de investigaciónacción. (Tesis inédita de doctorado ). Universidad de Granada, Granada. Recuperado de http://www.tesisenred.net/handle/10803/17279

Martín, J. (2014). Prácticas de clase con tic en el segundo ciclo de educación infantil. Estudio de casos. (Tesis inédita de doctorado). Universidad de Salamanca, Salamanca.

Martín-Pastor, E. (2012). Inclusión del alumnado inmigrante: evaluación de su comprensión lectora. (Tesis inédita de doctorado). Universidad de Salamanca, Salamanca.

Martos Sánchez, E. (2012). La normativa legal sobre educación musical en la España Contemporánea. Espiral. Cuadernos del profesorado, 6 (12), 43-50.

Meza García, C. (2010). Cultura escolar inclusiva en educación infantil: percepciones de profesionales y padres. (Tesis inédita de doctorado) Universidad de Salamanca, Salamanca. Recuperado de https://gredos.usal.es/jspui/bitstream/10366/76530/1/DPETP_Meza_Garcia_CL_Cultur a_escolar.pdf

Mir, M.L. y Ferrer, M. (2014). Aproximación a la situación actual de la formación del profesorado de educación infantil. Revista Electrónica Interuniversitaria de Formación del Profesorado, 17(2),235-255. DOI: http://dx.doi.org/10.6018/reifop.17.2. 181441

Monardes, C. (2011). Calidad de Vida de adolescentes inmigrantes extranjeros que cursan Educación Secundaria Obligatoria en Salamanca. (Tesis inédita de doctorado). Universidad de Salamanca, Salamanca.

Montoya, J.C. (2010). Música y medios audiovisuales. Planteamientos didácticos en el marco de la educación musical. (Tesis inédita de doctorado). Universidad de Salamanca, Salamanca.

Moreno González, A. (2011). Las nuevas competencias para el profesor el siglo XXI. CEE Participación Educativa, 16, 8-30.

Muntaner, J., Roselló, R. y De la Iglesia, B. (2016). Buenas prácticas en educación inclusiva. Educación Siglo XXI, 34 (1), 31-50. 
Mursell, J. L. (1943). Music in American Schools. Nueva York: Silver Burdett Company.

Mursell, J. L. (1948). The Psychology of Music. Nueva York: W. W. Norton and Company Inc.

Orden de 1 de junio, por la que se fija el Plan de Estudios en las Escuelas Normales, BOE núm 136 de 8 de junio de 1967, 7956 -7965.

Orden de 27 de Julio, por la que se aprueban las orientaciones pedagógicas para la Educación Preescolar, BOE núm. 186, de 4 de agosto de 1973, 15899-15906.

Orden $\mathrm{ECl} / 3854 / 2007$, de 27 de diciembre, por la que se establecen los requisitos para la verificación de los títulos universitarios oficiales que habiliten para el ejercicio de la profesión de Maestro en Educación Infantil, BOE núm. 312, de 29 de diciembre de 2007, 53735-53738.

Orden EDU/571/2005, de 26 de abril, por la que se crea fichero automatizado de datos de carácter personal denominado "Datos relativos al alumnado con Necesidades Educativas Específicas» de la Consejería de Educación. BOCYL núm. 86 de 6 de mayo de 2005, 7984-7985.

Orden EDU/721/2008, de 5 de mayo, por la que se regula la implantación, el desarrollo y la evaluación del segundo ciclo de la educación infantil en la Comunidad de Castilla y León, BOCYL núm. 89, de 12 de mayo de 2008, 16431-16435.

Orden EDU/1152/2010, de 3 de agosto, por la que se regula la respuesta educativa al alumnado con necesidad específica de apoyo educativo escolarizado en el segundo ciclo de Educación Infantil, Educación Primaria, Educación Secundaria Obligatoria, Bachillerato y Enseñanzas de Educación Especial, en los centros docentes de la Comunidad de Castilla y León, BOCYL núm. 156 de 13 de agosto de 2010, 3456-35476.

Orden EDU/641/2012, de 25 de Julio de 2012, por la que se regula la realización de las prácticas de las asignaturas del practicum de las enseñanzas universitarias de Grado en Educación Infantil y Grado en Educación Primaria en centros docentes sostenidos con fondos públicos de la Comunidad de Castilla y León, BOCYL núm. 146, de 31 de Julio de 2012, 534-564.

Orden EDU/363/2015, de 4 de mayo por el que se establece el currículum del bachillerato en la comunidad de Castilla y León. BOCYL. Núm 86, de 10 de mayo de 2015, 32481-32493.

Organización de las Naciones Unidas. (2008). Declaración Universal de los Derechos Humanos. United Nations. Recuperado de http://www.temoa.info/es/node/19618

Oriol, N. (2001). Estética y creatividad en la educación ante el nuevo milenio en la Educación Artística clave para el desarrollo de la creatividad. Aulas de verano, 9, 23-25. 
Oriol, N. (2002). La enseñanza del folklore en los colegios de la Comunidad de Madrid. Eufonía. Didáctica de la música, 25, 67-88.

Oriol N. (2004). Metodología cuantitativa y cualitativa en la investigación sobre la formación inicial del profesorado de educación musical para primaria. Aplicación a la formación instrumental. Revista Electrónica Complutense de Investigación en Educación Musical, 1, 3-6.

Oriol, N. (2005). La música en las enseñanzas de régimen general en España y su evolución en el siglo XX y comienzos del XXI. LEEME, 16. Recuperado de http://musica.rediris.es/leeme/revista/oriol2/pdf.

Oriol, N., Díaz, M. y Giráldez., A. (2007). Aportaciones teóricas y metodológicas a la educación musical. Barcelona: Graó.

Oriol N., Parra J.M. (1979). La expresión musical en la educación básica. Madrid: Alpuerto.

Pantano, Liliana (2003). Clasificación Internacional del Funcionamiento, de la Discapacidad y de la Salud (CIF): la versión en lengua española. La trastienda de la CIF. Del modelo cultural y social subyacente. Revista Siglo Cero, 205.

Pascual Mejía, P. (2006). Didáctica de la música para educación infantil. Madrid: Pearson Educación.

Pérez, A. (2004). Educar para humanizar. Madrid: Narcea

Pérez Prieto, M. (2001). La organización de la educación musical en España desde 1970: estudio a partir de los textos legales de ámbito estatal. Revista de Pedagogía de la Universidad de Salamanca, 13, 191-214.

Pliego, G. (2012). La filosofía praxial en la formación Universitaria del Profesorado de Educación Musical. (Tesis inédita de doctorado). Universidad de Salamanca, Salamanca.

Ramos, J., Guevara, M. A., Martínez, A., Arce, C., Del Rio, Y., Amescua, C., y CorsiCabrera, M. (1996). Evaluación de los estados afectivos provocados por la música. Revista Mexicana Psicología, 13(2), 131-145.

Real Decreto 69/1981, de 9 de enero, de ordenación de la Educación General Básica y fijación de las enseñanzas mínimas para el Ciclo Inicial, BOE núm. 15, de 17 de enero de 1981, 1096 - 1098.

Real Decreto 710/1982, de 12 de febrero, por el que se fijan las enseñanzas mínimas para el ciclo medio de la Educación General Básica.BOE núm. 106, de 4 de mayo de 1982, $11305-11305$. 
Real Decreto 334/1985, de 6 de marzo, de ordenación de la educación Especial, BOE núm. 65, de 16 de marzo de 1985, 6917 - 6920.

Real Decreto 1497/1987, de 27 de noviembre, por el que se establecen las directrices generales comunes de los planes de estudio de los títulos de carácter oficial y validez en todo el territorio nacional, BOE, núm. 298, de 14 de diciembre de 1987, 36639-36643.

Real Decreto 1440/1991, de 30 de agosto, por el que se establece el título universitario, oficial de Maestro, en sus diversas especialidades, BOE núm. 244, de 11 de octubre de 1991, 33003-33018.

Real Decreto 1457/1991, de 27 de septiembre, por el que se crean Centros y se autorizan enseñanzas en diversas Universidades, BOE núm. 24, de 12 de octubre de 1991, $33128-33129$.

Real Decreto 696/1995, de 28 de abril, de ordenación de la educación de los alumnos con necesidades educativas especiales, BOE núm. 131, de 2 de junio de 1995, 1617916185.

Real Decreto 55/ 2005 de 21 de enero, por el que se establece la estructura de las enseñanzas universitarias y se regulan los estudios universitarios oficiales de Grado, BOE núm. 21, de 25 de enero de 2005, 2842- 2846.

Real Decreto 1630/2006, de 29 de diciembre, por el que se establecen las enseñanzas mínimas del segundo ciclo de Educación infantil, BOE núm. 4, de 4 de enero de 2007, $474-482$.

Real Decreto 1393/2007, de 29 de octubre, por el que se establece la ordenación de las enseñanzas universitarias oficiales, BOE núm. 260, de 30 de octubre de 2007, 4403744048.

Real Decreto 1394/2007, de 29 de octubre, por el que se establece el título de Técnico Superior en Educación infantil y se fijan sus enseñanzas mínimas, BOE núm. 282, de 24 de noviembre de 2007, 48140-48177.

Real Decreto 1594/2011, de 4 de noviembre, por el que se establecen las especialidades docentes del Cuerpo de Maestros que desempeñen sus funciones en las etapas de Educación Infantil y de Educación Primaria reguladas en la Ley Orgánica 2/2006, de 3 de mayo, de Educación, BOE núm. 270, de 9 de noviembre de 2011, 116652 a 116657.

Real Decreto 1618/2011, de 14 de noviembre, sobre reconocimiento de estudios en el ámbito de la Educación Superior, BOE núm. 302, de 16 de diciembre de 2011, 23452983.

Real Decreto 476/2013, de 21 de junio, por el que se regulan las condiciones de cualificación y formación que deben poseer los maestros de los centros privados de 
Educación Infantil y de Educación Primaria, BOE núm. 167, de 13 de junio de 2013, 44352-44390.

Real Decreto 126/2014, de 28 de febrero, por el que se establece el currículo básico de la Educación Primaria, BOE núm. 52, de 1 de marzo de 2014, 19349 - 19420.

Resolución de 17 de mayo de 2010, de la Dirección General de Planificación, Ordenación e Inspección Educativa, por la que se organiza la atención educativa al alumnado con integración tardía en el sistema educativo y al alumnado en situación de desventaja socioeducativa, escolarizado en el segundo ciclo de Educación Infantil, BOCYL núm. 100 de 27 de mayo de 2010, 67543-67899.

Reyes, M.C., (2011). El rendimiento académico de los alumnos de primaria que cursan estudios artístico-musicales en la comunidad valenciana. (Tesis inédita de doctorado). Universidad de Valencia, Valencia. Recuperado de http://roderic.uv.es/handle/10550/25132

Rodríguez de Castro, F. (1994). Historia de la educación de la España contemporánea. Diez años de investigación. Madrid: MEC.

Rodríguez-Quiles, J. A. (2003). ¿Es necesaria una Educación Musical para todos? Revista de la lista europea de la música para la educación. http://musica.rediris.es/leeme/revista/rodriguezja03.pdf

Rouse, M. (2010). Reforming initial teacher education: a necessary but not sufficientcondition for developing inclusive practice. En Forlin, C. (Ed.). Teacher education for inclusión. Changing paradigms and innovative approaches (p. 47-55). USA and Canada: Routledge.

Ruíz Palomo E. y Santamaría Conde R.M. (2013). La formación musical en el profesorado de Educación Infantil. Estudios sobre el Mensaje Periodístico, 19, (3), 439-448.

Ruíz Palomo, E., Palmero, C. y Baños, V. (2015). Docencia en educación vocal y canto. Adaptaciones a las necesidades del aula. Edenatía 47, 205-219.

Sabbatella Riccardi, P. (2008). Educación Musical Inclusiva: Integrando perspectivas desde la Educación Musical y la Musicoterapia Educativa. FTC Fundaçao para a Ciencia e a Tecnología. "Musica. Arte. Dialogo. Civilización". Center for Intercultural Music Arts., 255-268.

Sánchez Caballero, D. (2015, marzo 15). La LOMCE desafina. Eldiario.es. Recuperado en http://www.eldiario.es/sociedad/profesores-Musica-LOMCE-obligatoria-

pierde_0_366063549.html

Sánchez V. (2013). La banda sonora musical en el cine español (1960-1969). La recreación de identidades femeninas a través de la música de cine en la filmografía 
española de los años sesenta. (Tesis inédita de doctorado). Universidad de Salamanca, Salamanca.

Santander Díaz, M. (2010). La reforma en la formación de los Maestros de Enseñanza Primaria: El plan profesional de 1931. Edudáctica. Educación y didáctica, ensayos ,119.Recuperado http://www.edudactica.es/Docus/Ensayos/Plan\%20Profesional\%20de \%201931.pdf.

Santos Jara, M. (2006). Evaluación de la inclusión educativa desde la preparación de los actores de la comunidad educativa: una mirada hacia los centros. Voces de la Alteridad, 1. México: u n a m.

Shapon-Shevin, M. (2013). La inclusión real: una pesrpectiva de justicia social.Revista de Investigación en educación 11(3), 71-85.

En http://webs.uvigo.es/reined/

Schafer, M. (1985). El nuevo paisaje sonoro. Buenos Aires: Ricordi americana.

Schafer, M. (1994). Hacia una educación sonora. Buenos Aires: Ricordi americana.

Scotto, P. A. (2017). Y a ustedes ¿qué música les gusta? Eufonía. Didáctica de la música. 71, 34-37.

Susinos Rada, T., Rojas Pernia, S. Y Lázaro Visa, S. (2011). La voz del alumnado y el cambio escolar en el camino hacia la inclusión educativa: aprendiendo de la experiencia de un centro de educación infantil y primaria. Revista latinoamericana de Educación Inclusiva. 5 (2). Recuperado en http://www.rinace.net/rlei/numeros/vol5num2/art4_htm.html

Swanwick , K. (1979). A Basis for Music Education. London: Routledge.

Tárraga, R., Grau, C. y Peirats, J. (2013). Creencias sobre la educación inclusiva de los futuros maestros y maestras de educación infantil y primaria. En $X$ congreso Internacional y XXX Jornadas de Universidad y Educación Especial. Zaragoza, 2013

Tárraga, R., Grau, C. y Peirats, J. (2013). Actitudes de los estudiantes del Grado de Magisterio y del Master de Educación Especial hacia la inclusión educativa. Revista Electrónica Interuniversitaria de Formación del Profesorado, 16(1), 55--72. doi: http://dx.doi.org/10.6018/reifop.16.1.179441

UNESCO (1990). Satisfacción de las necesidades básicas del aprendizaje. Jomtien, Tailandia: Autor.

UNESCO (1994). Declaración de Salamanca y Marco de acción ante las necesidades educativas especiales. París: Autor.

UNESCO (1994b). Informe Final de la Conferencia Mundial: Necesidades Educativas 
Especiales. Acceso y Calidad. Madrid: Autor/MEC.

UNESCO (2006). Orientaciones para la Inclusión: Asegurar el Acceso a la Educación para todos. París: Autor.

UNESCO (2006). Conferencia Mundial sobre Educación Artística. Lisboa: Autor.

UNESCO/OREALC (2007). Educación de calidad para todos: un asunto de derechos humanos. Documento de discusión sobre políticas educativas en el Marco de la II Reunión Intergubernamental del Proyecto Regional de Educación para América Latina y el Caribe. Santiago de Chile, 20-30 marzo.

UNESCO (2008). Presentación General de la 48a Reunión de la CIE "La Educación Inclusiva: El Camino Hacia El Futuro". Ginebra: Autor.

UNESCO (2014). Temario abierto sobre educación inclusiva. Santiago, Chile: Autor.

Vlachou, A. (1999). Caminos hacia una educación inclusiva. Madrid: La Muralla.

Vigo, B., Dieste, B. y Thurtson, A. (2016). Aportaciones de un estudio etnográfico sobre la participación de las familias a la formación crítica del profesorado en una escuela inclusiva. Revista Electrónica Interuniversitaria de Formación del Profesorado, 19 (1), 114. doi: http://dx.doi.org/10.6018/reifop.19.1.246341

Vigo, B. Y Soriano, J. (2014). Prácticas de enseñanza y aprendizaje creativo para una educación inclusiva en la formación inicial del profesorado. Experiencias de investigación. Revista nacional e internacional de educación inclusiva, 1, 30-45.

Willems, E. (1969). Las bases psicológicas de la educación musical. Buenos Aires: Eudeba.

Willems, E. (1981). El valor humano de la educación musical. Barcelona: Paidós.

Willems, E. (1993). La preparación musical de los más pequeños. Buenos Aires: Eudeba.

Zabalza, M. A., y Zabalza, M. A (2011). La formación del profesorado en Educación Infantil. Revista Participación Educativa - Tribuna Abierta, 16, 103-113. 
ANEXO 


\section{ANEXO I : CUESTIONARIO 1. FORMACIÓN MUSICAL DE LOS ESTUDIANTES}

\section{SECCIÓN 1ạ: Formación musical en Primaria.}

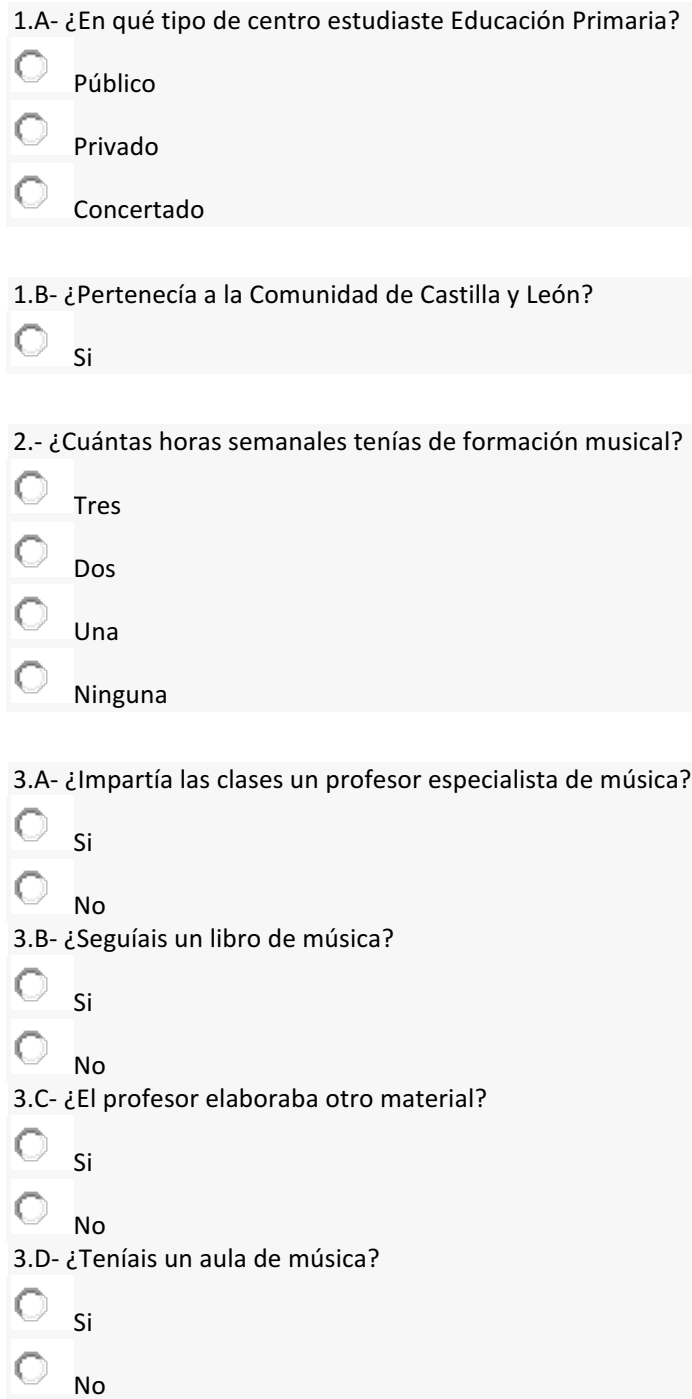

\begin{tabular}{|c|c|c|}
\hline 3.E- En las clases de música ... & $\mathrm{Si}$ & No \\
\hline $\begin{array}{l}\text { ¿Recibías formación musical?, es decir } \\
\text { ¿os enseñaba a cantar? }\end{array}$ & 0 & 0 \\
\hline ¿Os enseñaba a tocar la flauta dulce? & 0 & 0 \\
\hline $\begin{array}{l}\text { ¿Teníais otros instrumentos musicales } \\
\text { aparte de la flauta dulce? }\end{array}$ & 0 & 0 \\
\hline $\begin{array}{l}\text { ¿Recibíais formación instrumental? es } \\
\text { decir ¿̇os enseñaba a tocar otros } \\
\text { instrumentos aparte de la flauta dulce? }\end{array}$ & 0 & 0 \\
\hline $\begin{array}{l}\text { ¿Os enseñaba a bailar alguna danza o } \\
\text { coreografía? }\end{array}$ & 0 & 0 \\
\hline $\begin{array}{l}\text { ¿Recibíais formación auditiva?, es decir } \\
\text { ¿os enseñaba a escuchar música? }\end{array}$ & 0 & 0 \\
\hline
\end{tabular}


4.A- ¿En qué tipo de centro estudiaste la Educación Secundaria Obligatoria?

Público

Privado

Concertado

4.B- ¿Pertenecía a la Comunidad de Castilla y León?

Q Si

No

5.- ¿Cuántas horas semanales tenías de formación musical?

Q Tres

(1) Dos

(Una

( Ninguna

6.A- ¿Impartía las clases un profesor especialista de música?
( $\mathrm{Si}$
( No

6.B- ¿Seguíais un libro de música?

(Q) Si

(1) No

6.C- ¿Teníais un aula de música, o las recibíais en un aula ordinaria?

Q Aula de música

Aula ordinaria

6.D- En las clases de música ...
¿Recibías formación musical?, es decir
¿os enseñaba a cantar?
¿Teníais instrumentos musicales?
¿Recibíais formación instrumental? es
decir ¿̇os enseñaba a tocar
instrumentos?
¿Os enseñaba Historia de la música?
¿Os enseñaba a bailar alguna danza o
coreografía?
¿Recibíais formación auditiva?, es decir
¿os enseñaba a escuchar música?
(audiciones)

\section{SECCIÓN 3ạ: Formación musical en Bachillerato}

7.A- ¿En qué tipo de centro estudiaste el Bachillerato?

Público 


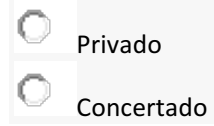

7.B- ¿Pertenecía a la Comunidad de Castilla y León?

(1) Si

( No

8- Además de haber estudiado la asignatura de Música en $2^{\circ}$ y $3^{\circ}$ ¿ ¿elegiste alguna vez Música como optativa?

Q Si

(O) No

9.A- ¿Impartía las clases un profesor especialista de música?

(Q)

( No

9.B- ¿Seguíais un libro de música?

(Q) $\mathrm{Si}$

Q No

9.C- ¿Teníais un aula de música, o las recibíais en un aula ordinaria?

Aula de música

Q Aula ordinaria

9.D- En las clases de música ...
¿Recibías formación musical?, es decir
¿os enseñaba a cantar?
¿Recibíais formación instrumental? es
decir ¿os enseñaba a tocar
instrumentos?
¿Os enseñaba Historia de la música?
¿Os enseñaba a bailar alguna danza o
coreografía?
¿Recibíais formación auditiva?, es decir
¿os enseñaba a escuchar música?
(audiciones)

\section{SECCIÓN 4ạ: Ciclo formativo de Grado Medio}

10- ¿Has cursado el título de Ciclo Formativo de Grado Medio en EDUCACIÓN INFANTIL?

Q Si

No

\section{SECCIÓN 5a:: Otro tipo de formación: Técnico superior}

11- ¿Has cursado el título de TECNICO SUPERIOR en Educación Infantil?

(2i 
12- ¿En alguna materia has estudiado algún contenido musical?

( Si

No

13- ¿Has aprendido ...
¿Canciones infantiles?
¿A bailar alguna danza o coreografía?
¿Tocar instrumentos?
¿Contar cuentos musicales?

14- ¿Has realizado algún tipo de práctica con niños en algún centro educativo?

(1) Si

(No

15- En estas prácticas, ¿̇has realizado algún tipo de actividad musical con niños?

( $\mathrm{Si}$

(No

\section{SECCIÓN 6a: Otro tipo de formación musical}

16- Aparte de formación musical recibida antes de entrar en la Universidad ¿has recibido alguna otra, o la sigues
recibiendo?
$\quad \mathrm{Si}$
17- Por favor, indica SI ...
¿Has pertenecido o perteneces, a algún
coro?
¿Has pertenecido o perteneces, a alguna
rondalla, tuna, pasacalle, o grupo de
danza?
¿Has pertenecido o perteneces, a algún
grupo musical?
¿Has recibido, o recibes, clases de alguna
Academia de Música?
¿Has cursado, o cursas, estudios en el
Conservatorio?

18- ¿Interpretas algún instrumento?

(2) $\mathrm{si}$

No

19- ¿Cual?

Enlace al que accedieron para cumplimentarlo: 
183

ANEXO II: CUESTIONARIO 2. CONOCIMIENTOS, DESTREZAS Y HEBILIDADES MUSICALES DE LOS ESTUDIANTES

1.- Indica el grado de conocimiento que tienes de:

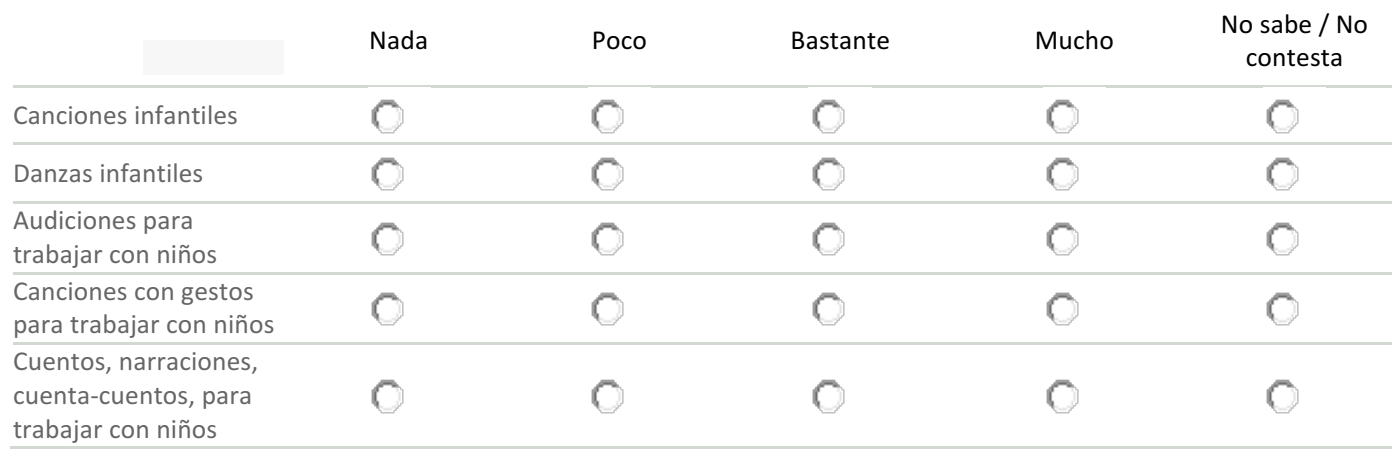

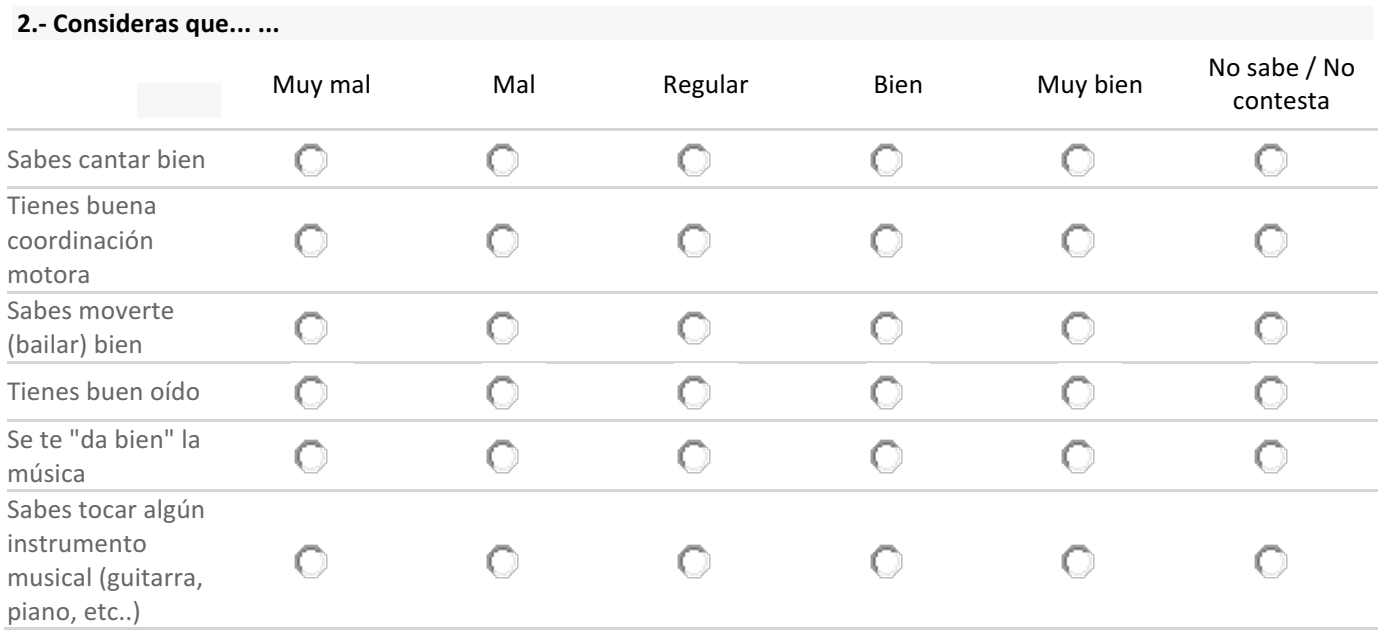

3.- ¿Consideras que sabes música?

Nada

Poco

Bastante

Mucho

4.- ¿Tienes nociones de...?

Ninguna
$\begin{aligned} & \text { Lenguaje musical para } \\ & \text { interpretar canciones } \\ & \text { con la flauta dulce }\end{aligned}$
$\begin{aligned} & \text { Lenguaje musical para } \\ & \text { leer una partitura }\end{aligned}$




Ninguna Bocas
sencilla
Ritmo para tocar
instrumentos escolares
5.- ¿Te han dicho alguna vez "que no sirves para la música"?
Punca
Bastantes
Muchas

6.- ¿Crees que debes de empezar tu formación musical desde "cero"?

(Q) Seguro que no

Puede que no

Puede que si

Seguro que si

7.- ¿Te da vergüenza realizar actividades musicales (cantar, bailar, etc...) en clase?

Ninguna

(Q) Poco

Bastante

( Mucha

Enlace al que accedieron para cumplimentarlo:

https://docs.google.com/forms/d/1LNd0TA7hBKEbh6oe5XmN3Q1nSWMIVw1U ac sHzt5iMI/viewform?edit requested=true 
ANEXO III: CUESTIONARIO 3. EL USO DE LA MÚSICA EN LOS CENTROS DE EDUCACIÓN INFANTIL

SECCIÓN 1ạ: Datos relativos al Centro y a las clases de prácticas

1.- ¿En qué tipo de centro educativo cursaste las prácticas de Infantil?

C. Público

Concertado

C. Privado

2- Tu tutor del centro educativo... ¿ंera?
C. Tutor
C P.T.
G.L.
A Apoyo

3A- ¿En qué ciclo las realizaste?
Primer ciclo
C. Segundo ciclo

4- ¿Cuántos alumnos has tenido en clase?
C Menos de 10
C. Entre 10 y 14
Entre 15 y 19
C. Entre 20 y 24

5A- De tus alumnos, cuántos presentan

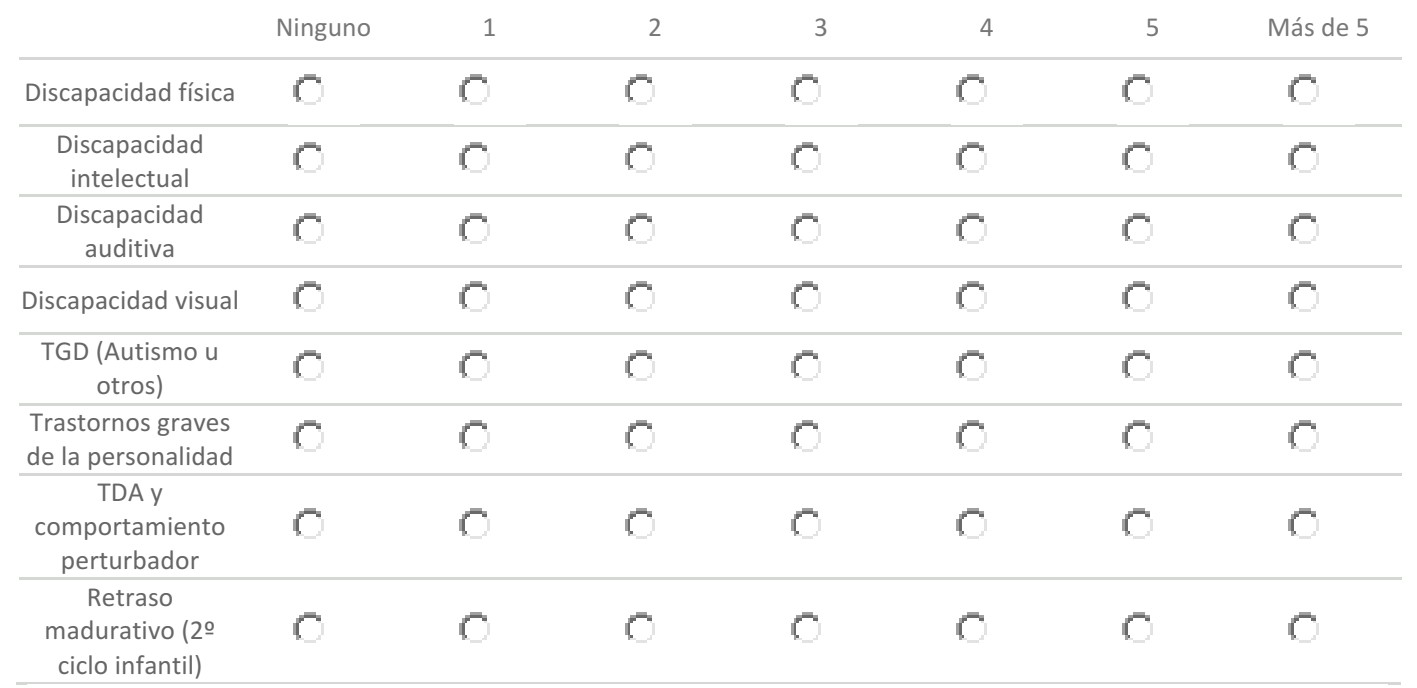

5B- De tus alumnos, ¿cuántos presentan "Necesidades de Compensación Educativa (ANCE)?

$\begin{array}{ccccc}\text { Ninguno } & 1 & & \\ \text { Especiales } \\ \text { condiciones }\end{array}$




\begin{tabular}{cccccccc} 
& Ninguno & 1 & 2 & 3 & 4 & 5 & Más de 5 \\
\hline $\begin{array}{c}\text { personales } \\
\text { (enfermedad } u \\
\text { hospitalización) }\end{array}$ & & & & & & & \\
\hline $\begin{array}{c}\text { Especiales } \\
\text { condiciones } \\
\text { geográficas, } \\
\text { sociales y } \\
\text { culturales }\end{array}$ & & 0 & 0 & $C$ & $C$ & & \\
\hline
\end{tabular}

5C- De tus alumnos, ¿cuántos presentan ...?

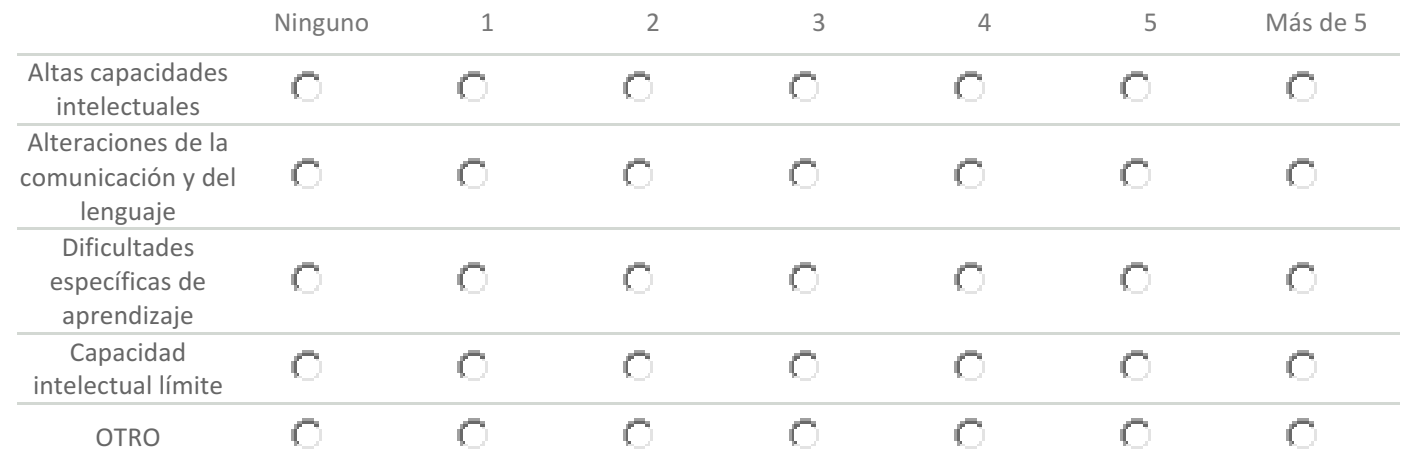

\section{SECCIÓN 2a: : El currículum de Música en la Educación Infantil.}

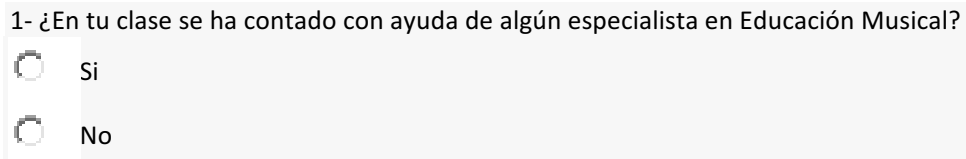

2- ¿Con qué frecuencia se utilizaba en las clases los siguientes contenidos específicos de educación musical?

\begin{tabular}{|c|c|c|c|c|}
\hline & Nunca & $A$ veces & Casi siempre & Siempre \\
\hline $\begin{array}{l}\text { Discriminar/identificar sonidos y ruidos de la vida } \\
\text { cotidiana (casa, naturaleza, mundo animal, ...) }\end{array}$ & $\mathrm{C}$ & 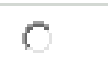 & Q & 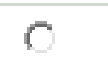 \\
\hline $\begin{array}{l}\text { Hacer sonidos y ritmos con el cuerpo (juegos } \\
\text { sonoros de imitación) }\end{array}$ & $C$ & $\mathrm{C}$ & 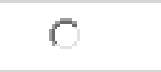 & $\mathrm{C}$ \\
\hline $\begin{array}{l}\text { Hacer sonidos con la voz, vocalizaciones, juegos } \\
\text { de imitación }\end{array}$ & $C$ & $\mathrm{C}$ & $\mathrm{B}$ & $\mathrm{C}$ \\
\hline Tocar instrumentos para acompañar canciones & $\mathrm{C}$ & $\mathrm{C}$ & $\mathrm{B}$ & $\mathrm{C}$ \\
\hline Cantar canciones & $\mathrm{C}$ & $\mathrm{C}$ & $\mathrm{C}$ & $\mathrm{C}$ \\
\hline $\begin{array}{l}\text { Hacer juegos musicales siguiendo distintas } \\
\text { melodías }\end{array}$ & $C$ & 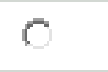 & G & $\mathrm{B}$ \\
\hline $\begin{array}{l}\text { Bailar o realizar coreografías (actividades de } \\
\text { movimiento sencillas) }\end{array}$ & $C$ & $B$ & $B$ & $\mathrm{C}$ \\
\hline $\begin{array}{l}\text { Audiciones musicales: escuchar breves obras } \\
\text { instrumentales y vocales }\end{array}$ & $C$ & $\mathrm{~B}$ & $B$ & B \\
\hline Representar historias utilizando sonidos y música & $\mathrm{C}$ & $\mathrm{B}$ & $\mathrm{B}$ & $\mathrm{B}$ \\
\hline Ver videos musicales & $\mathrm{C}$ & $\mathrm{C}$ & $C$ & $\mathrm{C}$ \\
\hline
\end{tabular}

4- ¿Se utilizaba la música en las "rutinas" y en determinadas tareas o momentos del día?

$\mathrm{Si}$

No

La entrada en el Centro

C

G. 


\begin{tabular}{lcc}
\hline Los buenos días & $\mathrm{C}$ & No \\
\hline El día de hoy & $\mathrm{C}$ & $\mathrm{C}$ \\
\hline El tiempo de hoy & $\mathrm{C}$ & $\mathrm{C}$ \\
\hline Las actividades & $\mathrm{C}$ & $\mathrm{C}$ \\
\hline La asamblea & $\mathrm{C}$ & $\mathrm{C}$ \\
\hline El aseo/higiene & $\mathrm{C}$ & $\mathrm{C}$ \\
\hline Siesta/Relajación & $\mathrm{C}$ & $\mathrm{C}$ \\
\hline Otros & $\mathrm{C}$ & \\
\hline
\end{tabular}

5- ¿Cantaban canciones en algunas actividades sociales vinculadas a distintos momentos de la vida: cumpleaños, Navidad, Día de la Paz, eventos deportivos, ¿etc?
C. Nunca
Algunas veces
Casi siempre
Siempre

6- ¿Qué tiempo total había asignado para trabajar los contenidos específicos de formación musical en la programación semanal

C. Ninguno / No específico

Una sesión diaria

Tres sesiones semanales

Dos sesiones semanales

U. Una sesión semanal

O. Otro:

\section{SECCIÓN 3ạ: Música e Inclusión}

1- Indica en qué medida te identificas con las siguientes afirmaciones sobre la importancia de la música en la Educación.

Aumenta la capacidad de memoria, atención
y concentración de los niños
Mejora la habilidad para resolver problemas
matemáticos y de razonamiento complejos
sntroduce a los niños a los sonidos y
aprendizaje de las palabras y fortalece el
Estimula la creatividad y la imaginación
infantil
Al combinarse con el baile, estimula los
sentidos, el equilibrio y el desarrollo muscular
Provoca la evocación de recuerdos e
imágenes con las que se enriquece el
intelecto
Estimula el desarrollo integral del niño/a al
actuar sobre las áreas del desarrollo
Mejora la comunicación con todo el grupo




Ayuda a resolver problemas de relación

2A- Realizar actividades musicales, frecuentemente te crea problemas ...

En la dinámica de clase

3- Indica el grado de participación de tu alumnado en las siguientes actividades:

Discriminar/identificar sonidos y ruidos de la vida cotidiana
(casa, naturaleza, mundo animal, ...
Hacer sonidos y ritmos con el cuerpo (juegos sonoros de
imitación)
Hacer sonidos con la voz, vocalizaciones, juegos de imitación
Tocar instrumentos para acompañar canciones
Cantar canciones
Hacer juegos musicales siguiendo distintas melodías
Bailar o realizar coreografías (actividades de movimiento
$\begin{aligned} & \text { sudiciones musicales: escuchar breves obras instrumentales y } \\ & \text { vocales } \\ & \text { Representar historias utilizando sonidos y música } \\ & \text { Ver videos musicales }\end{aligned}$

4- ¿Piensas que la actividad musical puede contribuir a adquirir habilidades comunicativas y de interacción?

$$
\sigma^{\mathrm{Si}}
$$

Solo si has respondido "SI" a esta pregunta rellena la 4B y la 4C. Si respondes "NO" pasa a la 5

4B- De los alumnos de tu clase, ¿̇con cuáles crees que las actividades musicales pueden contribuir a adquirir habilidades

\begin{tabular}{|c|c|c|c|c|}
\hline & Nunca & $A$ veces & Casi siempre & Siempre \\
\hline Alumnos con discapacidad física & & $B$ & & \\
\hline Alumnos con discapacidad intelectual & & & & \\
\hline Alumnos con discapacidad auditiva & & & & \\
\hline Alumnos con discapacidad visual & & & & \\
\hline Alumnos con Autismo (TGD) & & & & \\
\hline $\begin{array}{l}\text { Alumnos con trastornos graves de } \\
\text { personalidad }\end{array}$ & & & & \\
\hline $\begin{array}{l}\text { Alumnos con TDA y comportamiento } \\
\text { perturbador }\end{array}$ & & & & \\
\hline Alumnos con retraso madurativo & & & & \\
\hline Alumnos inmigrantes & & & 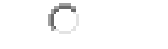 & 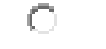 \\
\hline
\end{tabular}
comunicativas y de interacción? 


Alumnos con especiales condiciones sociales,
geográficas y culturales
Alumnos con altas capacidades intelectuales
$\begin{aligned} & \text { Alumnos con alteraciones de la comunicación } \\ & \text { Alumnol lenguaje } \\ & \text { aprendizaje } \\ & \text { Alumnos con capicultades específicas de }\end{aligned}$

5- ¿Piensas que las actividades musicales pueden proporcionar a tu alumnado un estímulo que enriquece los procesos cognitivos (pensamiento, lenguaje, aprendizaje y memoria)?

$$
G^{\mathrm{Si}}
$$

5B- ¿Del alumnado de tu clase, con cuales crees que las actividades musicales pueden proporcionales estímulos que enriquecen los procesos cognitivos (pensamiento, lenguaje, aprendizaje y memoria)?

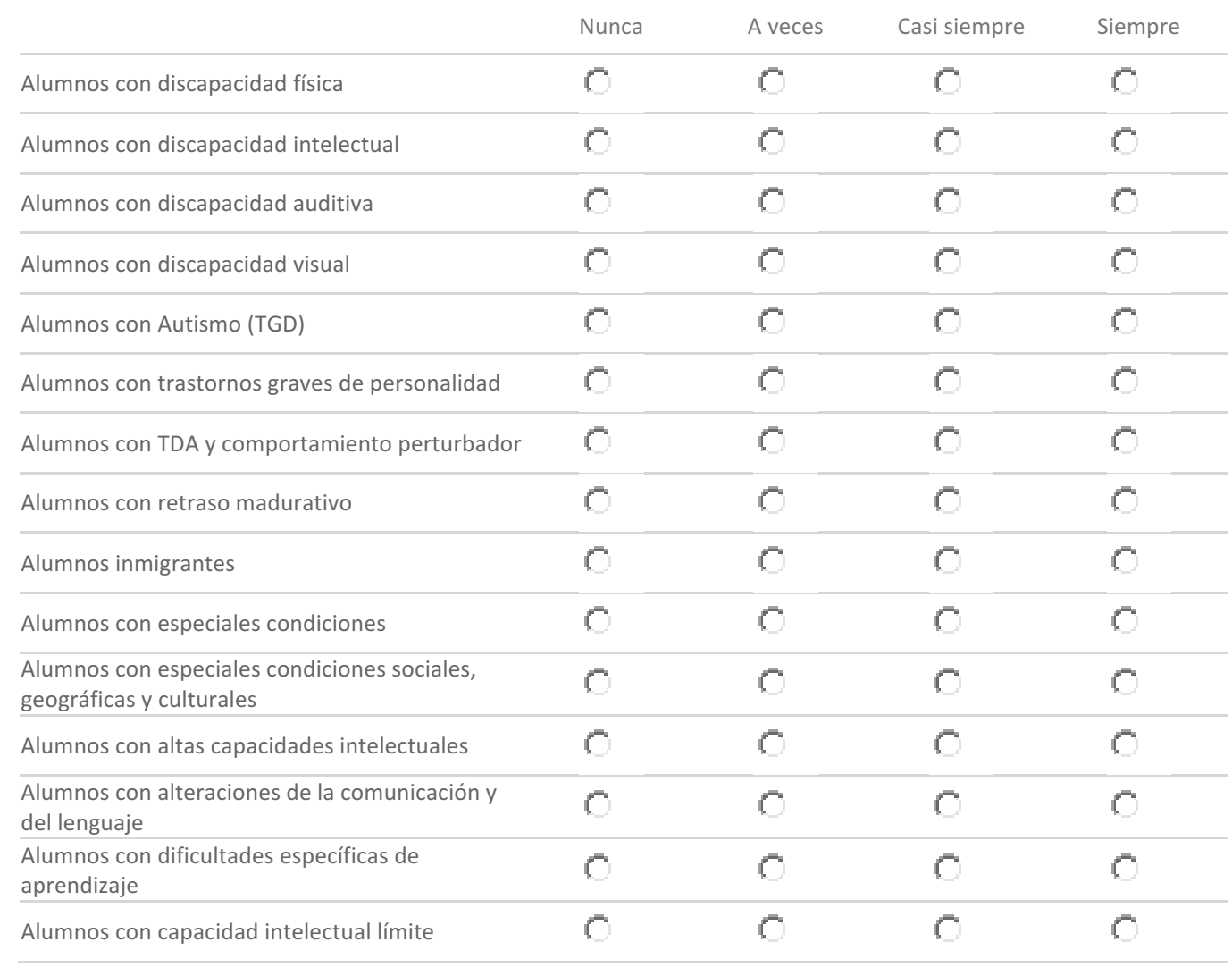

6- ¿Piensas que las actividades musicales pueden proporcionar a tu alumnado un apoyo afectivo?

$$
\text { E Ni }
$$

Solo si has respondido "SI" a esta pregunta rellena la 5B y la 5C. Si respondes "NO" pasa a la 7

6B- ¿Del alumnado de tu clase, con cuales crees que las actividades musicales pueden proporcionales un apoyo afectivo)?

$$
\text { Nunca A veces Casi siempre Siempre }
$$

Alumnos con discapacidad física

C C C C




\begin{tabular}{|c|c|c|c|c|}
\hline & Nunca & A veces & Casi siempre & Siempre \\
\hline Alumnos con discapacidad intelectual & & $E$ & & \\
\hline Alumnos con discapacidad auditiva & & & & \\
\hline Alumnos con discapacidad visual & & & & \\
\hline Alumnos con Autismo (TGD) & & & & \\
\hline Alumnos con trastornos graves de personalidad & & & & \\
\hline Alumnos con TDA y comportamiento perturbador & & & & \\
\hline Alumnos con retraso madurativo & & & & \\
\hline Alumnos inmigrantes & & & & \\
\hline Alumnos con especiales condiciones & & $\mathrm{B}$ & & \\
\hline $\begin{array}{l}\text { Alumnos con especiales condiciones sociales, } \\
\text { geográficas y culturales }\end{array}$ & & & & \\
\hline Alumnos con altas capacidades intelectuales & & & & \\
\hline $\begin{array}{l}\text { Alumnos con alteraciones de la comunicación y } \\
\text { del lenguaje }\end{array}$ & & & & \\
\hline $\begin{array}{l}\text { Alumnos con dificultades específicas de } \\
\text { aprendizaje }\end{array}$ & & & & \\
\hline Alumnos con capacidad intelectual límite & 8 & Q & $B$ & C \\
\hline
\end{tabular}

7- ¿Piensas que es bueno que tus alumnos participen en las actividades específicas de contenido musical: tocar instrumentos, cantar, danzar, escuchar audiciones, ¿̇etc....?

\begin{tabular}{|c|c|c|c|c|}
\hline & Nunca & A veces & Casi siempre & Siempre \\
\hline Alumnos con discapacidad física & & 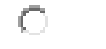 & & C \\
\hline Alumnos con discapacidad intelectual & & & & B \\
\hline Alumnos con discapacidad auditiva & & & & \\
\hline Alumnos con discapacidad visual & & & & \\
\hline Alumnos con Autismo (TGD) & & & & \\
\hline Alumnos con trastornos graves de personalidad & & & & \\
\hline Alumnos con TDA y comportamiento perturbador & & & & \\
\hline Alumnos con retraso madurativo & & 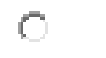 & & 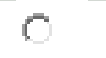 \\
\hline Alumnos inmigrantes & & 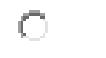 & & 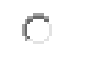 \\
\hline Alumnos con especiales condiciones & & 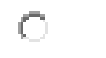 & 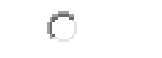 & $G$ \\
\hline $\begin{array}{l}\text { Alumnos con especiales condiciones sociales, } \\
\text { geográficas y culturales }\end{array}$ & & & & \\
\hline Alumnos con altas capacidades intelectuales & & & & \\
\hline $\begin{array}{l}\text { Alumnos con alteraciones de la comunicación y } \\
\text { del lenguaje }\end{array}$ & & & & \\
\hline $\begin{array}{l}\text { Alumnos con dificultades específicas de } \\
\text { aprendizaje }\end{array}$ & & & & \\
\hline Alumnos con capacidad intelectual límite & & $\mathrm{B}$ & C & $\mathrm{G}$ \\
\hline
\end{tabular}

8- ¿Participaba todo el alumnado en las actividades específicas de contenido musical: tocar instrumentos cantar, danzar, escuchar audiciones, ¿etc....? 


\begin{tabular}{|c|c|c|c|c|}
\hline & Nunca & A veces & Casi siempre & Siempre \\
\hline Alumnos con discapacidad física & $\mathrm{C}$ & $\mathrm{C}$ & $\mathrm{B}$ & $\mathrm{C}$ \\
\hline Alumnos con discapacidad intelectual & $C$ & $\mathrm{C}$ & $\mathrm{C}$ & $\mathrm{C}$ \\
\hline Alumnos con discapacidad auditiva & $C$ & C & $\mathrm{C}$ & $\mathrm{C}$ \\
\hline Alumnos con discapacidad visual & $C$ & $\mathrm{C}$ & $\mathrm{C}$ & $\mathrm{C}$ \\
\hline Alumnos con Autismo (TGD) & $\mathrm{C}$ & $\mathrm{C}$ & $\mathrm{C}$ & $\mathrm{C}$ \\
\hline Alumnos con trastornos graves de personalidad & $\mathrm{C}$ & $\mathrm{C}$ & $\mathrm{C}$ & $\mathrm{C}$ \\
\hline Alumnos con TDA y comportamiento perturbador & $C$ & $\mathrm{C}$ & $\mathrm{C}$ & C \\
\hline Alumnos con retraso madurativo & $C$ & $\mathrm{C}$ & $\mathrm{C}$ & $\mathrm{C}$ \\
\hline Alumnos inmigrantes & $\mathrm{C}$ & $\mathrm{C}$ & C & $\mathrm{C}$ \\
\hline Alumnos con especiales condiciones & $\mathrm{C}$ & $\mathrm{C}$ & $\mathrm{B}$ & $\mathrm{C}$ \\
\hline $\begin{array}{l}\text { Alumnos con especiales condiciones sociales, } \\
\text { geográficas y culturales }\end{array}$ & $\mathrm{C}$ & $\mathrm{C}$ & $B$ & $C$ \\
\hline Alumnos con altas capacidades intelectuales & $C$ & $\mathrm{C}$ & $\mathrm{B}$ & $\mathrm{C}$ \\
\hline $\begin{array}{l}\text { Alumnos con alteraciones de la comunicación y } \\
\text { del lenguaje }\end{array}$ & $C$ & $\mathrm{C}$ & $\mathrm{B}$ & $\mathrm{C}$ \\
\hline $\begin{array}{l}\text { Alumnos con dificultades específicas de } \\
\text { aprendizaje }\end{array}$ & $\mathrm{C}$ & $\mathrm{C}$ & $\mathrm{B}$ & $\mathrm{C}$ \\
\hline Alumnos con capacidad intelectual límite & $\mathrm{C}$ & C & $\mathrm{C}$ & $\mathrm{B}$ \\
\hline
\end{tabular}

\section{SECCIÓN 4ạ: Formación musical del profesorado en formación}

1- Valora la IMPORTANCIA de los siguientes contenidos musicales para la formación del Maestro en Educación Infantil, en la PERCEPCIÓN de la música.

Poco
importante $\quad$ Algo $\quad$ Bastante Muy importante

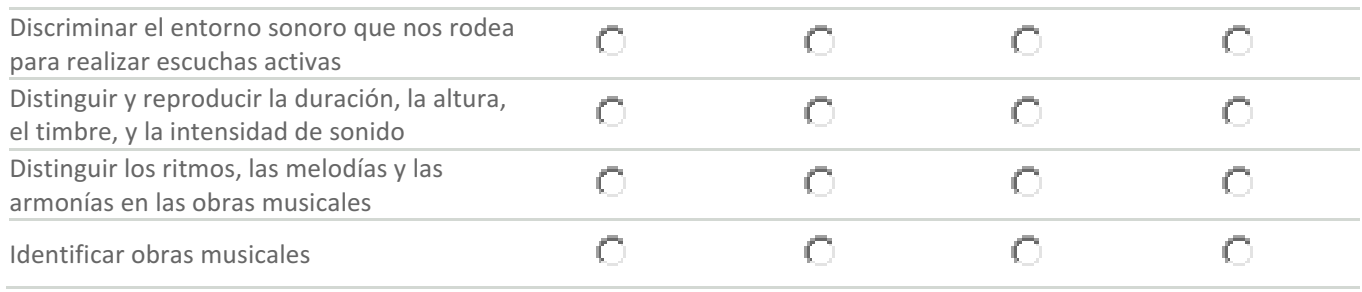

2- Valora la IMPORTANCIA de los siguientes contenidos musicales para la formación del Maestro en Educación Infantil, en la EXPRESIÓN de la música.

Poco
importante Algo Bastante Muy importante

Hacer música con el propio cuerpo (juegos
sonoros de imitación)
Tocar instrumentos musicales como medio
de expresión para acompañar canciones y
bailes
Cantar canciones infantiles vinculadas a
distintos momentos de la vida: cumpleaños,
Navidad, Día de la Paz, etc... (del repertorio
escolar, canciones del folklore, en otras
lenguas, etc...)




Bailar danzas infantiles y coreografías
sencillas
$\begin{aligned} & \text { Dramatización de situaciones, cuentos, } \\ & \text { historias y narraciones }\end{aligned}$

- Valora la IMPORTANCIA de los siguientes contenidos musicales para la formación del Maestro en Educación Infantil, en la CREATIVIDAD de la música.

\begin{tabular}{|c|c|c|c|c|}
\hline & $\begin{array}{l}\text { Poco } \\
\text { importante }\end{array}$ & Algo & Bastante & Muy importante \\
\hline $\begin{array}{l}\text { Hacer música con objetos sonoros e } \\
\text { instrumento }\end{array}$ & & & & \\
\hline $\begin{array}{l}\text { Improvisación rítmica por medio de } \\
\text { percusiones, vocablos e instrumentos }\end{array}$ & & & & \\
\hline $\begin{array}{l}\text { Creación de melodías y canciones de dos, } \\
\text { tres, sonidos }\end{array}$ & & & & \\
\hline Invención de coreografías sencillas & & & & \\
\hline $\begin{array}{l}\text { Improvisación y creación de situaciones } \\
\text { cotidianas y dramáticas, utilizando distintos } \\
\text { recursos (dramatizaciones, instrumentos, } \\
\text { mimo...) }\end{array}$ & & & & \\
\hline $\begin{array}{l}\text { Experimentación de gestos y movimientos } \\
\text { como recursos corporales para la expresión y } \\
\text { la comunicación }\end{array}$ & $\mathrm{B}$ & $\mathrm{B}$ & & $r$ \\
\hline
\end{tabular}

- Valora la IMPORTANCIA de los siguientes contenidos musicales para la formación del Maestro en Educación Infantil, en la REPRESENTACIÓN GRÁFICA de la música.

Poco Algo Bastante Muy importante
importante

Leer y escribir los elementos de la música
con grafías no convencionales
$\begin{aligned} & \text { Diseñas musicogramas (audiciones } \\ & \text { musicales) }\end{aligned}$
Representar ritmos
Leer y escribir las notas en el pentagrama

De los contenidos musicales que aprendiste durante tus estudios de Grado, ¿̇uáles han sido de mayor utilidad en tus prácticas?

\begin{tabular}{|c|c|c|c|c|}
\hline & Nada & Poco & Bastante & Mucho \\
\hline Tocar la flauta dulce & & $B$ & $E$ & \\
\hline Actividades de ritmo y movimiento & & C & & \\
\hline $\begin{array}{l}\text { Trabajo con el sonido (ruido, sonido, } \\
\text { silencio, parámetros, etc.) }\end{array}$ & & & & \\
\hline Trabajo con los instrumentos & & & & \\
\hline Actividades de audición & & $B$ & & \\
\hline $\begin{array}{l}\text { Aprender un amplio repertorio de canciones } \\
\text { infantiles }\end{array}$ & $r$ & $C$ & $C$ & \\
\hline
\end{tabular}

\section{Enlace al que accedieron para cumplimentarlo:}


https://docs.google.com/forms/d/1MKfdIYdDqlV2z7KZ09tOgpPXIgfDWH 3FSv31djUv0E/edit\#

ANEXO IV: CUESTIONARIO 4. COMPETENCIAS Y CURRICULO DE ESPRESIÓN MUSICAL EN EDUCACIÓN INFANTIL

\section{SECCIÓN 1a: : Datos relativos al Centro y de los alumnos donde trabajan los tutores}

1- El centro en donde trabajas es:
(C) Público
Concertado
(Q. Privado

2A- ¿En qué ciclo estás dando clase?
C. Primer ciclo
Gegundo ciclo

3- ¿Cuántos alumnos tienes en clase?

4A- De tus alumnos, cuántos presentan

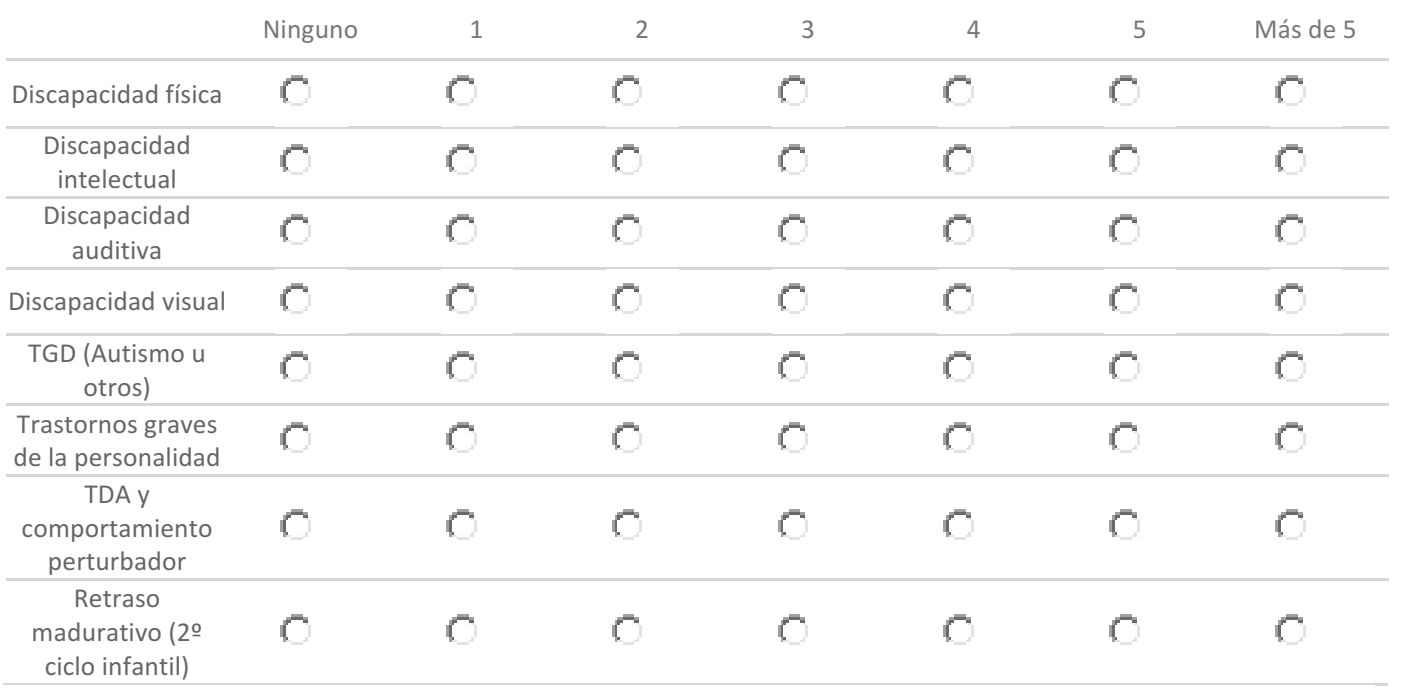

4B- De tus alumnos, ¿cuántos presentan "Necesidades de Compensación Educativa (ANCE)?

\begin{tabular}{|c|c|c|c|c|c|c|c|}
\hline & Ninguno & 1 & 2 & 3 & 4 & 5 & Más de 5 \\
\hline Inmigrantes & $G$ & 8 & $C$ & $C$ & & $C$ & $B$ \\
\hline $\begin{array}{c}\text { Especiales } \\
\text { condiciones } \\
\text { personales } \\
\text { (enfermedad u } \\
\text { hospitalización) }\end{array}$ & 6 & & & & & & \\
\hline $\begin{array}{l}\text { Especiales } \\
\text { condiciones } \\
\text { geográficas, } \\
\text { sociales y } \\
\text { culturales }\end{array}$ & $B$ & & $r$ & $B$ & & $B$ & \\
\hline
\end{tabular}

4C- De tus alumnos, ¿cuántos presentan ...?

$\begin{array}{ccccccc} & \text { Ninguno } & 1 & 2 & 3 & 4 & 5 \\ \text { Altas capacidades } \\ \text { intelectuales }\end{array}$




\begin{tabular}{|c|c|c|c|c|c|c|c|}
\hline & Ninguno & 1 & 2 & 3 & 4 & 5 & Más de 5 \\
\hline $\begin{array}{c}\text { Alteraciones de la } \\
\text { comunicación y del } \\
\text { lenguaje }\end{array}$ & $C$ & $C$ & $\mathrm{C}$ & $\mathrm{C}$ & $C$ & 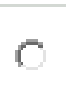 & $C$ \\
\hline $\begin{array}{l}\text { Dificultades } \\
\text { específicas de } \\
\text { aprendizaje }\end{array}$ & $B$ & $B$ & $C$ & $\mathrm{C}$ & $\mathrm{C}$ & $\mathrm{C}$ & 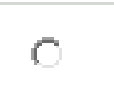 \\
\hline $\begin{array}{c}\text { Capacidad } \\
\text { intelectual límite }\end{array}$ & $B$ & $\mathrm{C}$ & $C$ & $\mathrm{C}$ & $\mathrm{C}$ & $\mathrm{B}$ & $B$ \\
\hline OTRO & $C$ & $\mathrm{C}$ & $\mathrm{C}$ & $C$ & $C$ & $\mathrm{C}$ & $B$ \\
\hline
\end{tabular}

\section{SECCIÓN 2ạ: El currículum de Música en la Educación Infantil.}

1- ¿En tu clase se ha contado con ayuda de algún especialista en Educación Musical?

C. Si

C No

2- ¿Con qué frecuencia se utilizaba en las clases los siguientes contenidos específicos de educación musical?

\begin{tabular}{|c|c|c|c|c|}
\hline & Nunca & A veces & Casi siempre & Siempre \\
\hline $\begin{array}{l}\text { Discriminar/identificar sonidos y ruidos de la vida } \\
\text { cotidiana (casa, naturaleza, mundo animal, ...) }\end{array}$ & $C$ & $\mathrm{C}$ & $\mathrm{C}$ & $C$ \\
\hline $\begin{array}{l}\text { Hacer sonidos y ritmos con el cuerpo (juegos } \\
\text { sonoros de imitación) }\end{array}$ & $C$ & $\mathrm{C}$ & $\mathrm{B}$ & $\mathrm{C}$ \\
\hline $\begin{array}{l}\text { Hacer sonidos con la voz, vocalizaciones, juegos } \\
\text { de imitación }\end{array}$ & $\mathrm{C}$ & $\mathrm{C}$ & $\mathrm{C}$ & $\mathrm{C}$ \\
\hline Tocar instrumentos para acompañar canciones & $\mathrm{C}$ & $\mathrm{C}$ & 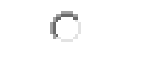 & $C$ \\
\hline Cantar canciones & $\mathrm{C}$ & $C$ & $C$ & $C$ \\
\hline $\begin{array}{l}\text { Hacer juegos musicales siguiendo distintas } \\
\text { melodías }\end{array}$ & $\mathrm{C}$ & $\mathrm{C}$ & $C$ & $C$ \\
\hline $\begin{array}{l}\text { Bailar o realizar coreografías (actividades de } \\
\text { movimiento sencillas) }\end{array}$ & $C$ & $C$ & $B$ & $\mathrm{C}$ \\
\hline $\begin{array}{l}\text { Audiciones musicales: escuchar breves obras } \\
\text { instrumentales y vocales }\end{array}$ & $\mathrm{C}$ & $\mathrm{C}$ & $C$ & $\mathrm{C}$ \\
\hline Representar historias utilizando sonidos y música & $C$ & $\mathrm{C}$ & $B$ & $C$ \\
\hline Ver videos musicales & $\mathrm{C}$ & $\mathrm{C}$ & $C$ & $C$ \\
\hline
\end{tabular}

3- ¿Se utilizaba la música en las "rutinas" y en determinadas tareas o momentos del día?

\begin{tabular}{ll}
\hline La entrada en el Centro \\
Los buenos días \\
Las actividade hoy \\
\hline La asamblea \\
El aseo/higiene \\
\hline Salida
\end{tabular}


4- ¿Cantaban canciones en algunas actividades sociales vinculadas a distintos momentos de la vida: cumpleaños, Navidad, Día de la Paz, eventos deportivos, ¿etc?
C. Nunca
Algunas veces
Casi siempre
Siempre

5- ¿Qué tiempo total había asignado para trabajar los contenidos específicos de formación musical en la programación semanal

C. Ninguno / No específico

C. Una sesión diaria

C. Tres sesiones semanales

C Dos sesiones semanales

Una sesión semanal

otro:

6- ¿Tienes en el horario escolar, tiempo asignado para salidas didáctico-musicales (por ej.: conciertos didácticos) en tu programación anual?

C si

CNo

\section{SECCIÓN 3ạ: Música e Inclusión}

1- Indica en qué medida te identificas con las siguientes afirmaciones sobre la importancia de la música en la Educación.

Aumenta la capacidad de memoria, atención
y concentración de los niños
Mejora la habilidad para resolver problemas
matemáticos y de razonamiento complejos
Introduce a los niños a los sonidos y
significados de las palabras y fortalece el
$\begin{aligned} & \text { Estimula la creatividad y la imaginación } \\ & \text { infantil } \\ & \text { Al combinarse con el baile, estimula los } \\ & \text { sentidos, el equilibrio y el desarrollo muscular } \\ & \text { Provoca la evocación de recuerdos e } \\ & \text { imágenes con las que se enriquece el } \\ & \text { intelecto } \\ & \text { Estimula el desarrollo integral del niño/a al } \\ & \text { actuar sobre las áreas del desarrollo } \\ & \text { Mejora la comunicación con todo el grupo } \\ & \text { Ayuda a resolver problemas de relación }\end{aligned}$

2A- Realizar actividades musicales, frecuentemente te crea problemas ...

Si

No

En la dinámica de clase
Con otros profesores


3- Indica el grado de participación de tu alumnado en las siguientes actividades:

Discriminar/identificar sonidos y ruidos de la vida cotidiana
(casa, naturaleza, mundo animal, ...
Hacer sonidos y ritmos con el cuerpo (juegos sonoros de
imitación)
Hacer sonidos con la voz, vocalizaciones, juegos de imitación
Tocar instrumentos para acompañar canciones
Cantar canciones
Hacer juegos musicales siguiendo distintas melodías
Bailar o realizar coreografías (actividades de movimiento
Audiciones musicales: escuchar breves obras instrumentales y
vocales
Representar historias utilizando sonidos y música
Ver videos musicales

4- ¿Piensas que la actividad musical puede contribuir a adquirir habilidades comunicativas y de interacción?

$$
G^{\text {Ni }}
$$

Solo si has respondido "SI" a esta pregunta rellena la 4B y la 4C. Si respondes "NO" pasa a la 5

4B- De los alumnos de tu clase, ¿con cuáles crees que las actividades musicales pueden contribuir a adquirir habilidades comunicativas y de interacción?

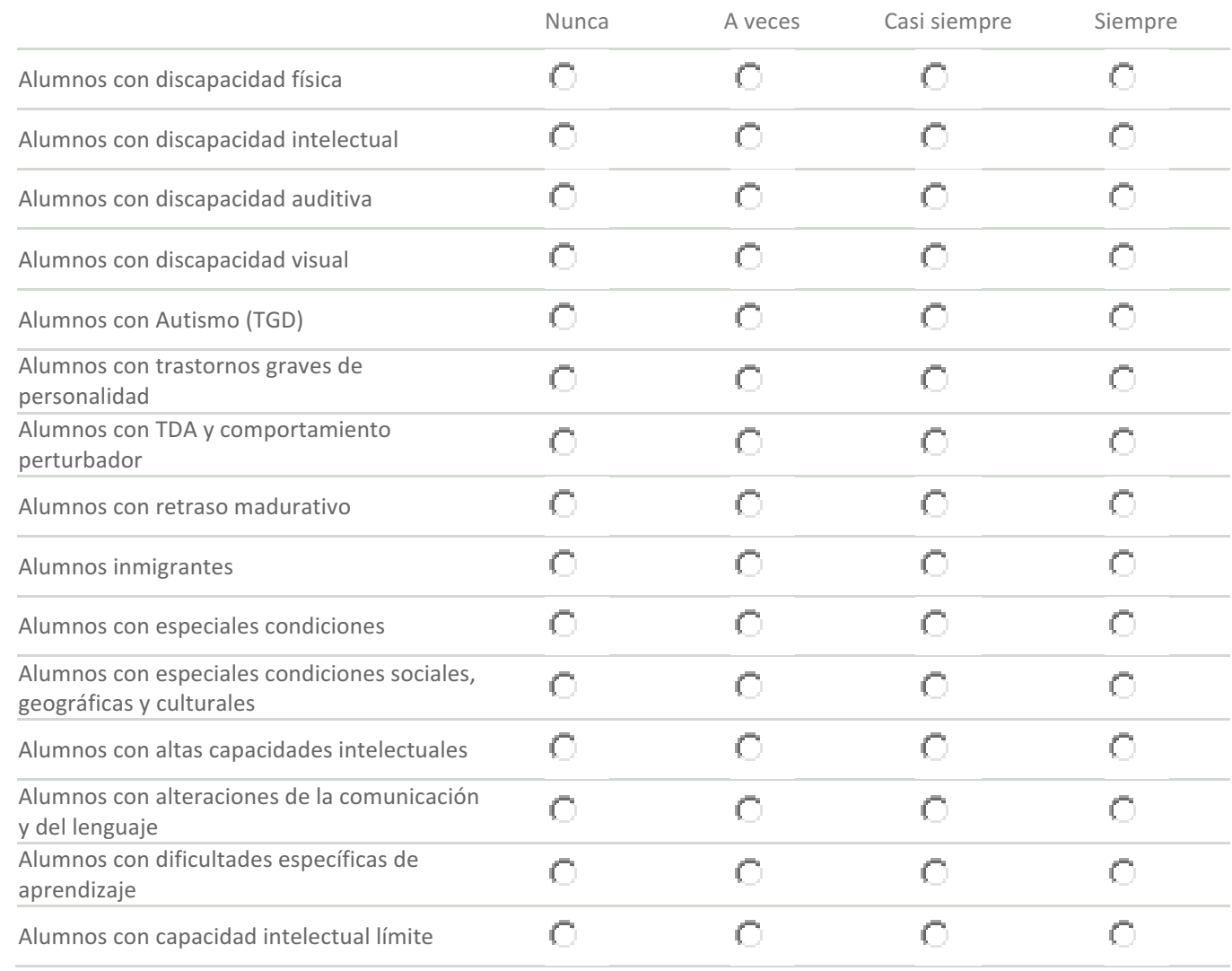

4C- Por favor, explica el por qué. 
5- ¿Piensas que las actividades musicales pueden proporcionar a tu alumnado un estímulo que enriquece los procesos cognitivos (pensamiento, lenguaje, aprendizaje y memoria)?

$$
\Leftrightarrow \text { Si }
$$

5B- ¿Del alumnado de tu clase, con cuales crees que las actividades musicales pueden proporcionales estímulos que enriquecen los procesos cognitivos (pensamiento, lenguaje, aprendizaje y memoria)?

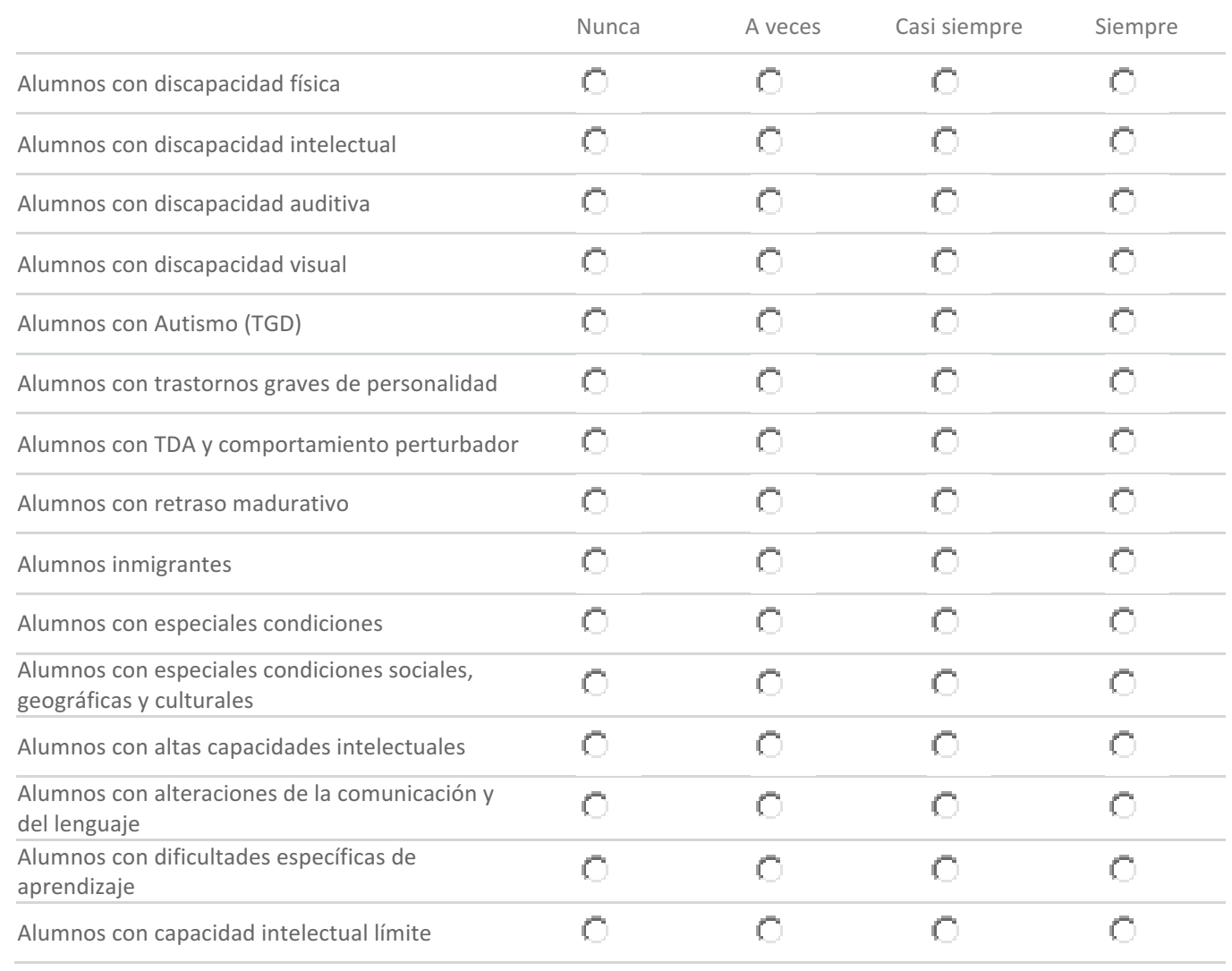

5C- Por favor, explica el por qué.

6- ¿Piensas que las actividades musicales pueden proporcionar a tu alumnado un apoyo afectivo?

$$
\text { C Ni }
$$

Solo si has respondido "SI" a esta pregunta rellena la 5B y la 5C. Si respondes "NO" pasa a la 7

6B- ¿Del alumnado de tu clase, con cuales crees que las actividades musicales pueden proporcionales un apoyo afectivo)?

\begin{tabular}{l} 
Alumnos con discapacidad física \\
Alumnos con discapacidad intelectual \\
\hline Alumnos con discapacidad auditiva \\
\hline Alumnos con discapacidad visual \\
\hline Alumnos con Autismo (TGD)
\end{tabular}




\begin{tabular}{|c|c|c|c|c|}
\hline & Nunca & A veces & Casi siempre & Siempre \\
\hline Alumnos inmigrantes & $B$ & $G$ & E & 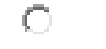 \\
\hline Alumnos con especiales condiciones & & C & & C \\
\hline $\begin{array}{l}\text { Alumnos con especiales condiciones sociales, } \\
\text { geográficas y culturales }\end{array}$ & & & & \\
\hline Alumnos con altas capacidades intelectuales & & & & \\
\hline $\begin{array}{l}\text { Alumnos con alteraciones de la comunicación y } \\
\text { del lenguaje }\end{array}$ & & & & \\
\hline $\begin{array}{l}\text { Alumnos con dificultades específicas de } \\
\text { aprendizaje }\end{array}$ & C & & & $B$ \\
\hline Alumnos con capacidad intelectual límite & $B$ & $\mathrm{C}$ & B & $\mathrm{B}$ \\
\hline
\end{tabular}

\section{C- Por favor, explica el por qué.}

7- ¿Piensas que es bueno que tus alumnos participen en las actividades específicas de contenido musical: tocar instrumentos, cantar, danzar, escuchar audiciones, ¿etc...?

\begin{tabular}{|c|c|c|c|c|}
\hline & Nunca & A veces & Casi siempre & Siempre \\
\hline Alumnos con discapacidad física & & & $B$ & \\
\hline Alumnos con discapacidad intelectual & & & & \\
\hline Alumnos con discapacidad auditiva & & & & \\
\hline Alumnos con discapacidad visual & & & B & \\
\hline Alumnos con Autismo (TGD) & & & $B$ & \\
\hline Alumnos con trastornos graves de personalidad & & & 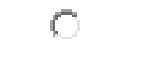 & \\
\hline Alumnos con TDA y comportamiento perturbador & 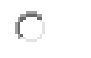 & & 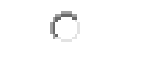 & \\
\hline Alumnos con retraso madurativo & 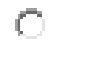 & & C & \\
\hline Alumnos inmigrantes & $B$ & & C & , \\
\hline Alumnos con especiales condiciones & 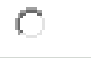 & & $B$ & $B$ \\
\hline $\begin{array}{l}\text { Alumnos con especiales condiciones sociales, } \\
\text { geográficas y culturales }\end{array}$ & & & 5 & \\
\hline Alumnos con altas capacidades intelectuales & & & 6 & t \\
\hline $\begin{array}{l}\text { Alumnos con alteraciones de la comunicación y } \\
\text { del lenguaje }\end{array}$ & & & & \\
\hline $\begin{array}{l}\text { Alumnos con dificultades específicas de } \\
\text { aprendizaje }\end{array}$ & & & & \\
\hline lumnos con capacidad intelectual & & & $\mathrm{B}$ & C \\
\hline
\end{tabular}

7B- Por favor, explica el por qué.

8- ¿Participaba todo el alumnado en las actividades específicas de contenido musical: tocar instrumentos cantar, danzar, escuchar audiciones, ¿etc...?

\begin{tabular}{ll}
\hline Alumnos con discapacidad física & \\
Alumnos con discapacidad intelectual & \\
\hline Alumnos con discapacidad auditiva & \\
Alumnos con discapacidad visual &
\end{tabular}




\begin{tabular}{|c|c|c|c|c|}
\hline & Nunca & A veces & Casi siempre & Siempre \\
\hline Alumnos con trastornos graves de personalidad & $B$ & & & C \\
\hline Alumnos con TDA y comportamiento perturbado & & & & C \\
\hline Alumnos con retraso madurativo & & & & C \\
\hline Alumnos inmigrantes & & & & C \\
\hline Alumnos con especiales condiciones & & & & $B$ \\
\hline $\begin{array}{l}\text { Alumnos con especiales condiciones sociales, } \\
\text { geográficas y culturales }\end{array}$ & & & & \\
\hline Alumnos con altas capacidades intelectuales & & & & $\mathrm{G}$ \\
\hline $\begin{array}{l}\text { Alumnos con alteraciones de la comunicación y } \\
\text { del lenguaje }\end{array}$ & & & & \\
\hline $\begin{array}{l}\text { Alumnos con dificultades específicas de } \\
\text { aprendizaje }\end{array}$ & & & & \\
\hline Alumnos con capacidad intelectual límite & & & $B$ & B \\
\hline
\end{tabular}

\section{SECCIÓN 4ạ: Formación musical del profesorado en formación}

1- Valora la IMPORTANCIA de los siguientes contenidos musicales para la formación del Maestro en Educación Infantil, en la PERCEPCIÓN de la música.

$\begin{array}{ccc}\text { Poco } & \text { Algo } & \text { Bastante } \\ \text { importante } & \text { Muy importante }\end{array}$

Discriminar el entorno sonoro que nos rodea
para realizar escuchas activas
$\begin{aligned} & \text { Distinguir y reproducir la duración, la altura, } \\ & \text { el timbre, y la intensidad de sonido }\end{aligned}$
$\begin{aligned} & \text { Distinguir los ritmos, las melodías y las } \\ & \text { armonías en las obras musicales }\end{aligned}$
Identificar obras musicales

2- Valora la IMPORTANCIA de los siguientes contenidos musicales para la formación del Maestro en Educación Infantil, en la EXPRESIÓN de la música.

Poco Algo Bastante Muy importante
importante

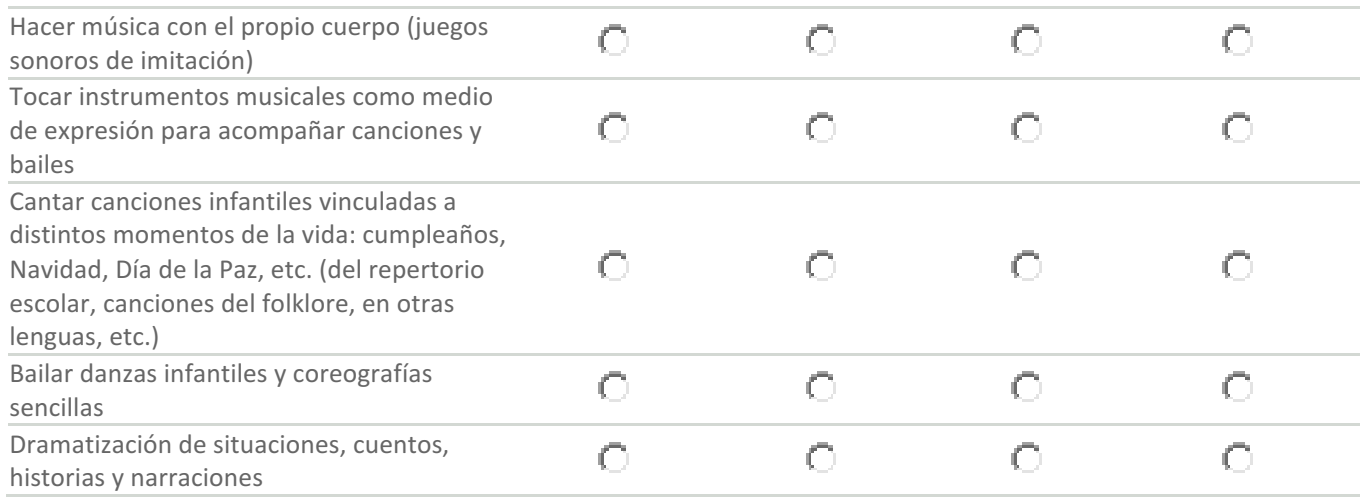

- Valora la IMPORTANCIA de los siguientes contenidos musicales para la formación del Maestro en Educación Infantil, en la CREATIVIDAD de la música.

$\begin{array}{lll}\text { Poco } & \text { Algo } & \text { Bastante }\end{array}$




$\begin{aligned} & \text { Hacer música con objetos sonoros e } \\ & \text { instrumento }\end{aligned}$
$\begin{aligned} & \text { Improvisación rítmica por medio de } \\ & \text { percusiones, vocablos e instrumentos }\end{aligned}$

- Valora la IMPORTANCIA de los siguientes contenidos musicales para la formación del Maestro en Educación Infantil, en la REPRESENTACIÓN GRÁFICA de la música.

Poco
importante $\quad$ Algo Bastante Muy importante

\begin{tabular}{|c|c|c|c|c|}
\hline $\begin{array}{l}\text { Leer y escribir los elementos de la música } \\
\text { con grafías no convencionales }\end{array}$ & $\mathrm{B}$ & $C$ & $C$ & $C$ \\
\hline $\begin{array}{l}\text { Diseñas musicogramas (audiciones } \\
\text { musicales) }\end{array}$ & $\mathrm{C}$ & C & $C$ & $C$ \\
\hline Representar ritmos & $\mathrm{C}$ & $C$ & $C$ & $\mathrm{C}$ \\
\hline Leer y escribir las notas en el pentagrama & $\mathrm{C}$ & $\mathrm{C}$ & $C$ & $C$ \\
\hline
\end{tabular}

\section{SECCIÓN 5ạ: La formación de los estudiantes en prácticas}

1- ¿Piensas que los futuros maestros reciben en su formación universitaria una enseñanza musical suficiente?
E. Si
C. No

2- ¿En términos generales, la formación musical que recibe un estudiante de Educación Infantil permite desarrollar la enseñanza del currículo de música cuando se incorpora al trabajo en este nivel?
C. Nunca
A veces
Casi siempre
Siempre

3- ¿Cuántos estudiantes en prácticas tutorizas?

4.- ¿Cómo calificarías el nivel de conocimientos adquirido en su formación para el uso didáctico-educativo de los contenidos musicales, respecto a:

$$
\begin{array}{cccc}
\text { Nada } & \text { Poco } & \text { Bastante } & \text { Muy } \\
\text { formado } & \text { formado } & \text { formado } & \text { formado }
\end{array}
$$

La percepción del sonido en el entorno cotidiano
$\begin{aligned} & \text { La expresión vocal } \\ & \text { musicales }\end{aligned}$




\begin{tabular}{lcccc} 
& $\begin{array}{c}\text { Nada } \\
\text { formado }\end{array}$ & $\begin{array}{c}\text { Poco } \\
\text { formado }\end{array}$ & $\begin{array}{c}\text { Bastante } \\
\text { formado }\end{array}$ & $\begin{array}{c}\text { Muy } \\
\text { formado }\end{array}$ \\
\hline $\begin{array}{l}\text { Los objetos sonoros y los instrumentos musicales de } \\
\text { construcción propia }\end{array}$ & $\mathrm{C}$ & $\mathrm{C}$ & $\mathrm{C}$ & $\mathrm{C}$ \\
\hline $\begin{array}{l}\text { El movimiento como medio de expresión y percepción } \\
\text { musical }\end{array}$ & $\mathrm{C}$ & $\mathrm{C}$ & $\mathrm{C}$ & $\mathrm{C}$ \\
\hline La danza, las coreografías & $\mathrm{C}$ & $\mathrm{C}$ & $\mathrm{C}$ & $\mathrm{C}$ \\
\hline La audición de pequeñas obras musicales & $\mathrm{C}$ & $\mathrm{C}$ & $\mathrm{C}$ \\
\hline 5.- El profesorado en prácticas está preparado para: & & & & \\
$\begin{array}{l}\text { Utilizar la música en las actividades transversales que } \\
\text { realiza con sus alumnos de infantil (uso de canciones, etc. }\end{array}$ & $\mathrm{C}$ & $\mathrm{C}$ & $\mathrm{C}$ & $\mathrm{C}$ \\
\hline $\begin{array}{l}\text { Cantar canciones con sus alumnos de infantil en distintas } \\
\text { actividades }\end{array}$ & $\mathrm{C}$ & $\mathrm{C}$ & $\mathrm{C}$ & $\mathrm{C}$ \\
$\begin{array}{l}\text { Realizar actividades con los instrumentos musicales } \\
\text { Realizar actividades de movimiento }\end{array}$ & $\mathrm{C}$ & $\mathrm{C}$ & $\mathrm{C}$ & $\mathrm{C}$ \\
\hline Realizar actividades de audición, cuentos sonoros, etc. & $\mathrm{C}$ & $\mathrm{C}$ & $\mathrm{C}$ & $\mathrm{C}$ \\
\hline
\end{tabular}

\section{SECCIÓN 6a: : Propuesta de currículo en el Grado de infantil y en los cursos de formación continua.}

1De los contenidos musicales que aprendiste durante tus estudios de Magisterio, ¿cuáles han sido de mayor utilidad en tus prácticas?

\begin{tabular}{|c|c|c|c|c|}
\hline & Nada & Poco & Bastante & Mucho \\
\hline Tocar la flauta dulce & & & & $G$ \\
\hline Actividades de ritmo y movimiento & & & & $B$ \\
\hline $\begin{array}{l}\text { Trabajo con el sonido (ruido, sonido, } \\
\text { silencio, parámetros, etc.) }\end{array}$ & & & & 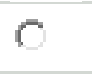 \\
\hline Trabajo con los instrumentos & & & & \\
\hline Actividades de audición & & & & \\
\hline $\begin{array}{l}\text { Aprender un amplio repertorio de canciones } \\
\text { infantiles }\end{array}$ & & & & $C$ \\
\hline
\end{tabular}

2- ¿Consideras que necesitarías trabajar con más recursos musicales?
(Gi
(C) No

3.- Necesitarías para trabajar con más recursos musicales:

Cursos de formación continua
Mayor formación en los alumnos de prácticas
$\begin{aligned} & \text { Ayuda de un especialista } \\ & \text { utilización } \\ & \text { Más tiempo para preparar las clases }\end{aligned}$




Conocer otras metodologías musicales

4. ¿Qué te gustaría que te hubiesen enseñado sobre música en tus estudios de Magisterio?

5. ¿Qué aconsejas que se les enseñe a los estudiantes del Grado sobre esta materia?

6- ¿Estarías interesado en asistir a cursos de formación continua?

Gi

Go

7.- Valora el grado de interés que tienes por participar en actividades de formación sobre los siguientes temas:

\begin{tabular}{|c|c|c|c|c|}
\hline & Bajo & Regular & Alto & Muy alto \\
\hline Adquisición de destrezas y habilidades musicales & 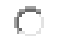 & $\mathrm{C}$ & & \\
\hline $\begin{array}{l}\text { Metodología y recursos para trabajar la música en } \\
\text { educación infantil }\end{array}$ & $B$ & & & \\
\hline $\begin{array}{l}\text { Contribución de la música a la mejora de la inclusión } \\
\text { educativa }\end{array}$ & $B$ & & & \\
\hline Las TIC para la enseñanza y el aprendizaje de la música & $B$ & $\mathrm{C}$ & $\mathrm{C}$ & $\mathrm{C}$ \\
\hline Otros & 0 & $\mathrm{C}$ & C & C \\
\hline
\end{tabular}

\section{SECCIÓN 7ạ: Consideraciones finales}

Por favor utiliza este espacio para incluir reflexiones, experiencias o sugerencias que consideres de interés para elevar la calidad de la enseñanza de la música y estimular el interés por la misma

Enlace al que accedieron para cumplimentar el cuestionario:

https://docs.google.com/forms/d/1vjaaS5opYjT8eOJHmcK_6E7lOrs_vrWkg_VYoy nbSO4/viewform?c=0\&w=1\&usp=mail_form_link 
ANEXO V: Carta dirigida a los directores de los centros de Educación infantil ofreciendo información y solicitando su participación en el estudio.

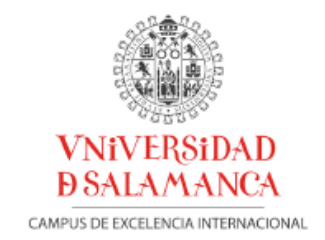

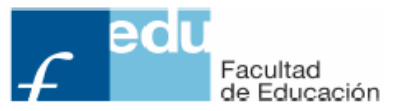

Salamanca

mayo 2014

Estimado/a director/a.

Mi nombre es Ana García Herrera; soy Coordinadora del Grado de Infantil, y profesora del Departamento de Didáctica de la Expresión Musical de la Facultad de Educación de la Universidad de Salamanca.

Estoy realizando en nuestra Universidad una investigación sobre la Formación musical y uso de la música para la inclusión en Educación Infantil: evaluación en maestros y futuros maestros

En el marco de la misma, he elaborado un cuestionario para valorar el uso de la Música en la práctica diaria del aula en infantil, y la preparación didácticomusical recibida por el alumnado durante el periodo de formación de la titulación de Grado de Maestro de Educación Infantil en la Universidad.

Sería muy importante contar con la opinión acerca de estos temas de los Especialista en Educación Infantil y, tutor/as de los alumnos en prácticas por lo que le rogaría que le hiciera llegar este cuestionario.

Si tiene alguna duda o necesita contactar conmigo puede hacerlo a través del correo electrónico indicado más abajo.

Un cordial saludo

Ana García Herrera. (anga@usal.es)

Coordinadora del Grado de Infantil.

Facultad de Educación. Universidad de Salamanca 
ANEXO VI: Carta dirigida a los Maestros-tutores de los centros de Educación infantil ofreciendo información y solicitando su participación en el estudio.
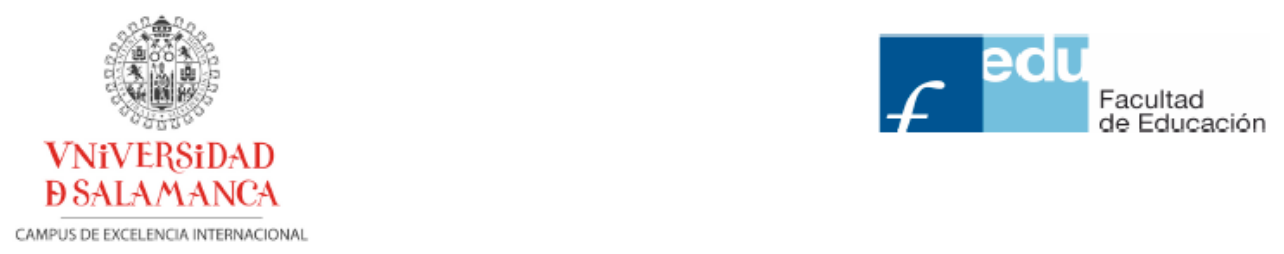

Salamanca $28 / \mathrm{N} / 2014$

Estimado/a compañero/a.

Mi nombre es Ana García Herrera; soy Coordinadora del Grado de Infantil, y profesora del Departamento de Didáctica de la Expresión Musical de la Facultad de Educación de la Universidad de Salamanca.

Estoy realizando en nuestra Universidad una investigación sobre La formación musical y uso de la música para la inclusión en Educación Infantil: evaluación en maestros y futuros maestros, a la que me permito invitarte a participar. En el marco de la misma, he elaborado un cuestionario para valorar el uso de la Música en la práctica diaria del aula en infantil, la eficacia de utilizar las actividades musicales para trabajar la inclusión en el aula y la preparación didáctico-musical recibida por el alumnado durante el periodo de formación de la titulación de Grado de Maestro de Educación Infantil en la Universidad.

El análisis de los datos obtenidos servirá de base objetiva para identificar las competencias musicales básicas que los futuros maestros de Educación Infantil deberían adquirir y ayudar a definir una propuesta de currículum de calidad en la formación universitaria que aborde dichos aspectos.

Sería muy importante contar con tu opinión acerca de estos temas como Especialista en Educación Infantil y, tutor/a de los alumnos en prácticas. En este sentido, quiero garantizar que las respuestas serán tratadas de manera anónima y confidencial, utilizándose rigurosa y exclusivamente para los fines indicados.

Puedes rellenar la encuesta online en la siguiente dirección:

https://docs.google.com/forms/d/1SfOItqwhKp9qDBb7CKQsIfXUsm29z8dPkMIQnjJmRE/viewform?c=0\&w=1\&usp=mail form I ink

El sistema informático no permite dejarlo a medias y después continuar en otro momento, por lo que es necesario realizarlo de una única vez. 
Agradezco de antemano tu colaboración; te ruego que seas los más sincero/a posible pues de ello dependerá la veracidad del estudio. Si tienes alguna duda o necesitas contactar conmigo puedes hacerlo a través del correo electrónico indicado más abajo.

Un cordial saludo

Ana García Herrera. (anga@usal.es)

Coordinadora del Grado de Infantil.

Facultad de Educación.

Universidad de Salamanca 
